\title{
AXIAL STRENGTH OF LIGHTWEIGHT SELF-CONSOLIDATING CONCRETE COLUMNS WITH ENGINEERED CEMENTITIOUS COMPOSITE CONFINEMENT
}

\author{
by \\ Sandeep Parajuli \\ M.Sc, Tribhuvan University, Nepal, 2009
}

\author{
A thesis \\ presented to Ryerson University \\ in partial fulfillment of the \\ requirements for the degree of \\ Master of Applied Science \\ in the \\ program of Civil Engineering \\ Toronto, Ontario, Canada, 2018 \\ (C) Sandeep Parajuli, 2018
}




\section{AUTHOR'S DECLARATION}

I hereby declare that I am the sole author of this thesis. This is a true copy of the thesis, including any required final revisions, as accepted by my examiners.

I authorize Ryerson University to lend this thesis to other institutions or individuals for the purpose of scholarly research.

I further authorize Ryerson University to reproduce this thesis by photocopying or by other means, in total or in part, at the request of other institutions or individuals for the purpose of scholarly research.

I understand that my thesis may be made electronically available to the public. 


\title{
AXIAL STRENGTH OF LIGHTWEIGHT SELF-CONSOLIDATING CONCRETE COLUMNS WITH ENGINEERED CEMENTITIOUS COMPOSITE CONFINEMENT
}

\author{
Sandeep Parajuli \\ Master of Applied Science, 2018 \\ Department of Civil Engineering \\ Ryerson University, Toronto, Canada
}

\begin{abstract}
Axial load behavior of confined columns with engineered cementitious composite (ECC) wrapping was investigated through experimental, analytical and finite element (FE) investigations. The variables in the study were: geometry (cylindrical and rectangular), presence or absence of longitudinal and tie reinforcement, ECC wrap thickness, types of concrete core (lightweight and normal weight self-consolidating concrete) and type of loading (applied through both core and wrap or core only). The effect of these variables on axial load-deformation response, strain characteristics, failure modes, ductility, energy absorption capacity and axial strength were evaluated. The confined concrete strengths predicted from existing analytical and developed FE models were found to be in good agreement with those of experiments. The axial load capacity and ductility were increased for columns with highest ECC wrap thickness $(50 \mathrm{~mm})$ while thinner wrap increased stiffness instead of ductility. Canadian code conservatively predicted axial strength of columns having increased thickness of ECC wrap.
\end{abstract}




\section{ACKNOWLEDGEMENTS}

I am sincerely thankful to my supervisor Dr. Khandaker M. Anwar Hossain, Professor of structural engineering, for his excellent guidance, support and patience during the development of this research. He constantly motivated me to complete my thesis.

I would also like to thank Mr. Nidal Jaalouk and late Mr. Min Yao, for their assistance during casting and testing in the concrete and structural laboratories.

Above all, I would like to thank my wife Muna for her love, support and patience during the writing and entire study period. 


\section{Table of Contents}

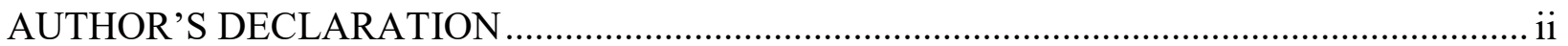

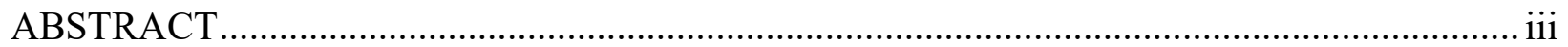

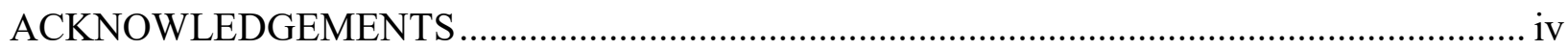

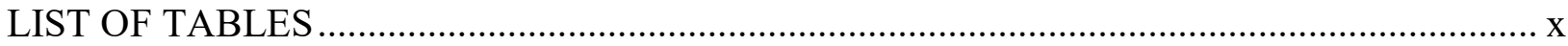

LIST OF FIGURES ….............................................................................................

LIST OF SYMBOLS AND ABBREVIATIONS ….........................................................

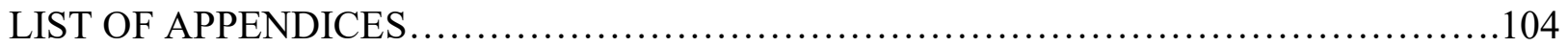

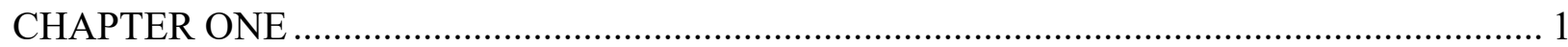

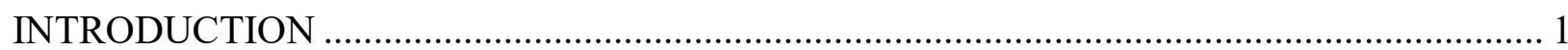

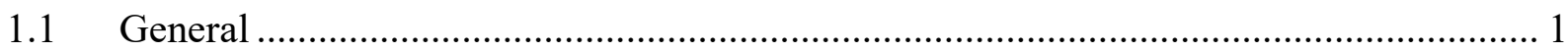

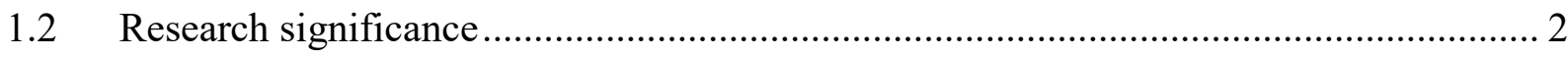

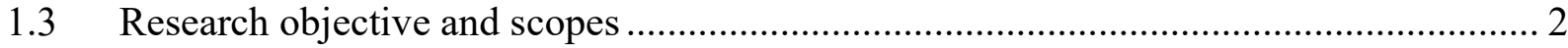

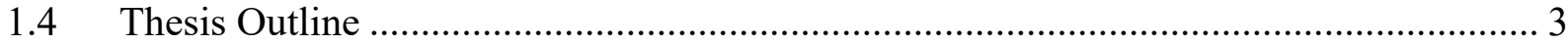

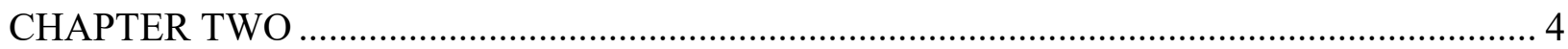

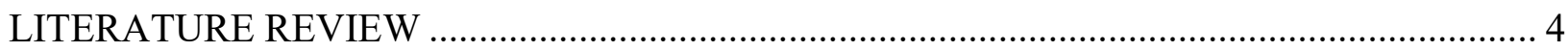

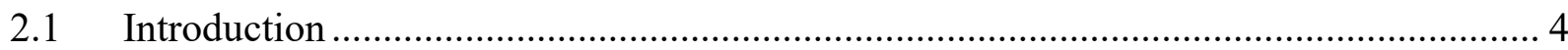

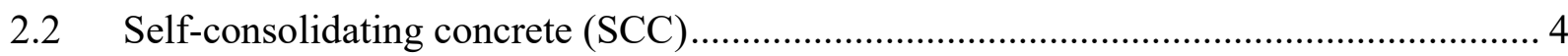

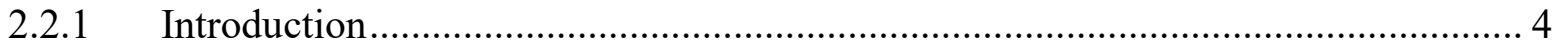

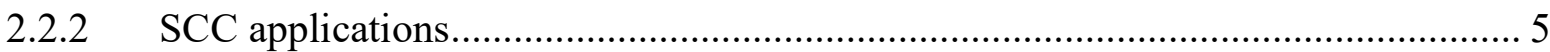

2.3 Light weight self-consolidating concrete (LWSCC) ........................................... 6

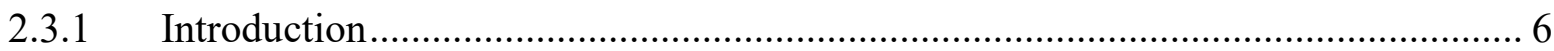

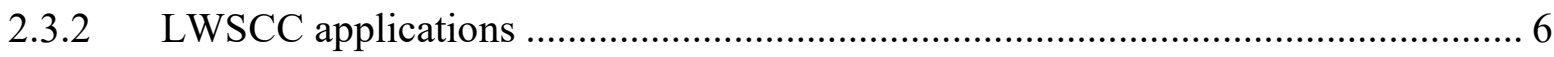

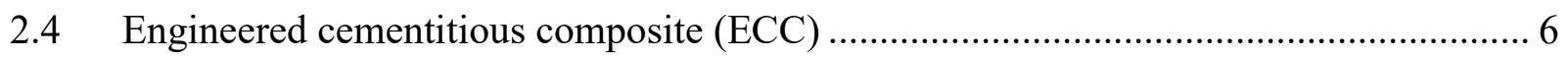

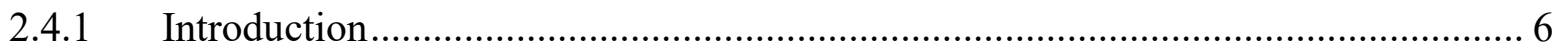

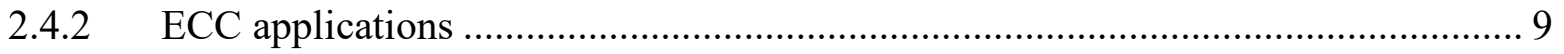

2.5 Column, concrete confinement and confinement models ......................................... 11 


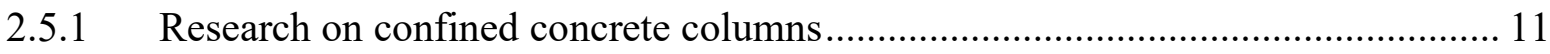

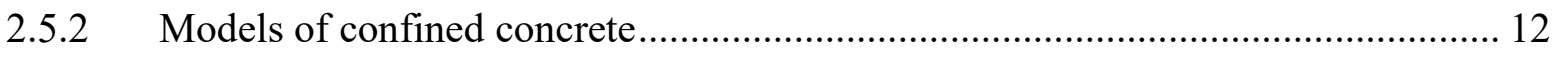

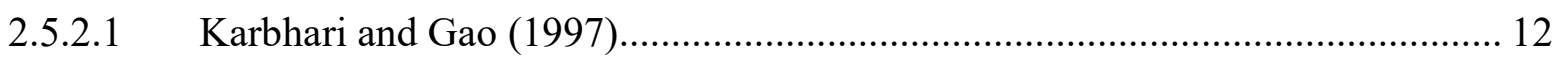

2.5.2.2 Mander, Priestley and Park (1988)................................................................. 13

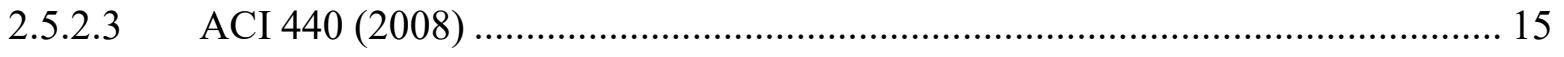

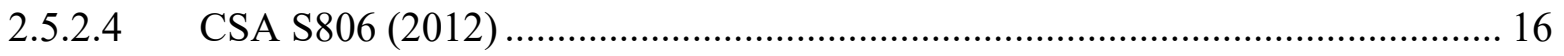

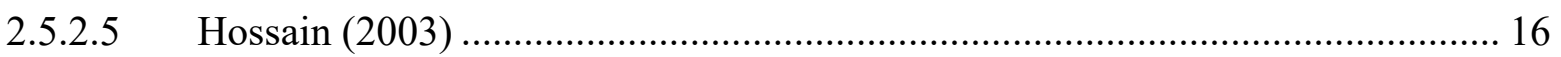

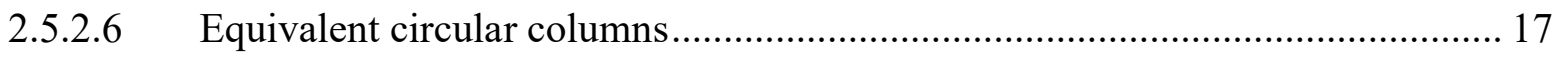

2.6 The finite element method (FEM) and modelling.................................................... 17

2.6.1 Concrete damaged plasticity model (CDP) in Abaqus FEM software .................... 18

2.6.2 Previous research studies conducted on finite element modeling of confined column 19

2.7 Review on miscellaneous topics including some testing methods............................... 20

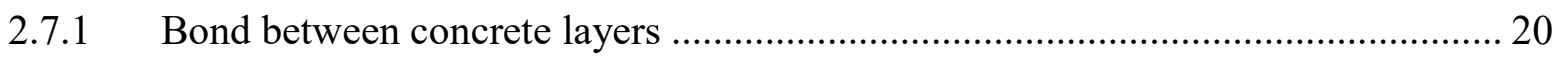

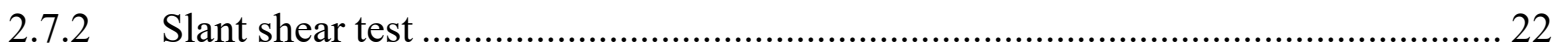

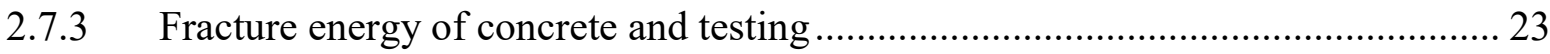

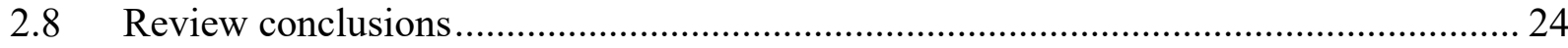

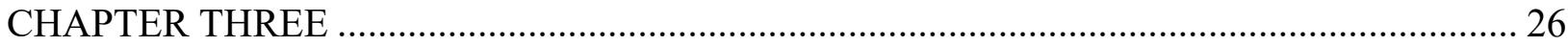

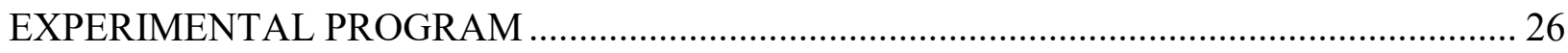

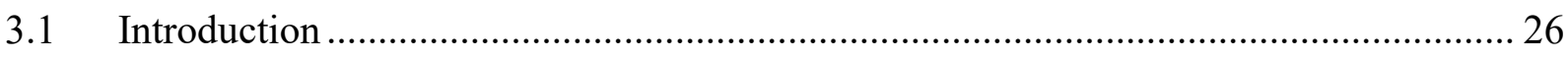

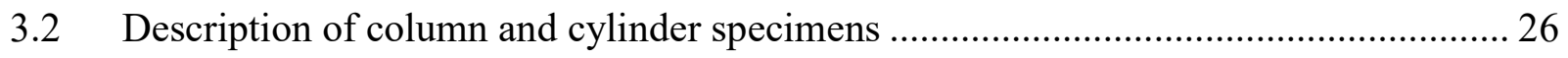

3.3 Materials used for casting columns ......................................................................... 30

3.4 Casting of columns with LWSCC core ……............................................................ 32

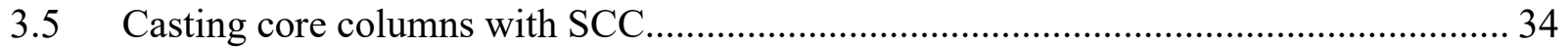

3.6 Casting of ECC wraps around LWSCC and SCC core columns ................................. 34

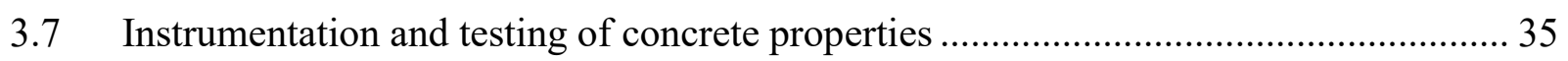

3.7.1 Compressive strength test of concrete cylinders as per ASTM C39/C39M (2014) 35

3.7.2 Modulus of elasticity and Poisson's ratio as per ASTM C469/C469M (2016)...... 36 
3.7.3 Splitting tensile strength test as per ASTM C496/C496M (2011)....................... 37

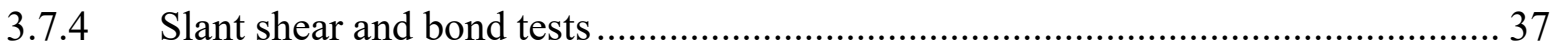

3.7.5 Three-point notched beam Test .................................................................. 38

3.8 Testing and instrumentation of cylindrical columns with ECC confinement ............... 39

3.9 Testing of square columns with ECC confinement................................................. 40

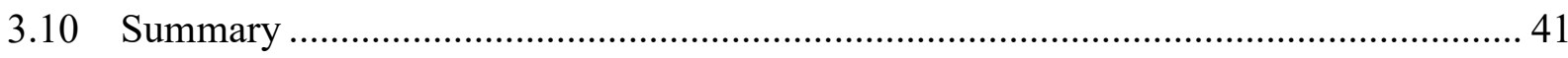

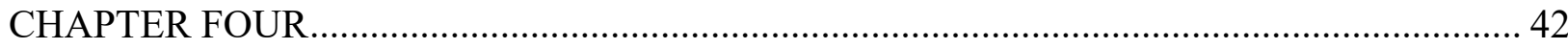

EXPERIMENTAL RESULTS AND DISCUSSIONS ............................................... 42

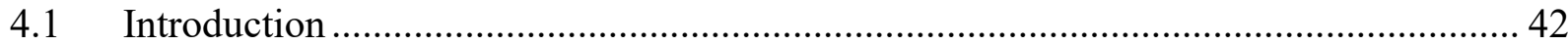

4.1.1 Fresh state and mechanical properties of concrete and re-bars......................... 42

4.1.2 Load vs. strain and deformation behavior during modulus of elasticity test......... 42

4.1.3 Load vs. displacement behavior during notched beam test ............................. 43

4.1.4 Bond strength between two concretes......................................................... 43

4.2 SCC and LWSCC cylindrical columns ........................................................... 46

4.2.1 General behavior of cylindrical columns ................................................... 47

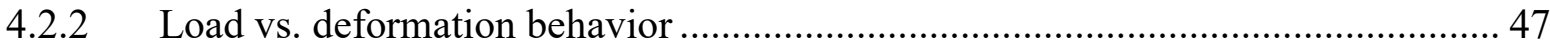

4.2.3 Failure mode and cracking behavior....................................................... 50

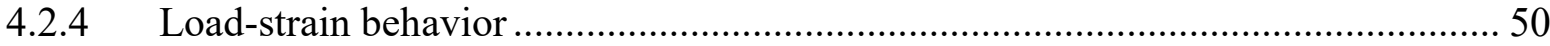

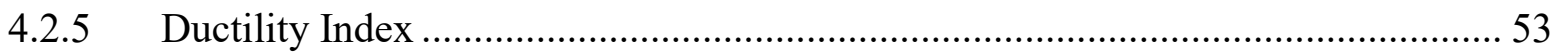

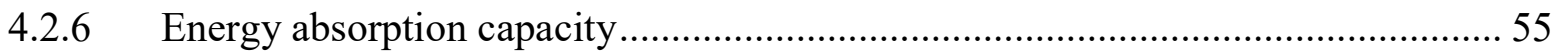

4.3 Reinforced untied SCC and LWSCC square columns with varying wrap thickness of ECC

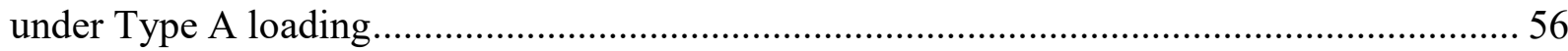

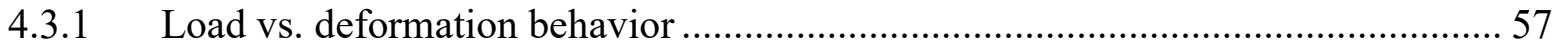

4.3.2 Failure mode and cracking behavior......................................................... 59

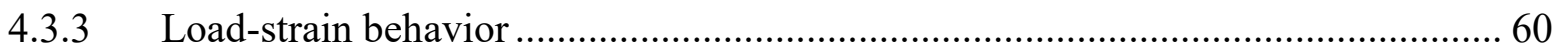

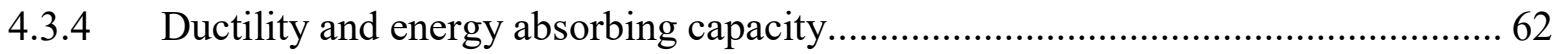

4.4 Reinforced tied square columns with varying thickness of ECC wrap -Type B loading64 


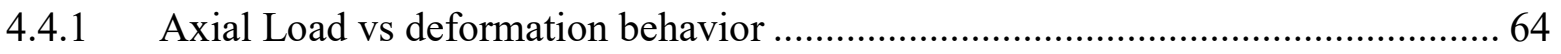

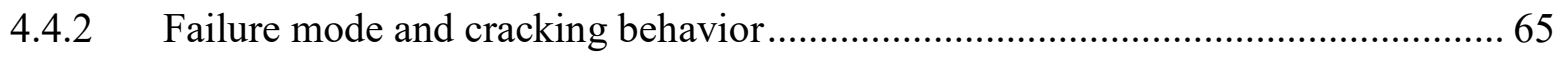

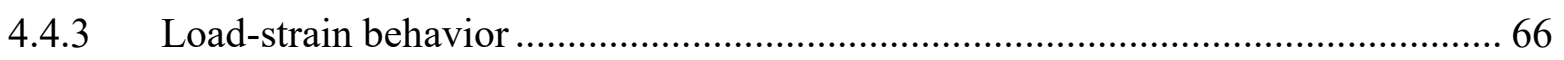

4.4.4 Ductility and energy absorbing capacity of tied reinforced columns ...................... 68

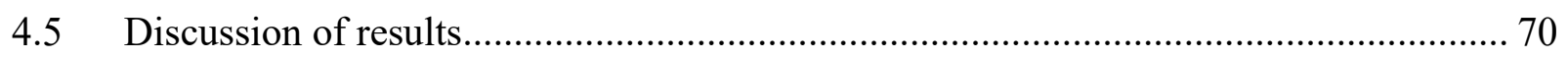

4.5.1 Influence of ECC wrap thickness on peak load and stiffness ................................ 70

4.5.2 Influence of Type A and Type B loading on peak load ...................................... 71

4.5.3 Influence of LWSCC and SCC on energy absorption capacity............................ 72

4.5.4 Influence of ECC wrap thickness on ductility index based on load-deformation curve 73

4.5.5 Influence of LWSCC and SCC on strain developments ...................................... 73

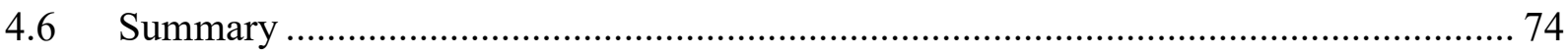

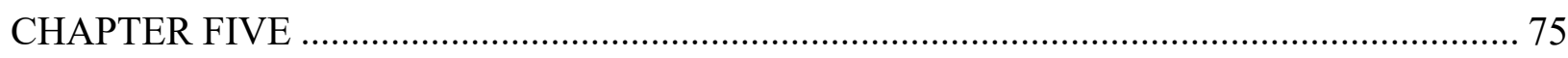

ANALYTICAL AND NUMERICAL ANALYSES OF COLUMNS WITH ECC

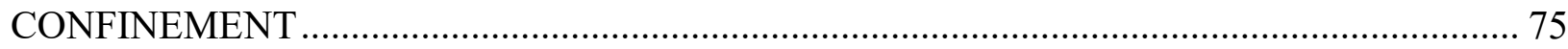

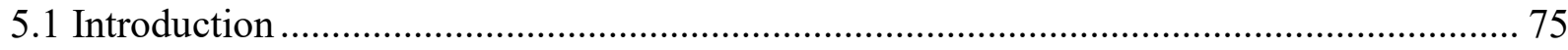

5.2 Quantification for effective confinement and compressive strength models for confined

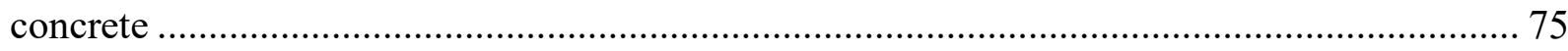

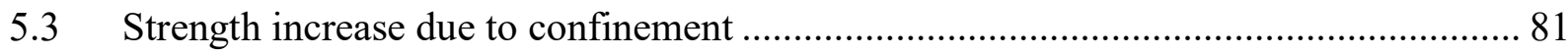

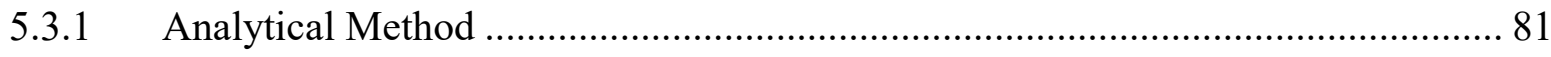

5.3.2 Theoretical analysis of loads based on experiments .......................................... 83

5.3.2.1 Analysis of columns under Type A loading (load applied through both core and wrap) $\quad 83$

5.3.2.2 Analysis of load contributions by wrap for columns under Type B loading ...... 85

5.3.2.3 Non-reinforced cylindrical columns with wrap .............................................. 85

5.3.3 Axial capacity of column based on CSA (2012) …………………………......... 86

5.3.4 Finite element modelling of columns .................................................................. 90 


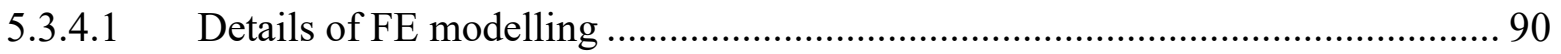

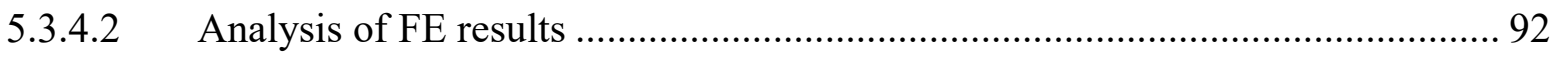

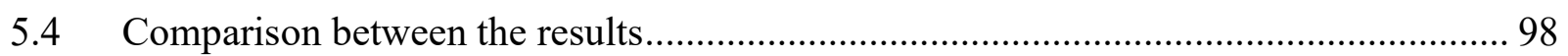

5.4.1. Non-reinforced cylindrical columns (Type B loading) ......................................... 99

5.4.2 Untied reinforced square column (Type A loading) .............................................. 99

5.4.3 Tied reinforced square column (Type B loading) ............................................... 100

5.4.4 Comparison between experimental and code based axial capacity of column ..... 100

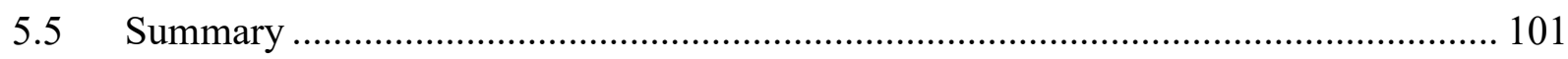

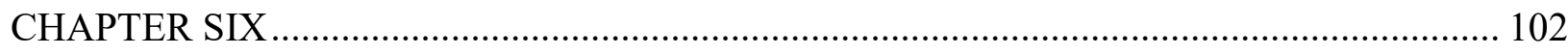

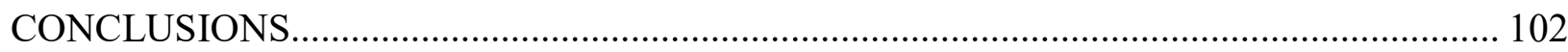

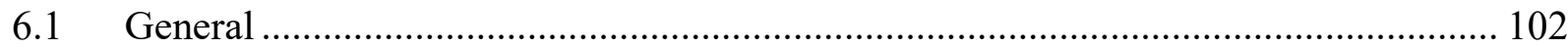

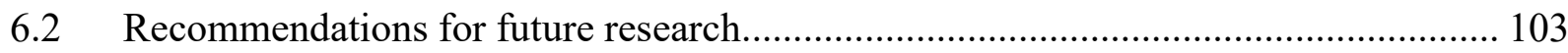

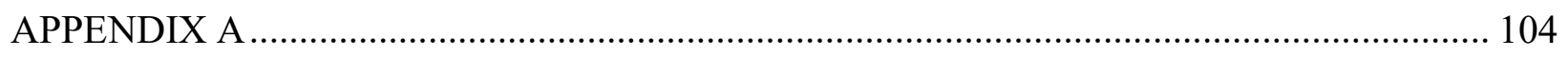

A1. Quantification for effective confinement and compressive strength models for confined

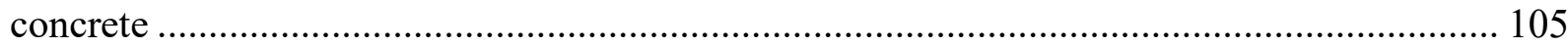

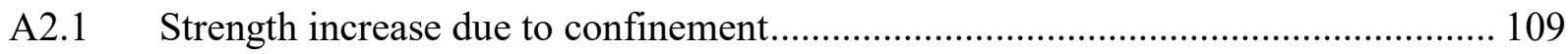

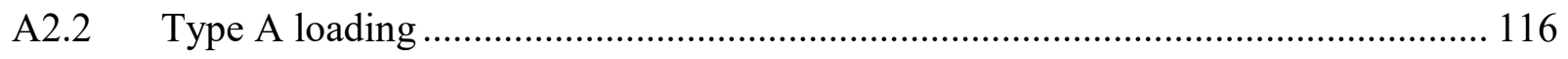

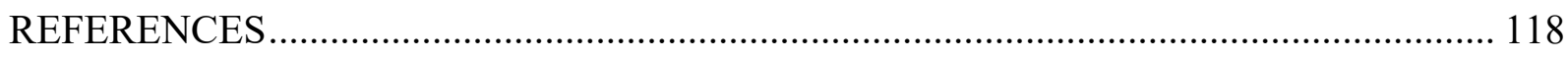




\section{LIST OF TABLES}

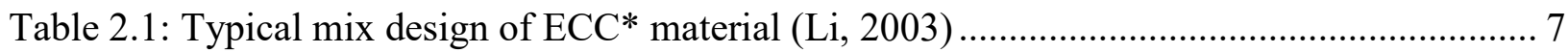

Table 2.2: Coefficients of cohesion and friction - CEB-FIP Model Code 1990 …………........... 21

Table 2.3: Coefficients of friction- PCI Design Handbook (2004) ............................................. 22

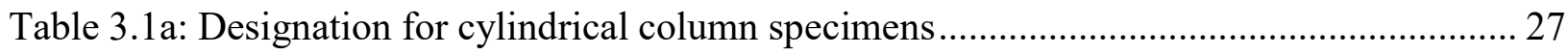

Table 3.1b: Designation for square LWSCC columns with or without ECC wrapping ................ 28

Table 3.1c: Designation for square SCC columns with or without ECC wrapping ..................... 28

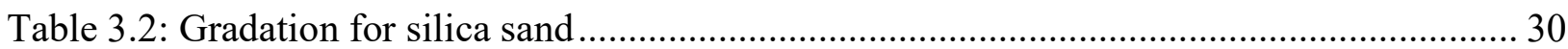

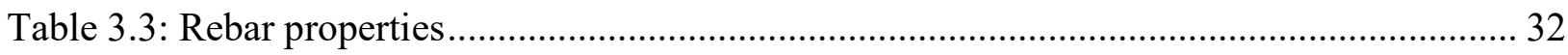

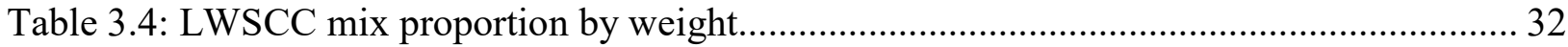

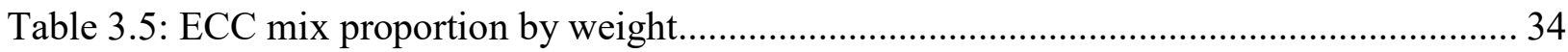

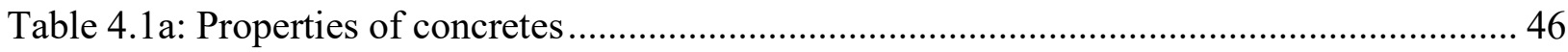

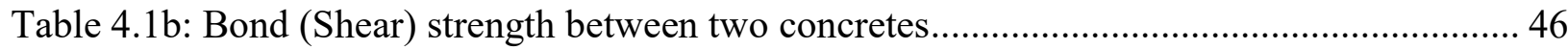

Table 4.2: Summary of test results of cylindrical column specimens ........................................... 48

Table 4.3: Ductility and energy absorbing capacity of cylindrical columns ................................ 54

Table 4.4: Summary of test results of reinforced untied square columns..................................... 58

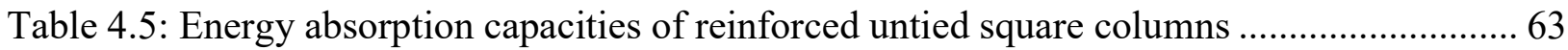

Table 4.6: Summary of test results based on load-deformation response of tied square columns 65

Table 4.7: Ductility and energy absorbing capacity of reinforced tied columns ............................ 68

Table 5.1: Confinement quantification in terms of lateral stress $\left(f^{\prime} l\right)$ for tested columns.............. 78

Table 5.2a: Analytical confined strength from Mander's model................................................ 81

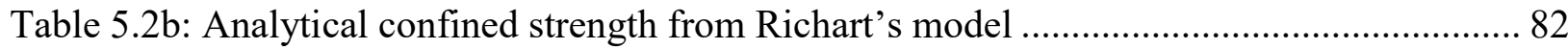

Table 5.3: Type A loading - Load sharing between different components of reinforced untied

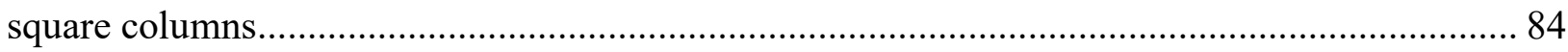

Table 5.4: Type B loading - Load increment due to ECC wrap in non-reinforced cylindrical

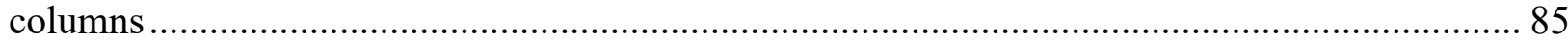

Table 5.5: Type B loading -Load increment due to ECC wrap in reinforced tied square columns

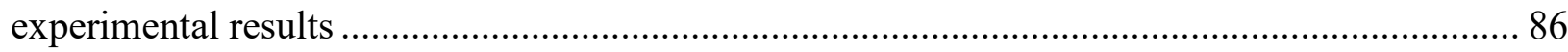

Table 5.6a: Code based axial capacity of non-reinforced cylindrical columns .............................. 87

Table 5.6b: Code based axial capacity of untied reinforced square columns................................ 88 
Table 5.6c: Code based axial capacity of tied reinforced square columns ............................. 89

Table 5.7: Material and interaction input parameters for FE model ....................................... 90

Table 5.8: Peak axial stress in concrete core from FE analysis ............................................. 98

Table 5.9: Non-reinforced cylindrical column-Type B loading $\left(f^{\prime} c c / f^{\prime} c\right)$................................. 99

Table 5.10: Untied reinforced square column-Type A loading $\left(f^{\prime} c c / f^{\prime} c\right)$................................ 99

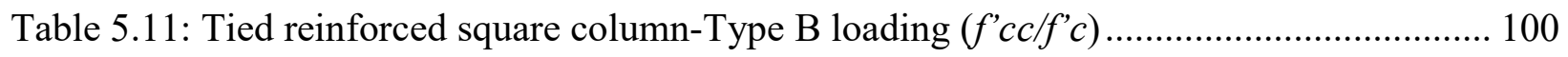




\section{LIST OF FIGURES}

Fig. 2.1: Self-consolidating concrete construction (www.oboa.on.ca)......................................... 4

Fig. 2.2: SCC used as a bridge bearing pad on Highway 7/400, Vaughan, ON ........................... 5

Fig. 2.3: Uniaxial tensile stress-strain curves of an ECC with 2\% PVA fibers ( $\mathrm{Li}, 2003)$............ 7

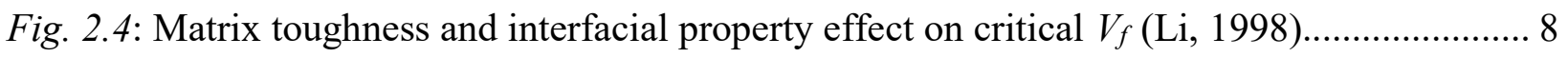

Fig. 2.5: Spray repair of the Mitaka dam with ECC for water-proofing (Sakata et al., 2004) ...... 9

Fig. 2.6: The Nabeaure tower in Yokohoma, Japan uses precast ECC coupling beams in building core for seismic resistance (Maruta et al., 2005) ..................................................................... 10

Fig. 2.7: ECC patch repair on Michigan bridge deck (Li et al., 2005 ....................................... 10

Fig.2.8: Stress-strain relation for monotonic loading of confined and unconfined concrete (Mander

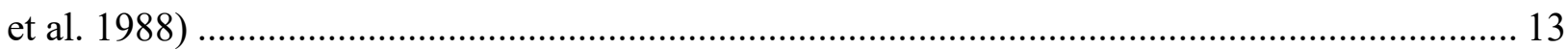

Fig.2.9: Dimension of the column with ties and main reinforcement ........................................ 14

Fig 2.10: Effective Confinement Area (Lam and Tang, 2003)................................................. 15

Fig. 2.11: Damage parameters (ABAQUS Documentation, Abaqus 6.14) …………………..... 19

Fig. 2.12: Average axial stress strain curve (Yu et al., 2010).................................................. 19

Fig. 2.13: Numerical-experimental comparison in stress vs. strain diagrams for square columns with internal steel reinforcements and external FRP jacket (Mazzucco et al. 2016).................... 20

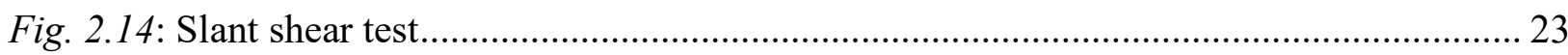

Fig.2.15: (a) Notched beam in three-point bending (b) Load-displacement (Bazant, 1992)........ 24

Fig. 3.1a: Section and elevation of cylindrical columns with and without ECC wraps (Dimensions in $\mathrm{mm}$ ) 29

Fig. 3.1b: Section and elevation of untied reinforced concrete columns with and without wrapping (Dimensions in $\mathrm{mm}$ ) 29

Fig. 3.1c: Section and elevation of tied reinforced concrete columns with and without wrapping

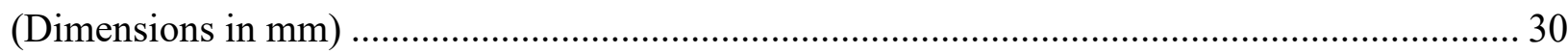

Fig. 3.2: Stress-strain responses of reinforcement bars (Sathiyamoorthy, 2016) ........................ 31

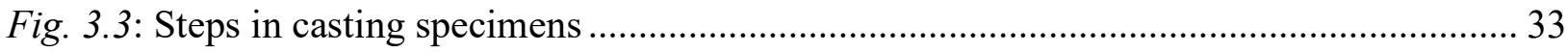

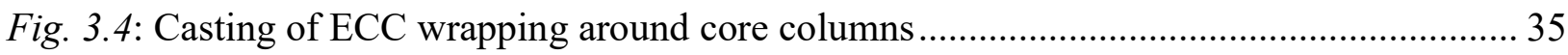

Fig. 3.5: Experimental set-up, instrumentation, and testing of concrete cylinders ...................... 36

Fig. 3.6: Location of strain gauges on control concrete cylinder ................................................ 36 
Fig. 3.7: Splitting test setup and testing as per ASTM C496/C496M (2011) .......................... 37

Fig. 3.8: Slant shear test setup and testing ..................................................................... 38

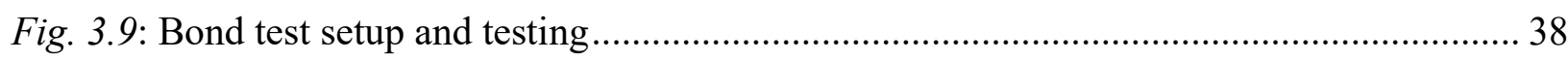

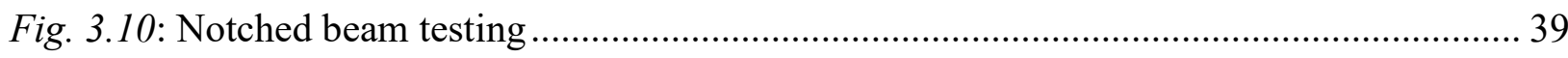

Fig. 3.11: Location of strain gauges and test set-up showing testing of ECC confined cylindrical

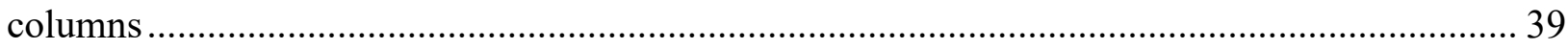

Fig. 3.12: Experimental set-up, instrumentation and testing of square columns...................... 40

Fig. 3.13: Location of strain gauge for columns and testing ........................................... 41

Fig. 4.1a: LWSCC load-strain and deformation responses during modulus of elasticity test...... 44

Fig.4.1b: SCC load-strain and deformation responses during modulus of elasticity test........... 44

Fig. 4.1c: ECC load-strain and deformation responses during modulus of elasticity test........... 44

Fig. 4.2a: LWSCC load-displacement response during notched beam test ............................ 45

Fig. 4.2b: SCC load-displacement response during notched beam test................................. 45

Fig. 4.2c: ECC load-displacement response during notched beam test................................. 45

Fig. 4.3a: Load-deformation responses for LWSCC cylindrical specimens under Type B loading 49

Fig. 4.3b: Load-deformation responses for SCC cylindrical specimens under Type B loading .. 49 Fig. 4.4: Testing of cylindrical columns showing crack patterns and failure modes ................. 50

Fig. 4.5a: Hoop strain development in cylindrical ECC column C-EC ................................ 51

Fig. 4.5b: Hoop strain development in cylindrical column between the interface (LWSCC/ECC)

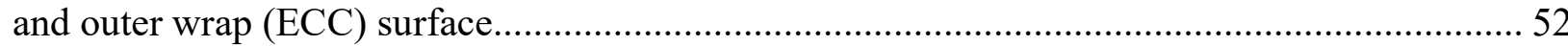

Fig. 4.5c: Hoop strain development in cylindrical column between the interface (SCC/ECC) and

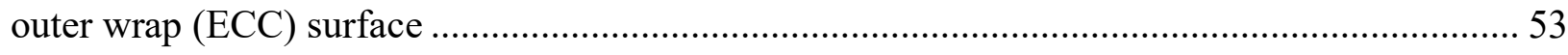

Fig. 4.6a: Load - strain curves for strain-based ductility index calculation ............................. 55

Fig. 4.6b: Ductility Index (strain based) for cylindrical columns......................................... 55

Fig. 4.7: Energy absorption capacity calculation from load-deformation curve ....................... 56

Fig. 4.8a: Load-deformation responses of reinforced untied LWSCC square columns under Type

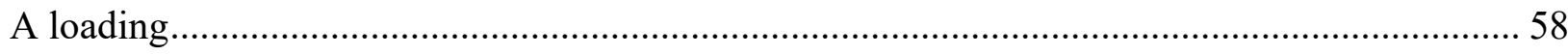

Fig. 4.8 b: Load-deformation responses of reinforced untied SCC square columns under Type A

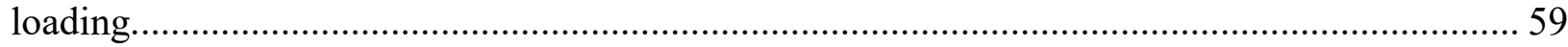

Fig. 4.9: Cracking patterns of reinforced untied columns .............................................. 60 
Fig. 4.10a: Hoop strain development in reinforced untied column between the interface (LWSCC/ECC) and outer wrap (ECC) surface 61

Fig. 4.10b: Hoop strain development in reinforced untied column between the interface (SCC/ECC) and outer wrap (ECC) surface . 62

Fig. 4.11: Ductility Index (strain based) for reinforced untied square columns....................... 63

Fig. 4.12: Load-deformation responses of reinforced tied columns under Type B loading ........ 65

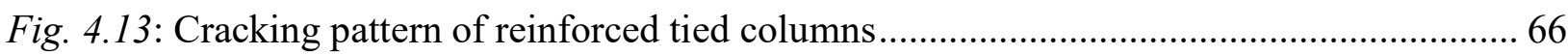

Fig. 4.14a: Hoop strain development in reinforced tied column between the interface (LWSCC/ECC) and outer wrap (ECC) surface 67

Fig. 4.14b: Hoop strain development in reinforced tied column between the interface (SCC/ECC)

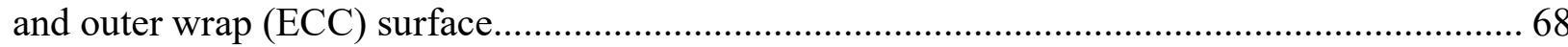

Fig. 4.15: Ductility Index from load-strain curve for tied square columns ............................. 69

Fig. 4.16: Energy Absorption capacity from load-deformation responses.............................. 69

Fig. 4.17: Influence of wrap thickness on load carrying capacity of columns ......................... 70

Fig. 4.18: Influence of wrap thickness to diameter (width) ratio on columns load carrying capacity 71

Fig. 4.19: Influence of Type A and Type B loading on peak load ........................................ 71

Fig. 4.20: Influence of Type A and Type B loading on columns peak load............................. 72

Fig. 4.21: Influence of Type A and Type B loading on peak load ........................................ 72

Fig. 4.22: Influence of $t / D(t / b)$ ratio loading on ductility index (DI) .................................. 73

Fig. 4.23: Interfacial hoop strain at peak load for various columns ...................................... 74

Fig. 5.1: Dimensions of square reinforced tied column with wraping .................................. 76

Fig. 5.2: Quantification of confining force in circular columns .............................................. 77

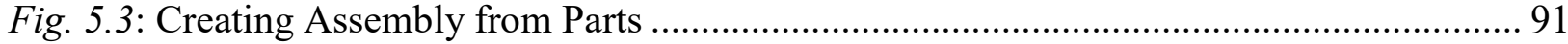

Fig. 5.4: Load and half-symmetry of column for analysis ................................................. 92

Fig. 5.5: Cylindrical column C-LW-50 response to increasing Type B load levels................... 93

Fig. 5.6: Cylindrical column C-SC-50 response to increasing Type B load levels .................... 94

Fig. 5.7: Reinforced tied square column S-LW-50T response to increasing Type B load levels 95

Fig. 5.8: Reinforced tied square column S-SC-50T response to increasing Type B load levels.. 96

Fig. 5.9: Reinforced untied square column S-LW-20 response to increasing Type A load levels97 
Fig.5.10: Axial stress-strain development in concrete core (top surface) for columns with 50mm

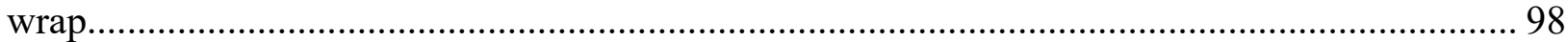




\section{LIST OF SYMBOLS AND ABBREVIATIONS}

ASTM American Society for Testing and Materials

CSA Canadian Standards Association

CFST Concrete filled steel tube

DI Ductility index

ECC Engineered cementitious composite

FRP Fiber reinforced polymer

HPC High performance concrete

HPFRCC High performance fiber reinforced cementitious composites

HRWRA High range water reducing admixtures

LWSCC Lightweight self -consolidating concrete

LVDT Linear variable differential transformers

NC Normal concrete

MDOT Michigan department of transportation

PE Polyethylene

PVA Poly-vinyl-alcohol

RC Reinforced concrete

SCC Self-consolidating concrete

SCM Supplementary cementing material

TWC Thin walled composite

Exp. Experiment

$\alpha_{1} \quad$ Average compression stress to the concrete strength ratio

Ag Gross sectional area of column

$b_{t}$ and $d_{t} \quad$ Dimensions of the rectangular tie

$\boldsymbol{\delta}_{\boldsymbol{o}} \quad$ Crack opening corresponding to the maximum bridging stress

$\boldsymbol{d}_{\boldsymbol{f}} \quad$ Diameter of the fiber

$d_{s} \quad$ Diameter of circular tie

D $\quad$ (Equivalent) Diameter

E Modulus of elasticity

$f^{\prime} c \quad$ Compressive strength of unconfined concrete 


\begin{tabular}{ll}
$f^{\prime} c c$ & Compressive strength of confined concrete \\
$\varepsilon_{c c}$ & Strain corresponding to confined concrete strength of $f^{\prime}{ }_{c c}$ \\
$\varepsilon_{f e}$ & Effective hoop strain level in the wrap attained at failure \\
$f_{l}$ & Confining pressure \\
$f^{\prime}{ }_{l}$ & Effective confining pressure \\
$f_{y}$ & Yield strength of tensile reinforcement bar \\
$k_{l}$ and $k_{c}$ & Factors associated with confining pressure and geometry as per CSA S806 \\
$n_{f}$ & Number of FRP layer \\
$\boldsymbol{g}$ & Snubbing factor \\
$G_{F}$ & Fracture energy \\
$J_{c}$ & Crack tip toughness \\
$k$ & Effective length factor of a column \\
$K_{a}$ & Efficiency factor based on geometry of the section \\
$k_{l}$ & Confinement effectiveness ratio \\
$\boldsymbol{L}_{\boldsymbol{f}}$ & Length of fiber \\
$l_{u}$ & Unsupported length of a column \\
$M_{l}$ & Smaller factored end moment of a column \\
$M_{2}$ & Larger factored end moment of a column \\
$M_{u}$ & Ultimate moment capacity \\
$P$ & Axial capacity of a column \\
$P_{f}$ & Factored axial force \\
$\varphi_{c}$ & Resistance factors for concrete \\
$\varphi_{s}$ & Resistance factors for steel \\
$R_{c}$ & Radius of corner of rectangular column \\
$r$ & Radius of gyration of a column \\
$\rho_{h}$ & Ratio of volume ties to volume of confined core \\
$\rho_{s c}$ & Ratio of area of longitudinal bars to area of confined core \\
$f_{y}$ & Clear spacing between the ties \\
& Reduction factor \\
\hline & Thickness of wrap \\
\hline &
\end{tabular}


$d \quad$ Degradation variable for elastic modulus

$d_{t}$ and $d_{c} \quad$ Tension and compression damage variables, respectively

${\tilde{\varepsilon_{t}}}^{p l}$ and ${\tilde{\varepsilon_{c}}}^{p l} \quad$ Equivalent tensile and plastic strains, respectively

$\varepsilon_{t}^{e l}$ and $\varepsilon_{c}^{e l} \quad$ Elastic strains in tension and compression, respectively

$v_{u} \quad$ Shear stress

$c \quad$ Coefficient of cohesion

$\mu \quad$ Coefficient of friction

$\tau_{f u, d} \quad$ Shear resistance due to concrete-to-concrete friction

$\sigma_{c d} \quad$ Average normal compressive stress

$\lambda \quad$ Modification parameter which depends on the concrete density

S/d Span to depth ratio of a prism (beam)

$K_{I} \quad$ Stress intensity factor

$\boldsymbol{\tau} \quad$ Fiber/matrix frictional bond strength

$\boldsymbol{V}_{\boldsymbol{f}}^{\text {crit }} \quad$ Critical volume for fiber fraction 


\section{CHAPTER ONE \\ INTRODUCTION}

\subsection{General}

Conventional concrete is a brittle cementitious material with low tensile strength and crack resistance, limited deformability and weak impact resistance properties. Such properties limit the applications of concrete in construction applications. The compressive strength of concrete is the main parameter for the design of concrete structures. However, as the strength increases, the brittleness of concrete increases, leading to less ductile concrete.

The need of strengthening old, damaged and deteriorated concrete in North America led the researcher to look for a new technology that could give a concrete relatively high ductility and strength. One of the way to enhance the strength and ductility is by providing confinement to the concrete. The confinement can be achieved by either wrapping, jacketing or filament winding. Various theories have been developed to predict the behavior of confined concrete columns using different confining material like steel, high strength concrete and composite materials. The use of steel tubes and fiber reinforced polymer (FRP) sheet as a thin confining material for columns has been studied extensively. Using Engineered Cementitious Composite (ECC) as a confining material can add to the strength and ductility of columns but a very little work has been done on ECC as confining material. ECC features high ductility and damage tolerance with fine multiple cracking under mechanical loading, including tensile and shear loadings. With material optimization, it is reported that tensile strain capacity in excess of $3 \%$ under uniaxial tensile loading has been obtained even with low fiber content. Compressive strength of ECC varies from $30 \mathrm{MPa}$ to $90 \mathrm{MPa}$, elastic modulus $20 \mathrm{GPA}$ to $25 \mathrm{GPa}$ and compressive strain capacity around $0.45-0.65 \%$ ( $\mathrm{Li}, 2007)$. Jacketing by ECC is gaining attention due to its highly ductile nature. Confining

columns made of comparatively weak lightweight concrete (LWC) with ECC wrapping can enhance strength and ductility. This warrants research to understand the structural behavior of columns especially made of lightweight concrete confined by ECC wrapping under axial compression. 


\subsection{Research significance}

Most of the existing researches have been focused on columns confined with FRP and steel tubes on circular column sections and analytical models for confined concrete strength and axial strength are derived for circular sections. The thickness of confining material is considered small compared to the section of confined columns, so the confining material is treated as a thin section, that is, a lamina or a sheet, for analysis. Again, very limited research studies have been conducted on rectangular and square columns using confining ECC of variable thickness. Lightweight selfconsolidating concrete (LWSCC) is comparatively new technology combining the beneficial properties of lightweight weight concrete (LWC) and self-consolidating concrete (SCC). Until to date no research has been conducted on reinforced LWSCC columns confined with ECC wrapping. Therefore, the structural behavior of confined reinforced/unreinforced tied/untied columns made LWSCC with ECC wrapping needs to be studied compared with their conventional SCC counterparts to assess the strength, ductility and confined concrete strength characteristics. The applicability of existing analytical and code-based models for strength and confined concrete strength should also need to be verified for columns made of new ECC wrapping material.

\subsection{Research objective and scopes}

This research consists of experimental, analytical and finite element (FE) investigations on concrete columns with ECC wrapping subjected to axial compression loading to failure. The variables in this study are: shape (circular and rectangular), core concrete types (SCC and LWSCC), presence or absence of longitudinal and tie reinforcement, thickness of ECC wrapping and types of loading.

The main objectives of this research are to:

- Conduct the experimental and FE investigations on the axial load behavior of reinforced/unreinforced tied/untied cylindrical/square SCC/LWSCC columns with or without ECC wrapping of variable thickness subjected to Type A and Type B loadings (load applied through both core and ECC warp only or through SCC/LWSCC concrete core).

- Analyze and compare the axial load behavior of columns based on load carrying capacity, load-deflection response, stress-strain development in core and wrap, load sharing among core/wrap/reinforcement, ductility, energy absorbing capacity and failure modes by 
providing emphasis on the effect of ECC wrap thickness, tie reinforcement, longitudinal reinforcement and type of concrete core (LWSCC/SCC).

- Carry out experimental tests on individual concrete types to determine mechanical and fracture properties.

- Compare the experimental results such as axial load capacity, confined concrete strength, stress-strain developments with those predicted by analytical/code-based equations and FE models to validate and evaluate their performance.

- Derive conclusion and make recommendations for future research studies.

\subsection{Thesis Outline}

This thesis consists of six chapters which are outlined as follows:

Chapter 1 discusses the need for confining columns and different types of confining materials. It introduces ECC as a possible confining concrete chosen due to its ductile characteristics.

Chapter 2 details literature review on materials used for composite columns and their various usages. Literature on confinement effect on concrete is also included.

Chapter 3 details geometric dimensions of column specimens. Column casting process are described along with instrumentation and testing of columns.

Chapter 4 reports experimental axial load-displacement, failure modes, axial capacities and stressstrain characteristics for tested columns. Experimental results from each type of columns are compared. Strength enhancement and confinement of different specimens are compared.

Chapter 5 compares the experimental results of the tested columns with those obtained from finite element models, existing theoretical and Canadian code-based equations.

Chapter 6 summarizes the findings of the research and provides recommendations for future research study. 


\section{CHAPTER TWO \\ LITERATURE REVIEW}

\subsection{Introduction}

Numerous research studies have been conducted in the past on concrete confinement and various models to define the behavior of confined concrete have been established. This chapter presents a literature review on various types of concretes, their applications and performance related to confinement in different structural elements such as confined composite columns, existing concrete confinement models, finite element modeling of confined concrete columns and other topics related to this research including tests and testing methods. Existing equations and codebased procedures for the determination of confined concrete strength and axial strength of confined columns are also discussed.

\subsection{Self-consolidating concrete (SCC)}

\subsubsection{Introduction}

SCC is a highly flowable and stable concrete that spreads and fills in the forms without consolidation as shown in Fig 2.1 (Khayat et al., 2000). Due to its flowing nature, SCC was used in structures with highly congested reinforcement bar in Japan for the areas with high seismic activity during late 1980's (Ozawa et al., 1989; Hossain and Lachemi, 2010). SCC is finding increased use in recent years and providing excellent alternative to conventional concrete (JSCE 1998).

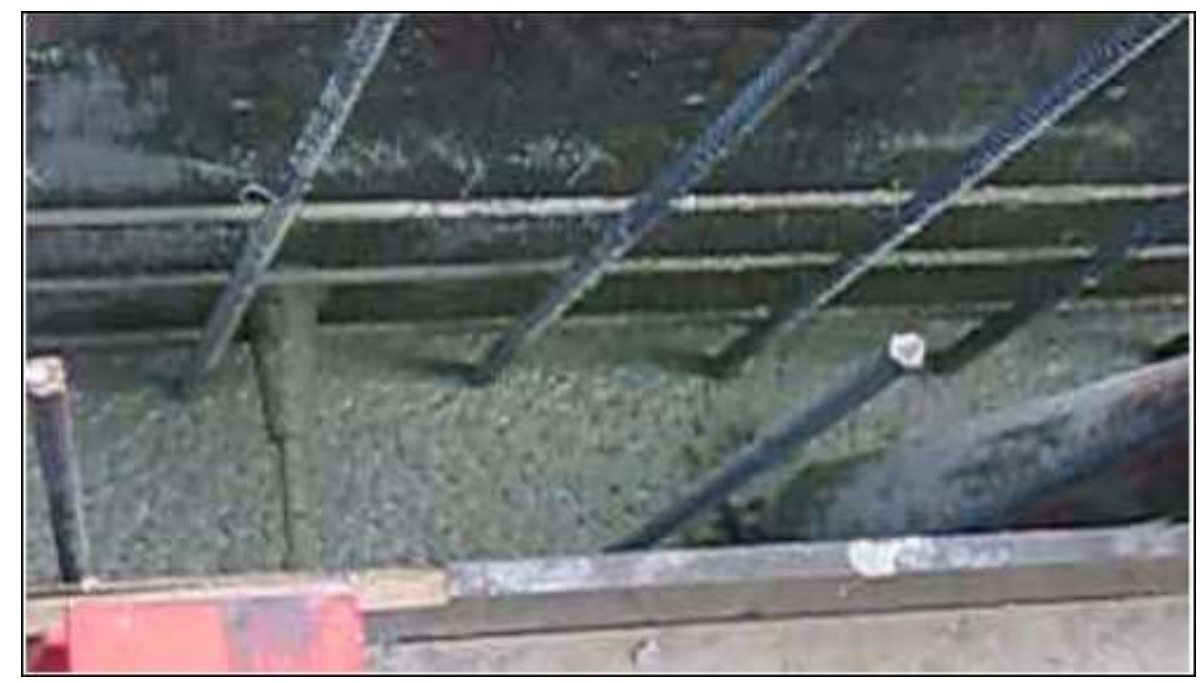

Fig. 2.1: Self-consolidating concrete construction (www.oboa.on.ca) 
The advantage of SCC is the improved productivity in transportation and placement of fresh concrete. As the water content is low due to use of superplasticizer, it provides fluidity and segregation resistance to give homogeneous concrete with ease of placement, less honey combs, high durability and superior finish. This can reduce the overall construction and maintenance cost. Thus, using SCC in construction projects can reduce the cost and time of concrete construction (Okamura 1996; EFNARC 2005; Yahia et al., 1999; Lachemi et al., 2003; Hossain and Lachemi, 2010; Hossain et al., 2010; Hassan et al., 2010).

\subsubsection{SCC applications}

One of the comparative investigation using normal concrete, shotcrete and SCC was done by Lacombe et al. (1999) as an overhead repair material. These concretes were used to repair three concrete blocks at a depth of approximately $40 \mathrm{~mm}$ on one surface of each block. SCC mixture used viscosity modifying agent (VMA) to reduce bleeding and segregation. After seven days, results showed that the normal concrete did not fill all the section and developed considerable segregation and large air pockets. SCC and shotcrete had a good bonding and performed well but the use of admixture for SCC made it expensive while skilled labor requirement for shotcrete made the cost to increase significantly. Thus, the study suggested more research to develop cost-effective SCC. Other applications for SCC as a repair material includes repair of chloride-induced deteriorated cast-in-place bridge built in the 1960's in the Swiss Alps, rehabilitation of the Webster parking garage in Sherbrooke and the rehabilitation of the Beauhamois Dam near Montreal (Campion and Jost 2000). Thus, SCC is finding increased use now a day, for example, in the construction of bridge bearing pads as shown in Fig.2.2.

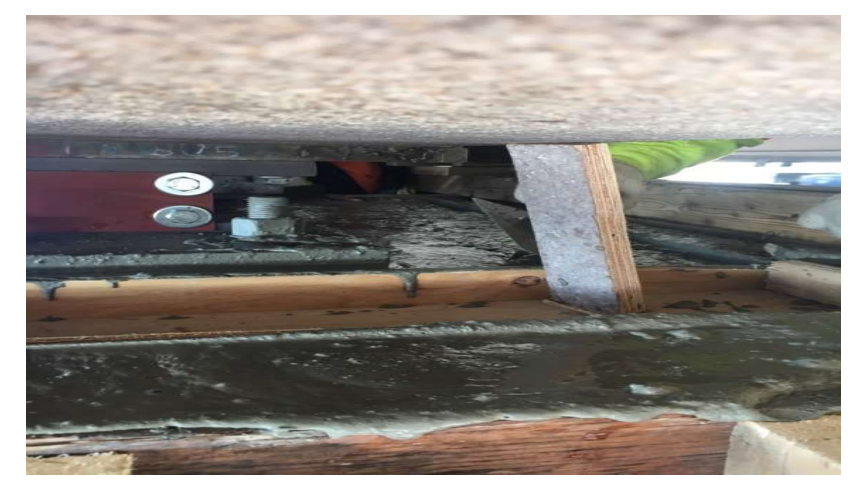

Fig. 2.2: SCC used as a bridge bearing pad on Highway 7/400, Vaughan, ON 


\subsection{Light weight self-consolidating concrete (LWSCC)}

\subsubsection{Introduction}

One of the latest innovations in concrete technology is the development of LWSCC combining the benefits of traditional SCC and lightweight concrete (LWC). LWSCC contributes less dead load to the structure and has better insulation and thermal characteristics with compressive strength up to 60MPa. As per ASTM C 330 (2017), structural LWSCC has minimum 28 days compressive strength of $17 \mathrm{MPa}$ and density in between $1120 \mathrm{~kg} / \mathrm{m}^{3}$ and $1920 \mathrm{~kg} / \mathrm{m}^{3}$. Generally, LWSCCs are designed based on experiments and empirical relationships. As lightweight aggregates (LWAs) are used, there is always a chance of segregation. Silica fume has been used for preventing segregation by making the mixture cohesive in recent studies (Lotfy, Hossain and Lachemi, 2016). ASTM classifies LWAs into three groups, structural, structural-insulating and insulating - ranges of strength, density and thermal properties vary in each of these groups. The failure of LWSCC occurs from interface between aggregates and cement paste matrix, aggregate itself or from the cement paste matrix. The tendency to form microcracks is reduced as the property of aggregates and cement matrix are similar.

\subsubsection{LWSCC applications}

Initial application of LWSCC was reported in Japan in 1922 for the construction of a cable-stayed bridge's main girder. LWSCC has found its place in precast stadium benches (Hubertova and Hela, 2007) and pre-stressed beams with spans reaching up to $20 \mathrm{~m}$ (Dymond, 2007). Various types of LWSCCs like foamed concrete and volcanic pumice aggregate concrete (VPC) were used as infill material in concrete filled steel tube (CFST) columns (Hunaiti, 1996; Hossain, 2003). Foamed concrete LWSCC had higher axial capacity contribution and more confinement compared with lightweight aggregate concrete, potentially due to better homogeneity of foamed concrete.

\subsection{Engineered cementitious composite (ECC)}

\subsubsection{Introduction}

ECC was developed to account for brittle behavior of normal concrete and to exhibit tensile ductility (Li, 2008). High-Performance Fiber-Reinforced Composites (HPFRCC) were developed using continuous and discontinuous fibers which showed high degree of ductility and strain hardening behavior. ECC was developed as a branch of HPFRCC with moderate tensile strength 
from $2 \mathrm{MPa}$ to $6 \mathrm{MPa}$ (Fischer et al., 2003; Li, 1993). ECC features high ductility and damage tolerance with fine multiple cracking under mechanical loading, including tensile and shear loadings. With material optimization, it is reported that tensile strain capacity in excess of $3 \%$ under uniaxial tensile loading has been obtained even with low fiber content. Typical ECC mix design of ECC using cement, silica sand, fly ash, polyvinyl alcohol (PVA) fiber and high range water reducing admixtures (HRWRAs) is presented in Table 2.1 (Li. 2003).

Table 2.1: Typical mix design of ECC* material ( $\mathrm{Li}, 2003)$

\begin{tabular}{|c|c|c|c|c|}
\hline Cement & Water & Silica Sand & Fly Ash & $\begin{array}{c}\text { High Water Reducing Admixture } \\
\text { (HRWRA) }\end{array}$ \\
\hline 1 & 0.58 & 0.8 & 1.2 & 0.013 \\
\hline
\end{tabular}

*2\% polyvinyl alcohol (PVA) fiber - ratios are by mass

Generally, fiber reinforced composites use high volume of fiber so special processing is required for the placement of the concrete. High volume of fiber is more costlier and weigh more. The composite properties depend on the fiber, matrix and interface properties, which can be engineered to obtain strain hardening and durable concrete such as Engineered Cementitious Composites (ECCs). Strain hardening material continues to carry load after crack initiates with large deformation. This can be seen from the typical uniaxial tensile stress-strain curves of an ECC reinforced with 2\% PVA fibers showing high tensile ductility of about 5\% as shown in Fig.2.3 (Li, 2003).

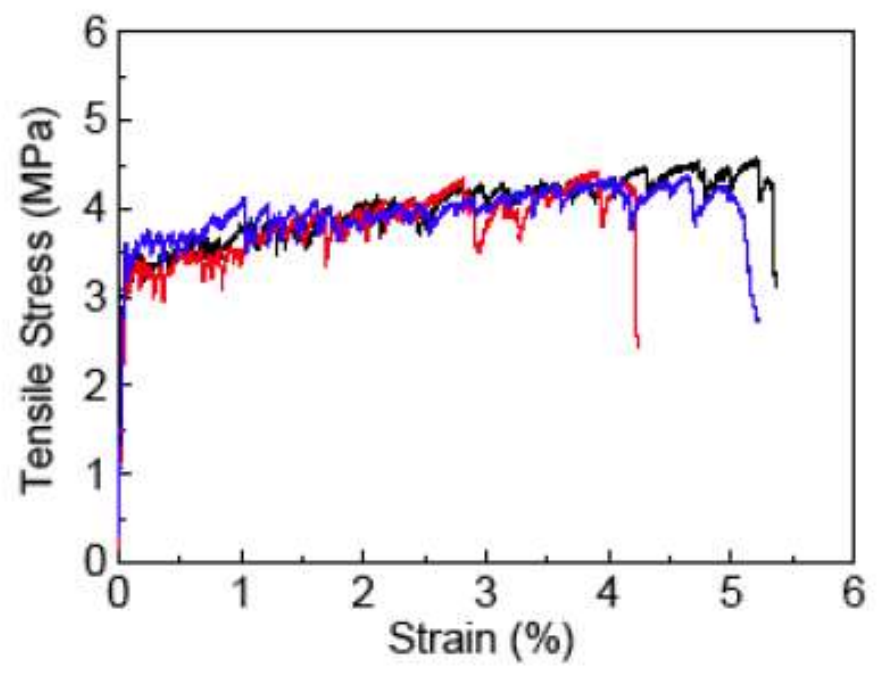

Fig. 2.3: Uniaxial tensile stress-strain curves of an ECC with 2\% PVA fibers ( $\mathrm{Li}, 2003)$ 
The condition for strain hardening for concrete is possible when a steady state crack extension occur and the initial crack strength must not exceed the fiber bridging strength. Li (1998) has expressed the critical volume for fiber fraction as:

$$
V_{f}^{c r i t}=\frac{12 J_{c}}{g \tau\left(\frac{L_{f}}{d_{f}}\right) \delta_{o}}
$$

where $\boldsymbol{V}_{\boldsymbol{f}}^{\text {crit }}$ : fiber volume fraction; $\boldsymbol{J}_{\boldsymbol{c}}$ : crack tip toughness; $\boldsymbol{g}:$ snubbing factor; $\boldsymbol{\tau}:$ fiber/matrix frictional bond strength; $\boldsymbol{L}_{\boldsymbol{f}}$ : length of fiber; $\boldsymbol{d}_{\boldsymbol{f}}$ : diameter of the fiber; $\boldsymbol{\delta}_{\boldsymbol{o}}$ : crack opening corresponding to the maximum bridging stress. Fig. 2.4 represents interrelationship among fiber volume fraction, matrix toughness and interfacial fiber-matrix bond strength as per Eq. 2.1 for design purposes.

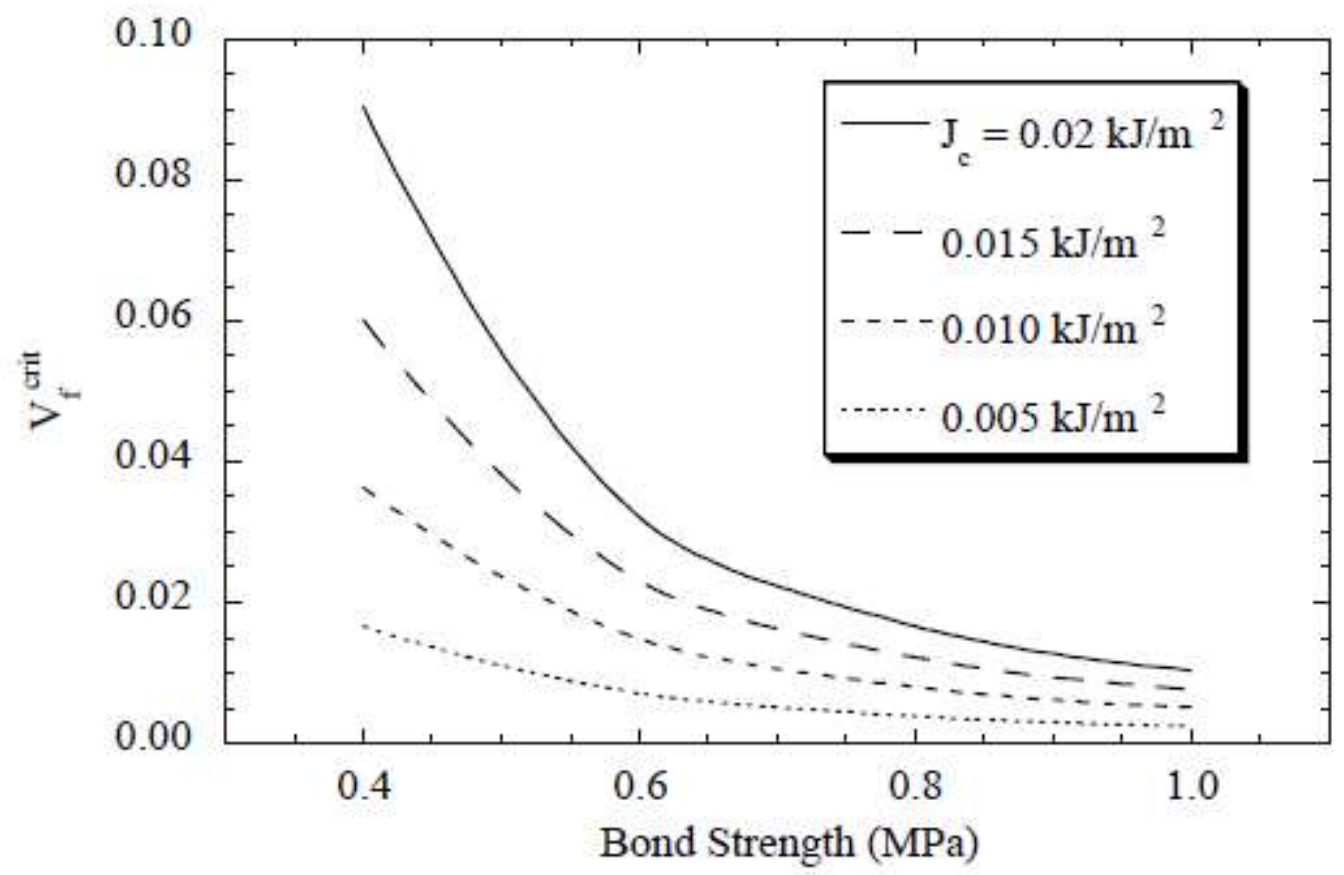

Fig. 2.4: Matrix toughness and interfacial property effect on critical $V_{f}(\mathrm{Li}, 1998)$

Several research studies have been done on Ryerson University on ECC materials to make it cost effective and technically efficient. Investigations done on ECC mixtures by replacing crushed sand with silica sand showed higher ductility for static loading and less damage under fatigue (Sherir, Hossain and Lechami, 2015). A study on composite slab with profiled steel deck comparing ECC and SCC showed ECC composite slab superior performance in terms of strength, ductility, energy 
absorption and shear bond resistance (Hossain et al. 2016). Inclusion of magnesium oxide in ECC showed self-healing capacity with higher flexure strength recovery (Sherir, Hossain and Lechami, 2017).

\subsubsection{ECC applications}

ECC is being used in number of projects recently. A 60 years old Mitaka Dam near Hiroshima had a severely damaged surface and had to be repaired against cracks, spalling and water leakage. ECC with thickness of $20 \mathrm{~mm}$ was sprayed on the surface over the $600 \mathrm{~m}^{2}$ (Fig. 2.5)

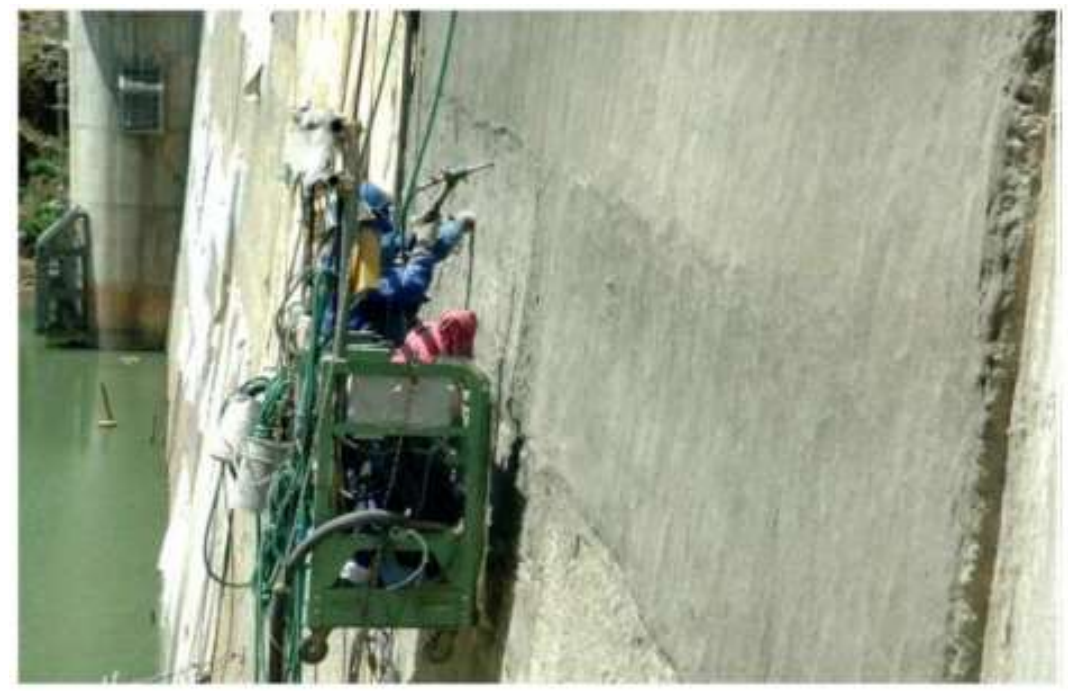

Fig. 2.5: Spray repair of the Mitaka dam with ECC for water-proofing (Sakata et al., 2004)

ECC was also used for coupling beams (Fig. 2.6) for high rise building in Japan at seismic zone due to its high energy absorbing capacity (Maruta et al., 2005). In 2002, Michigan department of transportation (MDOT) used ECC and patching concrete they have been using, in two sections of a deteriorated bridge deck (Fig.2.7). With live load and passing of more than six complete winter, the ECC patch showed minor microcracking less than $50 \mu \mathrm{m}$, whereas the repair concrete showed localized cracks of $3.5 \mathrm{~mm}$ thus repatch was done. ECC link slabs were also used to construct joint free bridges (Qian et al. 2009, Hossain et al. 2016), for example in Grove Street Bridge in Michigan (Fig. 2.8). 


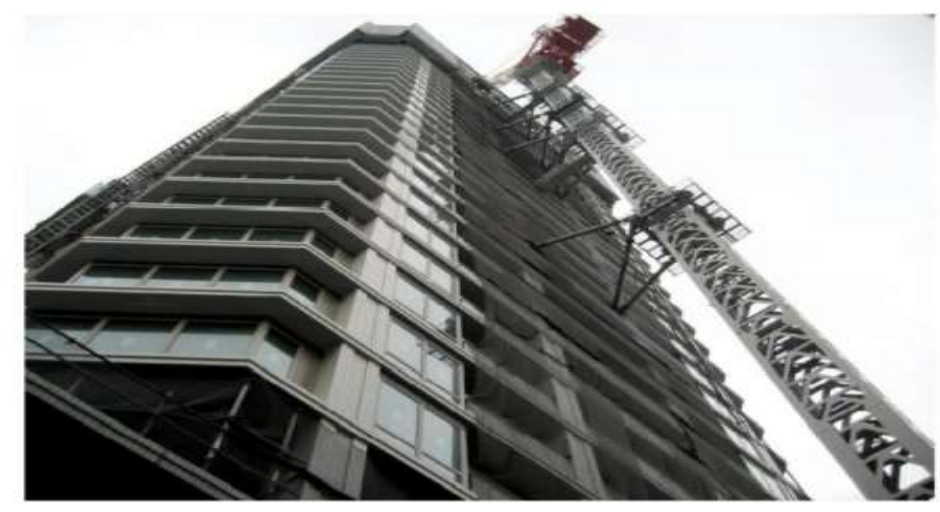

Fig. 2.6: The Nabeaure tower in Yokohoma, Japan uses precast ECC coupling beams in building core for seismic resistance (Maruta et al., 2005)

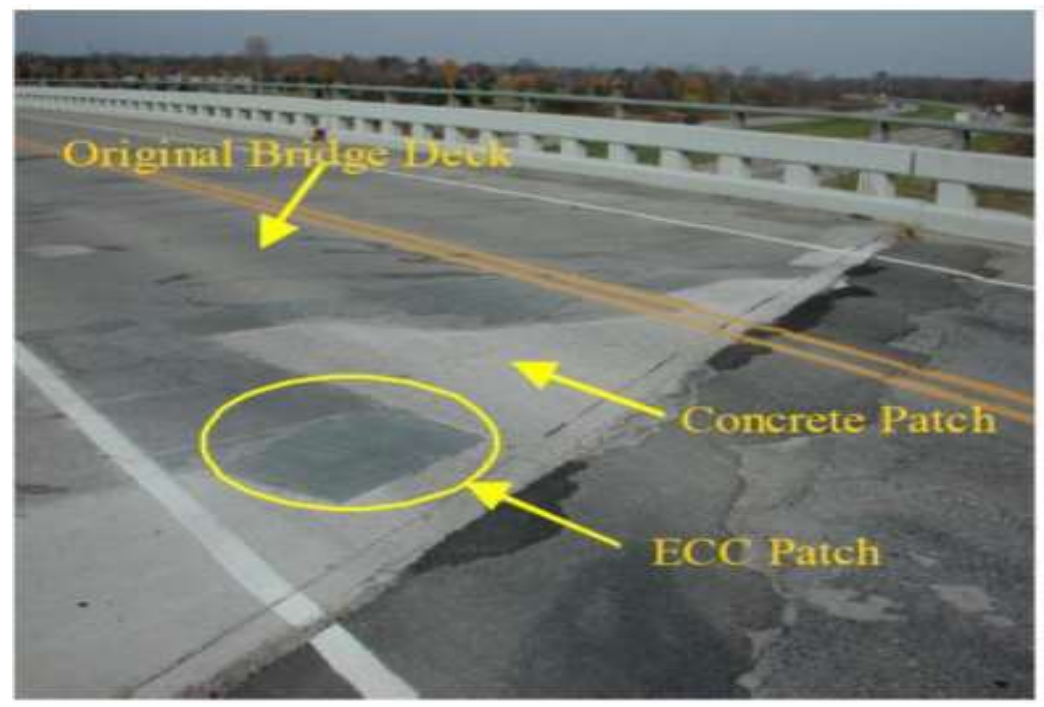

Fig. 2.7: ECC patch repair on Michigan bridge deck (Li et al., 2005)
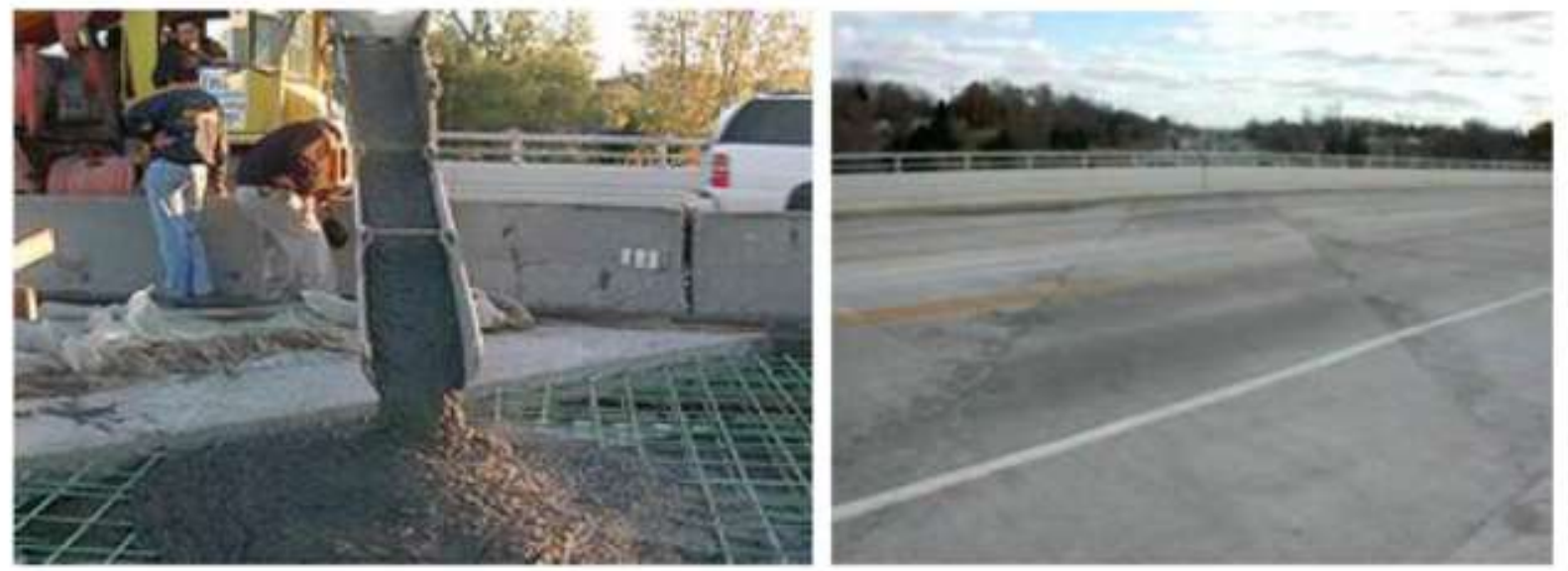

Fig. 2.8: ECC link-slab on Grove Street Bridge, Michigan (Qian et al., 2009) 


\subsection{Column, concrete confinement and confinement models}

CSA A23.3 (2014) defines columns as a member with a ratio of height to least lateral dimension of three or greater, used primarily to support axial compressive loads. Slenderness ratio is an important factor in deciding stability of column which is given by Eq. 2.2:

Slenderness ratio $=k l_{u} / r$

where $l_{u}=$ unsupported length, $r=$ radius of gyration and $k=$ effective length factor

Based on this ratio, a column can be categorized as: (a) Short Columns - strength of such column is derived from equilibrium of forces developed in column cross section, (b) Slender Columns such type of column is susceptible to buckling and second order $(\mathrm{P}-\Delta)$ effect.

CSA A23.3 (2014) recommends that slenderness effect in non-sway frames can be ignored if following condition Eq. 2.3 holds good:

$$
k l_{u} / r \leq \frac{25-1\left(\frac{M 1}{M 2}\right)}{\sqrt{\frac{P_{f}}{f^{\prime} c_{g} A_{g}}}}
$$

where $M_{1} / M_{2} \geq-0.5 ; M_{1}$ is the smaller factored end moment and $M_{2}$ is the larger factored end moment.

$P_{f}$ is the factored axial force, $f_{c}{ }_{c}$ is the specified compressive strength of concrete, $A_{g}$ is the gross sectional area of column.

\subsubsection{Research on confined concrete columns}

There are many literatures available on modeling of confined concrete column, mostly done on circular and rectangular columns with axial load. Square columns are suggested to be converted to an equivalent circular section for analysis. More studies have been carried out to find out the effect of confinement and Jacketing using different materials like fiber reinforced polymer (FRP) wraps, E-glass fibers and carbon, steel tube and aramid fiber. ECC is finding its way for confinement due to its strain hardening property.

Stress strain confinement model developed by Richart et al. (1929), Newman and Newman (1972), and Mander et al. (1988) were extended for FRP and CFST columns to predict the strength enhancement as a function of confining pressure by Fardis and Khalili (1982). These equations overestimate the strength of confined concrete.

Experiments conducted by Nanni and Bradford (1995) for 150 x $300 \mathrm{~mm}$ cylinders confined by FRP showed increased strength and were comparable to models given by Mander et al. (1988) and 
Fardis and Khalili (1982). These models proved to be sufficiently accurate for prediction of the strength but noted that passive confinement was not effective for the loading below unconfined concrete strength.

Mirmiran et al. (1998) investigated 30 cylindrical specimens and found strengths were less than that were given by existing confinement models. They concluded that the confinement was effective for length to diameter ratio from 2:1 to 5:1. Experiments done by Saafi et al. (1999) on short columns encased by FRP tubes indicated that the strength increase depends on strength of unconfined concrete, tube thickness and mechanical properties of the composite tube. Lam and Teng (2003) proposed two portions of stress-strain curve, first parabolic and second linear, to model the confinement. Rochette and Labossiere (2000) concluded that confined strength increases with specimen with rounded corners and thickness of fabric. Test conducted on carbon wrapped concrete columns by Shahawy et al. (2000) showed that the confinement model agrees with both carbon and glass fiber fabric when dilation of concrete is incorporated as a function of the stiffness of the jacket. Hossain (2003) found that the axial capacity of thin walled composite (TWC) column was about $30 \%$ higher than the sum of the individual capacities of concrete core and steel skin confinement.

Some of the analytical models are given below:

\subsubsection{Models of confined concrete}

Some of the existing models for confined concrete are presented in the following sections.

\subsubsection{Karbhari and Gao (1997)}

Karbhari and Gao (1997) have given the following model for compressive strength of confined concrete:

$$
\frac{f^{\prime} c c}{f^{\prime}{ }^{\prime}}=1+k_{1} \frac{f_{l}}{f^{\prime}{ }_{c}}
$$

where, $f^{\prime}{ }_{c c}$ and $f^{\prime}{ }_{c}$ are the compressive strength of confined and unconfined concrete, $k_{1}$ is the confinement effectiveness ratio which depends on concrete mix and the lateral pressure, $f_{l}$ is the confining pressure.

As per Richart et al. (1929) experiments, the average value of the $k_{1}=4.1$, whereas Balmer (1949) reported the value between 4.5 and 7.0 with an average value of 5.6. 


\subsubsection{Mander, Priestley and Park (1988)}

Mander et al. (1988) developed a model from multi-axial failure surface for confined concrete by both circular and rectangular ties. They suggested that the entire stress strain range was dependent on the peak stress and strain regardless of the arrangements of the reinforcement. They used equation given by Popovics (1973) to describe entire stress strain curve. Stress- strain relations of confined and unconfined concrete for monotonic loading according to Mander et al. (1988) are presented in Fig. 2.8.

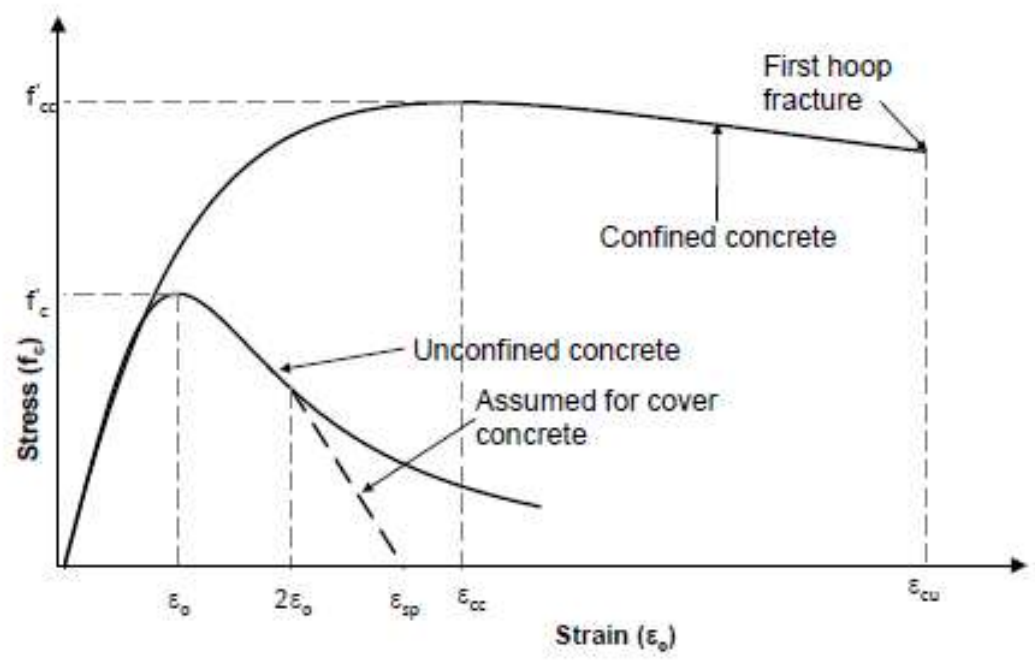

Fig.2.8: Stress-strain relation for monotonic loading of confined and unconfined concrete (Mander et al. 1988)

The model for compressive strength of confined concrete $\left(f^{\prime}{ }_{c c}\right)$ as per Mander et al. (1988):

$$
\frac{f_{c}}{f^{\prime} c c}=\frac{n \frac{\varepsilon_{C}}{\varepsilon_{C c}}}{(n-1)+\left(\frac{\varepsilon_{c}}{\varepsilon_{c c}}\right)^{n}}
$$

where $n=\frac{E_{c}}{E_{C}-E_{s e c}} ; E c=5000 \sqrt{f^{\prime}{ }_{c}(M P a)} ; E_{s e c}=\frac{f^{\prime} c c}{\varepsilon_{c c}} ; \varepsilon_{c c}$ is the strain corresponding to confined concrete strength of $f^{\prime}{ }_{c c}$ which is given by (2.6):

$$
\varepsilon_{c c}=\varepsilon_{c o}\left\{1+5\left(\frac{f^{\prime} c c}{f^{\prime} c}-1\right)\right\}
$$

The compressive strength of concrete is given by:

$$
\frac{f^{\prime}{ }_{c c}}{f^{\prime}{ }_{c}}=-1.254+2.254 \sqrt{ }\left(1+7.94 f^{\prime}{ }_{l} / f^{\prime}{ }_{c}\right)-2 \frac{f^{\prime}{ }_{l}}{f^{\prime}{ }_{c}}
$$

where $f^{\prime}{ }_{l}$ is effective confining pressure.

For circular section, 


$$
f^{\prime}{ }_{l}=\frac{k_{e} \rho_{h} f_{y h}}{2}
$$

For rectangular section,

$$
\begin{aligned}
& f^{\prime}{ }_{l x}=k_{e} \rho_{h x} f_{y h} \\
& f^{\prime}{ }_{l y}=k_{e} \rho_{h y} f_{y h}
\end{aligned}
$$

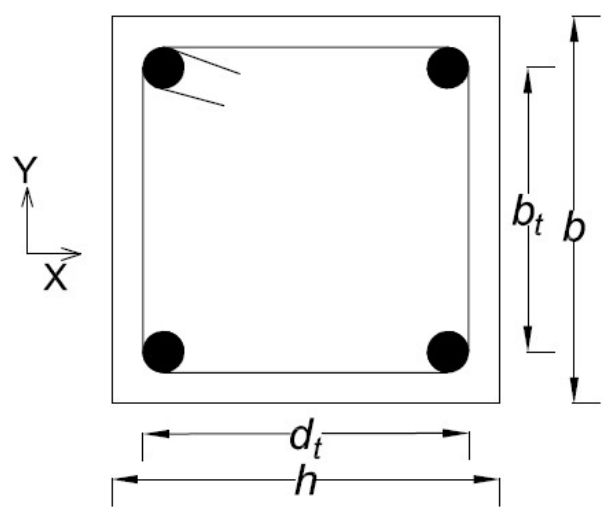

Fig.2.9: Dimension of the column with ties and main reinforcement

where $\rho_{h}$ is the ratio of volume ties to volume of confined core (as shown in Fig.2.9)

$$
\begin{aligned}
& \rho_{h}=\frac{4 A_{s}}{s D} \text { for circular ties } \\
& \rho_{h x}=\frac{A_{s}}{s d_{t}} \text { for rectangular ties } \\
& \rho_{h y}=\frac{A_{s}}{s b_{t}} \text { for rectangular ties }
\end{aligned}
$$

$f_{y h}$ is the yield strength of steel ties, $k_{e}$ is called confinement coefficient which can be given as:

$$
\begin{aligned}
& k_{e}=\frac{\left(1-\frac{s^{\prime}}{2 d_{s}}\right)^{2}}{1-\rho_{s c}} \text { for circular ties } \\
& k_{e}=\frac{1-\frac{s \prime}{2 d_{s}}}{1-\rho_{s c}} \text { for circular spirals } \\
& k_{e}=1-\left[\frac{\left(b_{t}^{2}+d_{t}^{2}\right)}{6\left(1-\rho_{s c}\right) b_{t} d_{t}}\right] \text { for rectangular ties }
\end{aligned}
$$

where $\rho_{s c}$ is the ratio of area of longitudinal bars to area of confined core, $s$ ' is clear spacing between the ties, $d_{s}$ is diameter of the tie, $b_{t}$ and $d_{t}$ are c/s dimension of the tie. 


\subsubsection{ACI 440 (2008)}

The ACI model (2008) for rectangular column defines shape factor $\left(k_{s}\right)$ as the ratio of the effective confinement area to the total area of concrete as per (2.12). The confined area of concrete is formed by the four parabolas intersecting the edges of the concrete at $45^{\circ}$.

The maximum confinement pressure $\left(f_{l}\right)$ provided by the wrap is given by;

$f_{l}=\frac{2 E_{f} t_{f} \varepsilon_{f e}}{D}$

$E_{f}$ is tensile modulus of the wrap

$t_{f}$ is the thickness of the wrap

$\varepsilon_{f e}$ is effective hoop strain level in the wrap attained at failure

$D$ is the equivalent diameter of the column

The maximum confined compressive strength $\left(f_{c c}^{\prime}\right)$ is given by $(2.13)$

$f_{c c}^{\prime}=\psi_{f} 3.3 \mathrm{~K}_{a} f_{l}$

$\psi_{f}=0.95$ is a reduction factor

$\mathrm{K}_{a}=k_{s}\left(\frac{b}{h}\right)^{2}$ is the efficiency factor based on geometry of the section

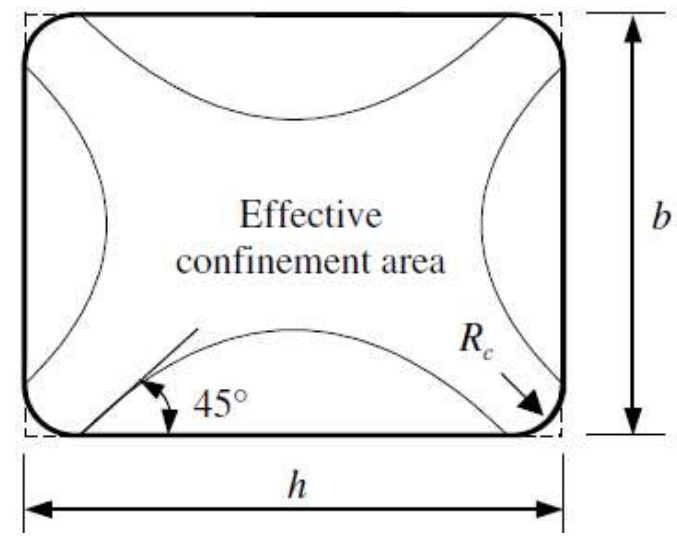

Fig 2.10: Effective Confinement Area (Lam and Tang, 2003)

$$
k_{s}=\frac{A_{e}}{A_{c}}=\frac{1-\frac{\left(\left(\frac{h}{b}\right)\left(b-2 R_{c}\right)^{2}+\left(\frac{b}{h}\right)\left(h-2 R_{c}\right)^{2}\right)}{3 A_{g}}-\rho_{s c}}{1-\rho_{s c}}
$$

The parameters are defined (with respect to Fig. 2.10) as:

$R_{C}$ : radius of corner

$A_{g}$ : Gross area of the column section with rounded corners, $A_{g}=b h-(4-\pi) R_{c}^{2}$

$\rho_{s c}$ : cross sectional area ratio of the longitudinal steel reinforcement. 


\subsubsection{CSA S806 (2012)}

CSA - S806 (2012), section 11.4.2.5 gives the axial capacity of a confined column jacketed with FRP which is based on confined compressive strength of concrete, $f^{\prime} c c$, determined as:

$f_{c c}^{\prime}=0.85 f_{c}^{\prime}+k_{l} k_{c} f_{l}$

where

$k_{l}=6.7\left(k_{c} f_{l}\right)^{-0.17}$

$k_{c}=1.0$ for circular and oval jackets

$=0.4$ for square and rectangular jack

$f_{l}=\frac{2 n_{f} t_{f} f_{f}}{D}$

where

$n_{f}$ is the no. of FRP layer

$t_{f}$ is the thickness of FRP jacket

$D$ the equivalent diameter of core concrete

$E_{f}$ is the modulus of elasticity of FRP

$f_{f u}$ is the ultimate tensile strength of FRP

$f_{f}=$ the smaller of $0.006 E_{f}$ or $f_{f u}$

The axial capacity $(P)$ of confined concrete is given by:

$P=k_{e}\left(\alpha_{1} \varphi_{c} f_{c c}^{\prime}\left(A_{g}-A_{s t}\right)+\varphi_{s} f_{y} A_{s t}\right)$

where

$k_{e}$ is a resistance factor of the column

$\varphi_{c}=0.6$ and $\varphi_{s}=0.85$, are resistance factors for concrete and steel, respectively

$\alpha_{1}=\left(0.85-0.0015 f_{c}^{\prime}\right) \geq 0.67$, is the average compression stress to the concrete strength ratio $f_{y}$ is the uniaxial yield stress of the steel, $A_{g}$ and $A_{s t}$ are gross sectional area of the column and area of the steel, respectively.

\subsubsection{Hossain (2003)}

Hossain (2003) conducted experimental investigation of 52 TWC columns and developed a model for confined strength of concrete $\left(f_{c c}\right)$ in TWC columns as per Eq. 2.14:

$$
f_{c c}=1.61(d)^{-0.1} f_{c}^{\prime}+\frac{1.56}{D / t-2} f_{y}
$$


where $f_{c c}$ is the compressive strength of confined concrete; $d$ is the diameter of concrete section in $\mathrm{mm}, f^{\prime}{ }_{c}$ is the compressive strength of $100 \mathrm{~mm}$ dia. cylinder in $\mathrm{MPa}, D$ is the outer diameter of steel tube, $t$ is thickness of the steel tube and $f_{y}$ is the uniaxial yield stress of the steel.

\subsubsection{Equivalent circular columns}

Most of the available models converts the cross-sectional dimension to equivalent circular diameter (D). ACI 440 (2008) has proposed the equivalent circular column diameter as:

$$
D=\sqrt{b^{2}+h^{2}}
$$

Lam and Teng (2003) defined equivalent diameter (D) as:

$$
D=\frac{2 b h}{b+h}
$$

where $b$ and $h$ are sectional dimension of rectangular columns.

\subsection{The finite element method (FEM) and modelling}

One of the most popular methods in the numerical analysis applied in engineering is the Finite Element Method. The late development of fast electronic computers has provided the designerengineer with robust, quick and powerful tools especially in the challenging area of geomechanics. The finite element approach was first investigated by Turner et al. (1956) for use in structural analysis. The principal idea behind the method is the subdivision of a continuous material into smaller elementary units the behavior of which can be easily described and expressed by known mathematical relations. Thus, the behavior of the whole can be simulated by a series of elements interacting with each other following some principles. Today's numerical codes offer a variety of elements for discretizing continuous systems and each element offers certain advantages and disadvantages. The most usual are the constant strain triangular element (CST) and the isoparametric quadrilateral element (Q4). The greatest advantage in the use of finite element modeling is the ability to closely represent the true conditions of the problem including gradual alterations in the model. The general steps in the formulation of a finite element model for a stressstrain problem are:

- Division of model into discrete elements connected at nodal points.

- Recognition and expression of the physical quantities (i.e., displacements) using known functions and by applying appropriate inter-elementary nodal conditions, by 
following the principle of continuity of displacements and zero strain for rigid displacement of an element.

- Assembly of all elementary stiffness matrices using appropriate stress-strain model and representation of a continuous system by assembly of a global stiffness matrix.

- Assembly of elemental equations and insertion of appropriate boundary conditions to obtain overall equilibrium equations.

- Numerical solution of the system of equations.

- Back calculation of strains.

- Final computation of stresses.

\subsubsection{Concrete damaged plasticity model (CDP) in Abaqus FEM software}

The commercial finite element software Abaqus 6.14 (Abaqus Analysis User's Guide, 2014) used continuum model defining tensile cracking and compressive crushing as the failure mechanisms in concrete. Total strain is additive of elastic strain and inelastic strain. CDP model assumes the degradation of elastic modulus $(E)$ by introducing a scalar degradation variable $(d)$ which is shown by Eq. 2.20 .

$E=(1-d) E_{0}$

$E_{o}$ is the initial modulus of elasticity. The value of $d$ is zero at damage initiation and takes maximum value of one for total loss of strength.

Fig.2.11 (ABAQUS Documentation, Abaqus 6.14) shows tensile and compression damage of a material using tensile damage variable $\left(d_{t}\right)$ and compression damage variable $\left(d_{c}\right) . \varepsilon_{t}^{p l}$ and $\tilde{\varepsilon}_{c}^{p l}$ are the equivalent tensile and plastic strains. $\varepsilon_{t}^{e l}$ and $\varepsilon_{c}^{e l}$ are elastic strains in tension and compression respectively. The stress-strain relation for uniaxial tension and compression with total tensile strain $\varepsilon_{t}$ and compressive strain $\varepsilon_{c}$ is given by Eqs. 2.21 and 2.22 .

$\sigma_{t}=\left(1-d_{t}\right) \cdot E_{0} \cdot\left(\varepsilon_{t}-\tilde{\varepsilon}_{t}^{p l}\right)$

$\sigma_{c}=\left(1-d_{c}\right) \cdot E_{0} \cdot\left(\varepsilon_{c}-\tilde{\varepsilon}_{c}^{p l}\right)$ 

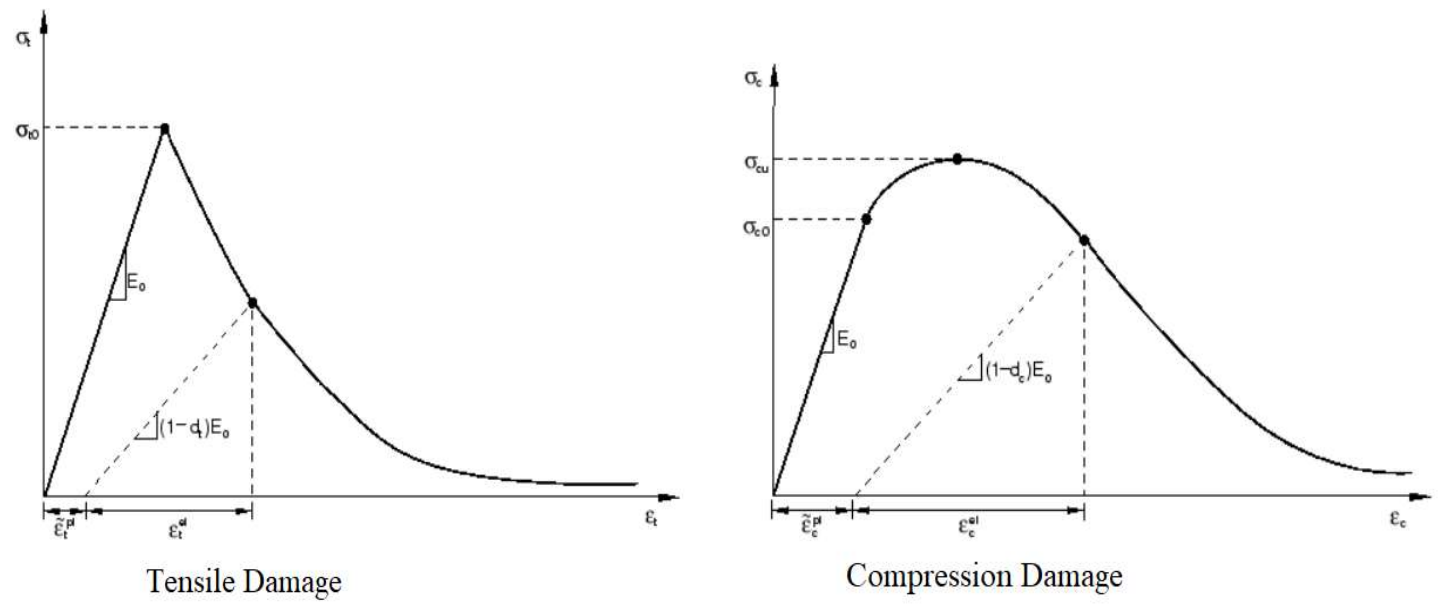

Fig. 2.11: Damage parameters (ABAQUS Documentation, Abaqus 6.14)

Tension stiffening defines strain softening behavior of concrete after failure. Defining tension stiffening also helps to transfer load between cracked concrete and reinforcement bars. One of the way to implement this behavior is to invoke fracture energy criteria in Abaqus model (ABAQUS Documentation, Abaqus 6.14).

\subsubsection{Previous research studies conducted on finite element modeling of confined column}

Most of the research studies done by using finite element modeling involves FRP as a confining material for columns. Yu et al. (2010) modelled a rectangular column in two different ways, one model used equivalent circular section with same area for the confined section of concrete and FRP tube as that of rectangular section with and another model used effective confining pressure and average lateral strain. The test results were in close agreement with FE models (Fig. 2.12).

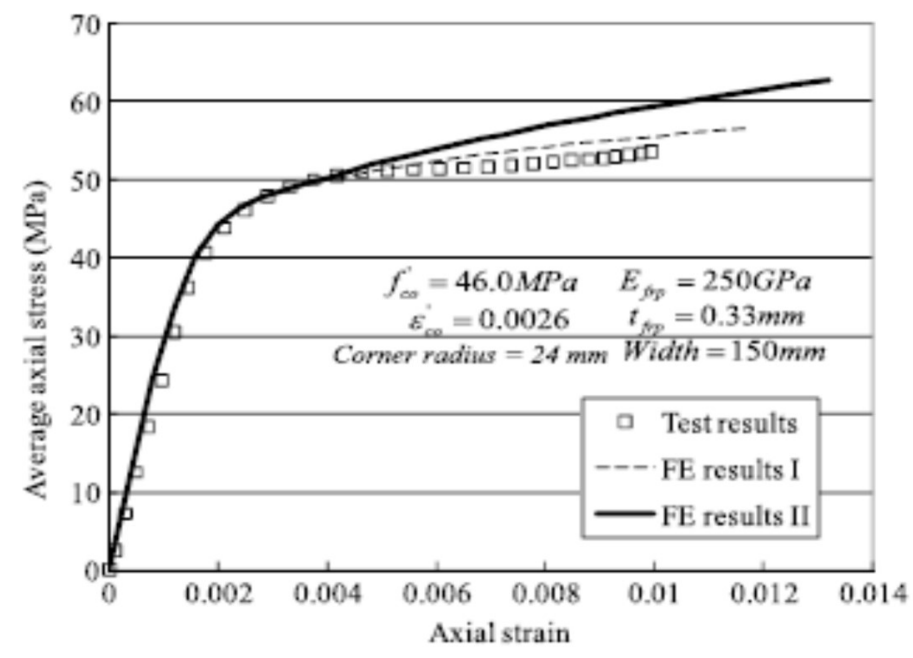

Fig. 2.12: Average axial stress strain curve (Yu et al., 2010) 
Mazzucco et al. (2016) developed a damage model for carbon FRP confined column with modified Mazar's damage law (1986) to study the role of cross-section shape. The comparison between FE and experimental results for circular and rectangular confined columns showed that FE result was able to predict axial and transverse response accurately under monotonic compressive loading (Fig.2.13).

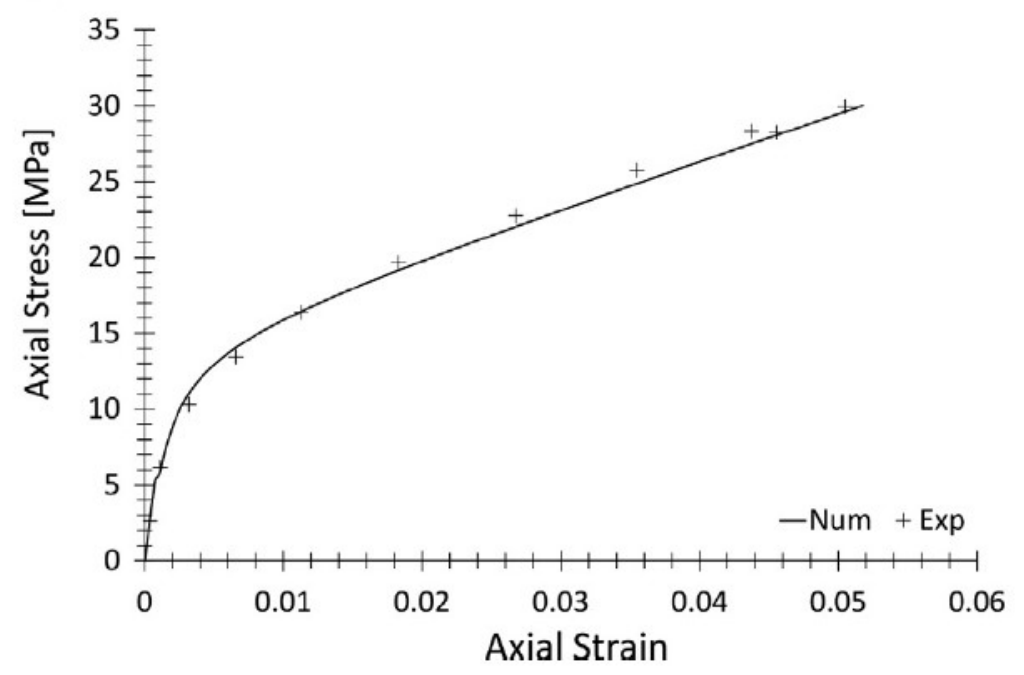

Fig. 2.13: Numerical-experimental comparison in stress vs. strain diagrams for square columns with internal steel reinforcements and external FRP jacket (Mazzucco et al. 2016)

\subsection{Review on miscellaneous topics including some testing methods}

\subsubsection{Bond between concrete layers}

Shear stress $\left(v_{u}\right)$ at the interface between concrete layers as given by CEB-FIP Model Code 1990 (1993) where no reinforcement is needed is:

$$
v_{u}=c f_{c t d}
$$

where $c$ : factor that depend on the roughness of the interface, given in Table 2.2; and $f_{c t d}$ : design tensile strength of the weakest concrete 
Table 2.2: Coefficients of cohesion and friction - CEB-FIP Model Code 1990

\begin{tabular}{|c|c|c|c|}
\hline \multicolumn{2}{|r|}{ Type of Surface } & \multirow{2}{*}{$\begin{array}{l}\text { Coefficient } \\
\text { of } \\
\text { cohesion } c\end{array}$} & \multirow{2}{*}{$\begin{array}{l}\text { Coefficient } \\
\text { of friction } \\
\mu\end{array}$} \\
\hline Category & Description & & \\
\hline \multirow{5}{*}{ Type 1 (Smooth) } & $\begin{array}{l}\text { I: a smooth surface, as obtained by } \\
\text { casting a steel or timber shutter }\end{array}$ & \multirow{5}{*}{$0.2^{*}$} & \multirow{5}{*}{0.6} \\
\hline & $\begin{array}{l}\text { II: a surface which lies between } \\
\text { trowelled or floated to a degree, } \\
\text { which is effectively smooth as (I) }\end{array}$ & & \\
\hline & $\begin{array}{l}\text { III: a surface which has been } \\
\text { trowelled or tamped in such a way } \\
\text { that small ridges, indentations or } \\
\text { undulations have been left }\end{array}$ & & \\
\hline & $\begin{array}{l}\text { IV: a surface achieved by slip } \\
\text { forming or vibro-beam screeding }\end{array}$ & & \\
\hline & $\begin{array}{l}\text { V: a surface achieved by extrusion } \\
\text { VI: a surface, which has been } \\
\text { deliberated textured by lightly } \\
\text { brushing the concrete when wet }\end{array}$ & & \\
\hline \multirow{4}{*}{ Type 2 (rough) } & $\begin{array}{l}\text { VII: as for (IV), but with more } \\
\text { pronounced texturing, as obtained } \\
\text { by brushing, by a transverse } \\
\text { screeder, by combining with a steel } \\
\text { rake or with and expanded metal }\end{array}$ & \multirow{4}{*}{0.4} & \multirow{4}{*}{0.9} \\
\hline & $\begin{array}{l}\text { VIII: a surface, which has been } \\
\text { thoroughly compacted, but no } \\
\text { attempt has been made to smooth, } \\
\text { tamp or texture the surface in any } \\
\text { way, having a rough surface with } \\
\text { coarse aggregate protruding, but } \\
\text { firmly fixed in the matrix }\end{array}$ & & \\
\hline & $\begin{array}{l}\text { IX. where the concrete has been } \\
\text { sprayed when wet, to expose the } \\
\text { coarse aggregate without } \\
\text { disturbing it }\end{array}$ & & \\
\hline & $\begin{array}{l}\text { X: a surface which has been } \\
\text { provided with mechanical shear } \\
\text { keys }\end{array}$ & & \\
\hline
\end{tabular}


* For very smooth surfaces (type I and II) it is recommended to use the value of $c=0.1$

For smooth interfaces, the shear resistance is:

$$
\tau_{f u, d}=0.40 \sigma_{c d}
$$

where, $\tau_{f u, d}$ is the shear resistance due to concrete-to-concrete friction; $\sigma_{c d}$ is the average normal compressive stress.

PCI Design Handbook (2004) has defined a modification parameter $\lambda$ which depends on the density of the concrete and has given coefficient of friction $(\mu)$ as shown in Table 2.3.

Table 2.3: Coefficients of friction- PCI Design Handbook (2004)

\begin{tabular}{l|c}
\hline \multicolumn{1}{c|}{ Crack interface condition } & Recommended $\boldsymbol{\mu}$ \\
\hline $\begin{array}{l}\text { Concrete to concrete, cast } \\
\text { monolithically }\end{array}$ & $1.4 \lambda$ \\
\hline $\begin{array}{l}\text { Concrete to hardened } \\
\text { concrete, with roughened } \\
\text { surface }\end{array}$ & $1.0 \lambda$ \\
\hline $\begin{array}{l}\text { Concrete to concrete } \\
\text { Concrete to steel }\end{array}$ & $0.6 \lambda$ \\
\hline
\end{tabular}

The value of $\lambda$ is taken as 0.75 for LWSCC. For normal concrete, $\lambda$ is 1.0 , and for sand-light weight concrete, $\lambda$ is 0.85 .

\subsubsection{Slant shear test}

The slant shear test was developed at the University of Arizona. Some authors like Kriegh (1976) states that this is a reliable method because it closely resembles the state of stress in a concrete. 


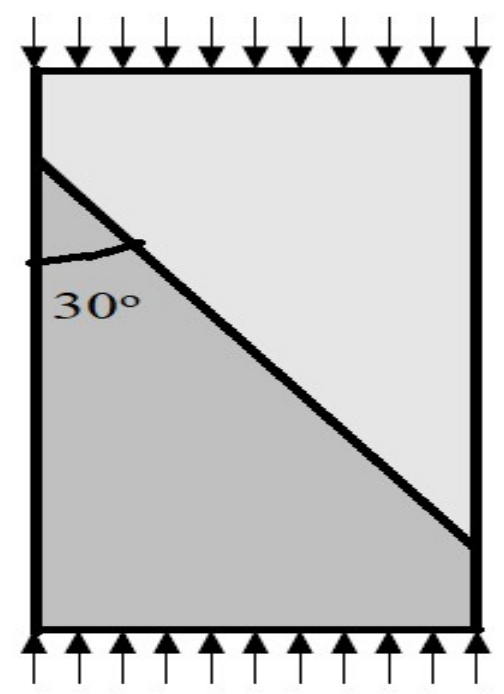

Fig. 2.14: Slant shear test

The test specimen is a composite concrete cylinder or a prism with an interface of $30^{\circ}$ with the longitudinal axis of the specimen (Fig.2.14). Standard compression test is performed on this cylinder until the failure occurs. The bond strength is obtained by dividing the load carried by the specimen at failure by the area of the bonded surface.

\subsubsection{Fracture energy of concrete and testing}

The fracture energy of a concrete can be determined by three-point bending test using notched beam. This test is similar to the standard modulus of rupture test and the first linear elastic fracture mechanics test standard for metals given by ASTM, 1983 (Bazant, 1992). The testing procedures are simpler with minimal alignment errors. The beam geometry for the test is shown Fig.2.15. The span to depth (S/d) ratio is $4: 1$ because formulas for opening mode stress-intensity factors for beams are given for $S / d=4$ or 8 . The test usually consists of the following steps:

- The beam is notched to depth $\mathrm{a}_{\mathrm{o}}$ at mid span by using diamond saw-cut.

- The load- deflection $\left(\delta_{\mathrm{LPD}}\right)$ or load-crack mouth opening displacement $(\mathrm{CMOD})$ response is recorded continuously by applying constant displacement rate, such that the failure is around in five minutes.

- The peak load "P" or the load PQ at the intersection with a secant of slope $95 \%$ of initial slope (Fig.2.15), is used to calculate the stress intensity from the following relationship.

The stress intensity factor for the beam with notch at the center is given by Shah, Swartz and Ouyang (1995). 

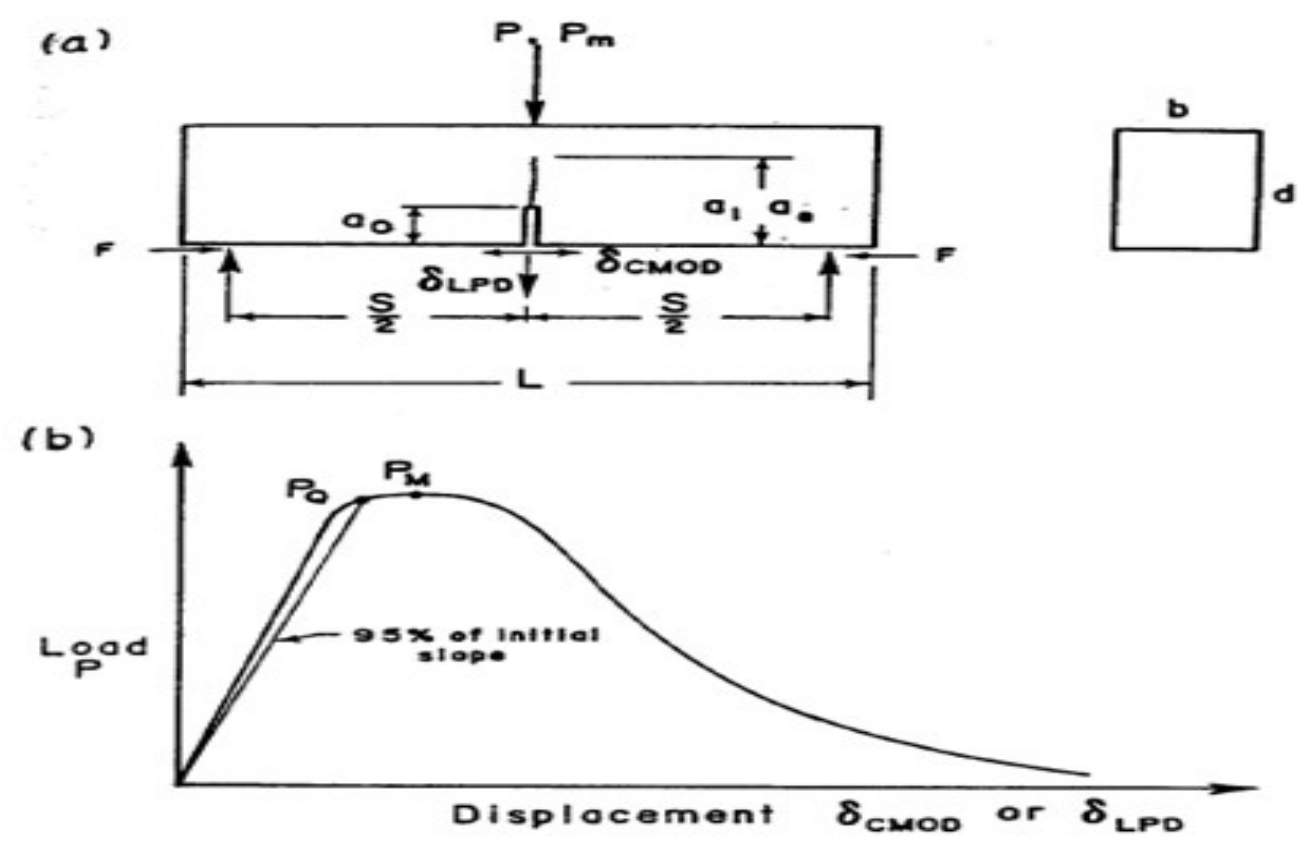

Fig.2.15: (a) Notched beam in three-point bending (b) Load-displacement (Bazant, 1992)

The stress intensity factor $\left(K_{I}\right)$ is given by:

$$
K_{I}=\sigma \sqrt{\pi a_{0}} g_{1}\left(\frac{a_{0}}{d}\right)
$$

where $\sigma=3 P S / 2 d^{2} b$

$$
g_{1}\left(\frac{a_{0}}{d}\right)=\frac{1.99-\frac{a_{0}}{d}\left(1-\frac{a_{0}}{d}\right)\left\{2.15-\frac{3.930}{d}+2.70\left(a_{0} / d\right)^{2}\right\}}{\sqrt{\pi}\left(1+2 \frac{a_{0}}{d}\right)\left(1-\frac{a_{0}}{d}\right)^{3 / 2}}
$$

for $S=4 d$

Round robin test conducted by Hillerborg to measure fracture energy $\mathrm{G}_{\mathrm{F}}$ were reported not so different from values determined according to RILEM recommendations (Elfgren and Shah, 1989). The fracture energy $\left(G_{F}\right)$ is given by:

$$
G_{F}=\frac{K_{I}^{2}}{E}
$$

where $\boldsymbol{E}$ is the elastic modulus of concrete

\subsection{Review conclusions}

Several studies have been carried out on axially loaded confined columns using normal concrete and SCC for circular sections. Different models are available to predict the strength of these 
confined concrete. Most of these research have been focused on using FRP and steel tubes as confinement providing material. Limited number of literatures are available on ECC being used as confining material. Again, the behavior of square confined columns under type A and type B loading also needs to be studied due to lack of literature. So, the need of research using ECC as confining material is necessary for these types of loading. The proposed research will lead to new insight on the mechanical behavior of confined concrete using ECC as a confining material. 


\section{CHAPTER THREE EXPERIMENTAL PROGRAM}

\subsection{Introduction}

An experimental program has been done to study the behavior of short square self-consolidating (SCC) and self-consolidating lightweight concrete (LWSCC) columns under axial compressive loading confined by strain hardening engineered cementitious composite (ECC) in the concrete and structure laboratories of Ryerson University.

The first set of tests consisted of casting three LWSCC and three SCC square columns with ECC wrap without using steel ties for longitudinal reinforcing bars. The thickness of ECC warp varied for each column. In the second set, three square LWSCC columns and one square SCC column having longitudinal steel reinforcement and lateral ties were casted with confined ECC wrapping. Third set consisted of three LWSCC and three SCC cylindrical specimens wrapped by ECC layer having varying thickness. The variables for the study consisted of thickness of ECC wrap, type of concrete material used for core of column (SCC and LWSCC), presence or absence of tie reinforcements and type of axial loading on the column, that is, loading applied through the whole cross section (Type A loading) and loading through the core only (Type B loading). Load deformation response, stress-strain curves, ductility index and energy absorption of the columns under Type A and Type B concentric axial loading were then obtained. Fourth set of test consisted of casting standard cylindrical concrete samples to determine compressive strength as per ASTM C469/C469M (2014) and modulus of elasticity and Poisson's ratio for different types of concrete used as per ASTM C39/C39M (2016).

\subsection{Description of column and cylinder specimens}

All square columns with core cross-section of $150 \mathrm{~mm} \times 150 \mathrm{~mm}$ and $900 \mathrm{~mm}$ in length were symbolized as ' $\mathrm{S}$ ' (Table 3.1). All cylindrical specimens with core diameter of $150 \mathrm{~mm}$ and length of $300 \mathrm{~mm}$ were denoted by 'C' (Table 3.1). Two different types of concrete were used for casting core specimens - Light Weight Self-Consolidating Concrete (LWSCC) designated as 'LW' and Self-Consolidating Concrete (SCC) designated as ' $\mathrm{SC}$ '. These specimens were wrapped around the perimeter by ECC layer of varying thickness (10 to $50 \mathrm{~mm}$ ). The thickness of ECC wrap was expressed by the numerical attachment on sample description/designation of specimens (Table 3.1a-c). Specimens having no ECC wrapping around the core had no numerical attachment. Four 
longitudinal reinforcing bars of $10 \mathrm{~mm}$ diameter were used for square columns (Table 3.1b-c). Ties were used at spacing of $150 \mathrm{~mm} \mathrm{c} / \mathrm{c}$ for six columns and all other columns were casted without ties. Tied columns are symbolized as ' $\mathrm{T}$ ' in the designation of specimens. Table 3.1a-c and Fig. 3.1a-c present the description and dimensions of the square and cylindrical specimens. For example, S-LW-20T represents a longitudinally reinforced square column with $20 \mathrm{~mm}$ ECC wrapping around LWSCC core with tie reinforcement.

Table 3.1a: Designation for cylindrical column specimens

\begin{tabular}{|c|c|c|c|c|}
\hline Designation & Description & Dimension & Sketch & $\begin{array}{c}\text { ECC wrap } \\
\text { thickness (mm) }\end{array}$ \\
\hline C-LW & LWSCC Core Cylinder & \multirow{9}{*}{ 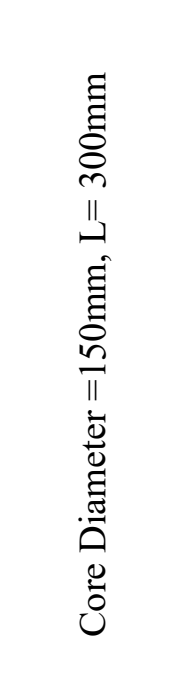 } & & \\
\hline $\mathrm{C}-\mathrm{SC}$ & SCC Core Cylinder & & & \\
\hline C-EC & ECC Cylinder & & & \\
\hline C-LW-20 & LWSCC Cylinder with 20mm ECC & & & 20 \\
\hline C-LW-30 & LWSCC Cylinder with 30mm ECC & & & 30 \\
\hline C-LW-50 & LWSCC Cylinder with $50 \mathrm{~mm}$ ECC & & & 50 \\
\hline C-SC-20 & SCC Cylinder with 20mm ECC Wrap & & & 20 \\
\hline C-SC-30 & SCC Cylinder with 30mm ECC Wrap & & & 30 \\
\hline C-SC-50 & SCC Cylinder with 50 mm ECC Wrap & & & 50 \\
\hline \multicolumn{5}{|c|}{ Core dimensions: $150 \mathrm{~mm}$ diameter and length of $300 \mathrm{~mm}$} \\
\hline
\end{tabular}


Table 3.1b: Designation for square LWSCC columns with or without ECC wrapping

\begin{tabular}{|c|c|c|c|c|}
\hline Designation & Description & Dimension & Sketch & $\begin{array}{c}\text { ECC } \\
\text { thickness } \\
(\mathbf{m m})\end{array}$ \\
\hline S-LW & LWSCC Core Column & \multirow{7}{*}{ 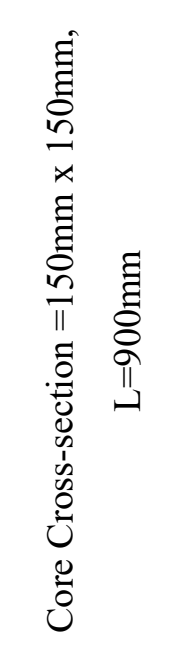 } & $\therefore$ & \\
\hline S-LW-20 & LWSCC Core Column with 20mm ECC Wrap & & & 20 \\
\hline S-LW-20T & LWSCC Core Column with 20mm ECC Wrap & & & 20 \\
\hline S-LW-25 & LWSCC Core Column with 20mm ECC Wrap & & & 25 \\
\hline S-LW-30 & LWSCC Core Column with 30mm ECC Wrap & & & 30 \\
\hline S-LW-30T & LWSCC Core Column with 30mm ECC Wrap & & & 30 \\
\hline S-LW-50T & LWSCC Core Column with 50mm ECC Wrap & & & 50 \\
\hline
\end{tabular}

Table 3.1c: Designation for square SCC columns with or without ECC wrapping

\begin{tabular}{|c|c|c|c|c|}
\hline Designation & Description & Dimension & Sketch & $\begin{array}{c}\text { ECC } \\
\text { thickness } \\
(\mathrm{mm})\end{array}$ \\
\hline S-SC & SCC Core Column & \multirow{5}{*}{ 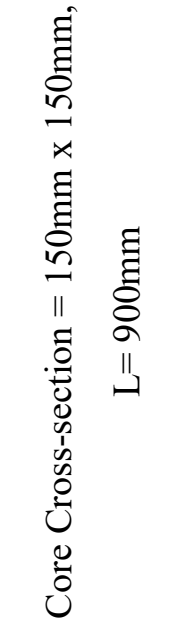 } & & \\
\hline S-SC-10 & SCC Core Column with $10 \mathrm{~mm}$ ECC Wrap & & & 10 \\
\hline S-SC-15 & SCC Core Column with $15 \mathrm{~mm}$ ECC Wrap & & & 15 \\
\hline S-SC-20 & SCC Core Column with $20 \mathrm{~mm}$ ECC Wrap & & & 20 \\
\hline S-SC-50T & SCC Core Column with 50mm ECC Wrap & & & 50 \\
\hline
\end{tabular}




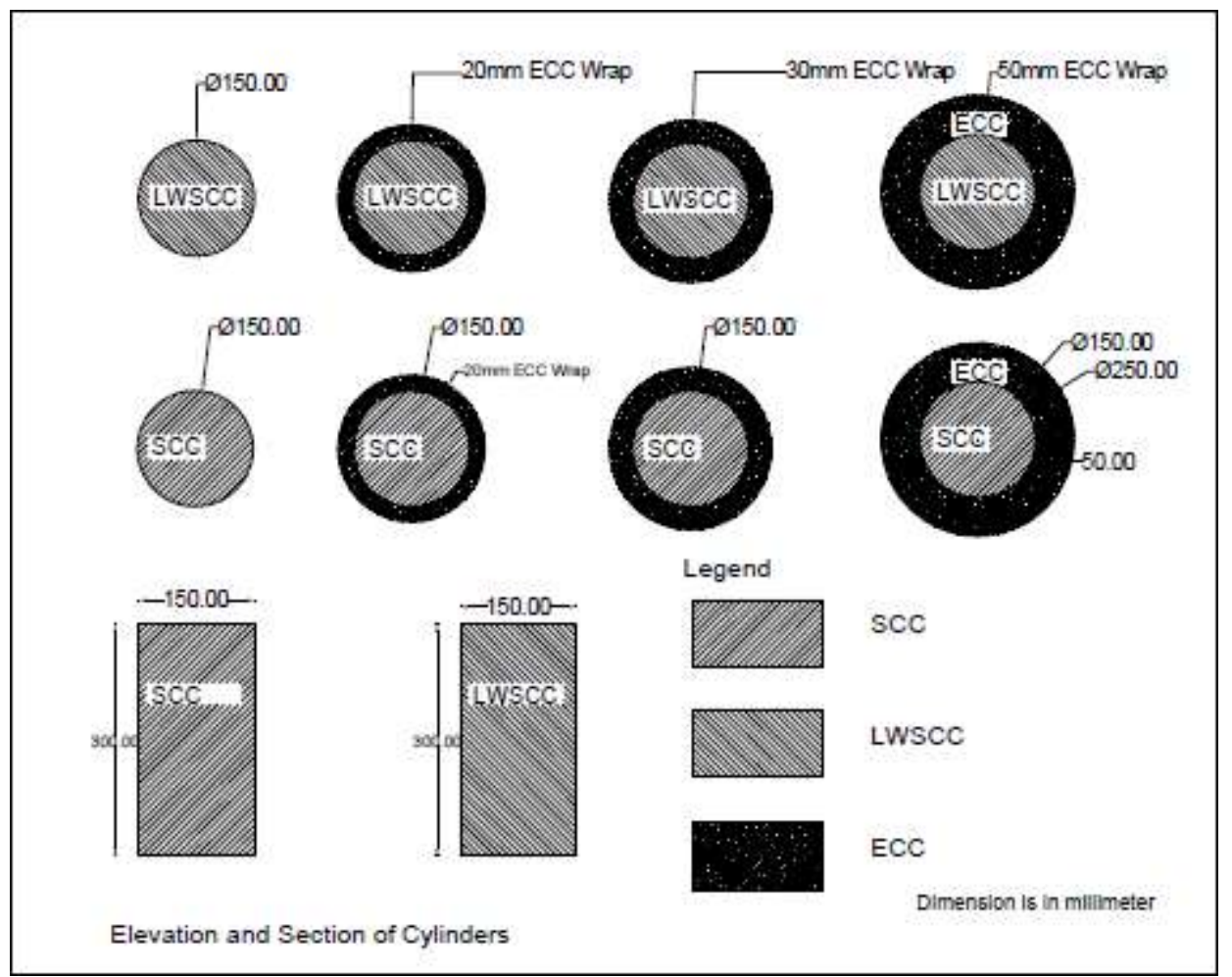

Fig. 3.1a: Section and elevation of cylindrical columns with and without ECC wraps

(Dimensions in $\mathbf{m m}$ )

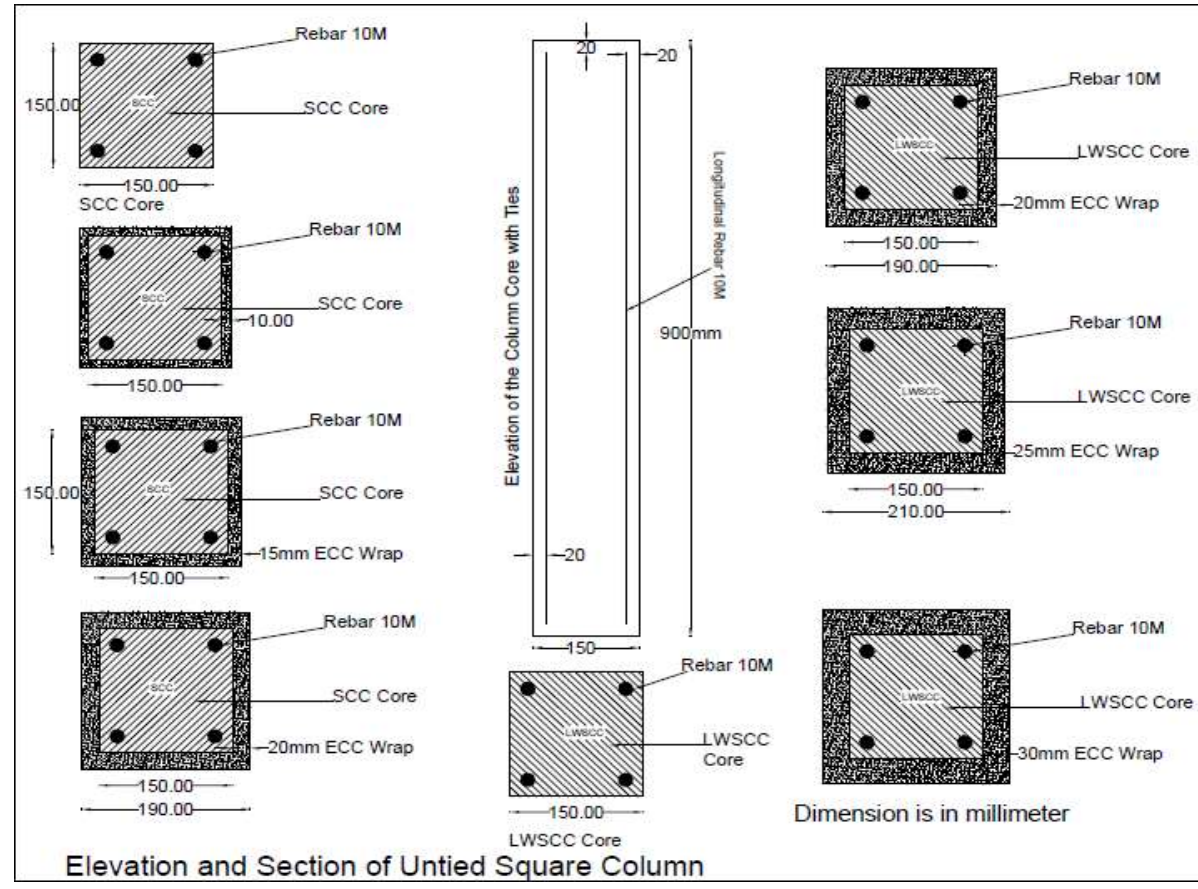

Fig. 3.1b: Section and elevation of untied reinforced concrete columns with and without wrapping (Dimensions in $\mathbf{m m}$ ) 


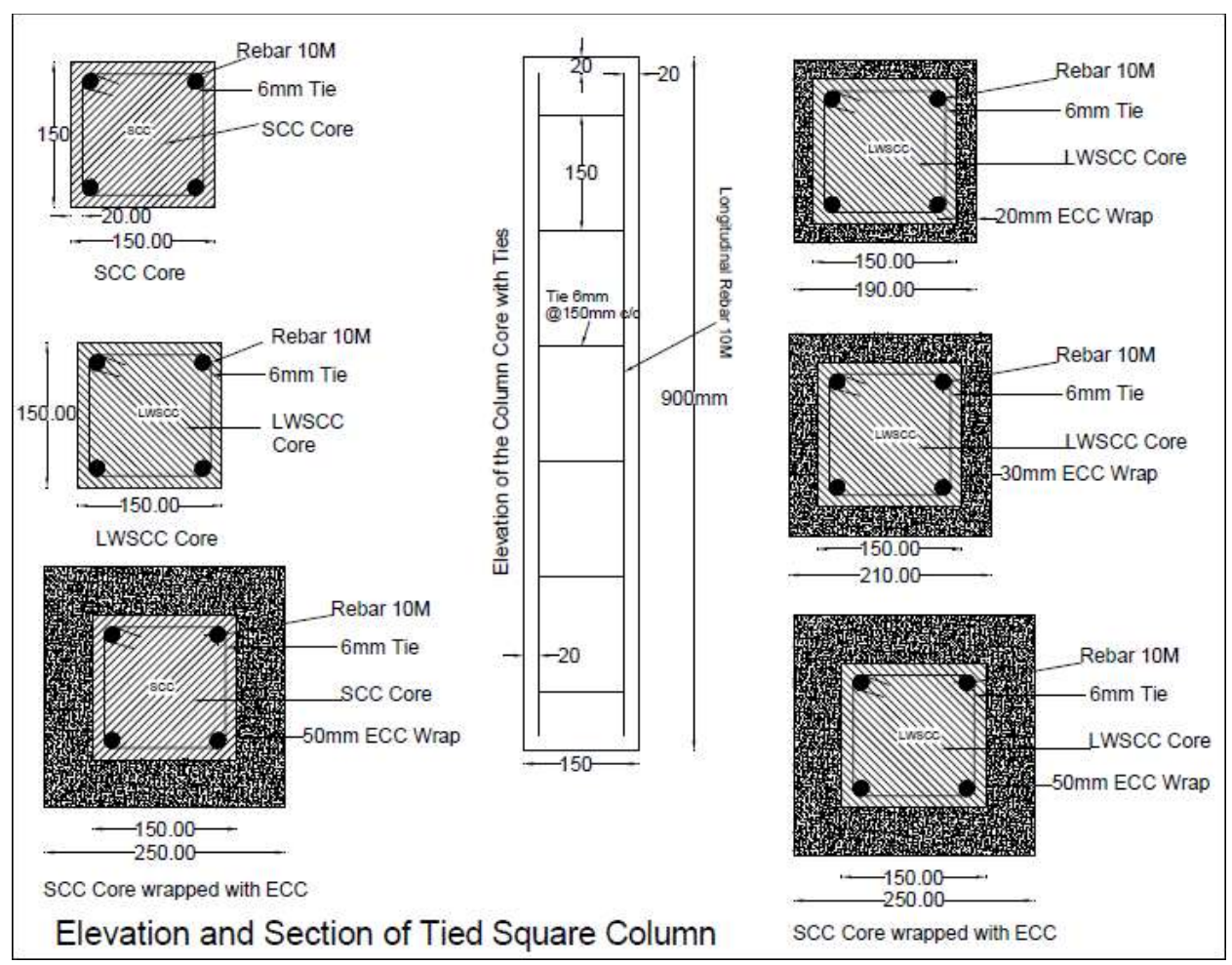

Fig. 3.1c: Section and elevation of tied reinforced concrete columns with and without wrapping (Dimensions in $\mathbf{m m}$ )

\subsection{Materials used for casting columns}

Two different concrete mixes were used in casting concrete columns. A commercially available SCC was used along with LWSCC and ECC mixes developed at Ryerson University. After casting of core columns with LWSCC or SCC, they were wrapped with ECC jackets.

SCC was a pre-blended and pre-packaged high performance flowable concrete containing Portland cement, silica fume, $10 \mathrm{~mm}$ aggregate and other carefully selected admixtures.

To impart ductility and toughness, only fine aggregates were used for ECC. Silica sand was used as a fine aggregate with the gradations shown in Table 3.2. General use hydraulic cement which meets or exceeds all applicable chemical and physical requirements of ASTM C150/C150M (2018) was used for all purpose.

Table 3.2: Gradation for silica sand

\begin{tabular}{|c|c|c|c|c|c|c|c|}
\hline Sieve number & $\# 40$ & $\# 50$ & $\# 70$ & $\# 100$ & $\# 140$ & $\# 200$ & $\# 270$ \\
\hline Sieve opening (mm) & 0.42 & 0.30 & 0.21 & 0.15 & 0.105 & 0.074 & 0.053 \\
\hline Passing (\%) & 100.0 & 97.8 & 83.1 & 35.6 & 6.3 & 0.9 & 0.4 \\
\hline
\end{tabular}


Class F fly ash $\left(\mathrm{SiO}_{2}: 59.5 \%, \mathrm{CaO}: 5.57 \%\right.$, specific gravity: 2.18$)$ was used as a partial replacement of cement in concrete which increased workability and imparted higher strength and durability. Silica fume (used in LWCC) filled the space between cement particle and formed a binder material called calcium silicate hydrate which gave improved hardened properties. It also helped the LWSCC by preventing segregation by making the mix more cohesive. The physical and chemical properties of silica fume used for $\mathrm{LWSCC}$ are $\mathrm{SiO}_{2}: 52 \%, \mathrm{CaO}: 5 \%$ and specific gravity of 2.38 . A high range water reducing admixture (HRWRA) helps in making concrete workable with low w/c ratio. For ECC, HRWRA containing polycarboxylate chemical composition is most suitable (Li, 2007). ADVA 757, a commercially available admixture was used in the production of ECC. PVA (Polyvinyl Alcohol) fiber which helps in bridging the crack formations and imparting strain hardening behavior to ECC was used. PVA fiber with a length of $8 \mathrm{~mm}$ and a diameter of 39 microns was used for ECC. Coarse and fine furnace slag lightweight aggregate complied with ASTM C 330/330M (2017) was used for making LWSCC. These aggregates were porous in nature and imparted reduced weight of the concrete. $10 \mathrm{~mm}$ and $6 \mathrm{~mm}$ dia. reinforcing bars having stressstrain characteristics shown in Fig. 3.2 and properties (Table 3.3) derived from coupon tests as per Sathiyamoorthy (2016) were used.

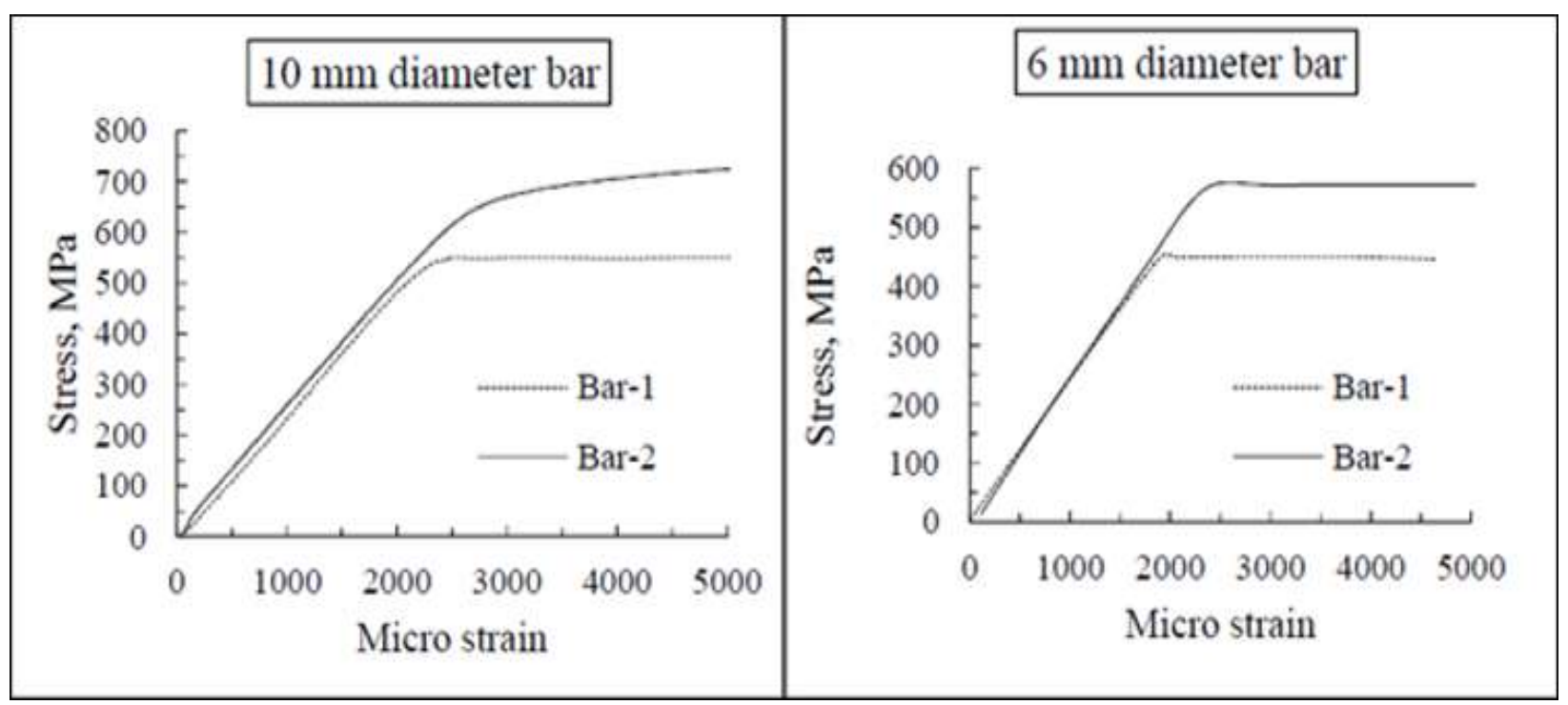

Fig. 3.2: Stress-strain responses of reinforcement bars (Sathiyamoorthy, 2016) 
Table 3.3: Rebar properties

\begin{tabular}{|l|c|c|c|c|c|c|}
\hline \multirow{2}{*}{$\begin{array}{l}\text { Rebar } \\
\text { diameter }\end{array}$} & \multicolumn{3}{|c|}{ Yield stress (MPa) } & \multicolumn{3}{c|}{ Yield micro-strain } \\
\cline { 2 - 7 } & Bar-1 & Bar-2 & Average & Bar-1 & Bar-2 & Average \\
\hline $\mathbf{6 ~ m m}$ & 450 & 448 & 449 & 1895 & 1892 & 1893 \\
\hline $\mathbf{1 0} \mathbf{~ m m}$ & 532 & 628 & 567 & 2330 & 2380 & 2355 \\
\hline
\end{tabular}

\subsection{Casting of columns with LWSCC core}

Formworks were made from plywood to cast columns (Fig. 3.3a). Readymade tubes were used to cast cylindrical specimens. As the light weight aggregates (fine and coarse) had high water absorbing capacity, they were soaked at least for three days before making the concrete mix. The water content of surface dry aggregates was determined to account for the total quantity of water required for the mixture. Mix proportion used of preparing LWSCC is given in Table 3.4.

\section{Table 3.4: LWSCC mix proportion by weight}

\begin{tabular}{|c|c|c|c|c|c|c|c|}
\hline Ingredients & $\begin{array}{c}\text { Cement } \\
\text { (Type } \\
10)\end{array}$ & Fly Ash & $\begin{array}{c}\text { Silica } \\
\text { Fume }\end{array}$ & $\begin{array}{c}\text { HRWRA, } \\
\mathrm{kg} / \mathrm{m}^{3}\end{array}$ & Water & $\begin{array}{c}\text { Fine Slag } \\
\text { aggregate }\end{array}$ & $\begin{array}{c}\text { Coarse } \\
\text { slag } \\
\text { aggregate }\end{array}$ \\
\hline Specification & 1 & 0.156 & 0.94 & 4.75 & 0.438 & 1.179 & 1.667 \\
\hline
\end{tabular}

Fixed horizontal mixture of 250 Liter capacity was used to mix the LWSCC (Fig. 3.3b). Saturated surface dry (SSD) slag aggregates were fed into the mixer, $75 \%$ of the total quantity of water was added and mixed for five minutes. Fly ash, cement and silica fume were added and mixed for one minute. Admixture (HRWRA) and remaining water were added and mixed for 15 minutes to complete the mixing operation. Columns were then casted with this concrete (Fig. 3.3c-d). 


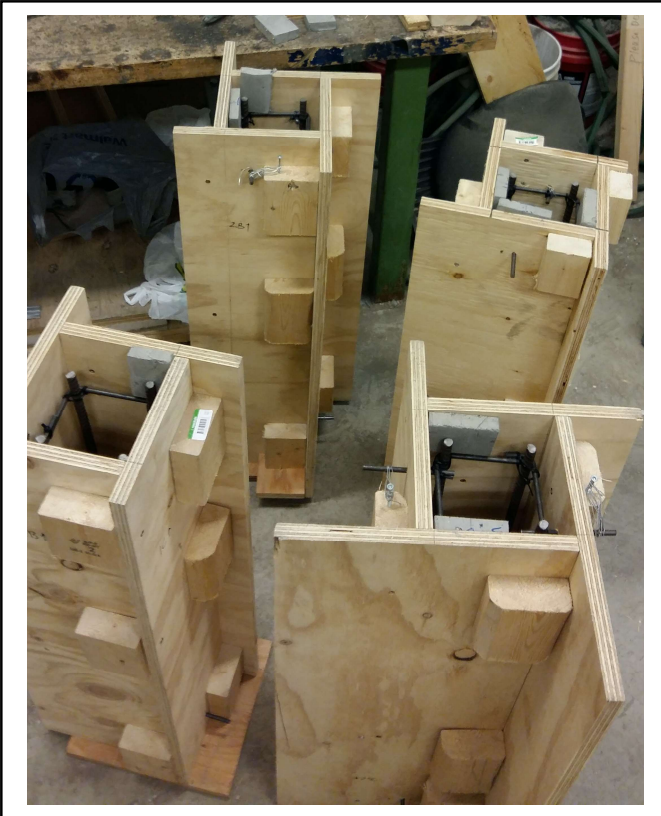

(a) Preparation of Forms
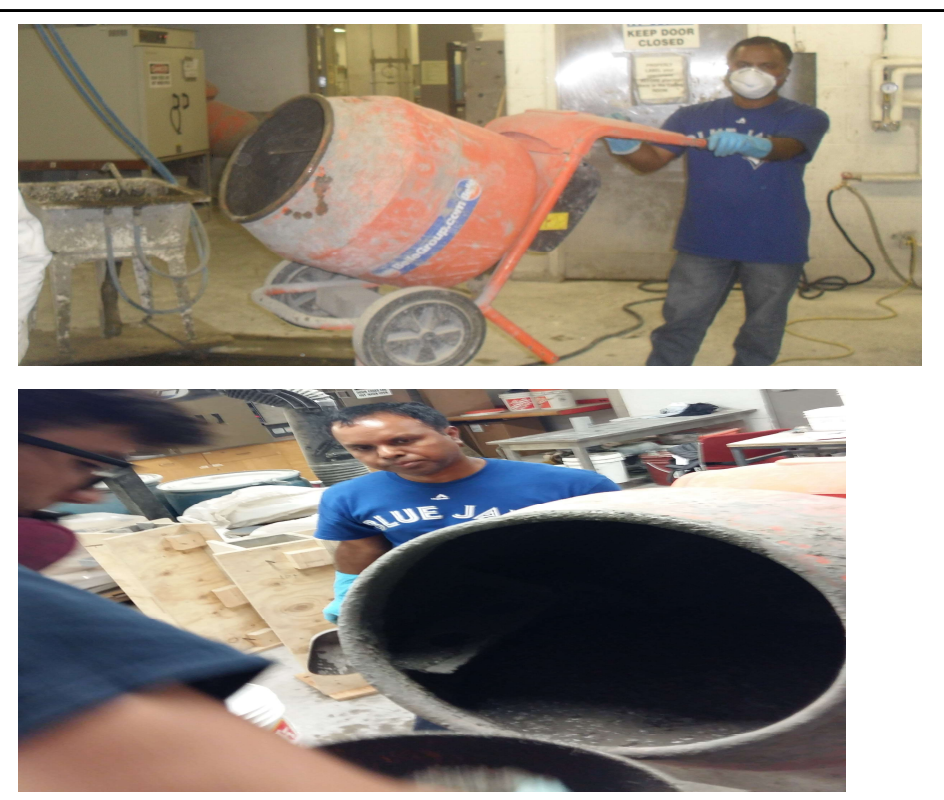

(b) Mixing Concrete in mixer

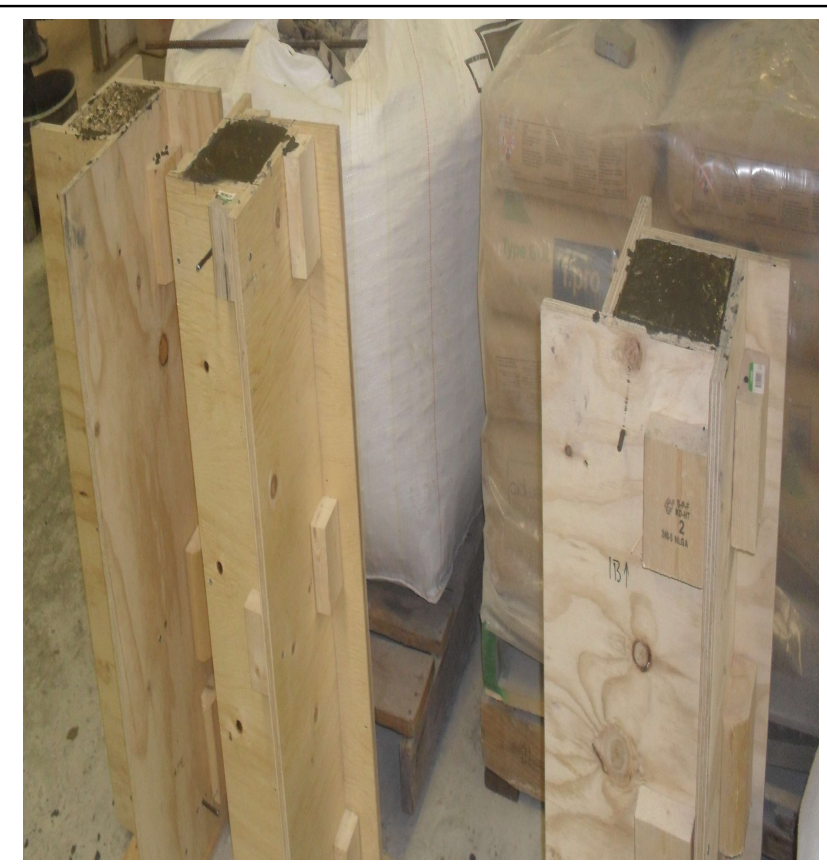

(c) Casting of Columns in formwork

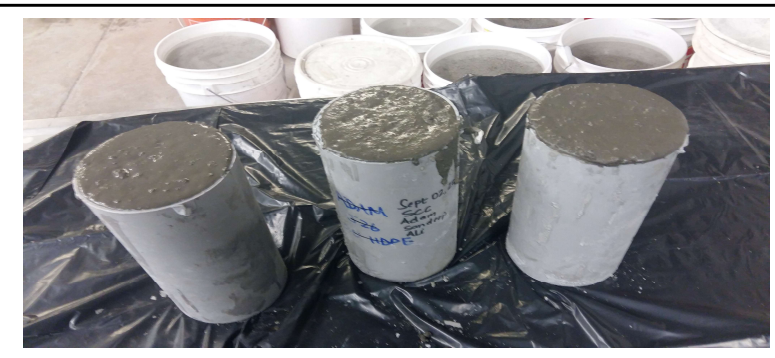

(d) Casting of cylindrical columns

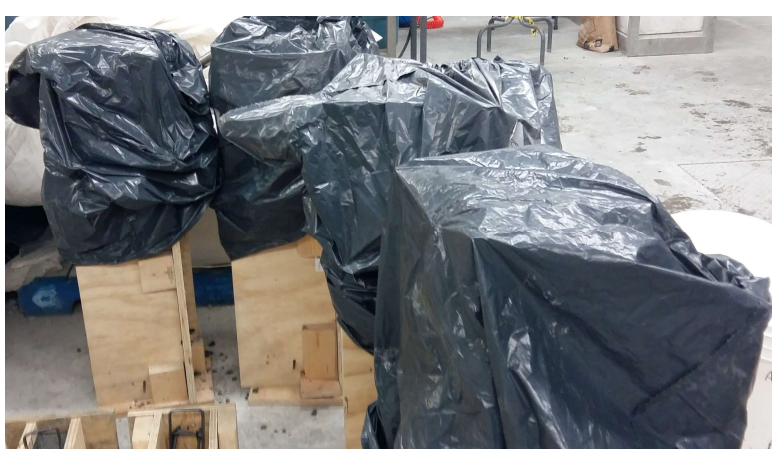

(e) Covering of columns with plastic sheet

Fig. 3.3: Steps in casting specimens 


\subsection{Casting core columns with SCC}

Commercial premix blend was used for making SCC. As per manufacturer's recommendation, 2.6 liters of water per $30 \mathrm{~kg}$ bag was used for mixing. $75 \%$ of water required was placed into the fixed horizontal mixture of $250 \mathrm{~L}$ capacity and the premix blend was added (Fig. 3.3b). Once the mixer had started, remaining water was added slowly. Mixing was continued till three minutes. After the mix was consistent, the mixer was stopped. Columns were then casted from this concrete. Columns were wrapped with plastic sheets to prevent from moisture lost after casting (Fig. 3.3e). Columns were demolded after 48 hours of casting and placed in a curing room.

\subsection{Casting of ECC wraps around LWSCC and SCC core columns}

After 7 days of casting and curing in curing room (maintained at $20^{\circ} \mathrm{C}$ and $95 \pm 5 \% \mathrm{RH}$ ), square and cylindrical columns were placed in the formworks to cast ECC wrapping of desired thickness. After casting, specimens were wrapped in plastic sheets for 24 hours, cured them for 7 days in the curing room and then air cured in the lab until tested. The mix proportion of ECC is shown in Table 3.5.

Table 3.5: ECC mix proportion by weight

\begin{tabular}{|l|l|l|c|l|l|l|}
\hline Ingredients & $\begin{array}{l}\text { Water } \\
(\mathrm{W})\end{array}$ & $\begin{array}{l}\text { Cement } \\
(\mathrm{C})\end{array}$ & $\begin{array}{l}\text { Fly ash } \\
(\mathrm{FA})\end{array}$ & $\begin{array}{l}\text { Silica } \\
\text { sand } \\
(\mathrm{S})\end{array}$ & $\begin{array}{l}\text { Fiber } \\
(\mathrm{PVA}), \\
\mathrm{kg} / \mathrm{m}^{3}\end{array}$ & $\begin{array}{l}\text { HRWRA, } \\
\mathrm{kg} / \mathrm{m}^{3}\end{array}$ \\
\hline Specification & 0.581 & 1 & 1.2 & 0.798 & 26 & 7.5 \\
\hline
\end{tabular}

Hobart type mixture with a capacity of 20 liters was used for mixing ECC materials. All the materials except PVA fiber was placed in the mixture and mixed for one minute. Water and HRWRA were then added and mixed for two minutes to get homogenous mix. PVA fibers were then added slowly during mixing so that they were distributed uniformly and mixing operation was continued for minimum additional three minutes until uniform mixture was seen. Cylindrical columns were cast from ECC. Square and cylindrical LWSCC and SCC core columns were then wrapped with ECC layers of required thickness (Fig. 3.4). 
Control specimens in the form of cylinders and beams were also cast with LWSCC, SCC and ECC to determine their mechanical properties. They were cured under the same conditions as column specimens and tested at the same age.

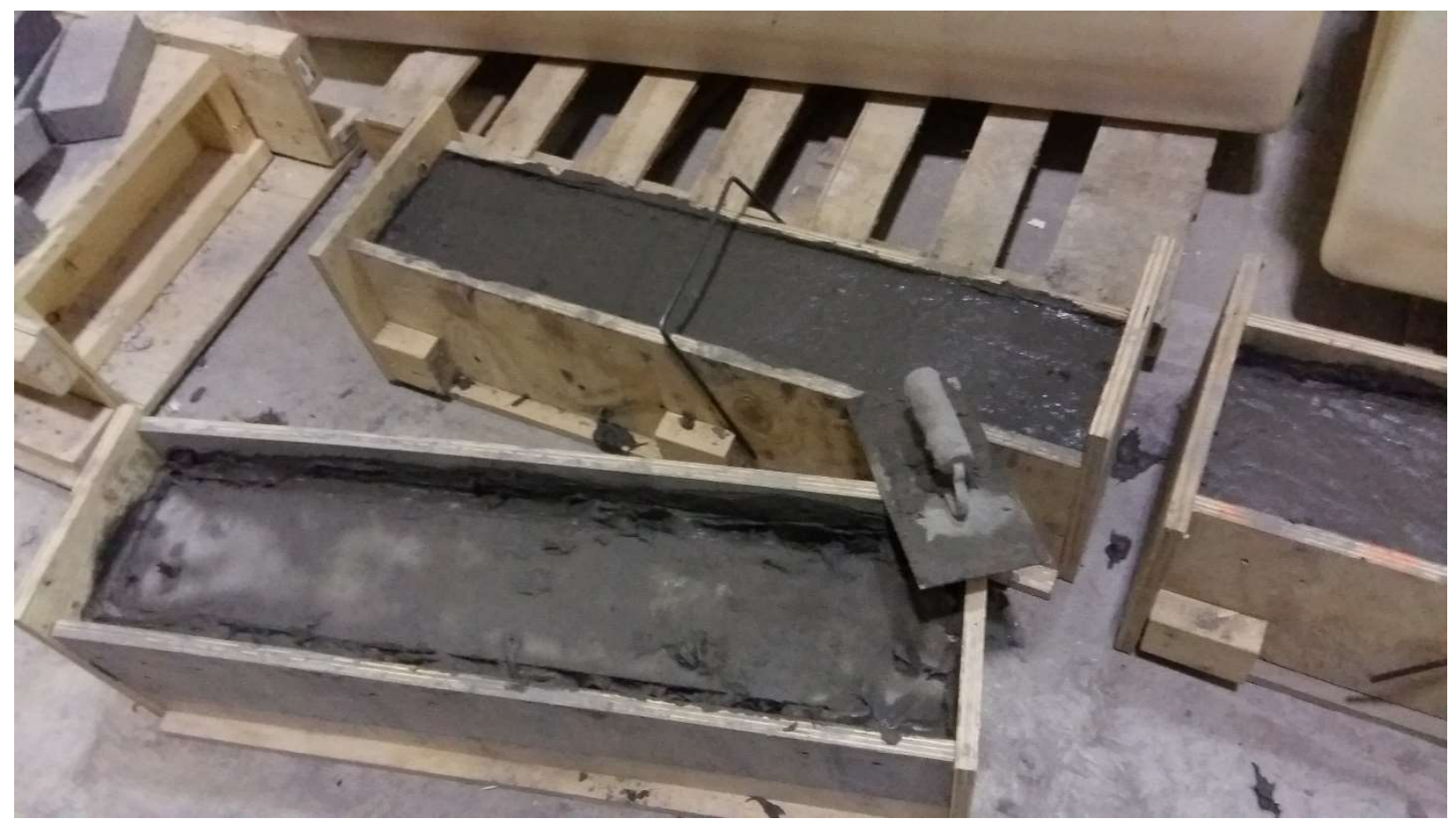

Fig. 3.4: Casting of ECC wrapping around core columns

\subsection{Instrumentation and testing of concrete properties}

Experiments for obtaining mechanical properties of concretes were conducted in the laboratory using control specimens made from ECC, LWSCC and SCC by installing strain gauges. These specimens were subjected to loading to failure and continuous data on load and deformation were obtained through computer aided data acquisition systems.

\subsubsection{Compressive strength test of concrete cylinders as per ASTM C39/C39M (2014)}

Standard cylinders of $100 \mathrm{~mm}$ x $200 \mathrm{~mm}$ were tested as per ASTM C39/C39M (2014) for the compressive strength of LWSCC, SCC and ECC cylinders at the age of testing. The cylinders were loaded in compression to get the failure load (Fig. 3.5). The compressive strength of cylinders was then obtained from the recorded failure load. 


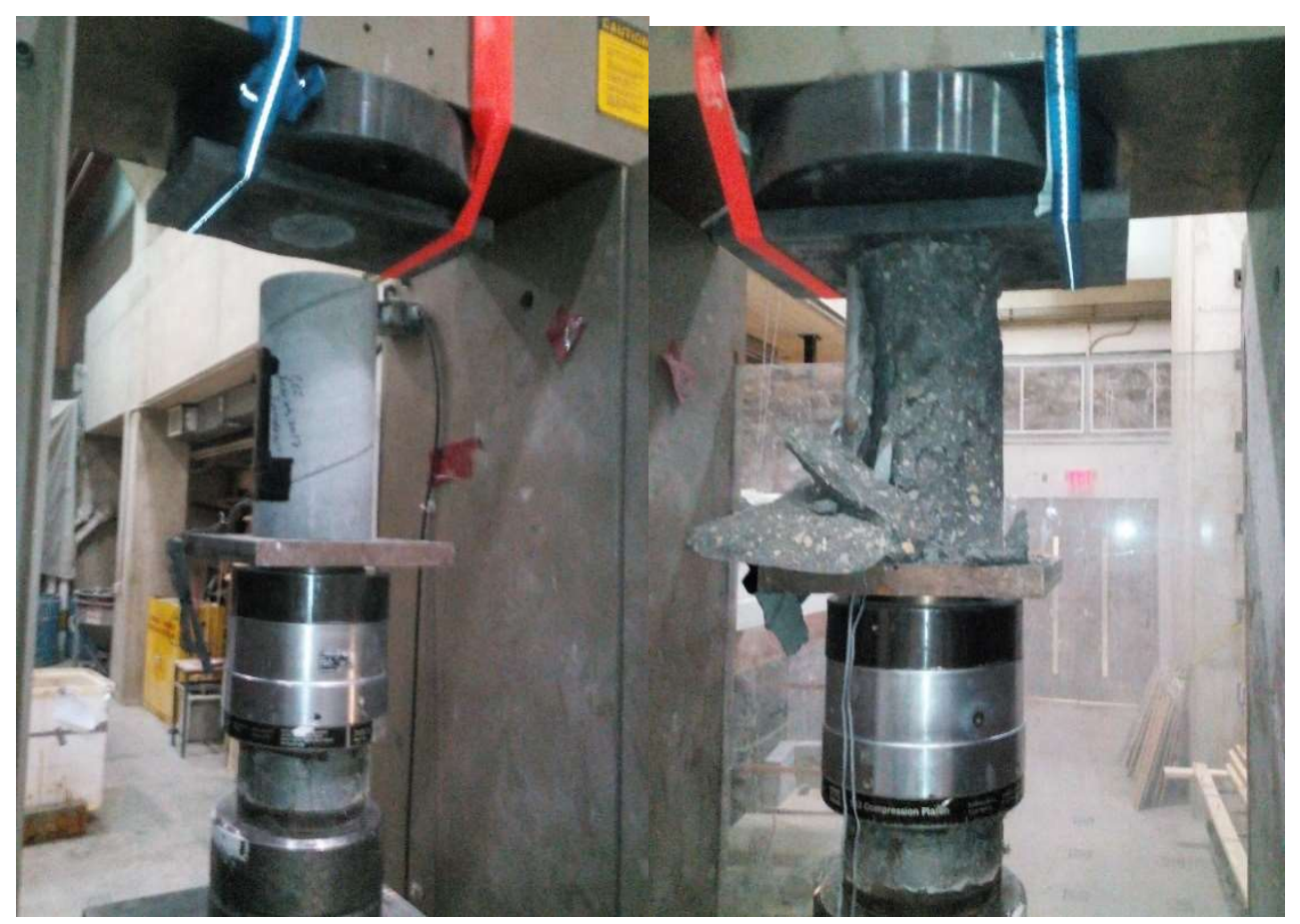

Fig. 3.5: Experimental set-up, instrumentation, and testing of concrete cylinders

\subsubsection{Modulus of elasticity and Poisson's ratio as per ASTM C469/C469M (2016)}

Modulus of elasticity and Poisson's ratio were determined as per ASTM C469/C469M (2016) procedures using the test results. One vertical and one horizontal strain gauges were installed at the mid height of $150 \mathrm{~mm}$ x $300 \mathrm{~mm}$ concrete cylinders (Fig. 3.6) made of LWSCC, SCC and ECC. MTS machine was used to load the specimens under compression. Load verses axial and tangential strain were recorded throughout the loading history until failure through a computer aided data acquisition system. Then the modulus of elasticity and Poisson's ratio were obtained using the gathered data.

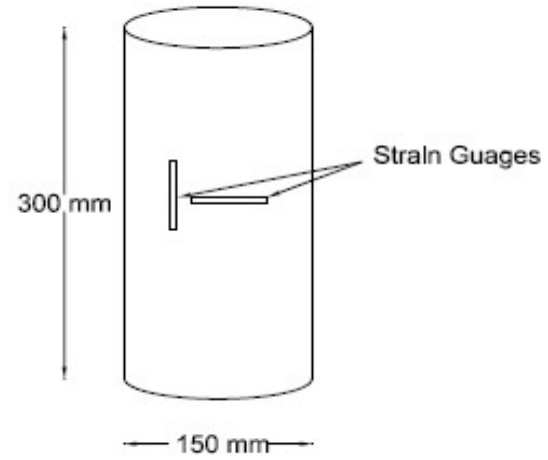

Fig. 3.6: Location of strain gauges on control concrete cylinder 


\subsubsection{Splitting tensile strength test as per ASTM C496/C496M (2011)}

Standard test cylinders of $100 \mathrm{~mm} \times 200 \mathrm{~mm}$ were tested for the splitting tensile strength of LWSCC, SCC and ECC as per ASTM C496/C496M (2011). Test set-up and failed specimens are shown in Fig. 3.7.
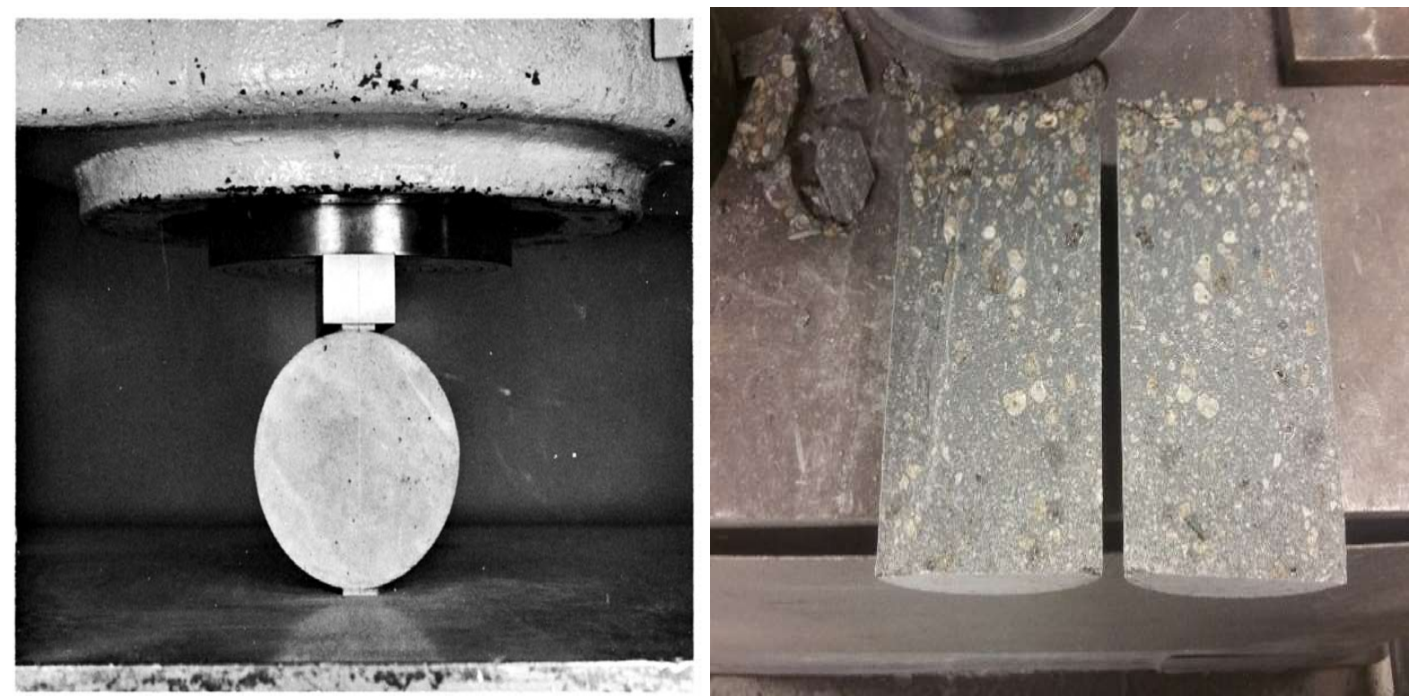

Fig. 3.7: Splitting test setup and testing as per ASTM C496/C496M (2011)

\subsubsection{Slant shear and bond tests}

Slant shear test (as shown in Fig. 3.8) was done using two companion cylindrical specimens made of LWSCC-ECC and SCC-ECC (100 mm x $200 \mathrm{~mm})$ which were cast in two halves with an interface angle of $30^{\circ}$ with the longitudinal axis of the specimen. They were loaded to failure under compression and the shear strength was obtained by dividing the failure load by the elliptical interface area shown in Fig. 3.8.

Bond between ECC wrapping and LWSCC/SCC core was also tested using cylindrical column specimens with ECC wrapping. The test set-up is shown in Fig. 3.9 where compression load was applied through the LWSCC/SCC core allowing core to slide against ECC wrap through a prefabricated hole (equal to the diameter of core concrete) in the steel load bearing plate. The failure load was recorded and the shear bond strength was obtained by dividing the failure load with the contact core-wrap surface area. Two companion specimens were tested. 

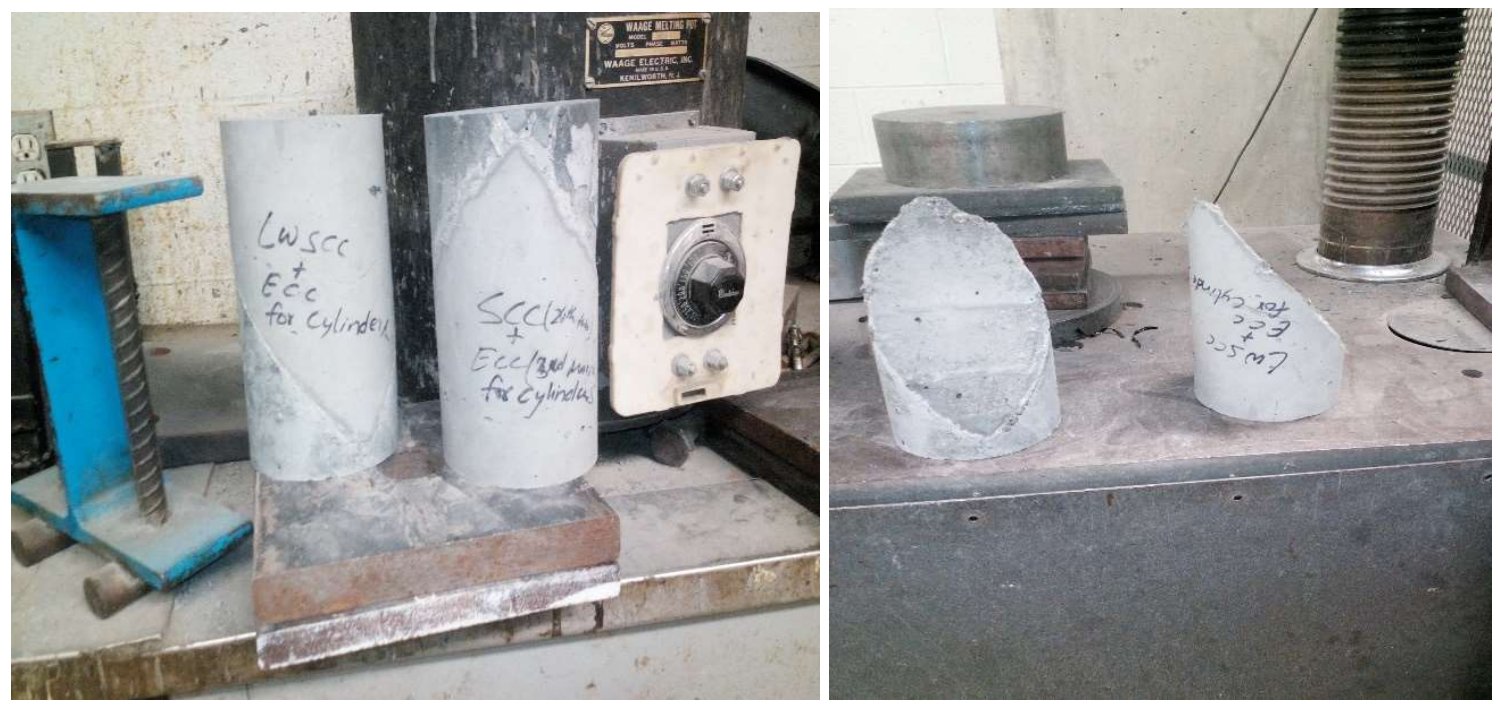

Fig. 3.8: Slant shear test setup and testing
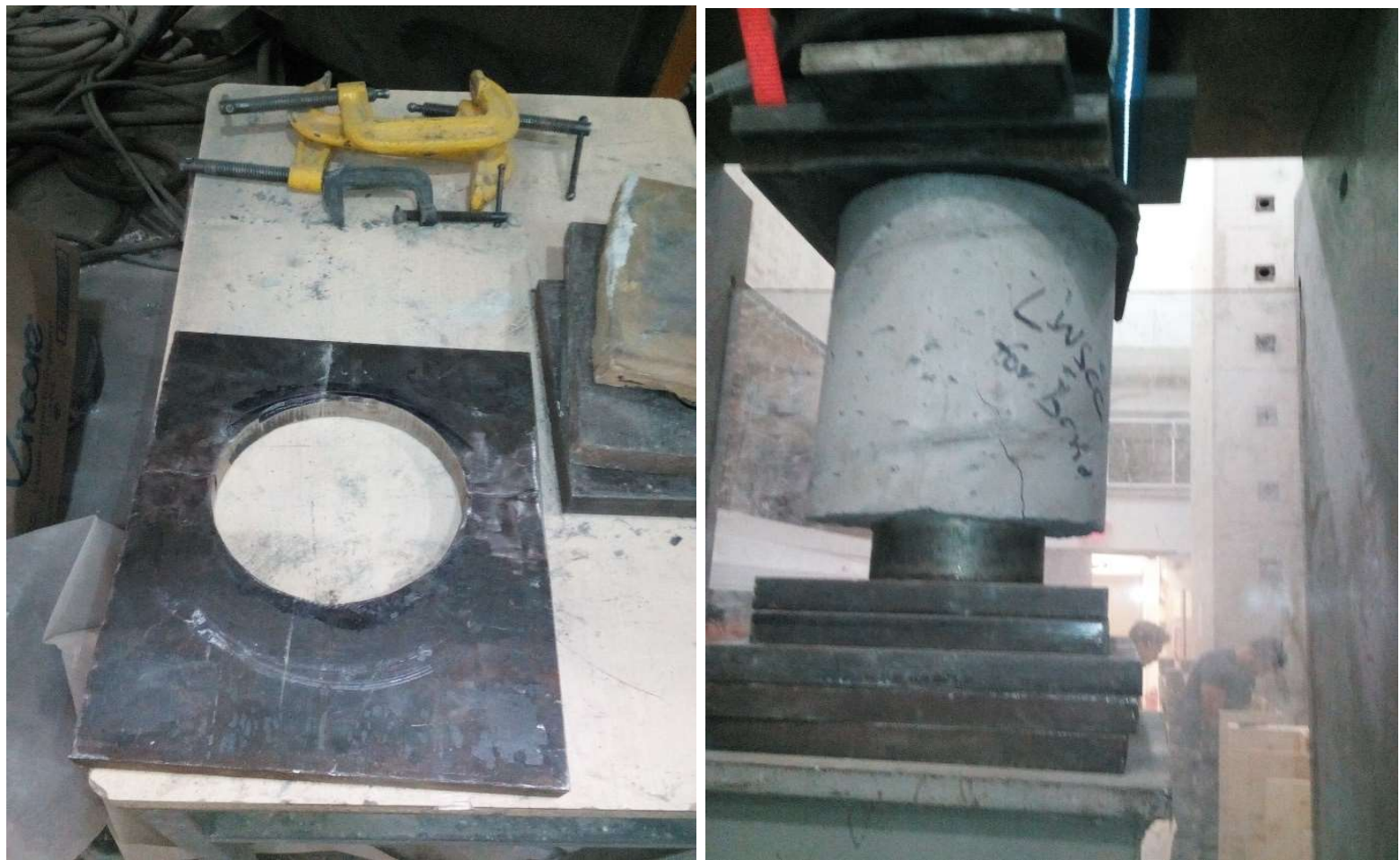

Fig. 3.9: Bond test setup and testing

\subsubsection{Three-point notched beam Test}

Two companion beam specimens made of LWSCC, SCC and ECC having width (b) $=50 \mathrm{~mm}$, depth $(\mathrm{d})=76 \mathrm{~mm}$ and effective length $(\mathrm{S})=304 \mathrm{~mm}$ with a notch at the middle (having a depth ( $\left.a_{0}\right)$ of $25 \mathrm{~mm}$ made by using diamond saw-cut) were tested under three-point loading as shown in Fig. 3.10. 

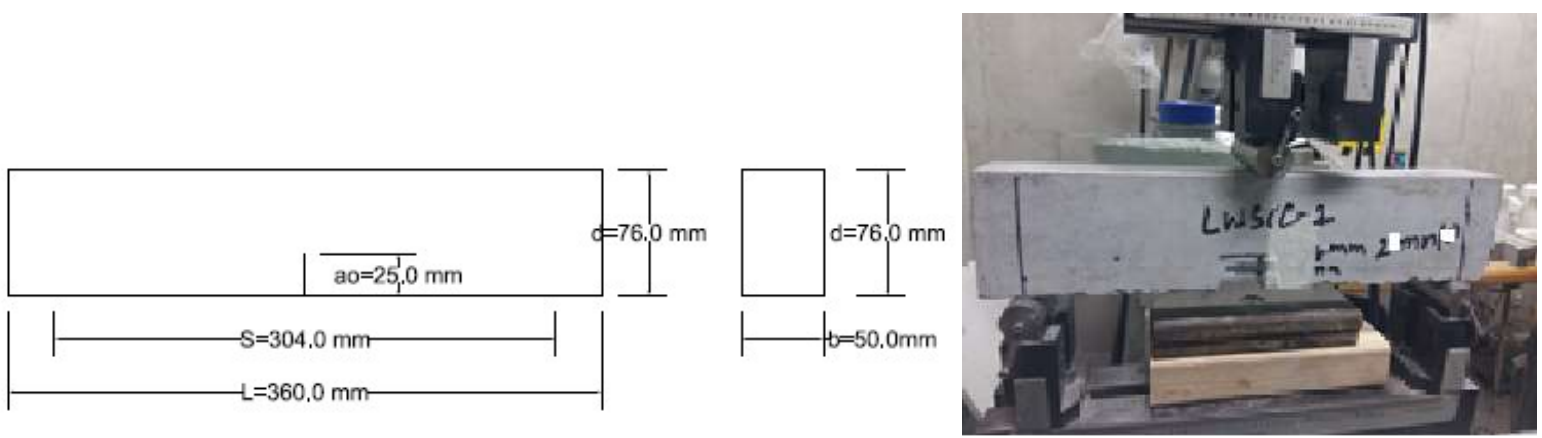

Fig. 3.10: Notched beam testing

The dimensions were designed to meet $\mathrm{S} / \mathrm{d}=4$. The beam was placed on MTS testing machine with the notch facing down. Load was applied continuously with a displacement rate of 0.0008 $\mathrm{mm} / \mathrm{s}$ till $25 \%$ of the failure load.

\subsection{Testing and instrumentation of cylindrical columns with ECC confinement}

Two horizontal strain gauges, one at the ECC-core interface and other at outer surface of the concrete at mid height (as shown in Fig. 3.11), were installed to monitor tangential/hoop strain development during loading history until failure of the columns. Axial load was applied through the core with a rate of $1 \mathrm{~mm} /$ minute. Axial load-displacement/strain responses were recorded and failure modes were observed.
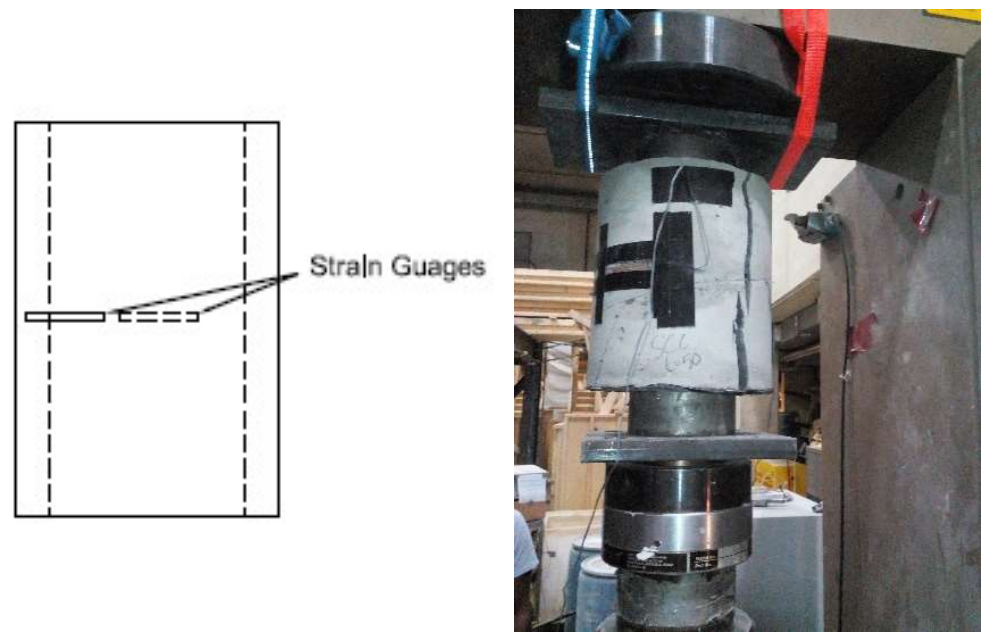

Fig. 3.11: Location of strain gauges and test set-up showing testing of ECC confined cylindrical columns 


\subsection{Testing of square columns with ECC confinement}

Vertical and horizontal stain gauges were installed on the outer surface at the mid-height of S-SC10, S-SC-15, S-SC-20, S-LW-20, S-LW-25 and S-LW-30 columns (Fig. 3.12). Load was applied through entire area (both core and ECC wrap) using MTS machine with a rate of $1 \mathrm{~mm} /$ minute. Axial load-displacement (through linear voltage displacement transducers 'LVDT')/ strain responses were recorded and the failure modes were observed.

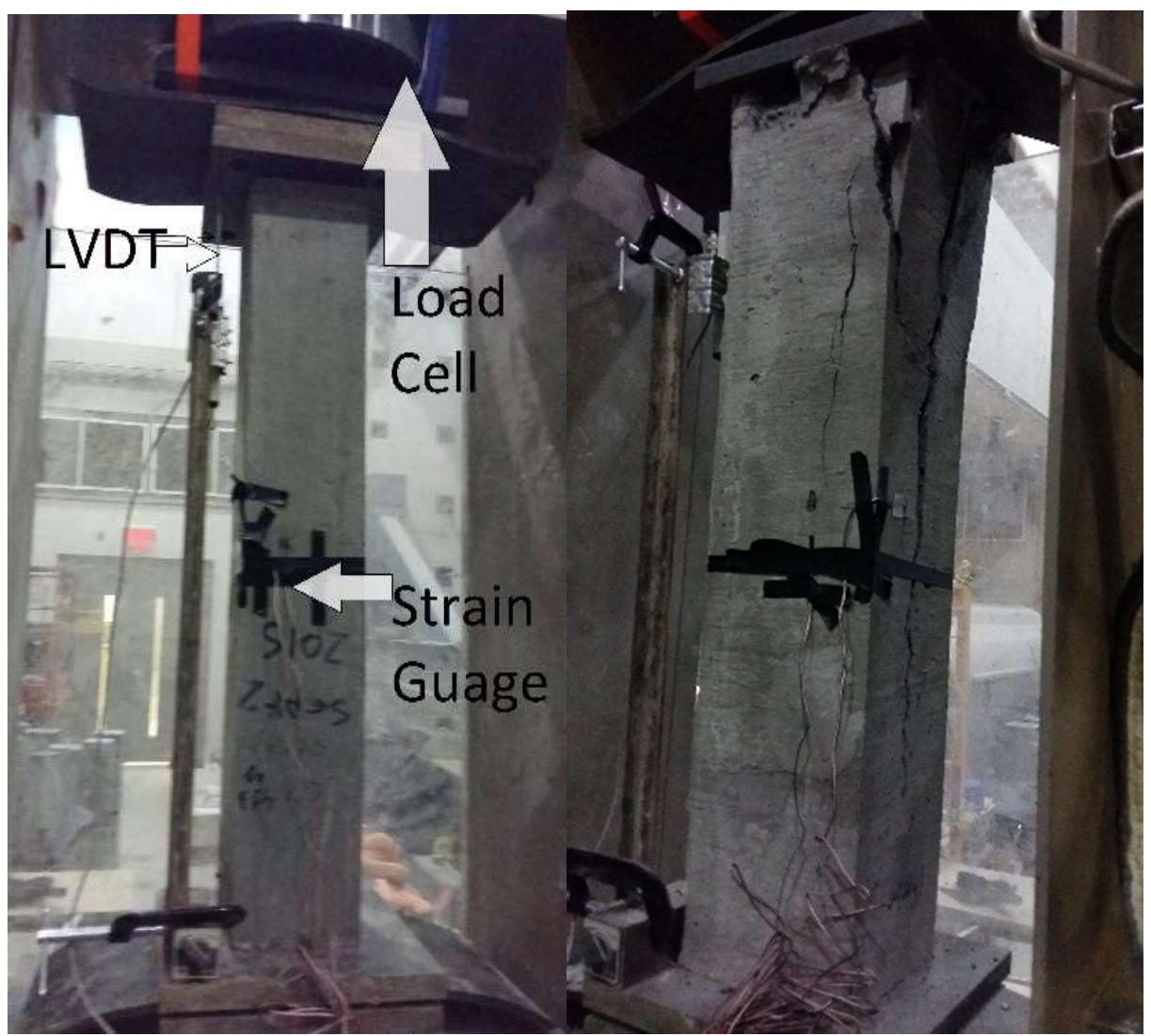

Fig. 3.12: Experimental set-up, instrumentation and testing of square columns

For columns S-LW-20T, S-LW-30T, S-LW-50T, and S-SC-50T, a horizontal strain gauge was installed in the tie bar of the core concrete and on the surface of the ECC wrap at the the same level (Fig. 3.13). The load was applied through the core of the column from MTS machine with a rate of $1 \mathrm{~mm} /$ minute (Fig. 3.13). The axial load-displacement (through linear voltage displacement transducers 'LVDT')/ strain responses were recorded, and the failure modes were observed. 

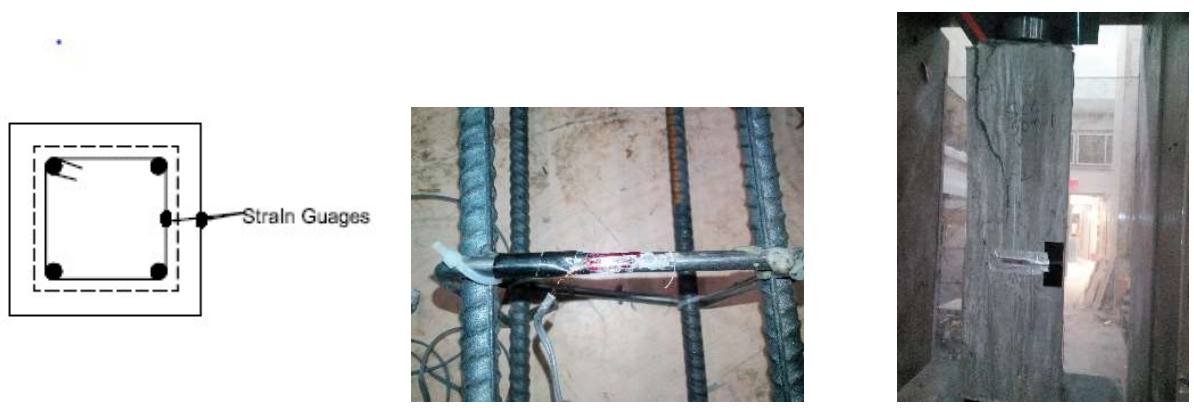

Fig. 3.13: Location of strain gauge for columns and testing

\subsection{Summary}

Experimentation and the test procedure of column specimens are described in this chapter which includes fabrication, casting, curing, instrumentation and testing. A total of twenty (20) specimens were tested to failure. Chapter Four presents and describes the test results. 


\section{CHAPTER FOUR \\ EXPERIMENTAL RESULTS AND DISCUSSIONS}

\subsection{Introduction}

The scope of the experimentation was to study the performance of columns due to confinement provided by ECC wrap. Tests results are analyzed and discussed with special reference to quantification of ECC confinement effect. These analyses are based on load-deflection responses, crack formation and propagation, ductility, energy absorption capacity, ultimate load, failure modes, ECC wrapping characterstics, material/geometric properties and stress-strain developments.

\subsubsection{Fresh state and mechanical properties of concrete and re-bars}

Experimental tests were conducted to determine modulus of elasticity, compressive strength, tensile splitting strength, shear bond strength and fracture properties of ECC, LWSCC and SCC used for columns (as described in Chapter 3). Due to it's strain hardening nature, ECC has higher yielding load than LWSCC and SCC. ECC has lower modulus of elasticity than SCC and comparable to LWSCC. Mechanical properties of concretes (modulus of elasticity, Poisson's ratio, compressive strength, splitting tensile strength and fracture characteristics in terms of stress intensity factor and fracture energy) at the age of testing are listed in Table 4.1a. It was observed that all mechanical properties of SCC were higher than those of LWSCC because of the larger aggregate size in its matrix, besides LWSCC had also porous and weak aggregates. On the other hand, ECC had higher mechanical properties of than SCC except lower modulus of elasticity and Poisson's ratio. Fresh state properties in terms of slump flow were determined for each concrete. The values of slump flow are provided in Table 4.1a.

\subsubsection{Load vs. strain and deformation behavior during modulus of elasticity test} LWSCC cylinder showed linear load-strain curve to $325 \mathrm{kN}$ approximately (Fig. 4.1a). The axial deformation increased non-linearly to $300 \mathrm{kN}$ and increased linearly to cracking load of $563 \mathrm{kN}$. After the cracking load, the slope of the curve started to decrease reaching the peak load of 584.85 $\mathrm{kN}$. 
SCC cylinder showed linear load-strain curve to $235 \mathrm{kN}$ approximately (Fig. $4.1 \boldsymbol{b})$. The axial deformation increased non-linearly to $300 \mathrm{kN}$ and increased linearly to cracking load of $683 \mathrm{kN}$. After the cracking load, the slope of the curve started to decrease reaching the peak load of 743.73 $\mathrm{kN}$.

ECC cylinder showed linear load-strain curve to $300 \mathrm{kN}$ approximately (Fig. 4.1c). The axial deformation increased non-linearly to $250 \mathrm{kN}$ and increased linearly to cracking load of $775 \mathrm{kN}$. After the cracking load, the slope of the curve started to decrease reaching the peak load of 878.61 $\mathrm{kN}$.

\subsubsection{Load vs. displacement behavior during notched beam test}

Load deflection curve for notched LWSCC beam (Fig. 4.2a) shows that the curve is non-linear upto $0.3 \mathrm{kN}$ and then the load-deflection curve is linear up to the point of first crack, which is approximately $1.0 \mathrm{kN}$, that is when the propagation of crack starts from pre-cracked section. The slope of the curve starts to decrease to reach the peak load of $1.45 \mathrm{kN}$ and the beam fails showing brittle behavior. SCC notched beam load displacement curve (Fig. 4.2b) did not show change in slope before the failure load of $1.69 \mathrm{kN}$ which indicted sudden failure of the beam. ECC notched beam curve (Fig. 4.2c) showed multiple occurrence of cracks for increasing load indicated by abrupt change in slopes until it reached peak load of $2.15 \mathrm{kN}$.

\subsubsection{Bond strength between two concretes}

The results obtained from slant shear test and bond test are given in Table 4.1b. It was observed that the slant shear test and interfacial bond test results depended on the compressive strength of the specimen. The compressive strength of SCC was $42 \mathrm{MPa}$ whereas the compressive strength of LWSCC was $33 \mathrm{MPa}$, so SCC/ECC shear stress was observed higher than LWSCC/ECC. The slant shear test produced higher bond stress than interfacial bond test as compared to bond test. 


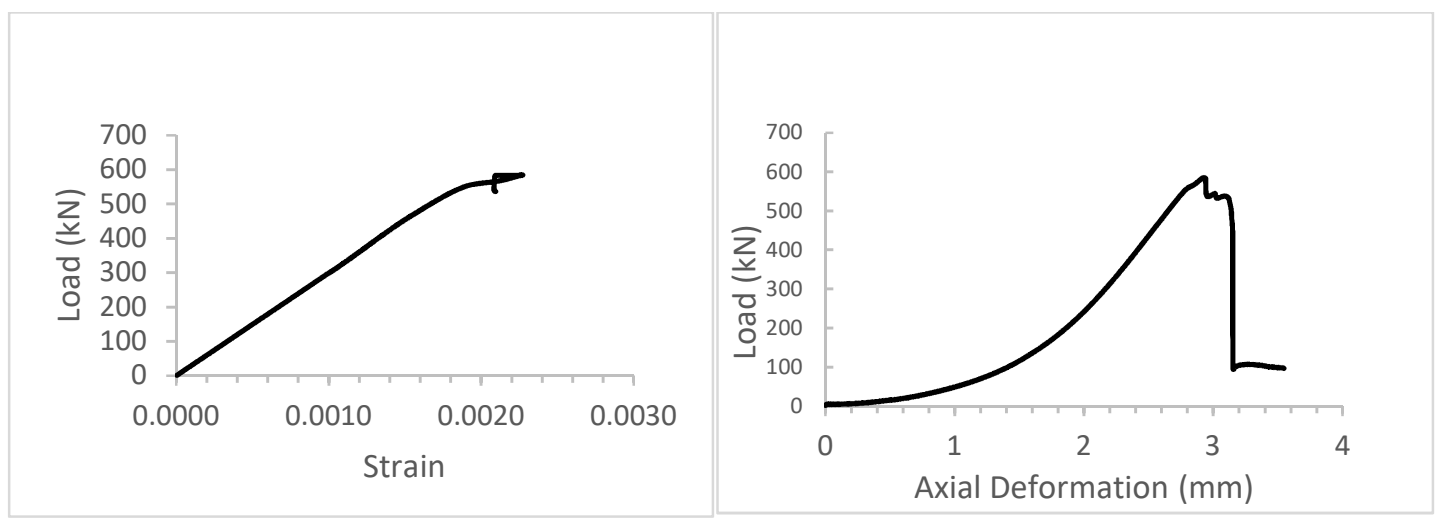

Fig. 4.1a: LWSCC load-strain and deformation responses during modulus of elasticity test
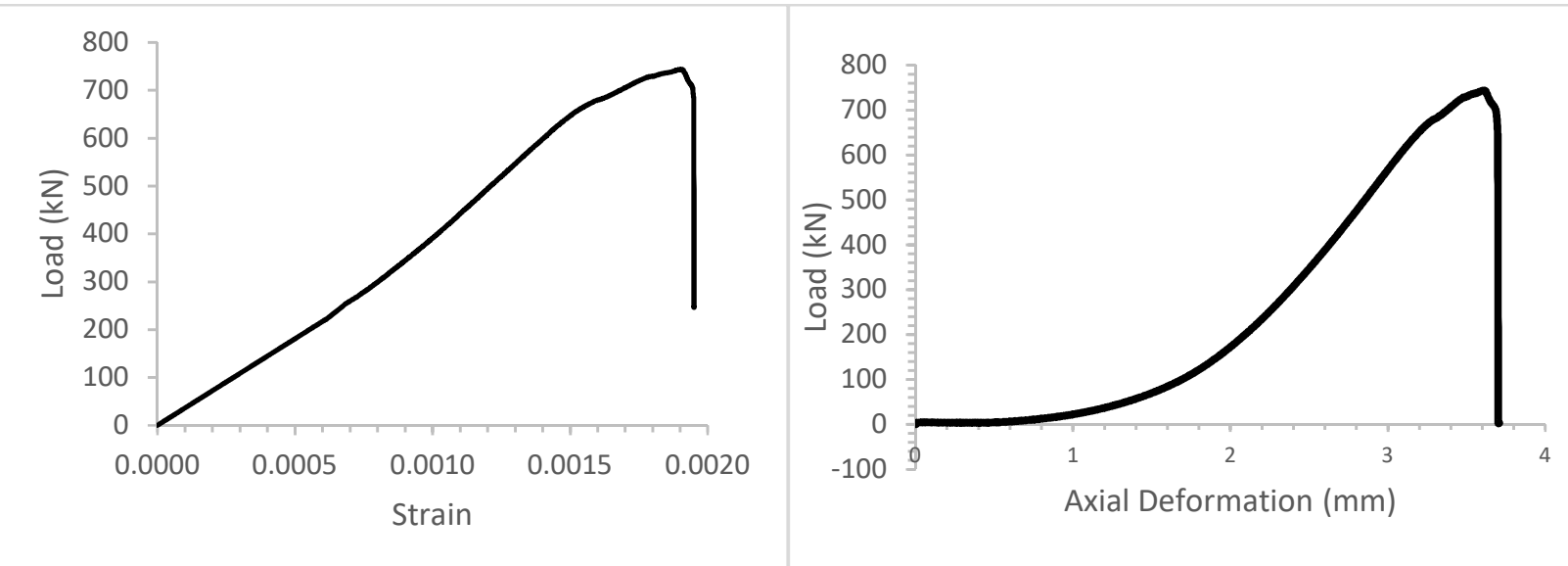

Fig.4.1b: SCC load-strain and deformation responses during modulus of elasticity test
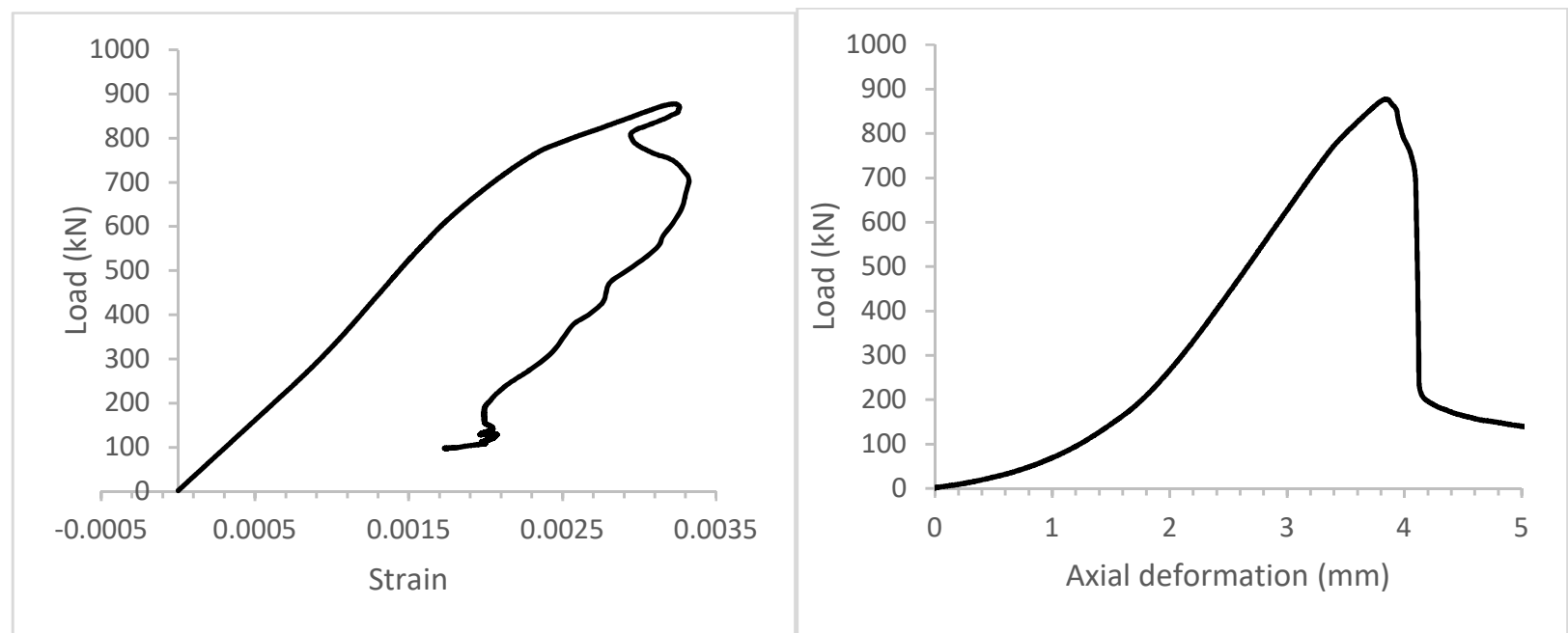

Fig. 4.1c: ECC load-strain and deformation responses during modulus of elasticity test 


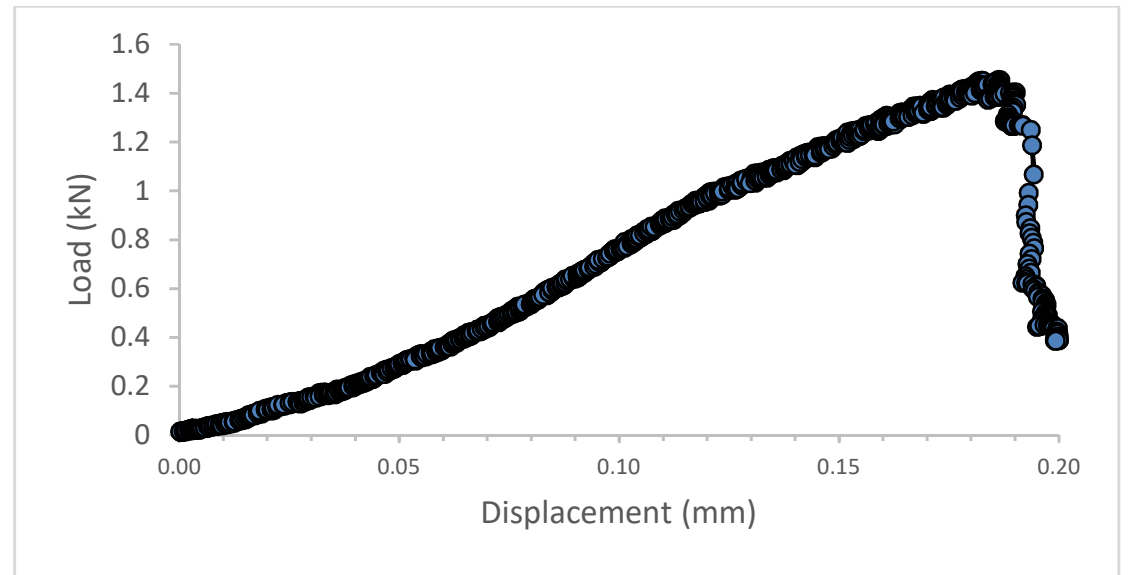

Fig. 4.2a: LWSCC load-displacement response during notched beam test

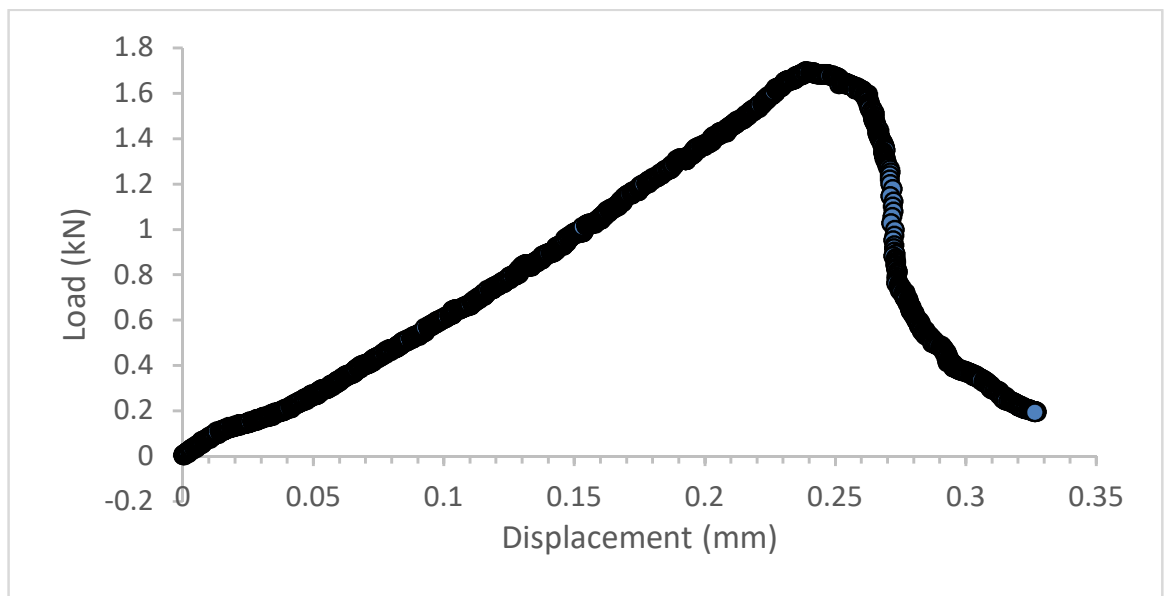

Fig. 4.2b: SCC load-displacement response during notched beam test

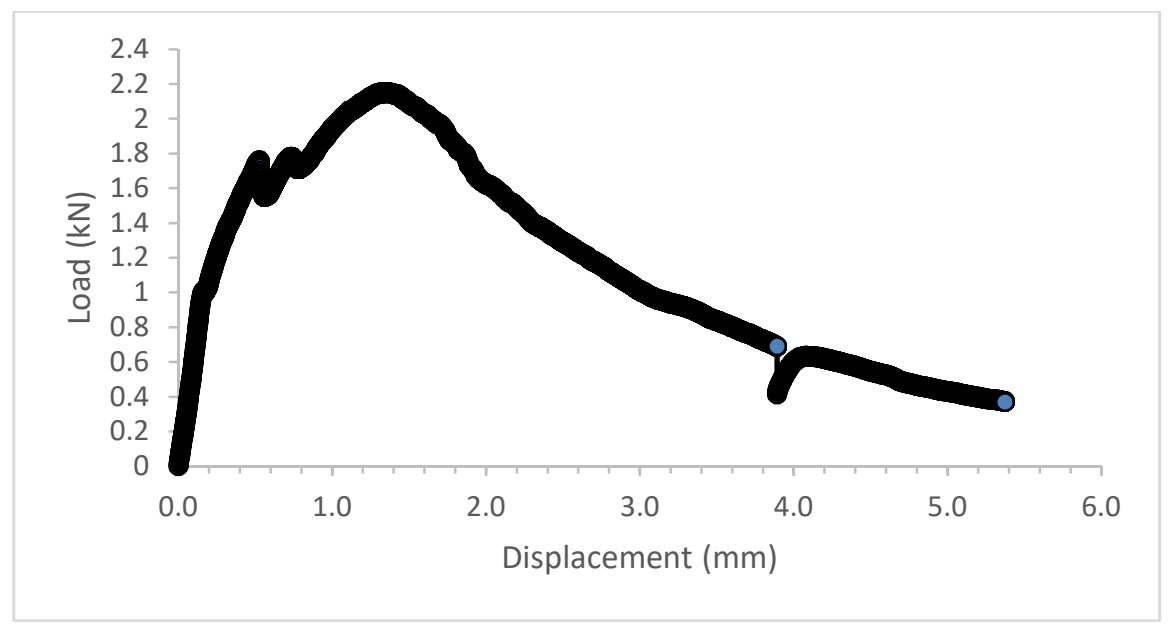

Fig. 4.2c: ECC load-displacement response during notched beam test 
Table 4.1a: Properties of concretes

\begin{tabular}{|c|c|c|c|}
\hline Material & LWSCC & SCC & ECC \\
\hline Modulus of Elasticity (MPa) & 16867 & 23213 & 18457 \\
\hline Poisson's Ratio & 0.16 & 0.23 & 0.17 \\
\hline Compressive Strength (MPa) & 33 & 42 & 49.7 \\
\hline Splitting tensile Strength (MPa) & 2.0 & 3.9 & 4.6 \\
\hline Stress Intensity Factor (K, MPa $\sqrt{ }$ m) & 0.57 & 0.77 & 1.06 \\
\hline Fracture Energy (GF, N/mm) & 0.02 & 0.03 & 0.06 \\
\hline Slump flow (mm) & 700 & 650 & 620 \\
\hline
\end{tabular}

Table 4.1b: Bond (Shear) strength between two concretes

\begin{tabular}{|l|c|c|c|c|}
\hline \multirow{2}{*}{ Interface } & \multicolumn{2}{|c|}{ Failure Load (kN) } & \multicolumn{2}{c|}{ Bond stress (MPa) } \\
\cline { 2 - 5 } & LWSCC/ECC & SCC/ECC & LWSCC/ECC & SCC/ECC \\
\hline Bond Test & 202.52 & 390.00 & 1.43 & 2.76 \\
\hline Slant Shear Test & 300.10 & 342.70 & 19.31 & 22.05 \\
\hline
\end{tabular}

\subsection{SCC and LWSCC cylindrical columns}

Non-reinforced SCC and LWSCC cylindrical columns confined with ECC wrapping of thickness of $20 \mathrm{~mm}, 30 \mathrm{~mm}$ and $50 \mathrm{~mm}$, respectively were tested by applying compression loading through the $150 \mathrm{~mm}$ core only (Type B loading). 


\subsubsection{General behavior of cylindrical columns}

In general, a small compressive load applied to a confined concrete puts all the cross section of the specimen under compression and due to lower its small Poisson's ratio, it behaves similar to unconfined normal concrete if the load is equal to its compressive strength. Cracks begin to develop when the load is increased more than yield stress of confined concrete, thus increasing Poisson's ratio. This causes failure by radial expansion of the wraping/jacket leading to crack formation.

Load-deformation responses obtained from compression test on LWSCC and SCC cylindrical specimens show that the curves start to decrease its slope indicating the reduction of stiffness of the cylinder. The stiffness (ratio of load and deformation) remains constant for initial straight-line segment of the curve. Once micro crack starts developing, the slope of the curve starts decreasing. Crack development is indicated by formation of kinks, that is, abrupt change in slope of load deformation curve during loading stage. Decrease in stiffness was observed in all the confined cylinders. With increasing thickness of ECC, there were more numbers of kink which can be attributed to the bridging effect by ECC fiber. Sharp brittle failure at ultimate load of core cylinder is shifted to higher load and higher deformation due to the presence of ECC Jacket.

Two different types of failure mode were identified under axial compression loading. One of the failure was indicated by vertical cracks on the surface of wrap and another type of failure was indicated by inclined cracks due to shear resulting bond stress between ECC wrap and confined concrete and radial expansion of the confined specimen.

\subsubsection{Load vs. deformation behavior}

Load-deformation responses of non-reinforced LWSCC and SCC cylindrical specimens are shown in Fig. 4.1 and Fig. 4.2, respectively with results summarized in Table 4.2. Initial stiffness for all the columns increased gradually with increase in load approximately between $150 \mathrm{kN}$ to $300 \mathrm{kN}$ due to machine stiffness, which depends on various nonlinearity induced due to seating load and non-elastic elements (Hockett and Gillis, 1971).

The LWSCC control cylindrical column (C-LW) without any ECC wrap had a peak load of approximately $584 \mathrm{kN}$ with axial displacement of $2.93 \mathrm{~mm}$. The peak stiffness (peak load/peak deformation) of the control cylinder C-LW was $200 \mathrm{kN} / \mathrm{mm}$. C-LW-20 column (with $20 \mathrm{~mm}$ ECC wrap) sustained a peak load of $759 \mathrm{kN}$ load with axial deformation of $4.26 \mathrm{~mm}$. The peak load in 
C-LW-20 column increased 30\% and there was 45\% increase in deformation at peak load. The peak stiffness (peak load/peak deformation) of the cylindrical column C-LW-20 was $178 \mathrm{kN} / \mathrm{mm}$ which is $11 \%$ less than the stiffness of control column. C-LW-30 column (with $30 \mathrm{~mm}$ ECC wrap) had increased load (peak) carrying capacity of $37 \%$ with $43 \%$ increase in peak deformation with respect to control column and showing an increase of $8 \%$ stiffness than C-LW-20. C-LW-50 column (with $50 \mathrm{~mm}$ ECC wrap) showed a 13\% decrease in peak stiffness than the column with $30 \mathrm{~mm}$ thick ECC wrap. The load (peak) carrying capacity increased by $29 \%$ with $53 \%$ of increased deformation than the control column.

The SCC control cylindrical column (C-SC) without any ECC wrap had a peak load of approximately $743 \mathrm{kN}$ with axial displacement of $3.61 \mathrm{~mm}$. Cylindrical column C-SC-20 (with 20 mm ECC wrap) did not attain the peak load of the control column which can be due to the problem associated with segregation, improper casting or handling during construction. Cylindrical C-SC30 (with $30 \mathrm{~mm}$ ECC wrap) showed increased peak stiffness of 23\% than the control column with increased load capacity of $23 \%$ and same peak deformation as the control column. Cylindrical CSC-50 (with $50 \mathrm{~mm}$ ECC wrap) had decreased stiffness of 30\% than the column C-SC-30 and showed similar stiffness as the control column. The load carrying capacity increased by $12 \%$ with considerable increased deformation of $31 \%$ compared to control column.

Table 4.2: Summary of test results of cylindrical column specimens

\begin{tabular}{|c|c|c|c|c|c|c|c|c|}
\hline $\begin{array}{c}\text { Non- } \\
\text { reinforced } \\
\text { cylindrical } \\
\text { column }\end{array}$ & $\begin{array}{c}\text { Type of } \\
\text { Loading }\end{array}$ & $\begin{array}{c}\text { Peak } \\
\text { Load } \\
(\mathrm{kN})\end{array}$ & $\begin{array}{c}\text { Peak } \\
\text { Deformation } \\
(\mathrm{mm})\end{array}$ & $\begin{array}{c}\% \\
\text { increase } \\
\text { in peak } \\
\text { load }\end{array}$ & $\begin{array}{c}\% \text { increase in } \\
\text { peak } \\
\text { deformation }\end{array}$ & $\begin{array}{c}\text { Peak } \\
\text { siffness } \\
(\mathrm{kN} / \mathrm{mm})\end{array}$ & $\begin{array}{c}\text { Initial } \\
\text { cracking } \\
\text { load (kN) }\end{array}$ & $\begin{array}{c}1^{\text {crack }} \\
\text { load as } \\
\% \text { of } \\
\text { peak } \\
\text { load }\end{array}$ \\
\hline $\begin{array}{c}\text { C-LW } \\
\text { control) }\end{array}$ & TYPE B & 585 & 2.93 & & & 200 & 563 & 96 \\
\hline C-LW-20 & TYPE B & 759 & 4.26 & 30 & 45 & 178 & 728 & 96 \\
\hline C-LW-30 & TYPE B & 802 & 4.18 & 37 & 43 & 192 & 632 & 79 \\
\hline C-LW-50 & TYPE B & 754 & 4.51 & 29 & 54 & 167 & 601 & 80 \\
\hline $\begin{array}{c}\text { C-SC } \\
\text { (control) }\end{array}$ & TYPE B & 744 & 3.61 & & & 206 & 683 & 92 \\
\hline C-SC-20 & TYPE B & 630 & 3.6 & -15 & & 175 & 308 & 49 \\
\hline C-SC-30 & TYPE B & 912 & 3.61 & 23 & & 253 & 439 & 48 \\
\hline C-SC-50 & TYPE B & 835 & 4.73 & 12 & 31 & 176 & 409 & 49 \\
\hline
\end{tabular}




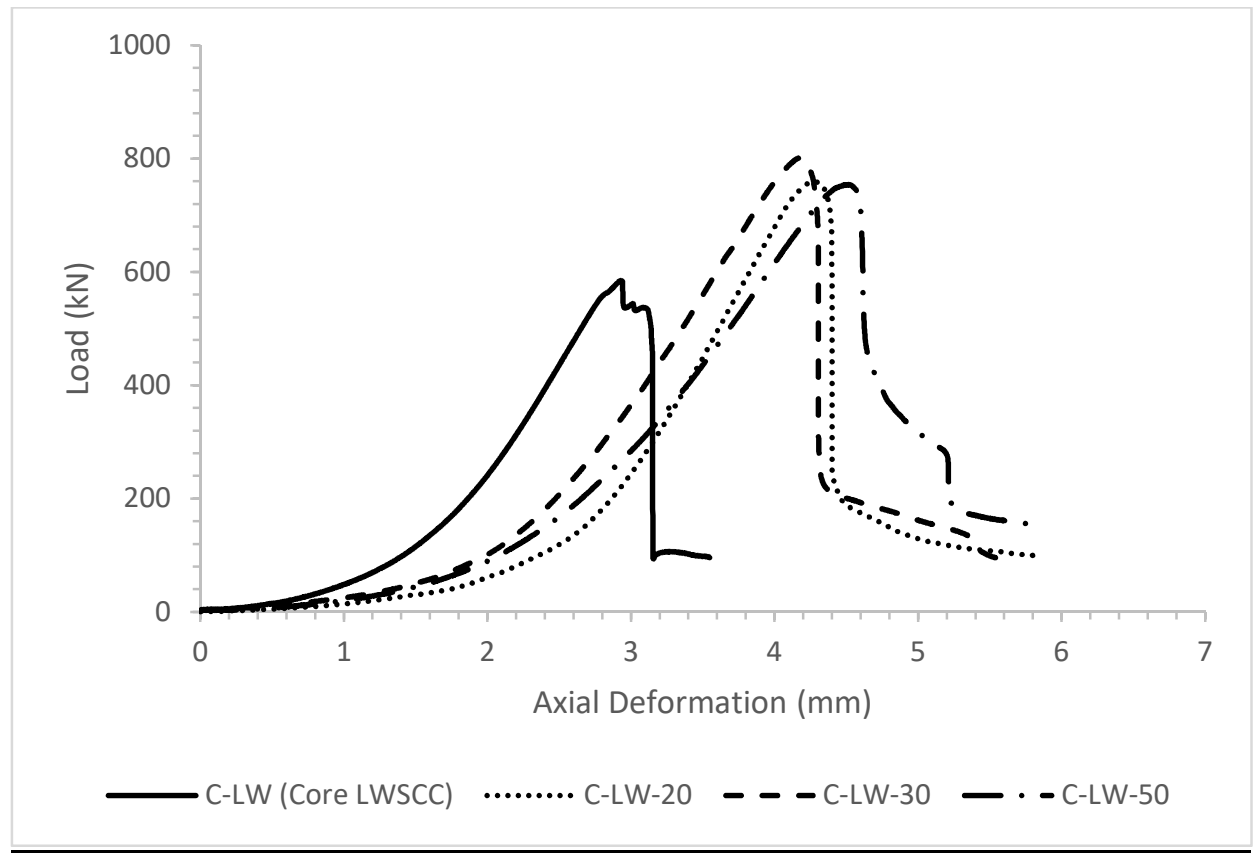

Fig. 4.3a: Load-deformation responses for LWSCC cylindrical specimens under Type B loading

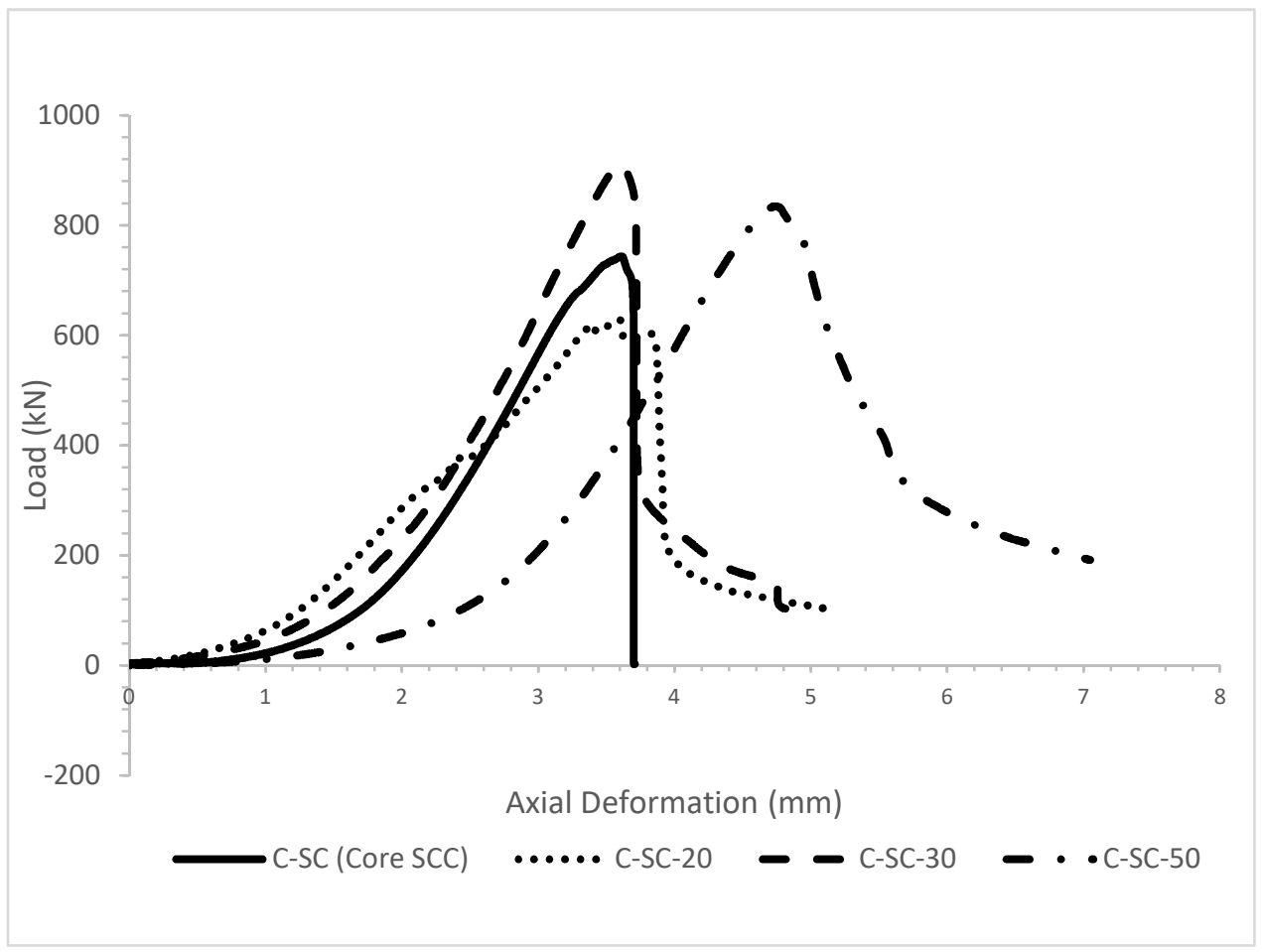

Fig. 4.3b: Load-deformation responses for SCC cylindrical specimens under Type B loading 


\subsubsection{Failure mode and cracking behavior}

Control SCC and LWSCC core cylindrical column specimens split at peak load showing brittle behavior (Fig. 4.5). The ultimate load for control LWSCC column was $585 \mathrm{kN}$ compared to 743 $\mathrm{kN}$ of its SCC counterpart (Table 4.2). Generally, for ECC wrapped LWSCC and SCC cylindrical columns, the crack initiated with a pop sound starting from the top of the cylinder and mostly travelled vertically (Fig. 4.3). All the cylinders showed vertical (tensile) crack, however SCC SSC-20 column showed inclined cracking with low load carrying capacity. For confined LWSCC cylindrical columns, the initial cracking load was higher than the ultimate load of core-control cylindrical column. Initial cracking load of confined SCC cylindrical columns were lower than the ultimate load of the core. The results and observations are tabulated in Table 4.2.
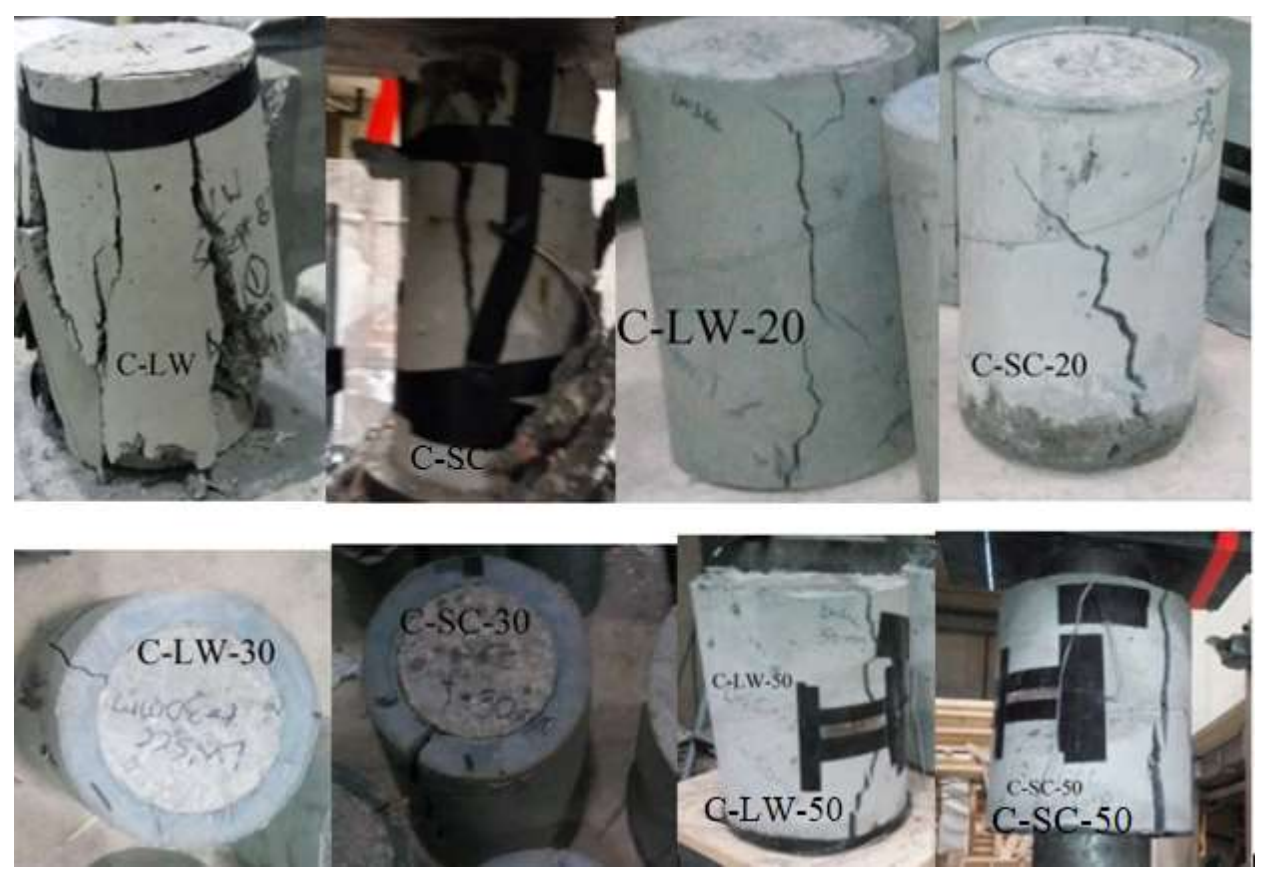

Fig. 4.4: Testing of cylindrical columns showing crack patterns and failure modes

\subsubsection{Load-strain behavior}

Load vs hoop strain response of ECC cylindrical column C-EC is shown in Fig. 4.5a. The development of hoop strain is initially slow to $200 \mathrm{kN}$ load and increased to the failure load of 878 $\mathrm{kN}$ with hoop strain of $\mathbf{0 . 0 0 1 6}$. After failure load, the hoop strain increased for almost same load level indicating the ductile behavior of ECC. 


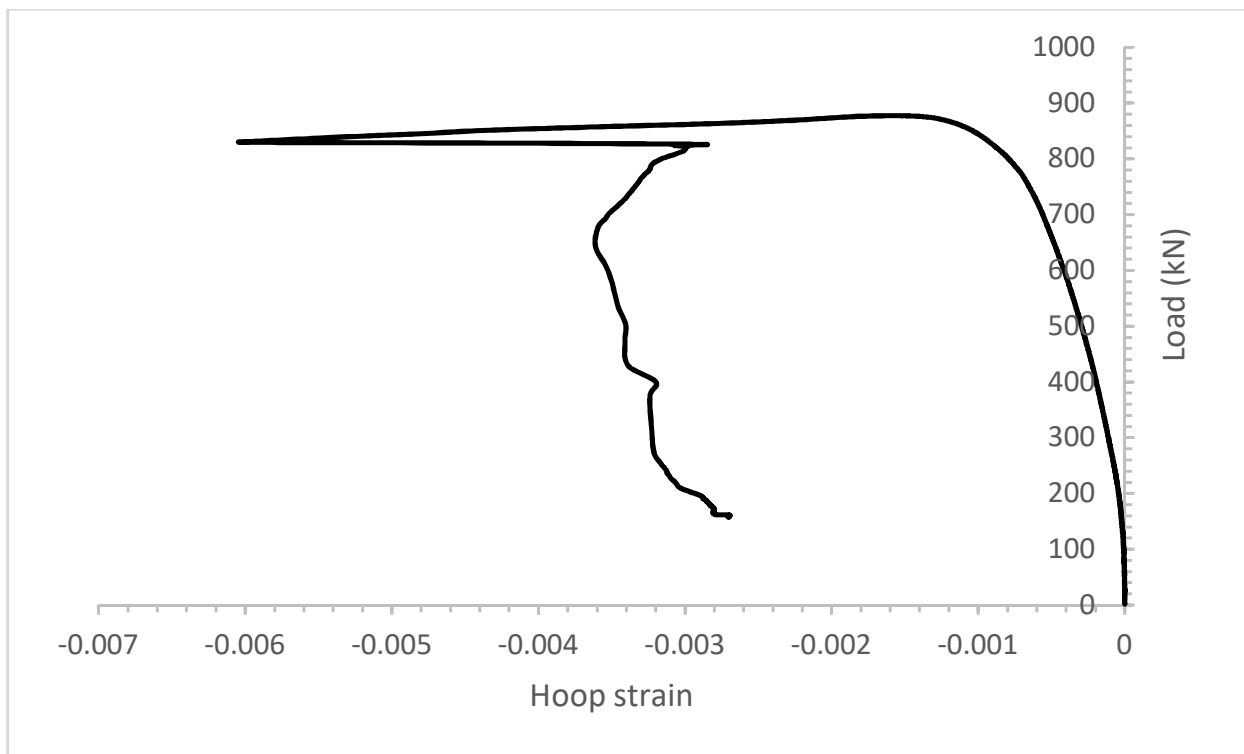

Fig. 4.5a: Hoop strain development in cylindrical ECC column C-EC

Fig. 4.5b shows hoop strain development in LWSCC cylinders at the interface of core cylinder and outer surface of the ECC wrap. The hoop strain of LWSCC control cylindrical column C-LW at failure load of $584 \mathrm{kN}$ reached 0.000348. Cylindrical column C-LW-20 at failure load of 759 $\mathrm{kN}$ reached interfacial hoop strain of 0.000389 which is 1.1 times higher than the hoop strain of control cylinder. The hoop strain in $20 \mathrm{~mm}$ thick ECC wrap was 0.001237 which is 1.3 times lower than hoop strain of ECC control cylinder at failure. Cylindrical column C-LW-30 at failure load of $801 \mathrm{kN}$ reached interfacial hoop strain of 0.00060 showing 1.7 times more strain capacity than column C-LW and 1.5 times higher than column C-LW-20. The hoop strain on 30mm ECC wrap was 0.000156 which is 10.3 times lower than ECC control cylinder. Cylindrical column C-LW-50 at failure load of $754 \mathrm{kN}$ reached interfacial hoop strain of 0.0033 which is 9.5 times increase in hoop strain capacity due to confinement effect and the hoop strain on the surface of 50mm thick ECC wrap was 0.000092 which is 17 times lesser that failure hoop strain of ECC control specimen. It can be inferred from these results that the confinement of core LWSCC cylindrical column increased the hoop strain capacity of the confined concrete. 


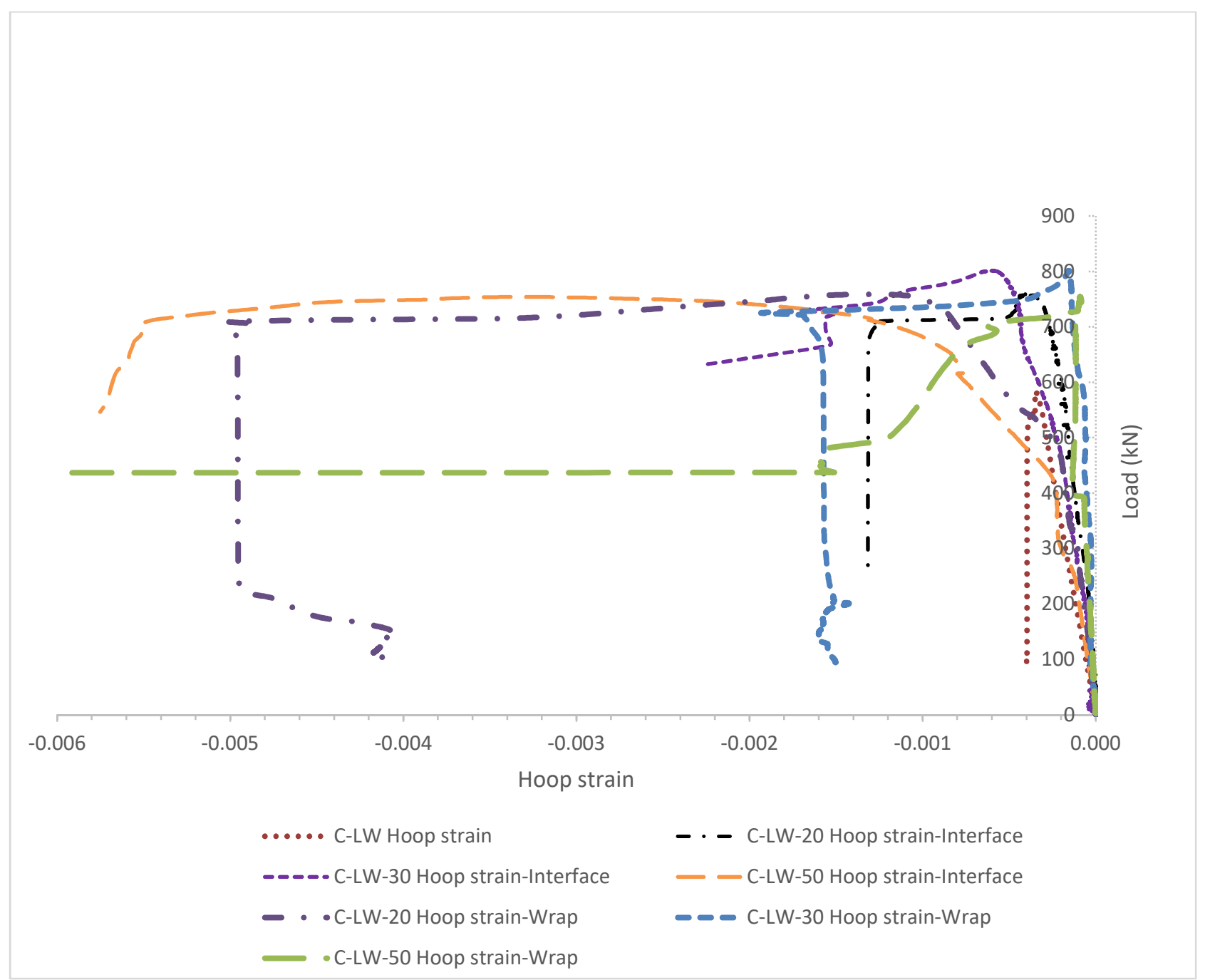

Fig. 4.5b: Hoop strain development in cylindrical column between the interface (LWSCC/ECC) and outer wrap (ECC) surface

Fig. 4.5c shows hoop strain development in SCC cylinders at the interface of core cylinder and outer surface of the ECC wrap. The hoop strain of SCC control cylindrical column C-SC at failure load of $744 \mathrm{kN}$ reached 0.000492 . Cylindrical column C-SC-20 at failure load of $629 \mathrm{kN}$ reached interfacial hoop strain of $0.000553,1.12$ times higher than the control cylinder and the hoop strain on ECC wrap was 0.007712 which is 5 times higher than hoop strain on ECC wrap. Both the values of hoop strains, at interface and wrap surface, are higher than failure hoop strain of SCC and ECC control cylinders. It is also observed that the cracking pattern of C-SC-20 column (Fig. 4.4) is different from other cylindrical specimens. Cylindrical column C-SC-30 at failure load of $911 \mathrm{kN}$ reached interfacial hoop strain of 0.002434 showing 5 times increased strain capacity and with 
hoop strain of 0.000017 on the ECC wrap surface. Cylindrical column C-SC-50 at failure load of $834 \mathrm{kN}$ reached interfacial hoop strain of $0.002939,6$ times higher than control cylinder, suggesting increased hoop strain capacity due to confinement effect. Strain gauges on ECC wrap of both C-SC-30 and C-SC-50 cylindrical columns were dislocated before the failure load due to crack propagation.

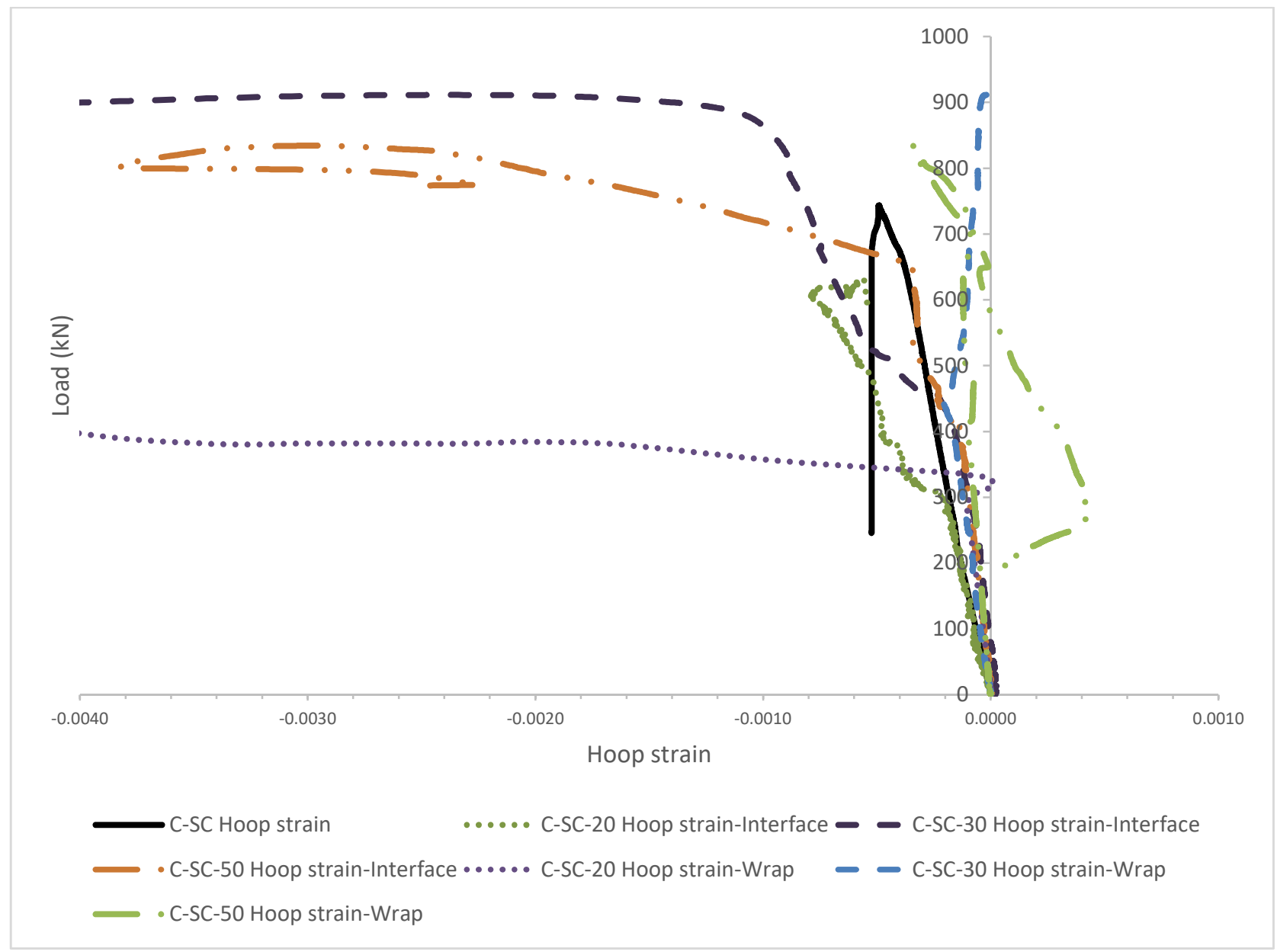

Fig. 4.5c: Hoop strain development in cylindrical column between the interface (SCC/ECC) and outer wrap (ECC) surface

\subsubsection{Ductility Index}

Cylindrical columns with ECC wrapping showed significant increase in strain-based ductility and deformation capacity which is expressed by Ductility Index (DI). DI shows the extent of deformation of column before failure. Strain based $\mathrm{DI}_{(\text {Strain) }}$ is expressed as axial strain at $85 \%\left(\varepsilon_{85}\right)$ 
of peak load on descending branch of stress-strain curve to strain at peak load $\left(\varepsilon_{\mathrm{p}}\right)$ as per Eq. 4.1. Deformation based $\mathrm{DI}_{\text {(Deformation) }}$ is expressed as deformation at $85 \%\left(\Delta_{85}\right)$ of peak load on ascending or descending branch of load-deformation curve to deformation at peak load $\left(\Delta_{\mathrm{p}}\right)$ as per Eq. 4.2.

$\mathrm{DI}_{(\text {Strain })}=\varepsilon_{85}$ (post-peak) $/ \varepsilon_{\mathrm{p}}$

$\mathrm{DI}_{(\text {Deformation) }}=\Delta_{\mathrm{p} /} \Delta_{85}$ (pre-peak)

Strain based ductility index $\left(\mathrm{DI}_{(\mathrm{Strain})}\right)$ was calculated based on (4.1) from load-strain curves shown in Fig. 4.6a. Ductility index of LWSCC and SCC cylinders increased with the increase of ECC wrap thickness. For wrap thickness of $20 \mathrm{~mm}$ to $50 \mathrm{~mm}$, ductility index increased from 3 to 15 which is shown in Table 4.3. Fig. 4.6b shows the parameters for ductility index for specimens CLW-50 and C-SC-50. In general, $\mathrm{DI}_{(\text {Strain) }}$ increased with the increase of ECC wrap thickness. Deformation base ductility was calculated based on Eq. 4.2 from load-deformation curves shown in Fig. 4.3. $\mathrm{DI}_{\text {(Deformation) }}$ did not show significant increase in ductility for cylindrical columns (Table 4.3).

Table 4.3: Ductility and energy absorbing capacity of cylindrical columns

\begin{tabular}{|c|c|c|c|c|c|c|c|}
\hline \multirow[t]{2}{*}{$\begin{array}{c}\text { Column } \\
\text { Designation }\end{array}$} & \multirow[t]{2}{*}{$\begin{array}{c}\text { ECC Wrap } \\
\text { thickness }(\mathrm{mm})\end{array}$} & \multirow[t]{2}{*}{$\begin{array}{l}\text { Type of } \\
\text { Loading }\end{array}$} & \multirow{2}{*}{$\begin{array}{c}\text { Strain } \\
\text { based } \\
\text { Ductility } \\
\text { Index } \\
\text { (DI) }\end{array}$} & \multicolumn{2}{|c|}{$\begin{array}{c}\text { Deformation } \\
\text { based } \\
\text { Ductility } \\
\text { Index (DI) }\end{array}$} & \multirow[t]{2}{*}{$\begin{array}{l}\text { Energy } \\
\text { (Joule) }\end{array}$} & \multirow[t]{2}{*}{$\begin{array}{l}\text { Energy } \\
\text { Ratio }\end{array}$} \\
\hline & & & & $\begin{array}{l}\text { Pre- } \\
\text { peak }\end{array}$ & $\begin{array}{l}\text { Post- } \\
\text { peak }\end{array}$ & & \\
\hline C-LW & & & GF & 1.11 & 1.08 & 535.1 & 1.00 \\
\hline C-LW-20 & 20 & Type B & 5.36 & 1.09 & 1.03 & 814.8 & 1.52 \\
\hline C-LW-30 & 30 & Type B & 5.22 & 1.1 & 1.03 & 988.67 & 1.85 \\
\hline C-LW-50 & 50 & Type B & 15.9 & 1.11 & 1.02 & 1027.86 & 1.92 \\
\hline $\mathrm{C}-\mathrm{SC}$ & & & 1 & 1.15 & 1.03 & 850.61 & 1.00 \\
\hline C-SC-20 & 20 & Type B & GF & 1.16 & 1.08 & 922.25 & 1.08 \\
\hline C-SC-30 & 30 & Type B & 14.96 & 1.11 & 1.03 & 1039.37 & 1.22 \\
\hline C-SC-50 & 50 & Type B & 14.88 & 1.1 & 1.06 & 1062.54 & 1.25 \\
\hline
\end{tabular}




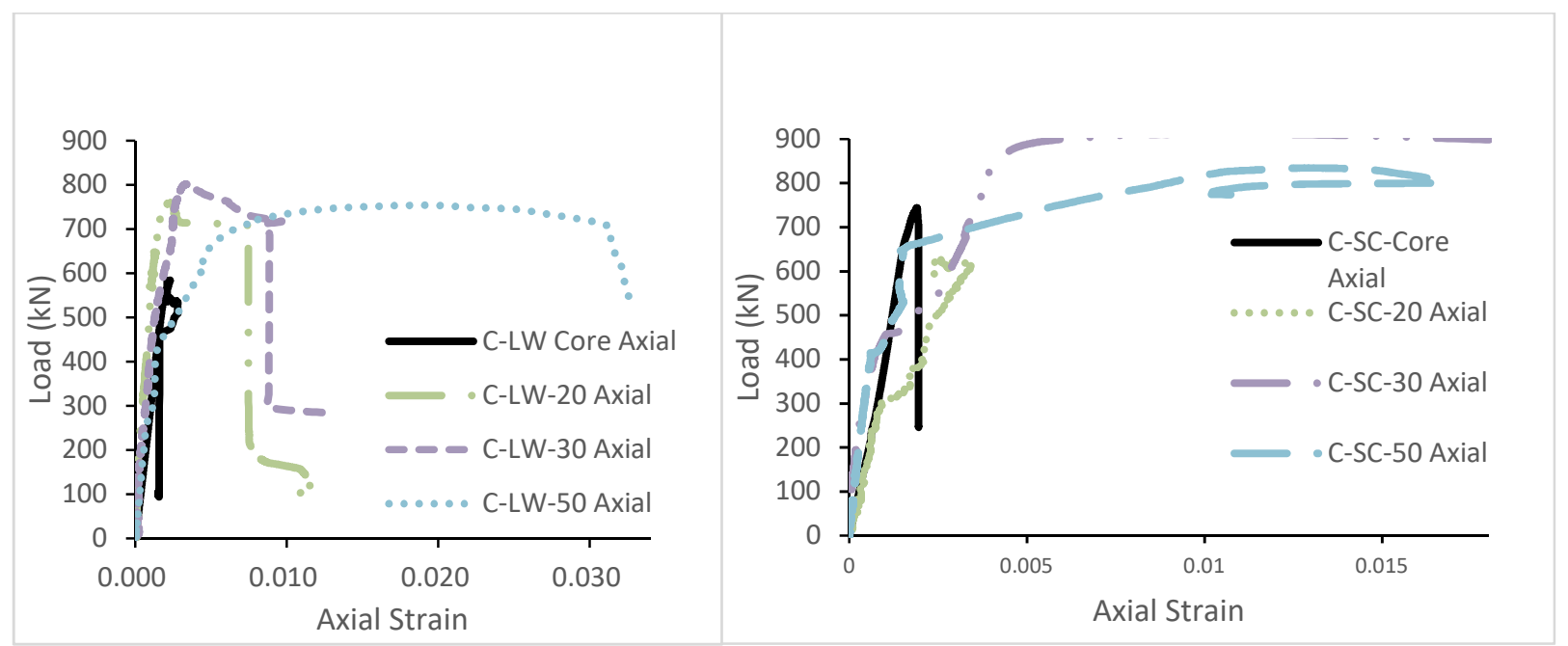

Fig. 4.6a: Load - strain curves for strain-based ductility index calculation
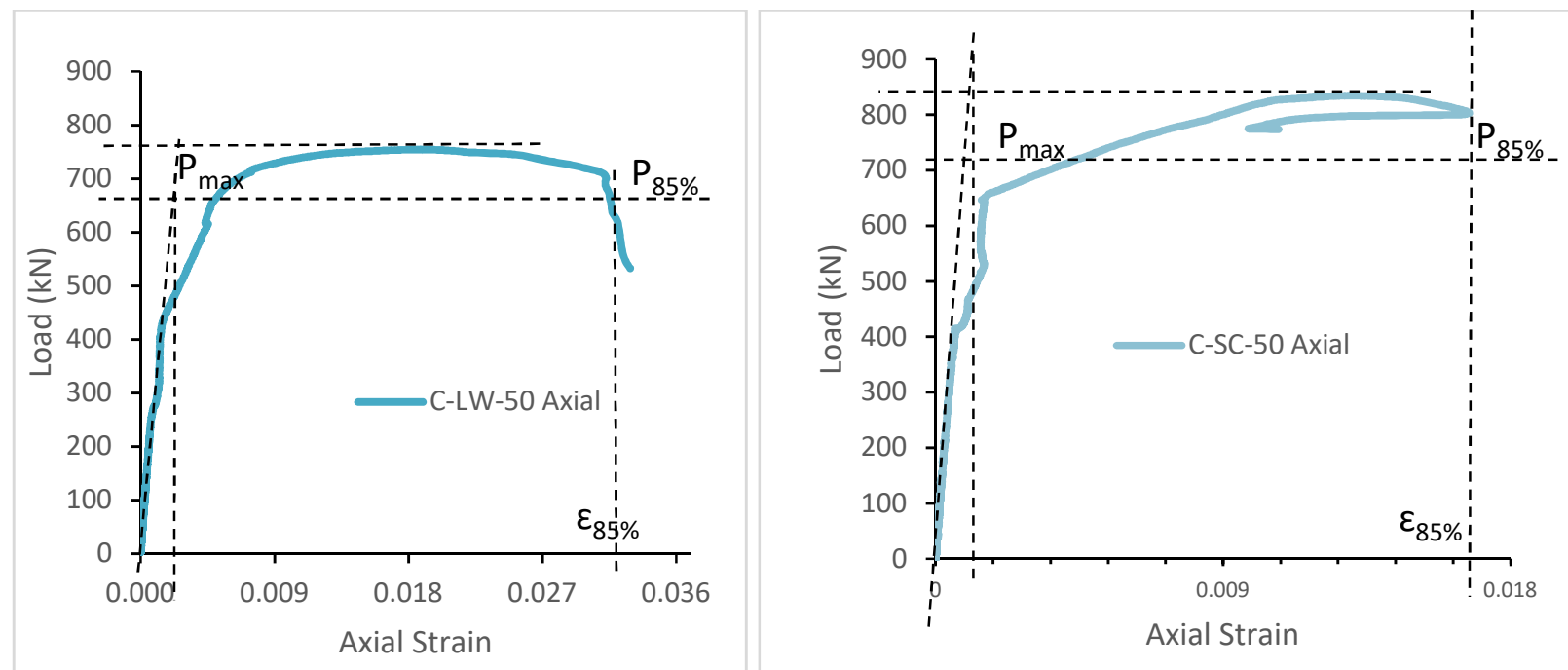

Fig. 4.6b: Ductility Index (strain based) for cylindrical columns

\subsubsection{Energy absorption capacity}

Energy absorbed by cylindrical columns are given in Table 4.3. The area covered by loaddeformation curve up to the ultimate/peak load of each specimen was defined as the amount of energy absorbed. Fig. 4.7 shows the area under the peak load for C-LW-50 specimen for typical energy calculation. The Energy Ratio was defined as increase in energy absorption capacity with respect to control cylindrical column. The energy ratio for LWSCC cylindrical column $20 \mathrm{~mm}$ thick ECC wrap was 1.52, $30 \mathrm{~mm}$ thick ECC wrap was 1.85 and $50 \mathrm{~mm}$ thick ECC wrap was 1.92, showing increase in energy absorption capacity when thickness of wrap was increased. SCC cylindrical column absorbed more energy with increasing thickness of ECC wrap. The energy 
ratio for SCC cylindrical column with $20 \mathrm{~mm}$ thick ECC wrap was 1.08, $30 \mathrm{~mm}$ thick ECC wrap was 1.22 and $50 \mathrm{~mm}$ thick ECC wrap was 1.25. SCC cylindrical columns showed higher energy absorbing capacity than LWSCC counter part due to higher load resisting capacity.

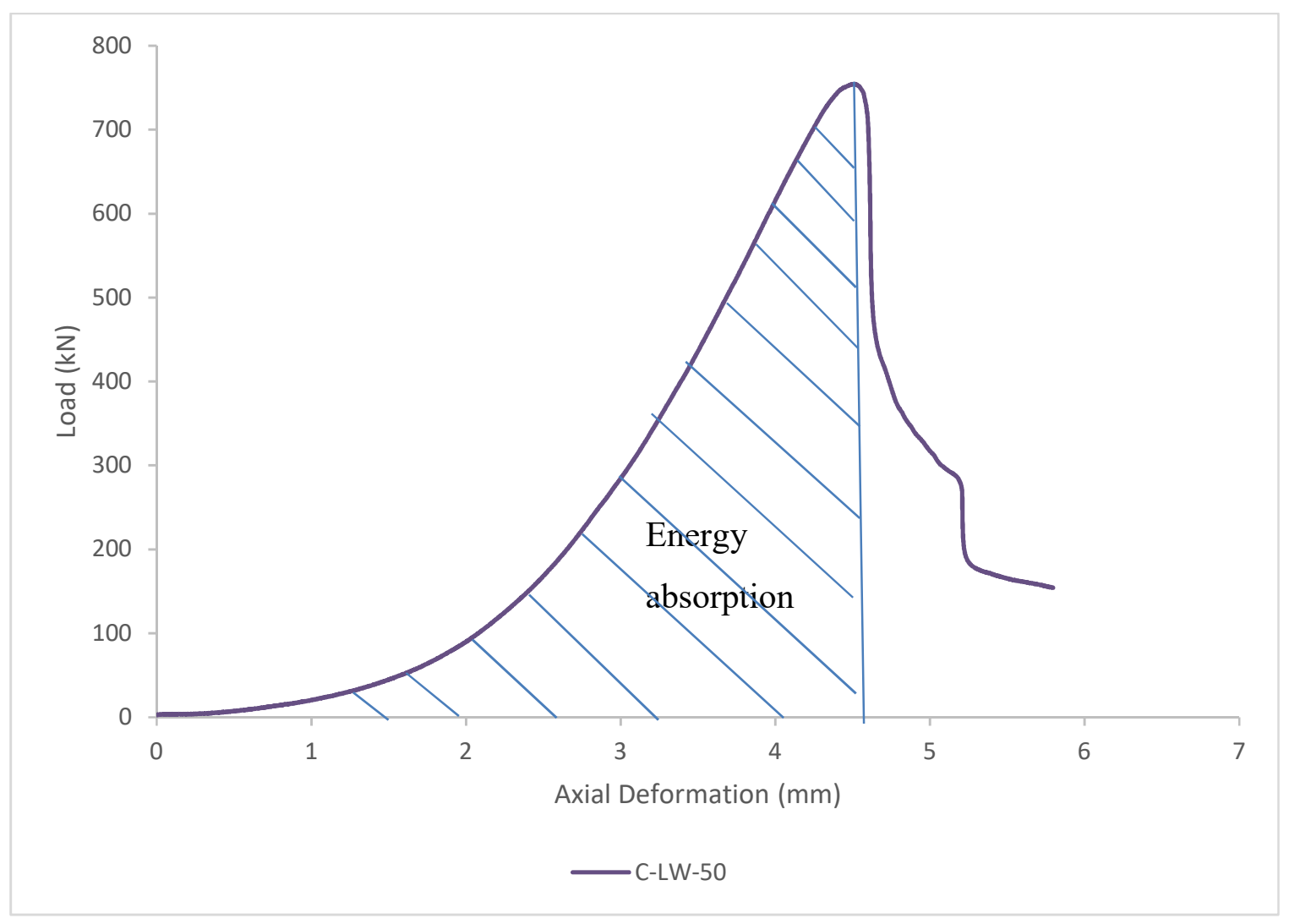

Fig. 4.7: Energy absorption capacity calculation from load-deformation curve

\subsection{Reinforced untied SCC and LWSCC square columns with varying wrap thickness of ECC under Type A loading \\ SCC and LWSCC columns were confined with ECC wrap thickness of $10 \mathrm{~mm}, 15 \mathrm{~mm}$ and $20 \mathrm{~mm}$ and subjected to Type-A loading through whole cross-sectional area (both core and wrap). Results are explained in terms of load-deformation responses, load-strain developments, failure modes, ductility and energy absorbing capacity.}




\subsubsection{Load vs. deformation behavior}

Load-deformation responses of square LWSCC columns are shown in Fig. $4.8 \boldsymbol{a}$ and the results are summarized in Table 4.4. The core LWSCC column (S-LW) without any ECC wrap (control column) had a peak load of approximately $383 \mathrm{kN}$ with axial displacement of $4.3 \mathrm{~mm}$ showing peak stiffness of $89 \mathrm{kN} / \mathrm{mm}$. Column S-LW-20 (with $20 \mathrm{~mm}$ ECC wrap) sustained a peak load of $1020 \mathrm{kN}$ load with axial deformation of $4.6 \mathrm{~mm}$. It showed $166 \%$ increase in load carrying capacity and $7 \%$ increase in deformation at peak load compared to control column with increase of peak stiffness of 149\% . Column S-LW-25 (with 25 mm ECC wrap) exhibited increased load carrying capacity of approximately $152 \%$ with $1 \%$ decrease in peak deformation than control column with increase of stiffness of 156\%. The column S-LW-30 (with $30 \mathrm{~mm}$ ECC wrap) showed increased load carrying capacity of $218 \%$ with decreased deformation of $3 \%$ than control column showing increased stiffness of 203\%. In general, increased ECC wrap thickness increased load carrying capacity and decreased deformation capability (increased stiffness) of columns.

Load-deformation curves for reinforced untied SCC columns without (control column) and with ECC wrap are compared in Fig. 4.8b and results are summarized in Table 4.4. The SCC control column (S-SC) without any wrap had a peak load of about $870 \mathrm{kN}$ with axial displacement of 3.84 mm with resulting peak stiffness of $227 \mathrm{kN} / \mathrm{mm}$. Column S-SC-10 (with $10 \mathrm{~mm}$ ECC wrap) exhibited a peak load of $1398 \mathrm{kN}$ showing 61\% increase in load carrying capacity and 45\% increase in peak deformation than control column with increased stiffness of $11 \%$ with respect to control column. S-SC-15 (with $15 \mathrm{~mm}$ ECC wrap) achieved a peak load of $1317 \mathrm{kN}$ showing $51 \%$ and $32 \%$ higher peak load and deformation than the control column. The increase in stiffness of column S-SC-15 was 15\%. Column S-SC-20 (with 20 mm ECC wrap) attained the highest peak load of $1424 \mathrm{kN}$ with peak deformation of $5.08 \mathrm{~mm}$ showing $64 \%$ and $32 \%$ higher peak load and peak deformation compared to control column with increased stiffness of $23 \%$. 
Table 4.4: Summary of test results of reinforced untied square columns

\begin{tabular}{|c|c|c|c|c|c|c|c|c|}
\hline $\begin{array}{c}\text { Reinforced } \\
\text { untied square } \\
\text { column }\end{array}$ & $\begin{array}{c}\text { Type of } \\
\text { Loading }\end{array}$ & $\begin{array}{c}\text { Peak } \\
\text { Load } \\
(\mathrm{kN})\end{array}$ & $\begin{array}{c}\text { Peak } \\
\text { Deformation } \\
(\mathrm{mm})\end{array}$ & $\begin{array}{c}\text { increase } \\
\text { in peak } \\
\text { load } \\
\text { in increase } \\
\text { in peak } \\
\text { deformation }\end{array}$ & $\begin{array}{c}\text { Peak } \\
\text { stiffness } \\
(\mathrm{kN} / \mathrm{mm})\end{array}$ & $\begin{array}{c}\text { Initial } \\
\text { Cracking } \\
\text { Load } \\
\text { crack } \\
\text { load } \\
\text { as\% } \\
\text { of } \\
\text { peak } \\
\text { load }\end{array}$ \\
\hline S-LW (control) & $\begin{array}{c}\text { TYPE } \\
\text { A }\end{array}$ & 384 & 4.3 & & & 89 & 193.3 & 50 \\
\hline S-LW-20 & $\begin{array}{c}\text { TYPE } \\
\text { A }\end{array}$ & 1020.3 & 4.6 & 166 & 7 & 222 & 340.8 & 33 \\
\hline S-LW-25 & $\begin{array}{c}\text { TYPE } \\
\text { A }\end{array}$ & 967.3 & 4.25 & 152 & -1 & 228 & 317.7 & 33 \\
\hline S-LW-30 & $\begin{array}{c}\text { TYPE } \\
\text { A }\end{array}$ & 1219.7 & 4.15 & 218 & -3 & 294 & 388.7 & 32 \\
\hline S-SC (control) & $\begin{array}{c}\text { TYPE } \\
\text { A }\end{array}$ & 870.7 & 3.84 & & & 227 & 402.7 & 46 \\
\hline S-SC-10 & $\begin{array}{c}\text { TYPE } \\
\text { A }\end{array}$ & 1398.1 & 5.57 & 61 & 45 & 251 & 604.5 & 43 \\
\hline S-SC-15 & $\begin{array}{c}\text { TYPE } \\
\text { A }\end{array}$ & 1317.9 & 5.05 & 51 & 32 & 261 & 626.9 & 48 \\
\hline S-SC-20 & $\begin{array}{c}\text { TYPE } \\
\text { A }\end{array}$ & 1424.3 & 5.08 & 64 & 32 & 280 & 1150.1 & 81 \\
\hline
\end{tabular}

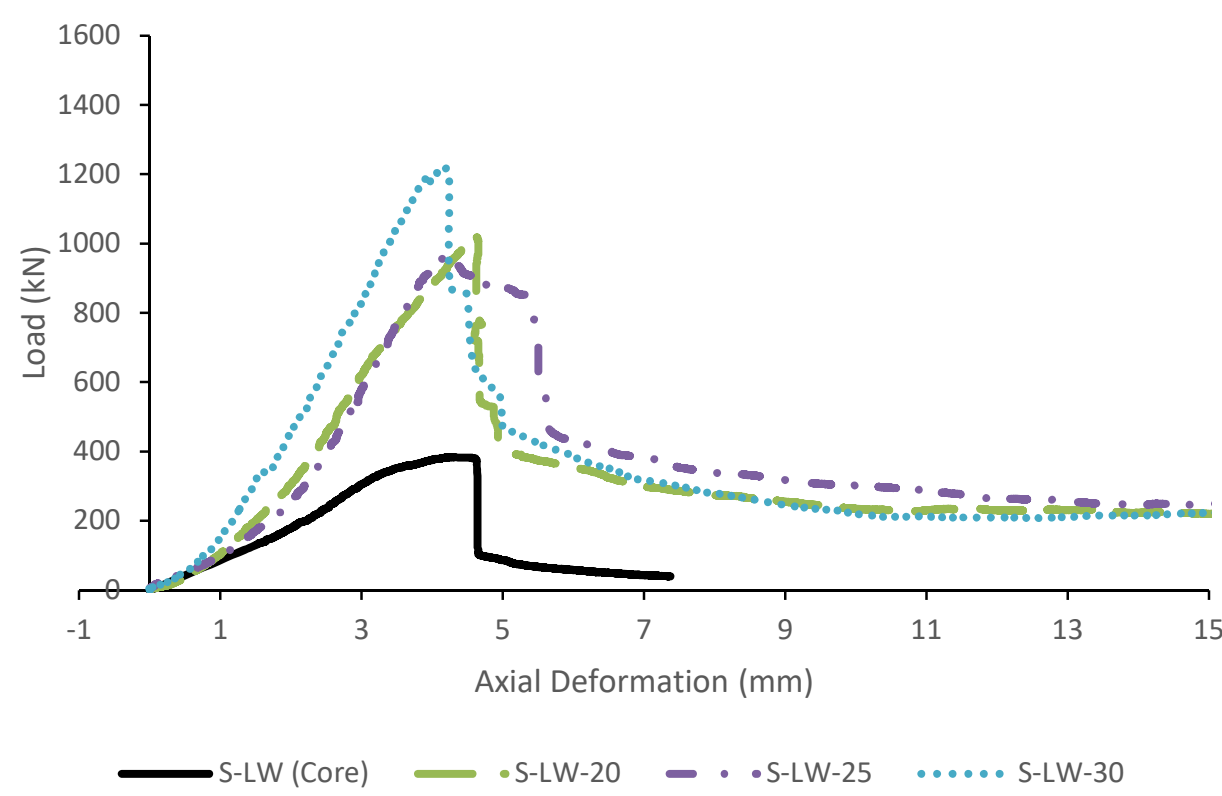

Fig. 4.8a: Load-deformation responses of reinforced untied LWSCC square columns under Type A loading 


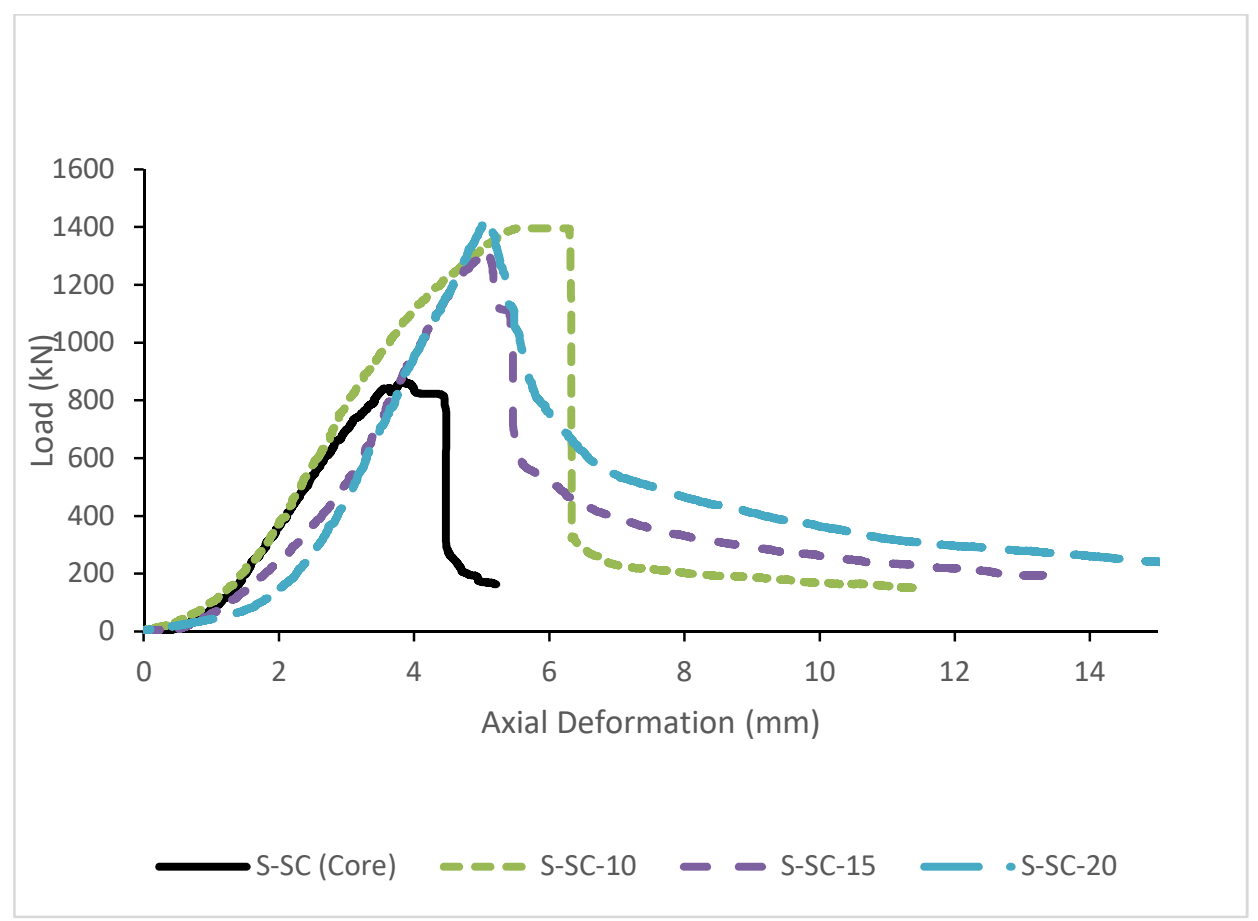

Fig. 4.8 b: Load-deformation responses of reinforced untied SCC square columns under Type A loading.

\subsubsection{Failure mode and cracking behavior}

Increase in compression load caused initial cracking accompanied by popping sound. As the compression load increased, crushing of concrete at the loading zone was observed. The crack generally propagated vertically downward from loading zone (Fig. 4.9). The crack initiated at lower load level in LWSCC columns compared to SCC columns as shown in Table 4.4. Two different types of failure mode were identified under axial compression loading. One of the failure was indicated by vertical cracks on the surface of wrap and another type of failure was indicated by combination of vertical and inclined cracks due to shear resulting from bond stress between ECC wrap and confined concrete (Fig. 4.9). 

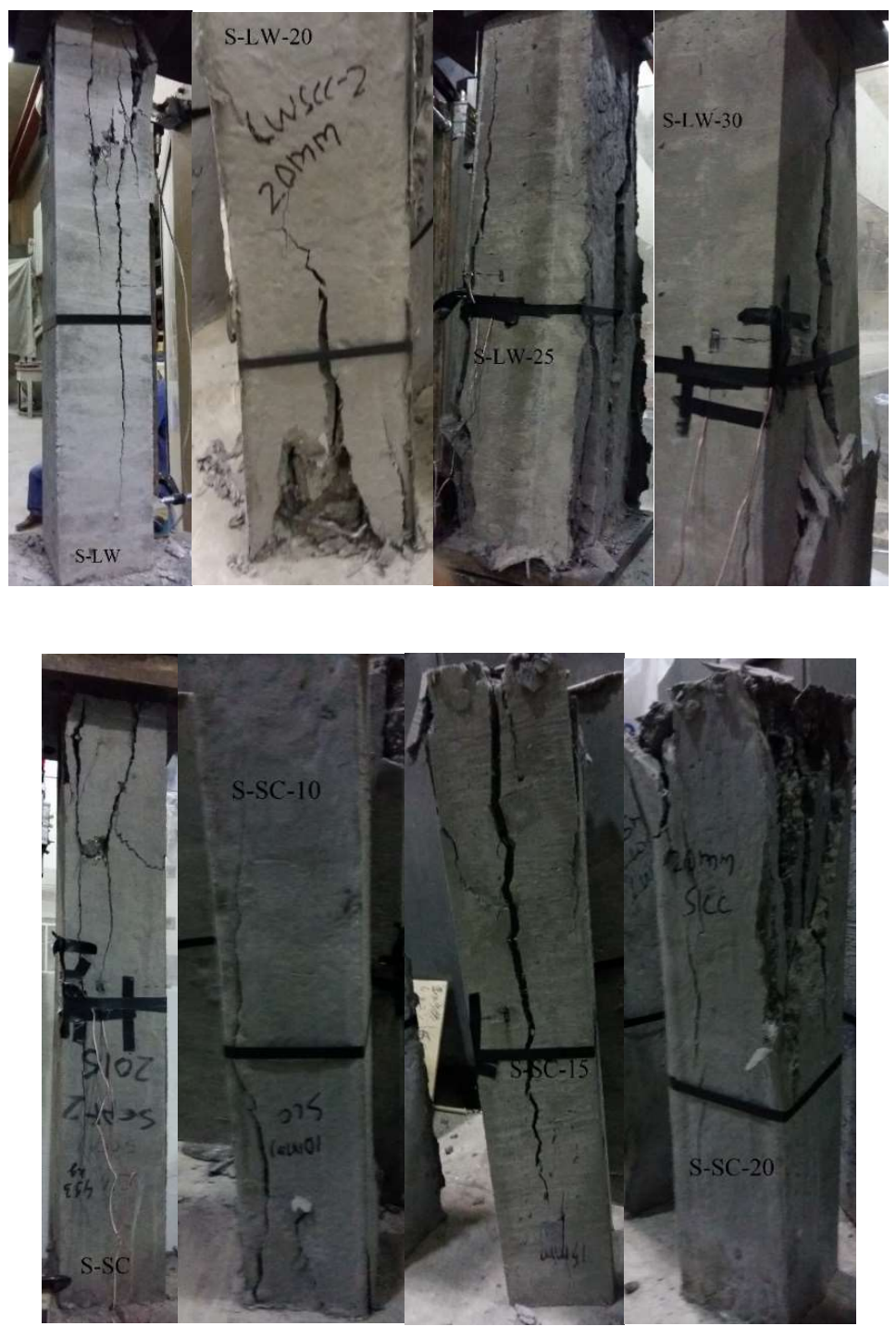

Fig. 4.9: Cracking patterns of reinforced untied columns

\subsubsection{Load-strain behavior}

Fig. 4.10a shows hoop strain development in reinforced untied LWSCC columns at the interface of core column and outer surface of the ECC wrap. The hoop strain of LWSCC control column SLW at failure load of $384 \mathrm{kN}$ reached 0.000213 . Column S-LW-20 at failure load of $1020.3 \mathrm{kN}$ reached interfacial hoop strain of 0.00045632 which is 2.1 times higher than control column hoop strain. Column S-LW-25 at failure load of $967.3 \mathrm{kN}$ reached interfacial hoop strain of 0.00009536, 0.44 times less than control column and the corresponding hoop strain was 0.000337 on the ECC wrap surface. Column S-LW-30 at failure load of $1219.7 \mathrm{kN}$ reached interfacial hoop strain 
0.00013472, 0.63 times less than the control. Readings from strain gauge attached to the surface of ECC wrap on S-LW-20 and S-LW-30 were affected by crack developed during loading the column.

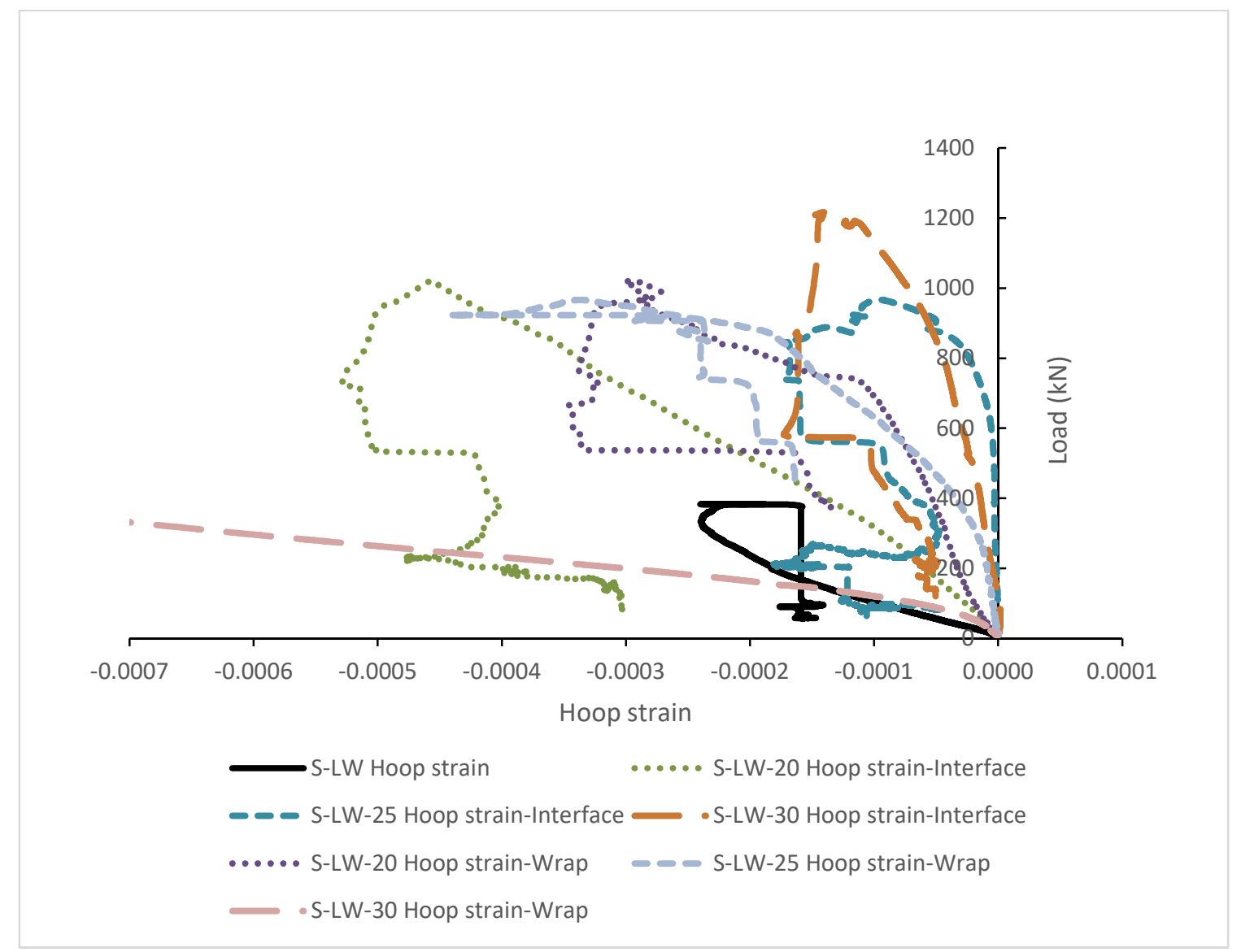

Fig. 4.10a: Hoop strain development in reinforced untied column between the interface (LWSCC/ECC) and outer wrap (ECC) surface

Fig. 4.10b shows hoop strain development in reinforced untied SCC columns at the interface of core column and outer surface of the ECC wrap. The hoop strain of SCC control column S-SC at failure load of $870.7 \mathrm{kN}$ reached 0.00055 . Column S-SC-10 at failure load of $1398 \mathrm{kN}$ reached interfacial hoop strain of 0.000458 showing 0.83 times decrease in hoop strain capacity. Column S-SC-15 at failure load of $1317.9 \mathrm{kN}$ reached interfacial hoop strain of 0.000170 showing 0.3 times decrease in hoop strain at the interface and the hoop strain on the ECC wrap surface was 0.000166. Column S-SC-20 at failure load of $1424.3 \mathrm{kN}$ reached interfacial hoop strain of $0.000146,0.26$ times lower than control column and hoop strain on the ECC wrap surface was 0.000320 . 


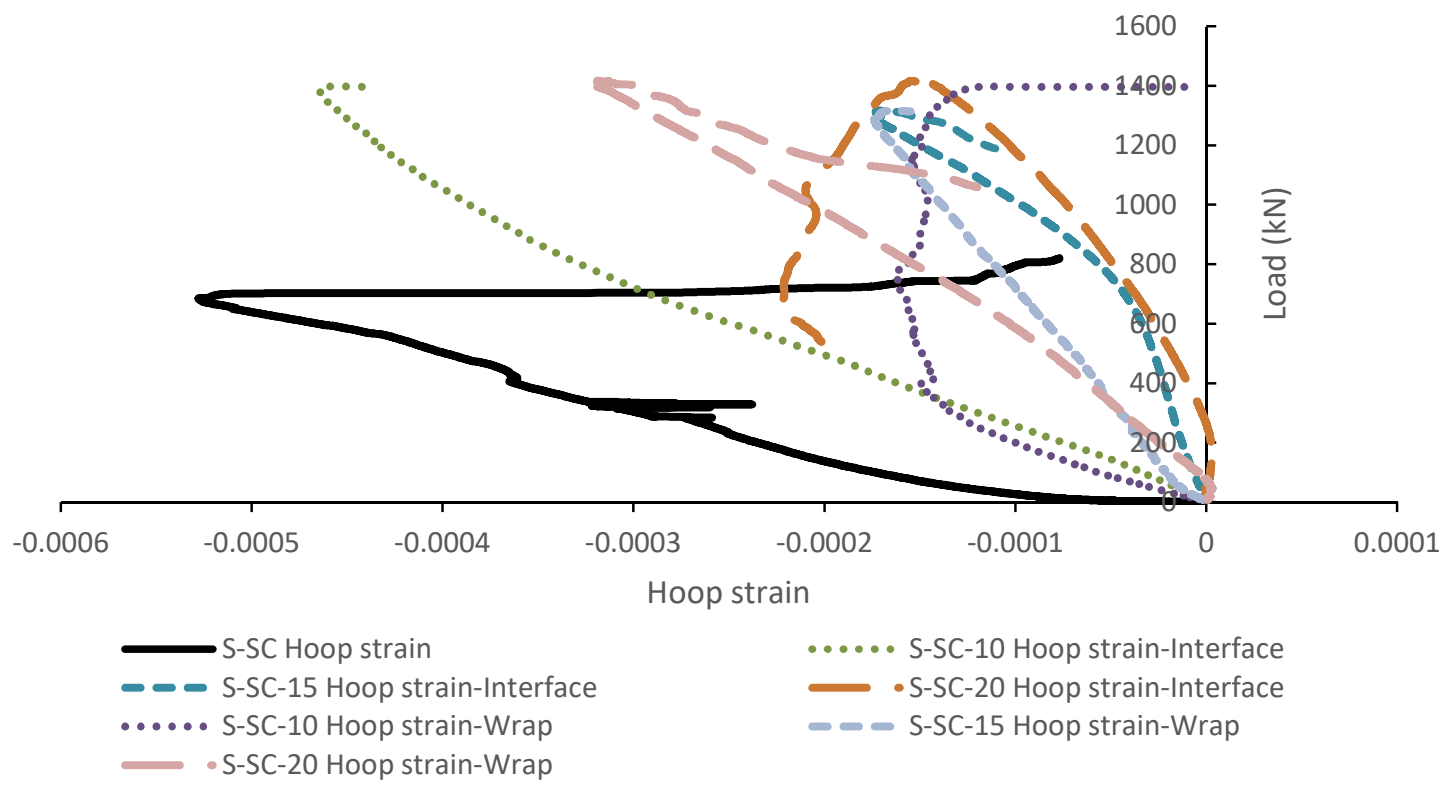

Fig. 4.10b: Hoop strain development in reinforced untied column between the interface (SCC/ECC) and outer wrap (ECC) surface

\subsubsection{Ductility and energy absorbing capacity}

Ductility is defined based on ductility indexes (DI) calculated based on load-strain and loaddeformation responses shown in Fig. 4.8 and Fig. 4.11, respectively (presented in Table 4.5).

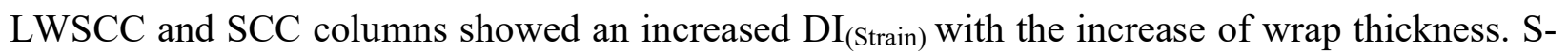
LW-25 showed significant increase in strain-based ductility than other columns but with lower peak load. For columns S-LW, S-SC, S-SC-10 and S-SC-15, strain-based ductility could not be computed due to strain gauge failure (Table 4.5). Ductility based on deformation (DI (Deformation) calculated with load-deformation curve showed little improvement in ductility. 


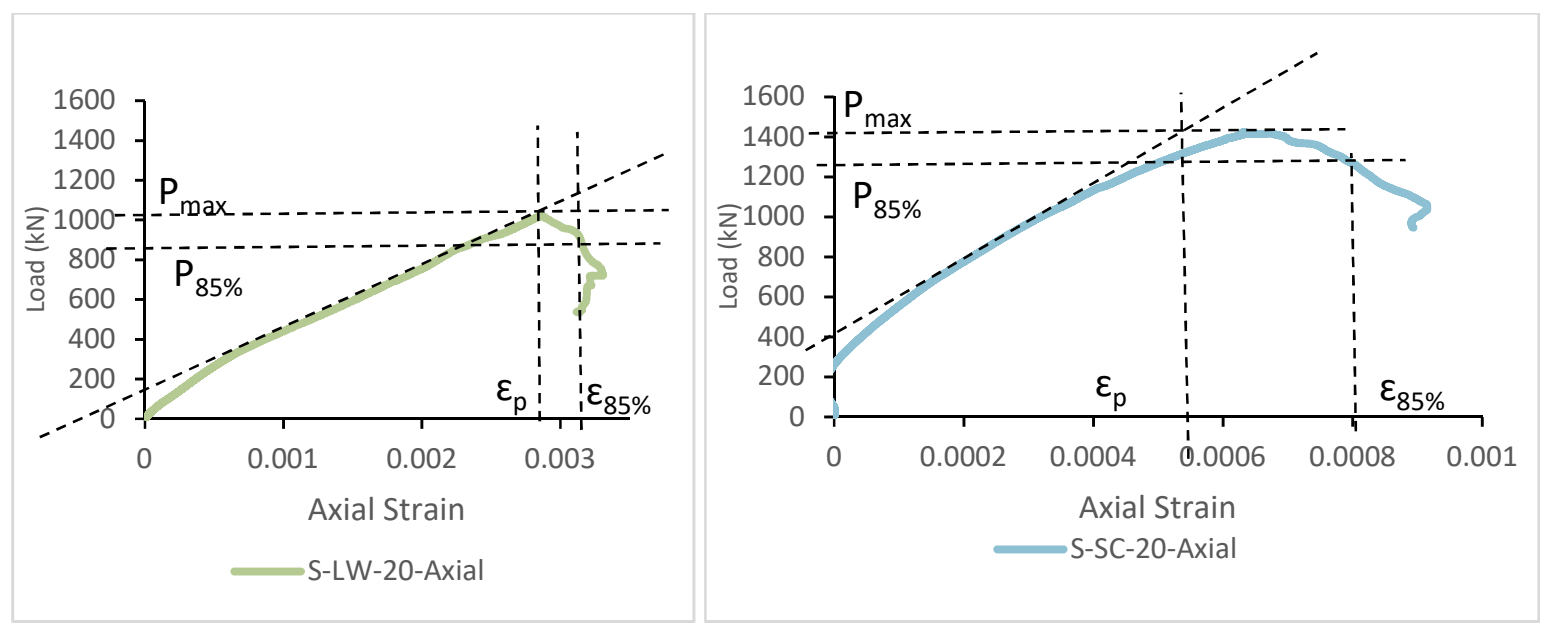

Fig. 4.11: Ductility Index (strain based) for reinforced untied square columns

Energy absorbing capacities of reinforced untied LWSCC and SCC columns presented in Table 4.5 are calculated based on the area covered by load-deformation curve up to the peak load of each column. Energy absorbing capacity increased with the increase of ECC wrap thickness for both reinforced untied square columns. The energy absorbed by LWSCC columns S-LW-20 was 2.32, S-LW-25 was 1.86 and S-LW-30 was 2.53 times more than that of LWSCC control column. The energy absorbed by SCC columns S-SC-10 was 2.64, S-SC-15 was 1.72 and S-SC-20 was 1.65 times higher than that of SCC control column. LWSCC column S-LW-20 showed higher energy ratio to its SCC counterparts compared with same thickness of the ECC wrap.

Table 4.5: Energy absorption capacities of reinforced untied square columns

\begin{tabular}{|c|c|c|c|c|c|c|c|}
\hline \multirow[t]{2}{*}{$\begin{array}{c}\text { Column } \\
\text { Designation }\end{array}$} & \multirow[t]{2}{*}{$\begin{array}{c}\text { ECC Wrap } \\
\text { thickness(mm) }\end{array}$} & \multirow[t]{2}{*}{$\begin{array}{l}\text { Type of } \\
\text { Loading }\end{array}$} & \multirow{2}{*}{$\begin{array}{c}\text { Strain } \\
\text { based } \\
\text { Ductility } \\
\text { Index } \\
\text { (DI) }\end{array}$} & \multicolumn{2}{|c|}{$\begin{array}{c}\text { Deformation } \\
\text { based } \\
\text { Ductility } \\
\text { Index (DI) }\end{array}$} & \multirow[t]{2}{*}{$\begin{array}{l}\text { Energy } \\
\text { (Joule) }\end{array}$} & \multirow[t]{2}{*}{$\begin{array}{c}\text { Energy } \\
\text { Ratio }\end{array}$} \\
\hline & & & & $\begin{array}{l}\text { Pre- } \\
\text { peak }\end{array}$ & $\begin{array}{l}\text { Post- } \\
\text { peak }\end{array}$ & & \\
\hline S-LW & 0 & & GF & 1.26 & 1.07 & 876.0 & 1.00 \\
\hline S-LW-20 & 20 & Type A & 1.11 & 1.17 & 1.00 & 2028.5 & 2.32 \\
\hline S-LW-25 & 25 & Type A & 14.13 & 1.16 & 1.28 & 1625.6 & 1.86 \\
\hline S-LW-30 & 30 & Type A & 2.03 & 1.2 & 1.02 & 2218.2 & 2.53 \\
\hline S-SC & 0 & & GF & 1.22 & 1.16 & 1439.9 & 1.00 \\
\hline S-SC-10 & 10 & Type A & GF & 1.3 & 1.13 & 3794.9 & 2.64 \\
\hline S-SC-15 & 15 & Type A & GF & 1.16 & 1.04 & 2479.7 & 1.72 \\
\hline $\mathrm{S}-\mathrm{SC}-20$ & 20 & Type A & 1.65 & 1.11 & 1.05 & 2368.8 & 1.65 \\
\hline
\end{tabular}

*GF-gauge failure; Type A loading: Load applied through both core and wrap; Energy ratio: Ratio of energy absorbed by wrapped column to control column 


\subsection{Reinforced tied square columns with varying thickness of ECC wrap -Type B loading}

Square LWSCC columns with varying ECC wrap thickness of $20 \mathrm{~mm}, 30 \mathrm{~mm}$ and $50 \mathrm{~mm}$ in addition to tied SCC column with ECC wrap thickness of $50 \mathrm{~mm}$ having same longitudinal and tie reinforcement were tested by applying axial load through the LWSCC/SCC core until failure.

\subsubsection{Axial Load vs deformation behavior}

Load-deformation responses for LWSCC/SCC columns are shown in Fig. 4.12 and the results are summarized in Table 4.6. Crack development was indicated by the formation of kinks. The LWSCC control column (S-LW-T) without any wrap had a peak load of approximately $566 \mathrm{kN}$ with axial displacement of $3.92 \mathrm{~mm}$. The peak stiffness of column S-LW-T was $144 \mathrm{kN} / \mathrm{mm}$. Column S-LW-20T (with $20 \mathrm{~mm}$ ECC wrap) sustained a peak load of $804 \mathrm{kN}$ with axial deformation of $3.12 \mathrm{~mm}$. It showed $42 \%$ increase in peak load carrying capacity with $20 \%$ decrease in peak deformation compared to the control column with increased stiffness of $79 \%$ than control column. Column S-LW-30T (with $30 \mathrm{~mm}$ ECC wrap) sustained a peak load of $881 \mathrm{kN}$ and 1.53 $\mathrm{mm}$ peak deformation with $56 \%$ higher load and $61 \%$ decrease in deformation compared to control column with increased stiffness of 300\%. Column S-LW-50T (with $50 \mathrm{~mm}$ ECC wrap) had peak load carrying capacity of $986 \mathrm{kN}$ with $74 \%$ increase and $2.89 \mathrm{~mm}$ peak deformation with $26 \%$ decrease compared to control columns. The increase in peak stiffness for the column S-LW-50T was $137 \%$. Overall, peak load/strength of the columns increased with the increase of ECC wrap thickness while causing increase in stiffness.

The SCC core column (S-SC-T) without any ECC wrap (control) had a peak load of about $709 \mathrm{kN}$ with axial displacement of $3.88 \mathrm{~mm}$ (Fig. 4.12 and Table 4.6) resulting peak stiffness of 183 $\mathrm{kN} / \mathrm{mm}$. Column S-SC-50T (with $50 \mathrm{~mm}$ ECC wrap) with peak load capacity of $1293 \mathrm{kN}$ with $2.56 \mathrm{~mm}$ deformation showing about $82 \%$ increase in load carrying capacity and $34 \%$ lower deformation than control column (Table 4.6) and the stiffness increased by 176\%. Overall, use of tie reinforcement increased the load carrying capacity of columns with or without ECC wrap with decrease in deformation. SCC tied column with ECC warp showed higher strength and lower deformation compared to its LWSCC counterpart. 
Table 4.6: Summary of test results based on load-deformation response of tied square columns

\begin{tabular}{|c|c|c|c|c|c|c|c|c|}
\hline $\begin{array}{c}\text { Reinforced } \\
\text { tied square } \\
\text { column }\end{array}$ & $\begin{array}{c}\text { Type of } \\
\text { Loading }\end{array}$ & $\begin{array}{c}\text { Peak Load } \\
(\mathrm{kN})\end{array}$ & $\begin{array}{c}\text { Peak } \\
\text { Deformation } \\
(\mathrm{mm})\end{array}$ & $\begin{array}{c}\% \\
\text { increase } \\
\text { in peak } \\
\text { load }\end{array}$ & $\begin{array}{c}\text { \% increase } \\
\text { in peak } \\
\text { deformation }\end{array}$ & $\begin{array}{c}\text { Peak } \\
\text { stiffness } \\
(\mathrm{kN} / \mathrm{mm})\end{array}$ & $\begin{array}{c}\text { Initial } \\
\text { Cracking } \\
\text { Load } \\
(\mathrm{kN})\end{array}$ & $\begin{array}{c}1^{\text {stack }} \\
\text { load } \\
\text { as } \% \\
\text { of } \\
\text { peak } \\
\text { load }\end{array}$ \\
\hline S-LW-T & TYPE B & 565.6 & 3.92 & - & - & 144 & 124.6 & 22 \\
\hline S-LW-20T & TYPE B & 804.7 & 3.12 & 42 & -20 & 258 & 269.9 & 34 \\
\hline S-LW-30T & TYPE B & 881.2 & 1.53 & 56 & -61 & 576 & 351.8 & 40 \\
\hline S-LW-50T & TYPE B & 986.9 & 2.89 & 74 & -26 & 341 & 155.8 & 16 \\
\hline S-SC-T & TYPE B & 709 & 3.88 & & & 183 & 408.2 & 58 \\
\hline S-SC-50T & TYPE B & 1293.8 & 2.56 & 82 & -34 & 505 & 840.8 & 65 \\
\hline
\end{tabular}

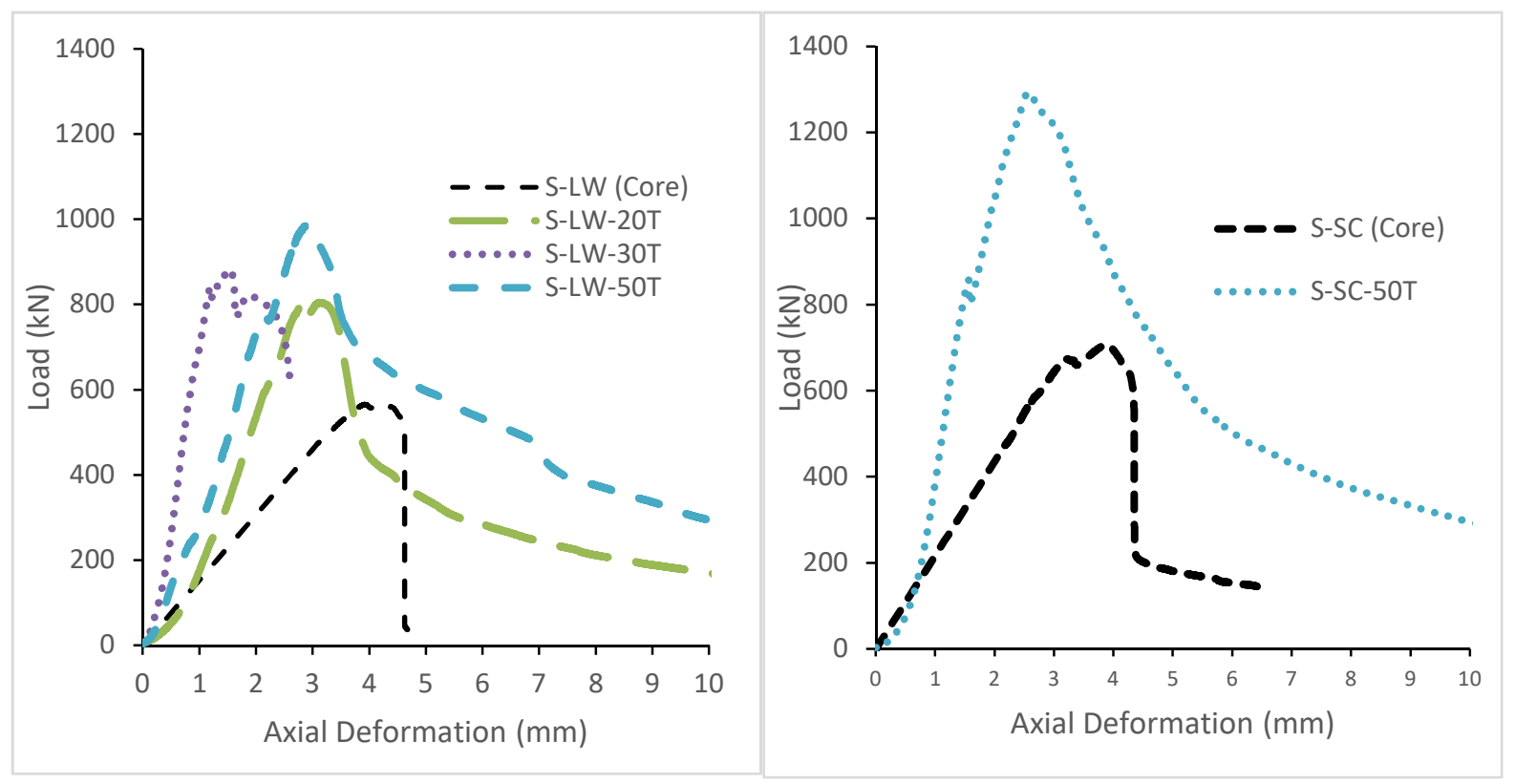

Fig. 4.12: Load-deformation responses of reinforced tied columns under Type B loading

\subsubsection{Failure mode and cracking behavior}

The first cracking loads for the tied columns are shown in Table 4.6. Tied square LWSCC columns showed that the crack initiated relatively at lower load with a "pop" sound before reaching the peak load. For tied SCC column the cracking load approached near to the peak load. Generally, most of the cracks started at the corners of the column (with narrower crack in the mid crosssection) travelling vertically up to middle third height of the column (Fig. 4.10). 


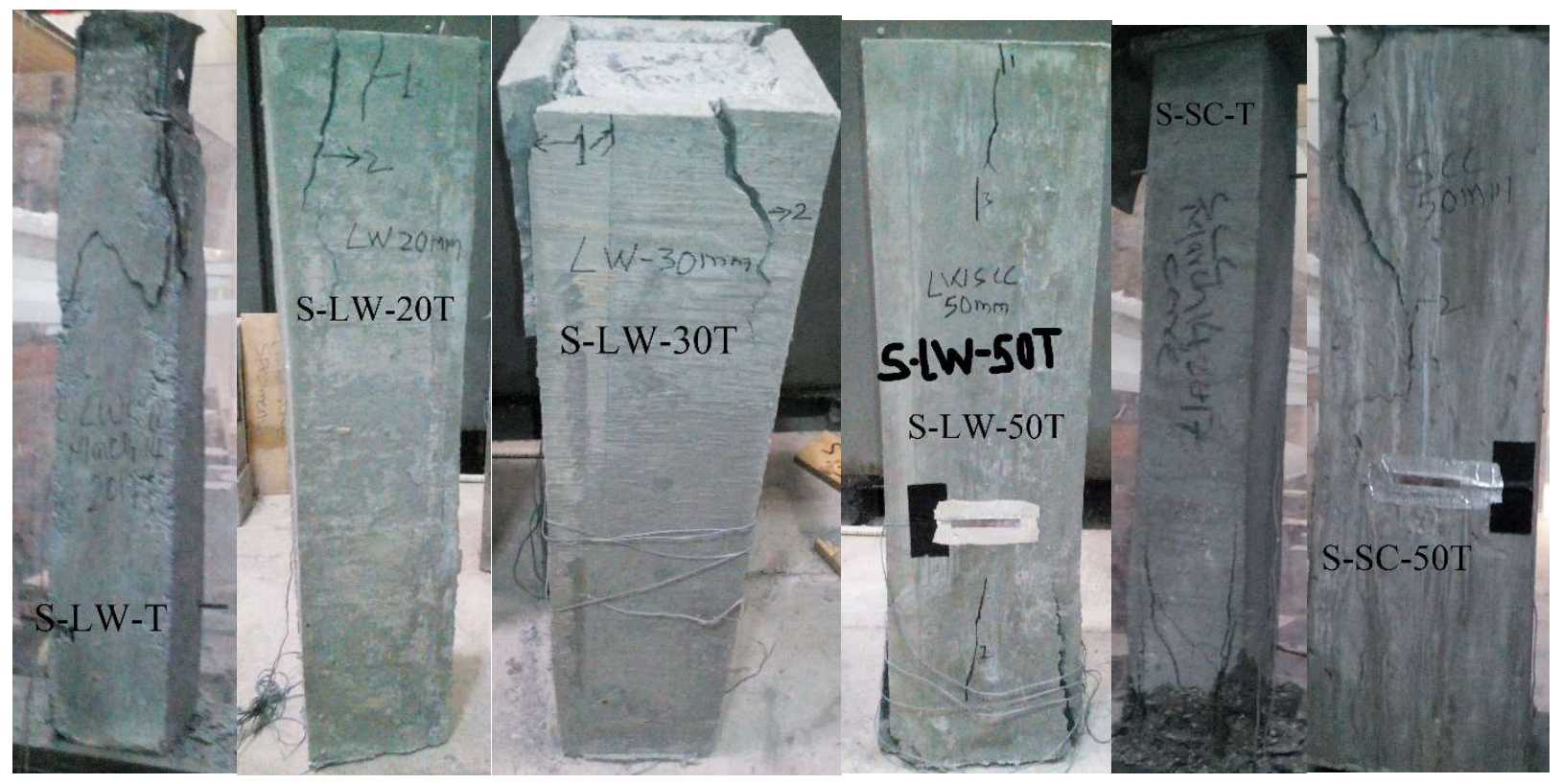

Fig. 4.13: Cracking pattern of reinforced tied columns

\subsubsection{Load-strain behavior}

Fig. 4.14a shows hoop strain development in reinforced tied LWSCC columns at the interface of core column and outer surface of the ECC wrap. The hoop strain of LWSCC control column SLW-T at failure load of $565.6 \mathrm{kN}$ reached 0.000159. Column S-LW-20T at failure load of 804.7 $\mathrm{kN}$ had 3.3 times increased interfacial hoop strain of 0.000536 and hoop strain on ECC wrap was 0.000214. Column S-LW-30T at failure load of $881.2 \mathrm{kN}$ reached interfacial hoop strain of 0.000156 similar to control column and on the ECC wrap surface the hoop strain was 0.000266 . The curve reversed after failure load which can be attributed to gauge failure. Column S-LW-50T at failure load of $986.9 \mathrm{kN}$ had hoop strain capacity of 0.000440, 2.7 times higher than control column and the hoop strain was 0.002449 on the ECC wrap surface. 


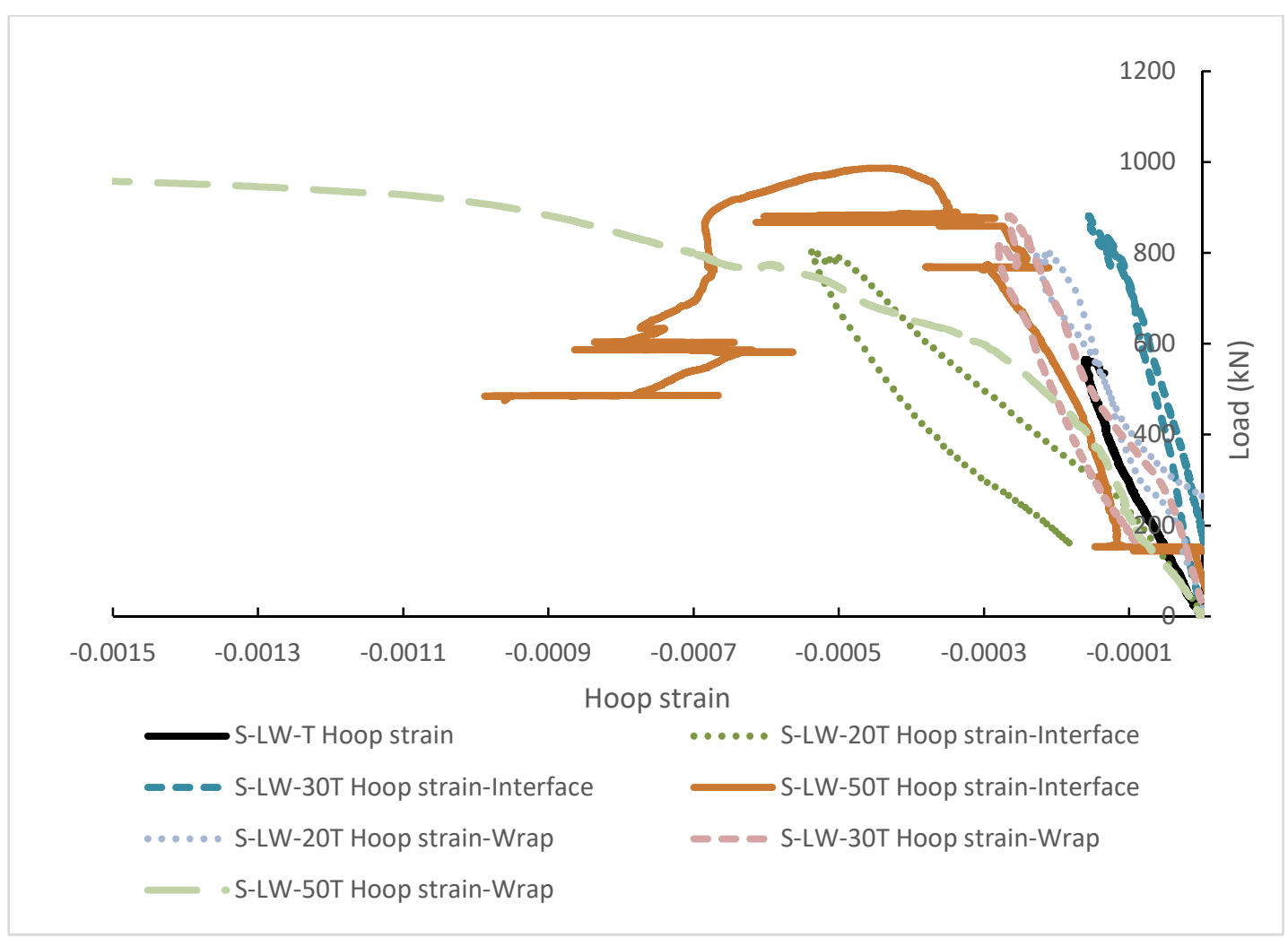

Fig. 4.14a: Hoop strain development in reinforced tied column between the interface (LWSCC/ECC) and outer wrap (ECC) surface

Fig. 4.14b shows hoop strain development in reinforced tied SCC columns at the interface of core column and outer surface of the ECC wrap. The hoop strain of SCC control column S-SC-T at failure load of $709 \mathrm{kN}$ was 0.000242 . Column S-SC-50T at failure load of $1293.8 \mathrm{kN}$ reached interfacial hoop strain of 0.000209 and increased for same load showing plasticization and the hoop strain was 0.000180 on the ECC wrap. 


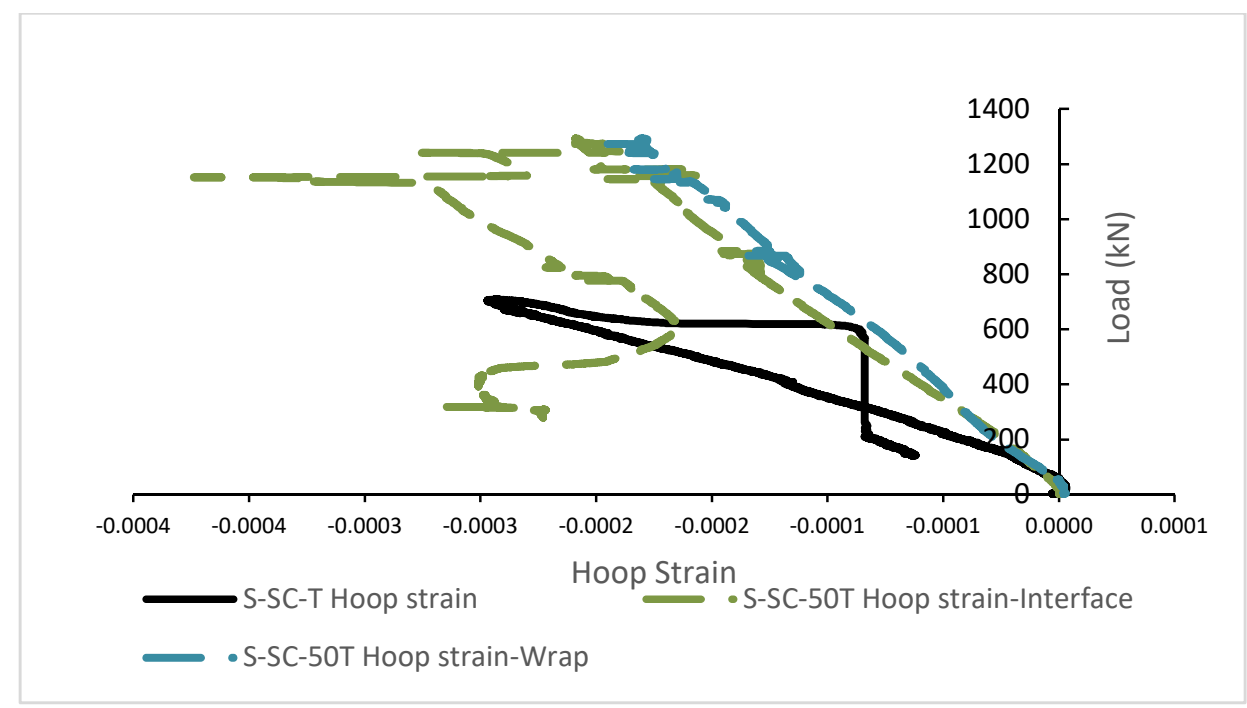

Fig. 4.14b: Hoop strain development in reinforced tied column between the interface (SCC/ECC) and outer wrap (ECC) surface

\subsubsection{Ductility and energy absorbing capacity of tied reinforced columns}

Ductility Index (DI) based on load-strain (Fig. 4.15) and load-deformation (Fig. 4.12) responses along with energy absorbing capacity based on load-deformation responses are presented in Table 4.7. The area covered by load-deformation response curve up to the peak load of each sample was used to calculate the amount of energy absorbed (Fig. 4.12). The strain-based ductility indexes was 1.85 while 1.78 for S-SC-50T. Deformation based ductility based on ascending loaddeformation curve small improvement in ductility for all the columns (Table 4.7).

Table 4.7: Ductility and energy absorbing capacity of reinforced tied columns

\begin{tabular}{|c|c|c|c|c|c|c|c|}
\hline \multirow[t]{2}{*}{$\begin{array}{c}\text { Column } \\
\text { Designation }\end{array}$} & \multirow[t]{2}{*}{$\begin{array}{c}\text { ECC Wrap } \\
\text { thickness(mm) }\end{array}$} & \multirow[t]{2}{*}{$\begin{array}{l}\text { Type of } \\
\text { Loading }\end{array}$} & \multirow{2}{*}{$\begin{array}{c}\text { Strain } \\
\text { based } \\
\text { Ductility } \\
\text { Index } \\
\text { (DI) }\end{array}$} & \multicolumn{2}{|c|}{$\begin{array}{c}\text { Deformation } \\
\text { based } \\
\text { Ductility } \\
\text { Index (DI) } \\
\end{array}$} & \multirow[t]{2}{*}{$\begin{array}{l}\text { Energy } \\
\text { (Joule) }\end{array}$} & \multirow[t]{2}{*}{$\begin{array}{l}\text { Energy } \\
\text { Ratio }\end{array}$} \\
\hline & & & & $\begin{array}{l}\text { Pre- } \\
\text { peak }\end{array}$ & $\begin{array}{l}\text { Post- } \\
\text { peak }\end{array}$ & & \\
\hline S-LW-T & 0 & & GF & 1.25 & 1.17 & 1167.6 & 1.00 \\
\hline S-LW-20T & 20 & Type B & GF & 1.28 & 1.13 & 1201.9 & 1.03 \\
\hline S-LW-30T & 30 & Type B & GF & 1.44 & 1.58 & 995.9 & 0.85 \\
\hline S-LW-50T & 50 & Type B & 1.85 & 1.19 & 1.18 & 1389.8 & 1.19 \\
\hline S-SC-T & 0 & & GF & 1.39 & 1.11 & 1123.0 & 1.00 \\
\hline S-SC-50T & 50 & Type B & 1.78 & 1.22 & 1.29 & 1540.5 & 1.37 \\
\hline
\end{tabular}

*GF-gauge failure; Type B loading: Load applied through concrete core; Energy ratio: Ratio of wrapped column to control column 


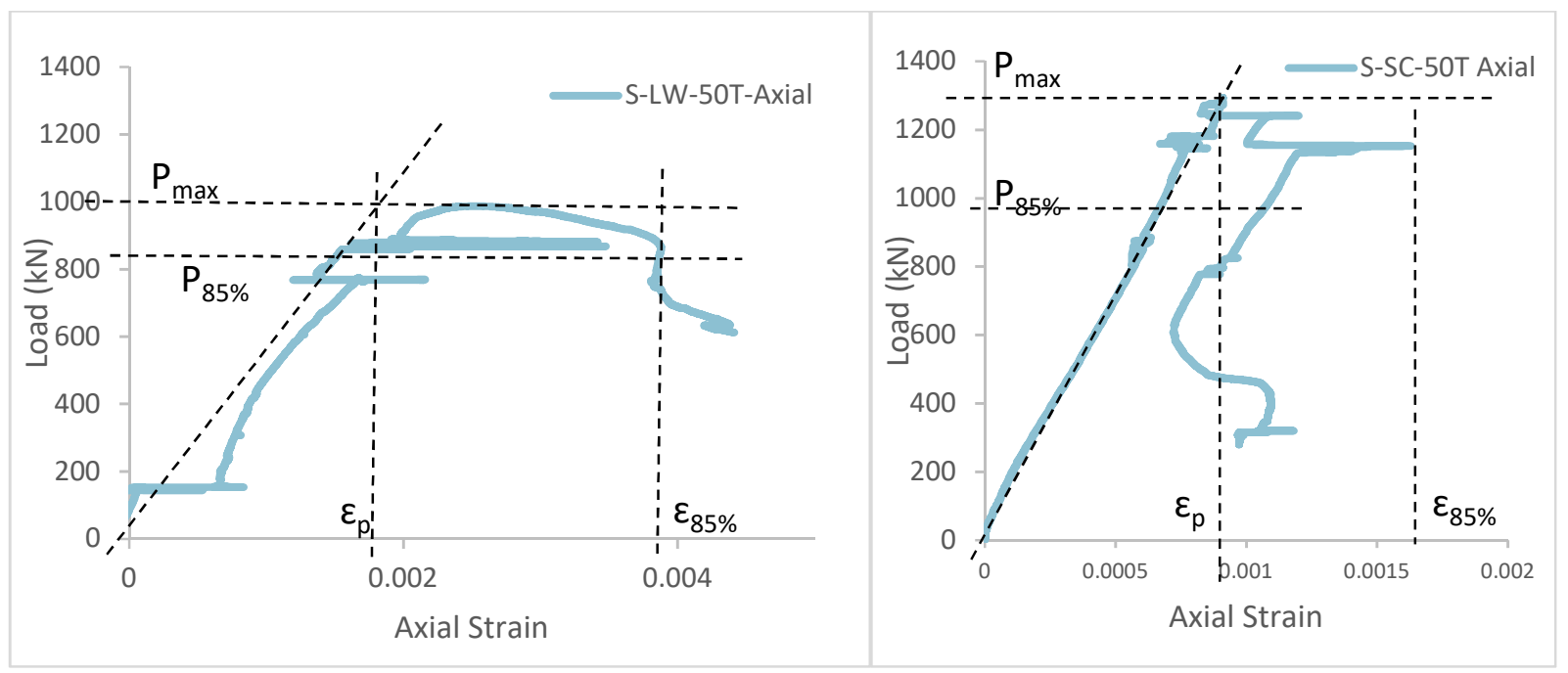

Fig. 4.15: Ductility Index from load-strain curve for tied square columns

The energy ratio of reinforced tied LWSCC columns S-LW-20T was 1.03, S-LW-30T was 0.85 and S-LW-50T was 1.19. The energy ratio of SCC columns, S-SC-50T, with $50 \mathrm{~mm}$ thick ECC wrap was 1.37. SCC column showed higher energy ratio to its LWSCC counterparts compared with same thickness of the ECC wrap.
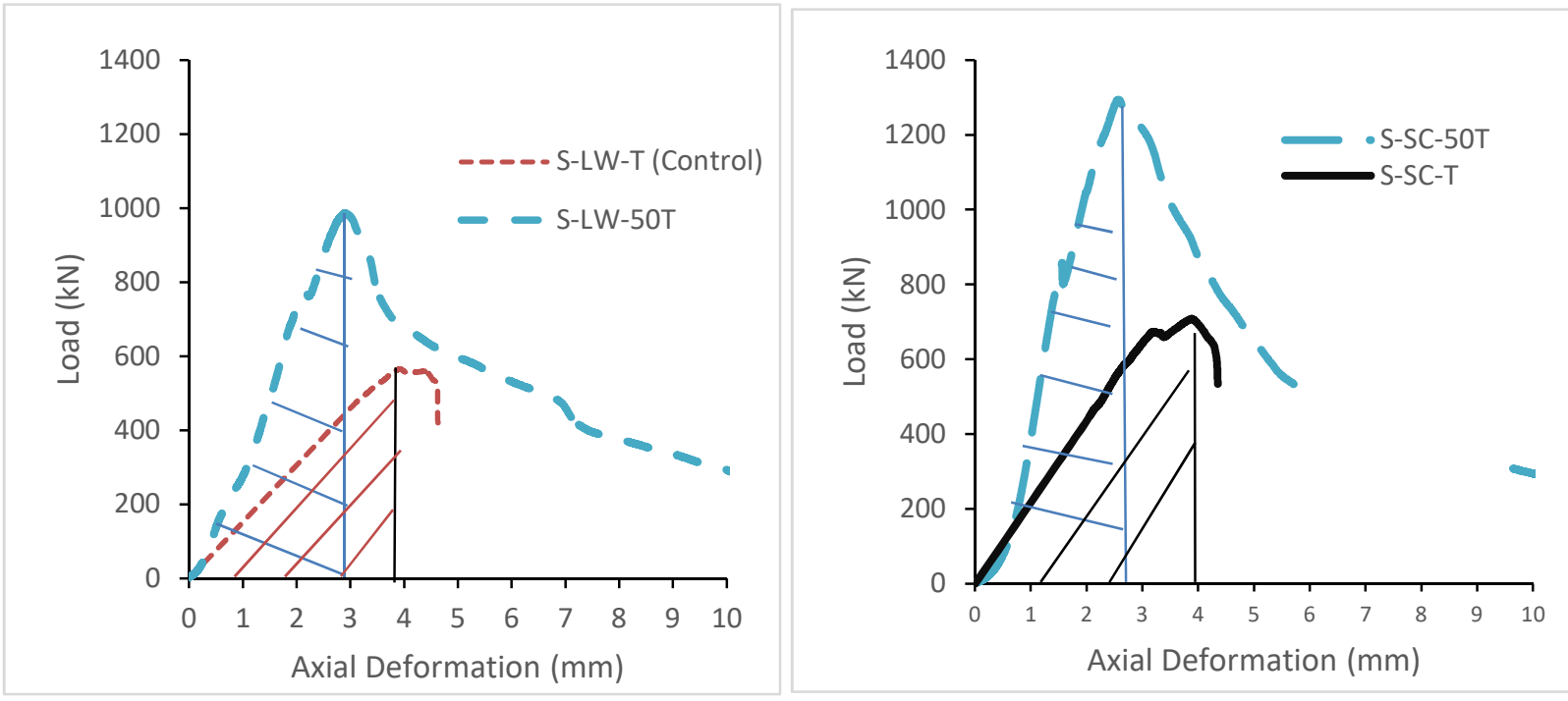

Fig. 4.16: Energy Absorption capacity from load-deformation responses 


\subsection{Discussion of results}

\subsubsection{Influence of ECC wrap thickness on peak load and stiffness}

LWSCC and SCC cylindrical/square columns showed increased load capacity with increasing thickness of ECC wrap (Fig. 4.17). Peak stiffness decreased for unreinforced cylindrical columns while it increased for reinforced square columns. LWSCC and SCC unreinforced cylindrical columns (C-LW-50 and C-SC-50) with 50 mm wrap under Type B loading showed 29\% and 12\% increase in load carrying capacity with $16 \%$ and $14 \%$ decrease in peak stiffness, respectively compared to control columns. Untied reinforced LWSCC and SCC square columns (S-LW-20 and S-SC-20) with $20 \mathrm{~mm}$ wrap under Type A loading showed 166\% and 64\% increase in load carrying capacity with peak increase of peak stiffness of $148 \%$ and $24 \%$, respectively. Tied reinforced LWSCC and SCC columns (S-LW-50T and S-SC-50T) with $50 \mathrm{~mm}$ wrap under Type B loading showed $74 \%$ and $82 \%$ increase in peak load with increase of peak stiffness of $137 \%$ and $177 \%$, respectively (Tables 4.2, 4.4 and 4.7 ) with respect to their unwrapped control columns.
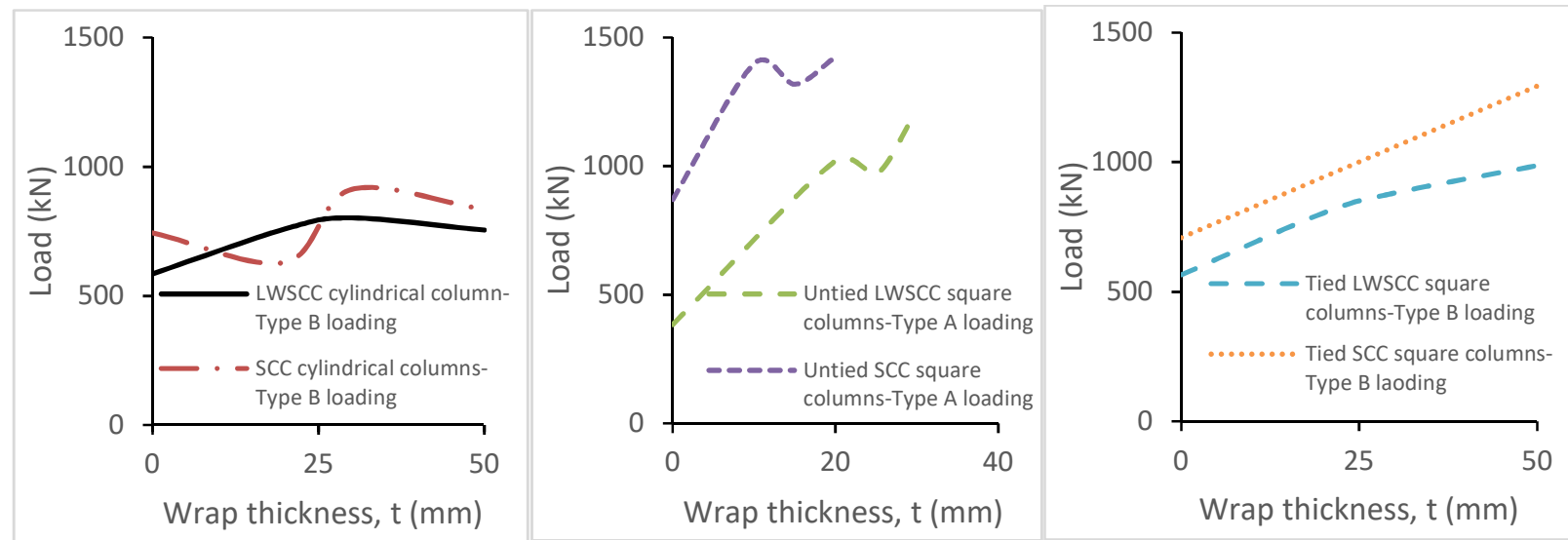

Fig. 4.17: Influence of wrap thickness on load carrying capacity of columns

Fig. 4.18 shows the effect of thickness (t) of ECC wrap to the diameter (D) of core column ratio $(t / D)$ for cylindrical columns and thickness of wrap to width of core ratio $(t / b)$ for square column on peak load. Load carrying capacity increased with increasing $t / D$ and $t / b$ ratios for cylindrical and square columns. Cylindrical SCC column (S-SC-20) showed decreased strength which might be due to deficiency in casting and curing process. SCC columns showed higher peak load capacity than LWSCC columns due to the higher compressive strength of $42 \mathrm{MPa}$ compared to LWSCC compressive strength of $33 \mathrm{MPa}$. 

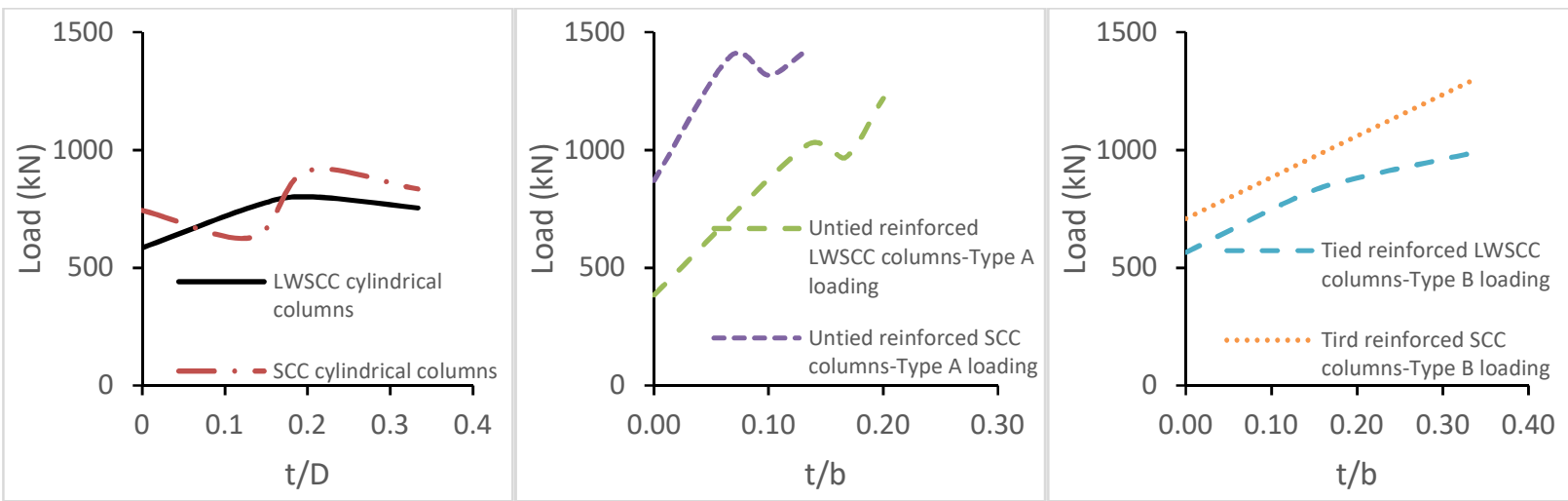

* $D$ is the core diameter of cylindrical column; $b$ is the core width of square column

Fig. 4.18: Influence of wrap thickness to diameter (width) ratio on columns load carrying capacity

\subsubsection{Influence of Type A and Type B loading on peak load}

Based on the observation of reinforced square LWSCC and SCC columns (Fig. 4.19), the load carrying capacity for Type A loading was higher than Type B loading with increasing thickness of ECC wrap. LWSCC column having 30mm thick wrap with Type A loading experienced 38\% more load than the LWSCC column with Type B loading. Untied reinforced SCC column (S-SC-20) with $20 \mathrm{~mm}$ thick ECC wrap sustained $131 \mathrm{kN}$ more load than tied reinforced SCC square column (S-SC-50T) with $50 \mathrm{~mm}$ thick ECC wrap.
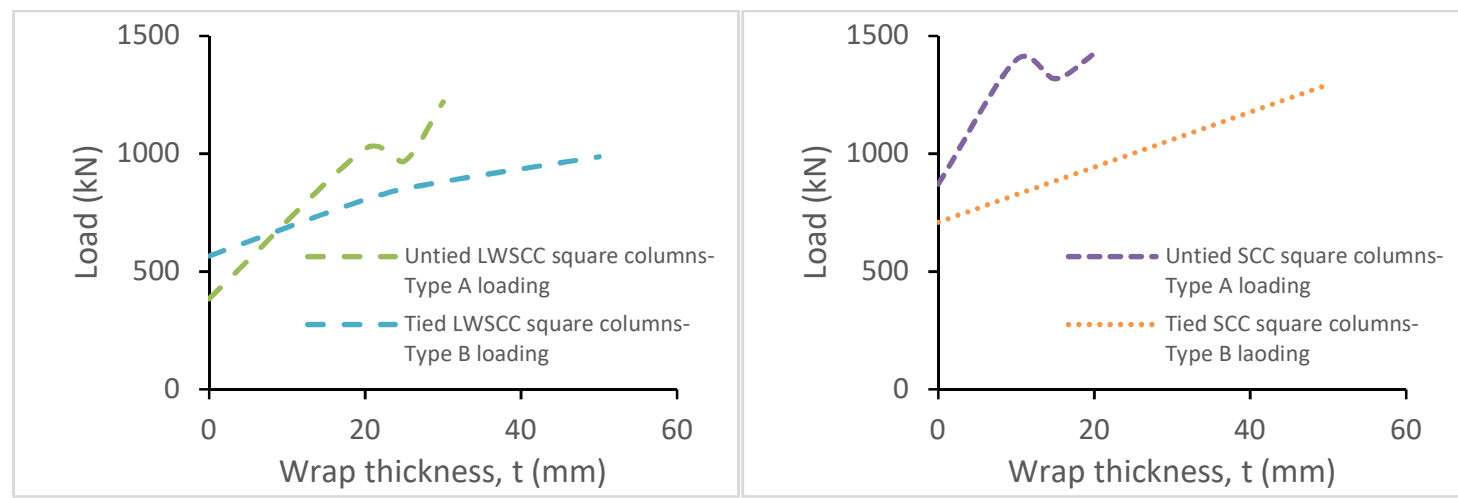

Fig. 4.19: Influence of Type A and Type B loading on peak load

Fig. 4.20 shows the effect of thickness of wrap to the diameter of core column ratio $(t / D)$ for cylindrical columns and thickness of wrap to width of core ratio $(t / b)$ for square column on peak load under Type A and Type B loading. Column under Type A loading sustained more load than column under Type B loading with increasing $t / b$ ratio. 

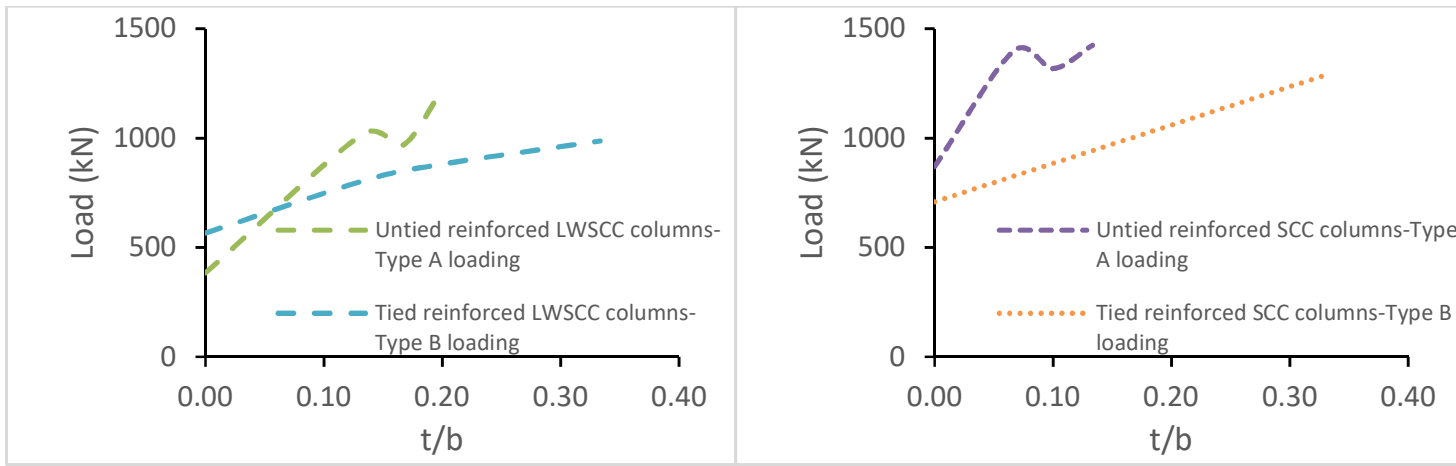

* $b$ is the core width of square column

Fig. 4.20: Influence of Type A and Type B loading on columns peak load

\subsubsection{Influence of LWSCC and SCC on energy absorption capacity}

The peak load of SCC was higher than LWSCC due to its higher compressive strength, so the energy absorbed by SCC columns were higher than LWSCC columns.
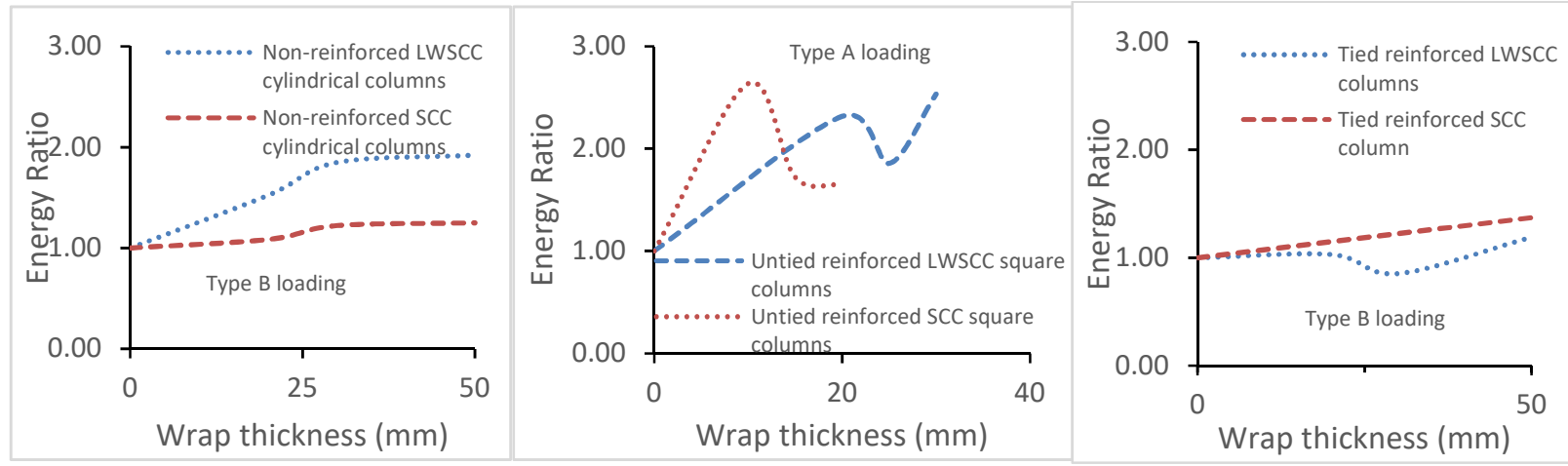

Fig. 4.21: Influence of Type A and Type B loading on peak load

Fig. 4.21 shows the influence of wrap on energy absorption in terms of energy ratio defined as the ratio of energy absorbed by wrapped column to the energy absorbed by unwrapped control column. Tables 4.3, 4.5 and 4.7 show energy ratio for cylindrical and square columns. There was an increase of 53\% energy ratio in LWSCC non-reinforced cylindrical column compared to its SCC counterpart with $50 \mathrm{~mm}$ thick ECC wrap. Untied reinforced LWSCC square column showed 41\% increase in energy ratio than its SCC counterpart with $20 \mathrm{~mm}$ thick ECC wrap. However, for tied reinforced square columns, the energy ratio for SCC column was $13 \%$ more than that of its LWSCC counterpart with $50 \mathrm{~mm}$ thick ECC wrap. Based on these observation, untied LWSCC column benefitted more from ECC wrap than tied columns. 


\subsubsection{Influence of ECC wrap thickness on ductility index based on load-deformation curve}

Fig. 4.22 shows the influence of $t / D$ and $t / b$ on ductility index (DI) based on peak deformation for cylindrical and square column, respectively under Type A and Type B loading. Tables 4.3, 4.5 and 4.7 shows ductility index (DI) for cylindrical and square columns. There is no significant ductility enhancement based on ascending branch of load-deformation curve. However, for most of the cases, pre-peak ductility seemed to be increased with the increase of $t / D$ or $t / b$ ratio.
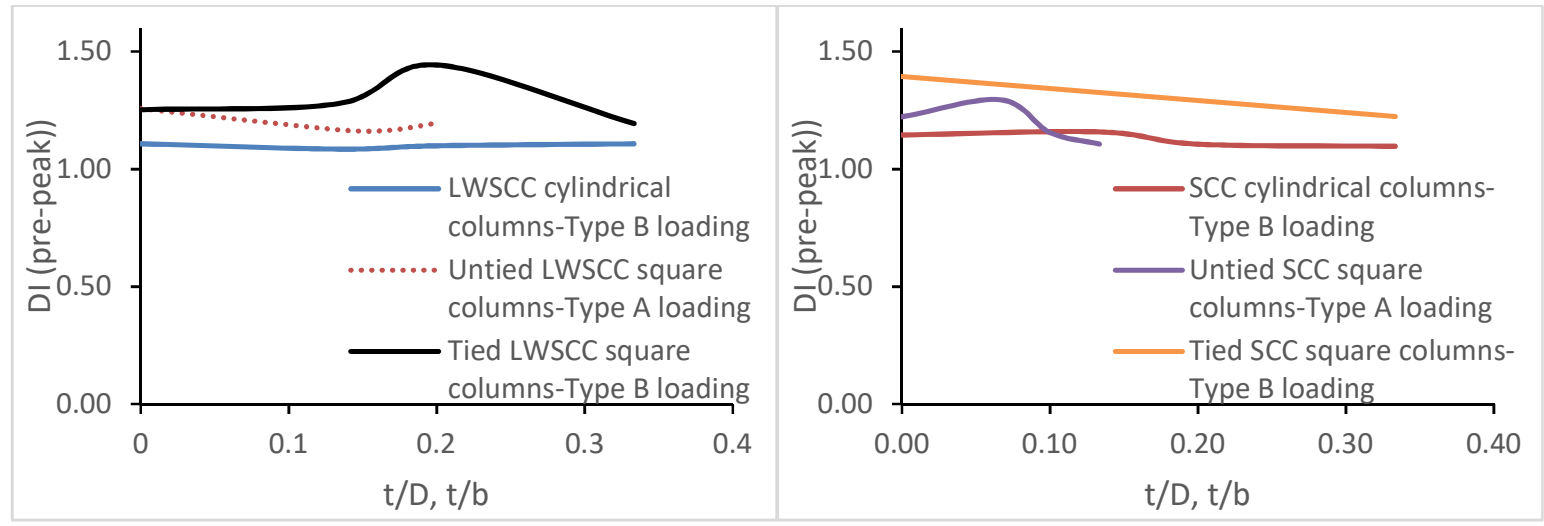

Fig. 4.22: Influence of $t / D(t / b)$ ratio loading on ductility index (DI)

\subsubsection{Influence of LWSCC and SCC on strain developments}

Fig. 4.23 shows the hoop strain of different columns at peak load. Interfacial hoop strain capacity of SCC columns up-to the wrap thickness of $30 \mathrm{~mm}$ is more than LWSCC counterpart. For $50 \mathrm{~mm}$ thick wrap, the strain capacities of cylindrical and square LWSCC column are more than their SCC counterpart, indicating LWSCC columns with $50 \mathrm{~mm}$ ECC wrap are benefitted more than SCC counterparts. 


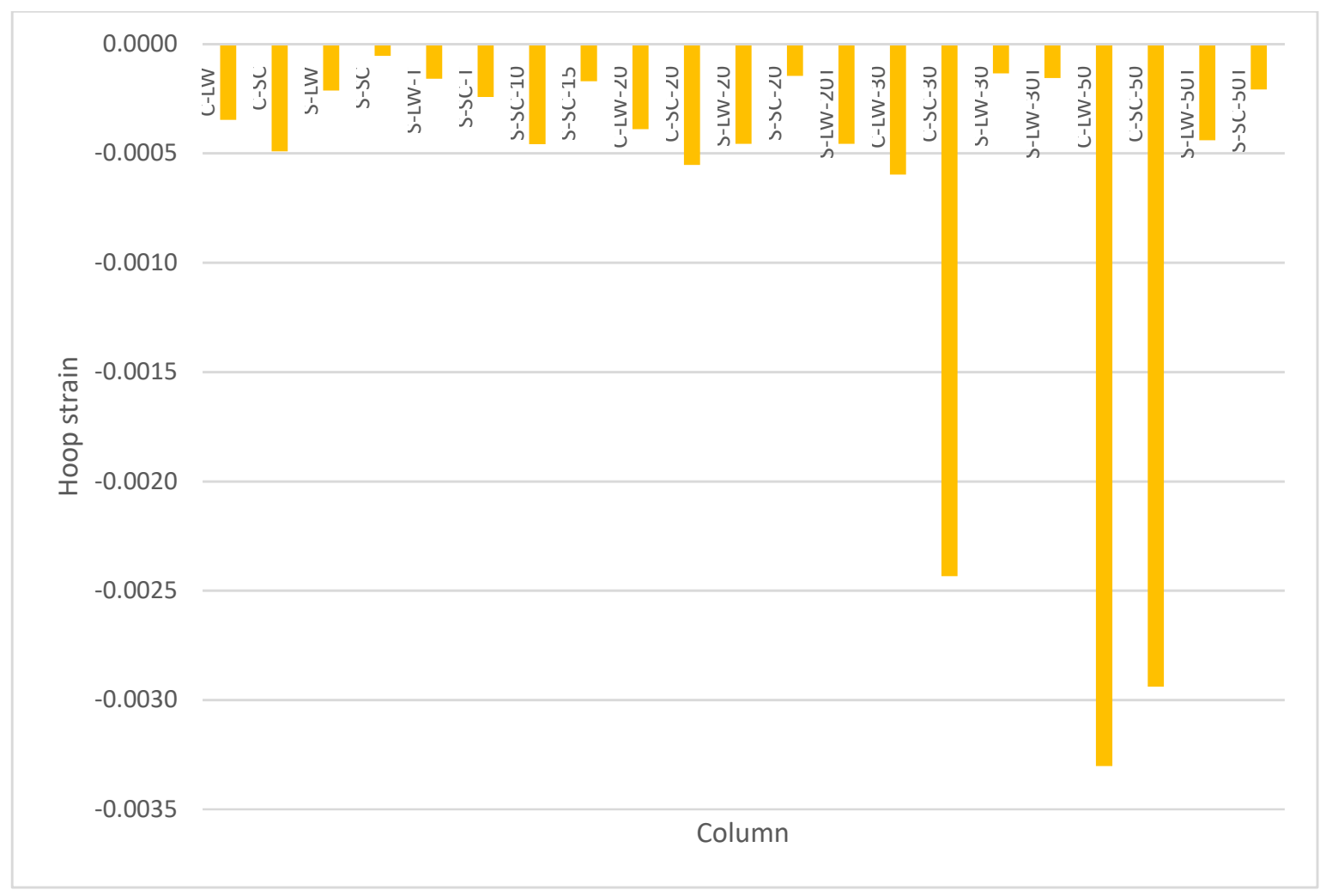

Fig. 4.23: Interfacial hoop strain at peak load for various columns

\subsection{Summary}

In this chapter, load-deflection responses of columns, crack formation and propagation, ductility, energy absorption capacity, ultimate load, failure modes, ECC wrapping characterstics, material/geometric properties and stress-strain developments of LWSCC/SCC columns were described based on the experimental results. LWSCC/SCC columns showed increased load carrying capacity with increasing ECC thickness and increased energy absorption capacity. Almost all the cracks developed spread vertically generating from loading zone. The ductility did not increase significantly for all wrapping thickness expect 50mm thick ECC wrap. Columns under Type A loading showed more load carrying capacity than columns under Type B loading. Wrapping of columns increased the stiffness of columns instead of ductility for thinner section of the wrap, however for thick ECC wrap, the ductility increased. 


\section{CHAPTER FIVE}

\section{ANALYTICAL AND NUMERICAL ANALYSES OF COLUMNS WITH ECC CONFINEMENT}

\subsection{Introduction}

This Chapter describes analytical and numerical analyses in conjunction with experimental results of lightweight self-consolidating concrete (LWSCC) and self-consolidating concrete (SCC) unreinforced cylindrical and longitudinally reinforced (with and without ties) square columns with engineered cementitious composite (ECC) wrapping or confinement.

\subsection{Quantification for effective confinement and compressive strength models for confined concrete}

The model developed by Mander et al. (1988) can be used to calculate the confined compressive strength of concrete $\left(f^{\prime} c c\right)$ :

$\frac{f^{\prime}{ }_{c c}}{f^{\prime}{ }_{c}}=-1.254+2.254 \sqrt{1+\frac{7.94 f^{\prime} l}{f^{\prime}{ }_{c}}}-2 \frac{{f^{\prime}}{ }^{\prime}}{f^{\prime}{ }_{c}}$

The Richart et al. (1929) model can also be used to calculate the confined compressive strength of concrete $\left(f^{\prime} c c\right)$ :

$$
\frac{f^{\prime}{ }_{c c}}{f^{\prime}{ }_{c}}=1+4.1 \frac{f^{\prime}{ }_{l}}{f^{\prime}{ }_{c}}
$$

where $f_{l}^{\prime}$ is the effective passive confining stress and $f_{c}^{\prime}$ is the unconfined compressive strength of concrete. Once $f_{l}^{\prime}$ is calculated, the confined compressive strength of concrete can be calculated. $f_{l}^{\prime}$ can be due to: (a) tie reinforcements in reinforced concrete column, (b) wrapping in column and (c) combined tie reinforcement and wrapping in column.

As per Mander et al. (1988), the effective confinement stress, $\left(f_{l}\right)$ for square column (in x and y directions) with wrapping of thickness (t) as shown in Fig. 5.1 and circular column with ties (Fig. 5.2), is dependent on the geometry which is defined as:

For square column:

$\left(f^{\prime}{ }^{\prime}\right)=f_{l x}{ }^{\prime}=f_{l y}{ }^{\prime}=k_{e} \rho_{h} f_{y}$

where $k_{e}$ is the shape factor for the column, $\rho_{h}\left(=\frac{A_{s}}{s b}\right)$ is the reinforcement ratio for ties, $\rho_{h}\left(=2 \frac{t}{b}\right)$ for confining wrap with " $t$ " thickness, $f_{y}$ is the tensile strength of confining material. 
For square and rectangular columns with zero corner rounding:

$k_{e}=1-\left[\frac{\left(b^{2}+h^{2}\right)}{6\left(1-\rho_{s c}\right) b h}\right]$

and for ties:

$k_{e}=1-\left[\frac{\left(b_{t}^{2}+d_{t}^{2}\right)}{6\left(1-\rho_{s c}\right) b_{t} d_{t}}\right]$

where $b$ and $h$ are sectional dimensions of column and $\rho_{s c}$ is the cross-sectional area ratio of the longitudinal steel reinforcement. $b_{t}$ and $d_{t}$ are side lengths of a tie (Fig. 5.1).
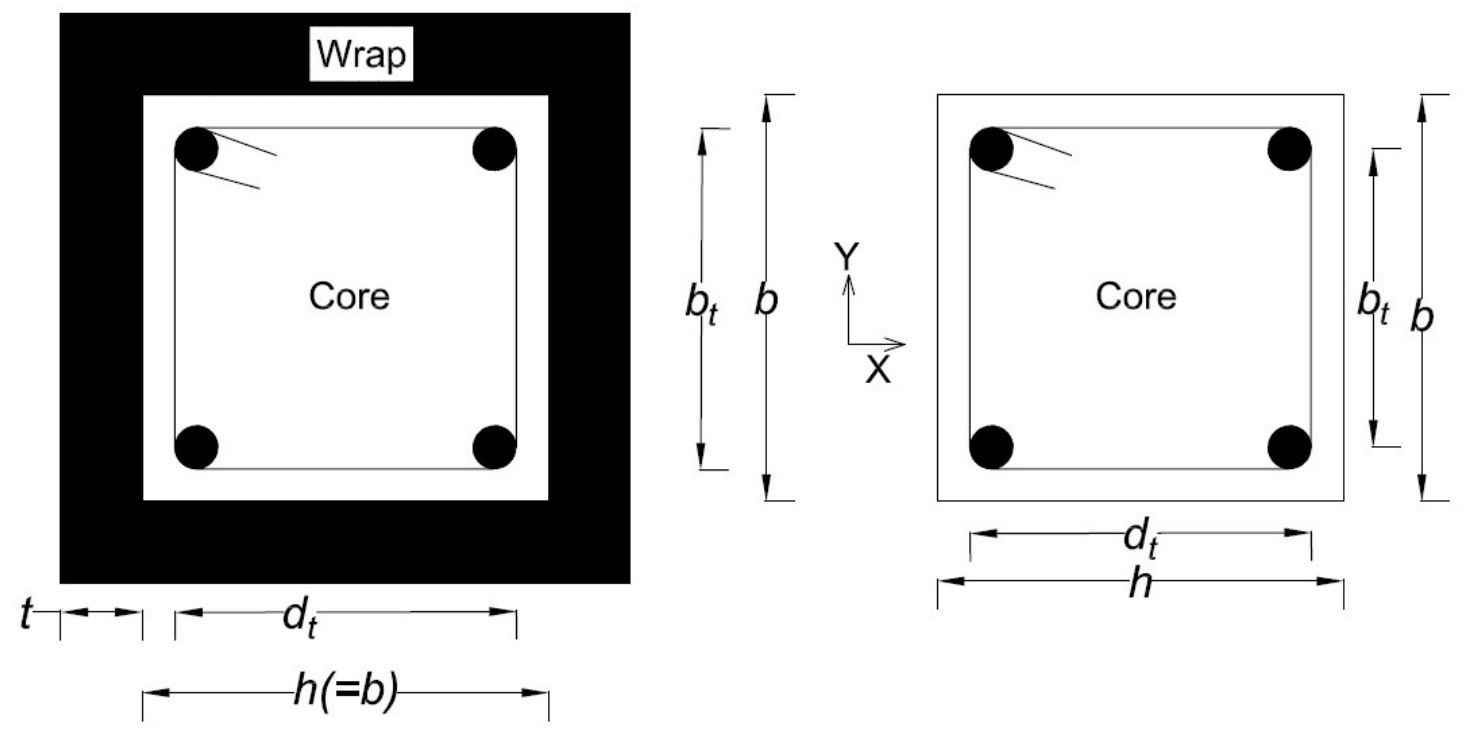

Fig. 5.1: Dimensions of square reinforced tied column with wraping

For circular column, confinement due to ties is (Fig. 5.2):

$f^{\prime}{ }_{l}=\frac{k_{e} \rho_{h} f_{y h}}{2}$

The shape factor for circular ties with clear spacing " $s$ " and diameter " $d$ " is given by:

$k_{e}=\frac{\left(1-\frac{s}{2 d}\right)^{2}}{1-\rho_{s c}}$

where $\rho_{h}\left(=\frac{A_{s}}{s b}\right)$ is the reinforcement ratio for ties 
For circular column with full concrete ECC wrap of " $t$ " thickness and tensile strength $f_{y}$, the shape factor equals $1,\left(k_{e}=1\right)$, so the confinement is the same as given by Richart et al. (1929) shown in Eq. 5.10.

Richart et al. (1929) derived lateral stress $\left(f^{\prime} l\right)$ in the confined concrete of axially loaded reinforced circular columns with evenly spaced lateral ties (tie spacing of $s$ ) shown in Fig. 5.2. Let $A_{c}$ be the sectional area of the concrete between the ties, $d$ is the diameter of the concrete, $f_{y}$ is the yield strength of the tie and $A_{s}$ is the sectional area of the tie.

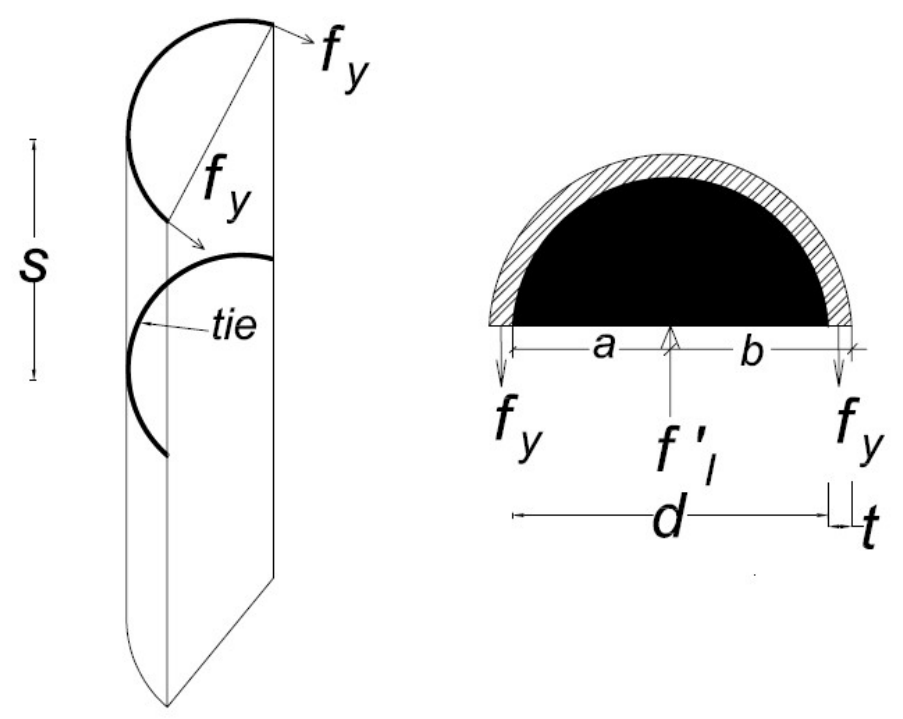

Fig. 5.2: Quantification of confining force in circular columns

Using force equilibrium (Fig. 5.2):

$2 A_{s} f_{y}=f^{\prime}{ }_{l} d s ; \quad \frac{4 A_{s}}{d . s} f_{y}=2 f^{\prime}{ }_{l}$

Ratio of volume of ties to the volume of confined section $\left(\rho_{h}\right.$. can be defined as:

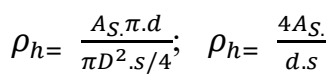

Substituting $\rho_{h}$ from Eq. 5.7 in Eq. 5.8:

$\rho_{h} f_{y}=2 f^{\prime}{ }_{l}$;

$f^{\prime}{ }_{l}=\rho_{h} \cdot f_{y} / 2$

Similarly, for axially loaded circular columns (Fig. 5.2) with ECC wrap (of thickness ' $t$ ') confinement, lateral stress $\left(f^{\prime}\right)$ in the confined concrete can be derived as:

$f^{\prime}{ }_{l}=2 f_{y} t / d$ 
where $b$ is the outer radius, $a$ is the inner radius $(a=d / 2)$ as per Fig. 5.2. Total confinement effect on concrete is the summation of confinements provided by the ties and the concrete wrap. Richart et al. (1929) model can be used to derive lateral stress $\left(f^{\prime} l\right)$ for quantification of confinement by transforming square column into equivalent circular column of diameter $\sqrt{h^{2}+b^{2}}$.

The confinement in terms of lateral stress $\left(f^{\prime} l\right)$ produced by different thickness of ECC wrap in tested non-reinforced cylindrical and reinforced (tied or non-tied) square columns using Mander (1988) and Richart (1929) models are given in Table 5.1. Detailed calculations are provided in the Appendix A.

Eqs. 5.3 and 5.10 show that the confining stress $\left(f^{\prime} l\right)$ is proportional to $t / D$ ratio for cylindrical column and $t / b$ ratio for square column. Higher confining stress imparts more confined strength to the core concrete which is also observed from experimental results shown in chapter four (Fig.

\subsection{8)}

Table 5.1: Confinement quantification in terms of lateral stress $\left(f^{\prime}{ }^{\prime}\right)$ for tested columns

\begin{tabular}{|c|c|c|c|c|c|c|}
\hline \multirow{4}{*}{$\begin{array}{c}\text { Thickness of } \\
\text { ECC wrap (mm) }\end{array}$} & \multirow{4}{*}{$\begin{array}{c}\text { Column } \\
\text { designation }\end{array}$} & \multicolumn{5}{|c|}{ Analytical confinement in terms of lateral stress $\left(f_{l}^{\prime}\right)(\mathrm{MPa})$} \\
\hline & & \multirow{3}{*}{$\begin{array}{c}\text { Non-reinforced } \\
\text { cylindrical } \\
\text { columns: } \\
\text { Richart/Mander } \\
\text { (without Ties) }\end{array}$} & \multicolumn{4}{|c|}{ Reinforced square columns } \\
\hline & & & \multicolumn{2}{|c|}{ Mander (1988) } & \multicolumn{2}{|c|}{ Richart (1929) } \\
\hline & & & $\begin{array}{l}\text { (without } \\
\text { ties) }\end{array}$ & (with ties) & (without ties) & (with ties) \\
\hline 10 & $\mathrm{~S}-\mathrm{SC}-10$ & & 0.41 & & 0.43 & \\
\hline 15 & S-SC-15 & & 0.61 & & 0.65 & \\
\hline 20 & $\begin{array}{l}\text { C-LW-20, } \\
\text { C-SC-20, } \\
\text { S-SC-20, } \\
\text { S-LW-20, } \\
\text { S-LW-20T }\end{array}$ & $\begin{array}{c}1.23 \\
(\mathrm{C}-\mathrm{LW}-20, \\
\text { C-SC-20) }\end{array}$ & $\begin{array}{c}0.81 \\
(\mathrm{~S}-\mathrm{SC}-20, \\
\text { S-LW-20) }\end{array}$ & $\begin{array}{c}1.32 \\
(\mathrm{~S}-\mathrm{LW}-20 \mathrm{~T})\end{array}$ & $\begin{array}{c}0.87 \\
(\mathrm{~S}-\mathrm{SC}-20, \\
\text { S-LW-20) }\end{array}$ & $\begin{array}{c}1.96 \\
(\mathrm{~S}-\mathrm{LW}-20 \mathrm{~T})\end{array}$ \\
\hline 25 & S-LW-25 & & 1.01 & & 1.08 & \\
\hline 30 & $\begin{array}{l}\text { C-LW-30, } \\
\text { C-SC-30, } \\
\text { S-LW-30, } \\
\text { S-LW-30T }\end{array}$ & $\begin{array}{c}1.84 \\
(\mathrm{C}-\mathrm{LW}-30, \\
\text { C-SC-30) }\end{array}$ & $\begin{array}{c}1.22 \\
(\mathrm{~S}-\mathrm{LW}-30)\end{array}$ & $\begin{array}{c}1.72 \\
(\mathrm{~S}-\mathrm{LW}-30 \mathrm{~T})\end{array}$ & $\begin{array}{c}1.30 \\
(\mathrm{~S}-\mathrm{LW}-30)\end{array}$ & $\begin{array}{c}2.39 \\
(\mathrm{~S}-\mathrm{LW}-30 \mathrm{~T})\end{array}$ \\
\hline 50 & $\begin{array}{c}\text { C-LW-50, } \\
\text { C-SC-50, S- } \\
\text { LW-50T, } \\
\text { S-SC-50T }\end{array}$ & $\begin{array}{c}3.07 \\
(\mathrm{C}-\mathrm{LW}-50, \\
\text { C-SC-50) }\end{array}$ & & $\begin{array}{c}2.53 \\
(\mathrm{~S}-\mathrm{LW}-50 \mathrm{~T}, \\
\text { S-SC-50T) }\end{array}$ & & $\begin{array}{c}3.26 \\
\text { (S-LW-50T, } \\
\text { S-SC-50T) }\end{array}$ \\
\hline
\end{tabular}


Sample calculations for C-LW-50 and S-LW-50T are shown below.

\section{C-LW-50 sample calculation of effective confinement}

This is non-reinforced circular column so Richart and Mander model gives same confinement stress.

Thickness of wrap $(t)=50 \mathrm{~mm}$; Tensile strength of ECC wrap $\left(f_{y}\right)=4.6 \mathrm{MPa}$

Diameter of concrete core column $(d)=150 \mathrm{~mm}$

Effective confinement is given by:

${f^{\prime}}_{l}=2 f_{y} t / d$

$=2 * 4.6 * 50 / 150=3.07 \mathrm{MPa}$

\section{$\underline{\text { S-LW-50T sample calculation of effective confinement }}$}

This is reinforced tied column, so confinement due to ties and wrap needs to be considered.

\section{Mander's model sample calculation}

\section{a. Confinement provided by ties:}

Yield strength of tie $=449 \mathrm{MPa}$

Cross-sectional area of longitudinal steel $=100 \mathrm{~mm}^{2}$

Length of tie $\left(b_{t}=d_{t}\right)=(150-20-20) \mathrm{mm}=110 \mathrm{~mm}$

Longitudinal reinforcement ratio $\left(\rho_{s c}\right)=\{$ Cross-sectional area of steel/area confined by tie $\}=\left(4^{*}\right.$ $100) /(110 * 110)=0.033$

Shape factor $k_{e}=1-\left[\frac{\left(b_{t}^{2}+d_{t}^{2}\right)}{6\left(1-\rho_{s c}\right) b_{t} d_{t}}\right]$

$$
\begin{aligned}
& =1-\left[\left(110^{2}+110^{2}\right) /(6 *(1-0.033) * 110 * 110)\right] \\
& =0.655
\end{aligned}
$$

Reinforcement ratio for ties $\left(\rho_{h}\right)=\frac{\text { Cross-sectional area of tie }}{s * b_{t}}=28.3 /(150 * 110)=0.00172$

Confinement due to ties $f_{l x}{ }^{\prime}=f_{l y}{ }^{\prime}=k_{e} \rho_{h} f_{y}$

$$
=0.655 * 0.00172 * 449 \mathrm{MPa}=\mathbf{0 . 5 0 5} \mathrm{MPa}
$$

\section{b. Confinement provided by $50 \mathrm{~mm}$ ECC wrap:}

Splitting tensile strength of ECC wrap $=4.6 \mathrm{MPa}$

Thickness of wrap $(t)=50 \mathrm{~mm}$

$b=h=150 \mathrm{~mm}$ 
Longitudinal reinforcement ratio $\left(\rho_{s c}\right)=\{$ Cross-sectional area of steel/area confined by ECC $\operatorname{wrap}\}=(4 * 100) /(150 * 150)=0.0177$

Shape factor $k_{e}=1-\left[\frac{\left(b^{2}+h^{2}\right)}{6\left(1-\rho_{s c}\right) b h}\right]=1-\left[\left(150^{2}+150^{2}\right) /\left(6^{*}(1-0.0177)^{*} 150^{*} 150\right)\right]$

$$
=0.66
$$

Reinforcement ratio for ECC wrap $\left(\rho_{h}\right)=2 \frac{t}{b}=2 * 50 / 150=0.667$

Confinement due to wrap $f_{l x}{ }^{\prime}=f_{l y}{ }^{\prime}=k_{e} \rho_{h} f_{y}=0.66 * 0.667 * 4.6=2.03 \mathrm{MPa}$

Total confinement due to wrap and ties $=(2.03+.505) \mathrm{MPa}=\mathbf{2 . 5 3} \mathrm{MPa}$

\section{Richart's model sample calculation}

The square column needs to be converted to circular column with diameter " $d$ " to use Richart's model.

\section{a. Confinement provided by ties:}

Equivalent diameter of tie $(d)=\sqrt{ }\left(d_{t}^{2}+b_{t}^{2}\right)=\sqrt{ }\left(110^{2}+110^{2}\right)=155.56 \mathrm{~mm}$

Ratio of volume of ties to the volume of confined section $\left(\rho_{h .}\right)=\frac{4 A_{S .} .}{d . s}=(4 * 28.3 / 155.56 * 150)=0.0048$

$$
\begin{aligned}
f^{\prime}{ }_{l} & =\rho_{h} \cdot f_{y} / 2 \\
& =0.0048 * 449 / 2=\mathbf{1 . 0 8} \mathbf{M P a}
\end{aligned}
$$

\section{b. Confinement provided by $50 \mathrm{~mm}$ ECC wrap:}

Splitting tensile strength of ECC wrap $=4.6 \mathrm{MPa}$

Thickness of wrap $(t)=50 \mathrm{~mm}$

$b=h=150 \mathrm{~mm}$

Equivalent diameter of column $(d)=\sqrt{ }\left(b^{2}+h^{2}\right)=\sqrt{ }\left(150^{2}+150^{2}\right)=212.13 \mathrm{~mm}$

$$
\begin{aligned}
{f^{\prime}}_{l} & =2 f_{y} t / d \\
& =2 * 4.6 * 50 / 212.13=\mathbf{2 . 1 7} \mathbf{~ M P a}
\end{aligned}
$$

Total confinement due to wrap and ties $=(1.08+2.17) \mathrm{MPa}=3.26 \mathrm{MPa}$

Confinement in terms of lateral stress $\left(f^{\prime} l\right)$ for square column by Richart Model was higher than that of Mander Model because there is no modification factor associated with it (Table 5.1). Overall, an increase in ECC wrap thickness increased confinement stress in both cylindrical and 
square columns. Addition of tie bars also significantly increased the confinement stress. Confining effect is also higher in circular columns compared to their square counterparts. Since the analytical expression for confinement is only related to yield strength of wrap and its geometry, this expression does not deal with the interaction between core concrete and the wrap.

\subsection{Strength increase due to confinement}

\subsubsection{Analytical Method}

The confined compressive strength of core concrete based on Eq. 5.1 by Mander et al. (1988) and Eq. 5.2 by Richart et al. (1929) are summarized in Table 5.2. Sample calculations are provided. The strength prediction by Mander's model is higher than predicted by Richart's model as shown in Table 5.2. Strength increase in cylindrical columns were less than that of reinforced tied square column counterparts as predicted by the models.

Table 5.2a: Analytical confined strength from Mander's model

\begin{tabular}{|c|c|c|c|c|c|c|}
\hline \multirow{5}{*}{ 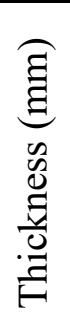 } & \multicolumn{6}{|c|}{ Analytical Strength $f_{c c}^{\prime}(\mathrm{MPa})$} \\
\hline & \multicolumn{6}{|c|}{ Mander (1988) } \\
\hline & \multicolumn{2}{|c|}{ Cylinder } & \multicolumn{4}{|c|}{ Square } \\
\hline & \multirow[b]{2}{*}{ LWSCC } & \multirow[b]{2}{*}{ SCC } & \multicolumn{2}{|c|}{ LWSCC } & \multicolumn{2}{|c|}{ SCC } \\
\hline & & & Untied & Tied & Untied & Tied \\
\hline 10 & - & - & - & - & $\begin{array}{c}44.75 \\
(\mathrm{~S}-\mathrm{SC}-10) \\
\end{array}$ & - \\
\hline 15 & - & - & - & - & $\begin{array}{c}46.08 \\
(\mathrm{~S}-\mathrm{SC}-15)\end{array}$ & - \\
\hline 20 & $\begin{array}{c}40.81 \\
(\mathrm{C}-\mathrm{LW}-20)\end{array}$ & $\begin{array}{c}49.95 \\
(\mathrm{C}-\mathrm{SC}-20)\end{array}$ & $\begin{array}{c}38.31 \\
(\mathrm{~S}-\mathrm{LW}-20)\end{array}$ & $\begin{array}{c}41.33 \\
(\mathrm{~S}-\mathrm{LW}-20 \mathrm{~T})\end{array}$ & $\begin{array}{c}47.37 \\
(\mathrm{~S}-\mathrm{SC}-20) \\
\end{array}$ & - \\
\hline 25 & - & - & $\begin{array}{c}39.54 \\
(\mathrm{~S}-\mathrm{LW}-25)\end{array}$ & - & - & - \\
\hline 30 & $\begin{array}{c}44.28 \\
(\mathrm{C}-\mathrm{LW}-30)\end{array}$ & $\begin{array}{c}53.36 \\
(\mathrm{C}-\mathrm{SC}-30) \\
\end{array}$ & $\begin{array}{c}40.75 \\
(\mathrm{~S}-\mathrm{LW}-30)\end{array}$ & $\begin{array}{c}43.62 \\
(\mathrm{~S}-\mathrm{LW}-30 \mathrm{~T}) \\
\end{array}$ & - & - \\
\hline 50 & $\begin{array}{c}50.54 \\
(\mathrm{C}-\mathrm{LW}-50)\end{array}$ & $\begin{array}{c}60.18 \\
(\mathrm{C}-\mathrm{SC}-50)\end{array}$ & - & $\begin{array}{c}47.90 \\
(\mathrm{~S}-\mathrm{LW}-50 \mathrm{~T})\end{array}$ & - & $\begin{array}{c}57.38 \\
(\mathrm{~S}-\mathrm{SC}-50 \mathrm{~T})\end{array}$ \\
\hline
\end{tabular}


Table 5.2b: Analytical confined strength from Richart's model

\begin{tabular}{|c|c|c|c|c|c|c|}
\hline \multirow{5}{*}{$\begin{array}{l}\text { Thickness } \\
\text { (mm) }\end{array}$} & \multicolumn{6}{|c|}{ Analytical Strength $f^{\prime}{ }_{c c}(\mathrm{MPa})$} \\
\hline & \multicolumn{6}{|c|}{ Richart (1929) } \\
\hline & \multicolumn{2}{|c|}{ Cylinder } & \multicolumn{4}{|c|}{ Square } \\
\hline & \multirow{2}{*}{ LWSCC } & \multirow{2}{*}{ SCC } & \multicolumn{2}{|c|}{ LWSCC } & \multicolumn{2}{|c|}{ SCC } \\
\hline & & & Untied & Tied & Untied & Tied \\
\hline 10 & - & - & - & - & $\begin{array}{c}43.78 \\
\text { (S-SC- } \\
10)\end{array}$ & - \\
\hline 15 & - & - & - & - & $\begin{array}{c}44.67 \\
\text { (S-SC- } \\
15)\end{array}$ & - \\
\hline 20 & $\begin{array}{c}38.03 \\
(\mathrm{C}-\mathrm{LW}- \\
20)\end{array}$ & $\begin{array}{c}47.03 \\
(\mathrm{C}-\mathrm{SC}-20)\end{array}$ & $\begin{array}{c}36.56 \\
(\mathrm{~S}-\mathrm{LW}-20)\end{array}$ & $\begin{array}{c}41.02 \\
(\mathrm{~S}-\mathrm{LW}-20 \mathrm{~T})\end{array}$ & $\begin{array}{c}45.56 \\
\text { (S-SC- } \\
20)\end{array}$ & - \\
\hline 25 & - & - & $\begin{array}{c}37.45 \\
(\mathrm{~S}-\mathrm{LW}-25)\end{array}$ & - & - & - \\
\hline 30 & $\begin{array}{c}40.54 \\
(\mathrm{C}-\mathrm{LW}- \\
30) \\
\end{array}$ & $\begin{array}{c}49.54 \\
(\mathrm{C}-\mathrm{SC}-30)\end{array}$ & $\begin{array}{c}38.33 \\
(\mathrm{~S}-\mathrm{LW}-30)\end{array}$ & $\begin{array}{c}42.80 \\
(\mathrm{~S}-\mathrm{LW}-30 \mathrm{~T})\end{array}$ & - & \\
\hline 50 & $\begin{array}{c}45.57 \\
(\mathrm{C}-\mathrm{LW}- \\
50)\end{array}$ & $\begin{array}{c}54.57 \\
(\mathrm{C}-\mathrm{SC}-50)\end{array}$ & - & $\begin{array}{c}46.36 \\
(\mathrm{~S}-\mathrm{LW}-50 \mathrm{~T})\end{array}$ & - & $\begin{array}{c}55.36 \\
(\mathrm{~S}-\mathrm{SC}-50 \mathrm{~T})\end{array}$ \\
\hline
\end{tabular}

\section{S-LW-50T sample calculation of confined strength $\left(f^{\prime} c c\right)$}

$f^{\prime}{ }_{c}=33 \mathrm{MPa}$ (Compressive strength of LWSCC)

\section{Mander's model (1988):}

Total confinement $\left(\left(f^{\prime} l\right)\right)$ due to wrap and ties: $2.53 \mathrm{MPa}$ (calculated in section 5.1 above)

Using Mander's model given by (5.1):

$$
\begin{aligned}
& \frac{f_{c c}^{\prime}}{f_{c}^{\prime}}=-1.254+2.254 \sqrt{1+\frac{7.94 f^{\prime}{ }_{l}}{f^{\prime}{ }_{c}}}-2 \frac{f^{\prime}{ }_{l}}{f_{c}^{\prime}} \\
& f^{\prime}{ }_{c c}=33 *(-1.254+2.254 \sqrt{ }(1+7.94 * 2.53 / 33)-2 * 2.53 / 33) \\
& =33 *(-1.254+2.254 * \sqrt{ }(1+7.94 * 0.0767)-2 * 0.0767 \\
& =33 *(-1.254+2.254 * 1.268-0.153)=33 * 1.451 \\
& =47.90 \mathrm{MPa}
\end{aligned}
$$




\section{Richart's model (1929):}

Using Richart's model given by Eq. 5.2:

$\frac{f^{\prime}{ }_{c c}}{f^{\prime}{ }_{c}}=1+4.1 \frac{f^{\prime}{ }_{l}}{f^{\prime}{ }_{c}}$

Total confinement $\left(\left(f^{\prime} l\right)\right)$ due to wrap and ties: 3.26 MPa (calculated in section 5.1 above)

$f^{\prime}{ }_{c c}=33 *(1+4.1 * 3.26 / 33)=33 *(1+4.1 * 0.987)=33 * 1.405$

\section{$=46.36 \mathrm{MPa}$}

\subsubsection{Theoretical analysis of loads based on experiments}

\subsubsection{Analysis of columns under Type A loading (load applied through both core and wrap)}

The applied axial compression load $(P)$ is shared by the wrap, core and reinforcing steel for Type A loading. Let $P_{w}, P_{c}$ and $P_{s}$ be the load taken by wrap, core and longitudinal rebar reinforcement, respectively. The axial deformation of the column due to load $\mathrm{P}$ is considered to be $\Delta$. All the components have the same deformation as expressed in Eq. 5.11:

$\Delta=\Delta_{w}=\Delta_{c}=\Delta_{S}$

where $\Delta_{w}, \Delta_{c}$ and $\Delta_{\mathrm{s}}$ are deformation in wrap, core concrete and steel, respectively.

If $A_{w}, A_{c}$ and $A_{s}$ are areas of wrap, concrete and steel respectively, then the deformation in each component in column with length " $L$ " can be expressed by:

$\Delta_{w}=\frac{P_{w} L}{A_{w} E_{w}}, \Delta_{c}=\frac{P_{c} L}{A_{c} E_{c}}, \Delta_{S}=\frac{P_{s} L}{A_{s} E_{S}}$

From Eq. 5.4 and Eq. 5.5, load carried by each component are:

$P_{w}=\frac{\Delta A_{w} E_{w}}{L}, P_{c}=\frac{\Delta A_{c} E_{c}}{L}, P_{s}=\frac{\Delta A_{s} E_{S}}{L}$

But,

$\mathrm{P}=\mathrm{P}_{\mathrm{w}}+\mathrm{P}_{\mathrm{c}}+\mathrm{P}_{\mathrm{s}}$

Combining Eq. 5.6 and Eq. 5.7,

$P=\frac{\Delta}{L}\left(A_{w} E_{w}+A_{c} E_{c}+A_{s} E_{s}\right)$ and $\frac{\Delta}{L}=\varepsilon$ (strain)The expression can be written as:

$\varepsilon=P /\left(A_{w} E_{w}+A_{c} E_{c}+A_{s} E_{s}\right)$

Therefore, stresses in wrap, concrete and steel can be given as:

$$
\begin{aligned}
\sigma_{w} & =\varepsilon E_{w} \\
\sigma_{c} & =\varepsilon E_{c} \\
\sigma_{s} & =\varepsilon E_{s}
\end{aligned}
$$


Compressive loads carried by each component are:

$$
\begin{aligned}
& \mathrm{P}_{\mathrm{w}}=\sigma_{\mathrm{w}}{ }^{*} \mathrm{~A}_{\mathrm{w}}=\varepsilon E_{w} A_{w} \\
& \mathrm{P}_{\mathrm{c}}=\sigma_{\mathrm{c}}{ }^{*} \mathrm{~A}_{\mathrm{c}}=\varepsilon E_{c} A_{c} \\
& \mathrm{P}_{\mathrm{s}}=\sigma_{\mathrm{s}}{ }^{*} \mathrm{~A}_{\mathrm{s}}=\varepsilon E_{s} A_{s}
\end{aligned}
$$

Table 5.3 summarizes load shared by each of the column components of reinforced untied square columns subjected to Type A loading (sample calculations are provided). It can be noted that the load contributions of $20 \mathrm{~mm}$ thick ECC wrap were $20.64 \%$ and $16.57 \%$ for LWSCC and SCC column, respectively. For every $5 \mathrm{~mm}$ thickness increase of ECC wrap, the load contribution of the wrap was increased by $3 \%$ to $4 \%$. It was also observed that strength increased with increase of ECC wrap thickness up to $30 \mathrm{~mm}$ but beyond $30 \mathrm{~mm}$, strength started to decrease. The higher load capacity for Type A loading can be attributed to the composite action of column rather than confining action because passive confinement is provided by tensile strength of the wrap whereas composite action is due to the compressive strength. The results are presented in Table 5.3. It is interesting to note that the LWSCC columns were more benefitted by the ECC wrapping than their SCC counterparts in Type A loading as evident from the maximum $27.75 \%$ load contribution of ECC wrap in LWSCC columns compared to maximum $16.57 \%$ in their SCC counterparts.

\begin{tabular}{|c|c|c|c|c|c|c|}
\hline \multirow{2}{*}{ Column } & \multirow{2}{*}{$\begin{array}{c}\text { Wrap } \\
\text { thickness } \\
(\mathrm{mm})\end{array}$} & \multirow{2}{*}{$\begin{array}{l}\text { Peak } \\
\text { Load } \\
(\mathrm{kN})\end{array}$} & \multicolumn{3}{|c|}{ Load contribution $(\mathrm{kN})$} & \multirow{2}{*}{$\begin{array}{c}\text { \% load } \\
\text { contributior } \\
\text { by ECC } \\
\text { wrap }\end{array}$} \\
\hline & & & $\mathrm{ECC}$ & Re-bar & Core & \\
\hline S-LW (control) & & 384.0 & & 67.8 & 316.2 & \\
\hline S-LW-20 & 20 & 1020.3 & 210.6 & 143.1 & 666.6 & 20.64 \\
\hline S-LW-25 & 25 & 967.3 & 235.6 & 129.3 & 602.4 & 24.36 \\
\hline S-LW-30 & 30 & 1219.7 & 338.4 & 155.7 & 725.5 & 27.75 \\
\hline S-SC (control) & & 870.7 & & 117.5 & 753.2 & \\
\hline S-SC-10 & 10 & 1398.1 & 131.7 & 170.8 & 1095.6 & 9.42 \\
\hline S-SC-15 & 15 & 1317.9 & 173.2 & 154.4 & 990.3 & 13.14 \\
\hline S-SC-20 & 20 & 1424.3 & 236.0 & 160.3 & 1028.0 & 16.57 \\
\hline
\end{tabular}

Table 5.3: Type A loading - Load sharing between different components of reinforced untied square columns

\section{Sample calculation for load shared by wrap, core concrete and steel in S-LW-30 column} Experimental peak load $(P)=1219.7 \mathrm{kN}$

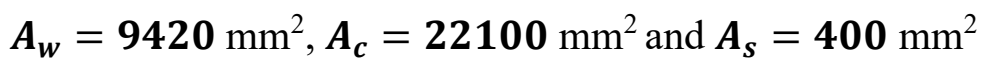


$\boldsymbol{E}_{\boldsymbol{w}}=18457 \mathrm{MPa}, \boldsymbol{E}_{\boldsymbol{c}}=16867 \mathrm{MPa}$ and $\boldsymbol{E}_{\boldsymbol{s}}=200000 \mathrm{MPa}$

Total axial strain $(\varepsilon)$ based on Eq. 5.15 :

$\varepsilon=P /\left(A_{w} E_{w}+A_{c} E_{c}+A_{s} E_{s}\right)$

$$
=1219.7 * 1000 /(9420 * 18457+22100 * 16867+400 * 200000)=1219.7000 /(626625640)=
$$

0.00195

From Eq. 5.17, the load shared by each component are obtained as follows:

$P_{w}=\varepsilon E_{w} A_{w}=0.00195 * 18457 * 9420 / 1000=338.42 \mathrm{kN}$

$P_{c}=\varepsilon E_{c} A_{c}=0.00195 * 16867 * 22100 / 1000=725.56 \mathrm{kN}$

$P_{s}=\boldsymbol{\varepsilon} \boldsymbol{E}_{\boldsymbol{s}} \boldsymbol{A}_{\boldsymbol{s}}=0.00195 * 200000 * 400 / 1000=155.72 \mathrm{kN}$

\subsubsection{Analysis of load contributions by wrap for columns under Type B loading}

The strength gain in columns due to Type B loading is due to confinement provided by ECC wrap and tie reinforcement. ECC wrap failed in tension due to radial expansion of core concrete.

\subsubsection{Non-reinforced cylindrical columns with wrap}

The strength gain in these columns was due to confinement provided by ECC wrap. ECC wrap failed in tension due to radial expansion of core concrete as confirmed from the experiment. Table 5.4 shows the strength gain in such cylindrical columns due to varying thickness of ECC wrap. The strength increase in SCC cylindrical columns was found to be lower than LWSCC cylindrical columns. The strength gain of $29.78 \%, 37.05 \%$ and $28.99 \%$ were observed in LWSCC columns with $20 \mathrm{~mm}$ (C-LW-20), $30 \mathrm{~mm}$ (C-LW-30) and $50 \mathrm{~mm}$ (C-LW-50) thick ECC wrap, respectively compared to their control counterpart without ECC wrap. Strength increase in cylindrical SCC column C-SC-30 was $22.59 \%$ and C-SC-50 was $12.22 \%$.

Table 5.4: Type B loading - Load increment due to ECC wrap in non-reinforced cylindrical columns

\begin{tabular}{|l|c|c|c|c|}
\hline \multicolumn{1}{|c|}{ Column } & $\begin{array}{c}\text { Wrap thickness } \\
(\mathrm{mm})\end{array}$ & $\begin{array}{c}\text { Peak Load } \\
(\mathrm{kN})\end{array}$ & $\begin{array}{c}\text { Load increment due to } \\
\text { ECC }(\mathrm{kN})\end{array}$ & $\begin{array}{c}\text { \% load increment due to } \\
\text { ECC wrap }\end{array}$ \\
\hline C-LW (control) & & 584.8 & & 29.78 \\
\hline C-LW-20 & 20 & 759.0 & 174.2 & 37.05 \\
\hline C-LW-30 & 30 & 801.6 & 216.7 & 28.99 \\
\hline C-LW-50 & 50 & 754.4 & 169.5 & -15.34 \\
\hline C-SC (control) & & 743.7 & & 22.59 \\
\hline C-SC-20 & 20 & $629.6^{*}$ & -114.1 & 12.22 \\
\hline C-SC-30 & 30 & 911.7 & 168.0 & \\
\hline C-SC-50 & 50 & 834.6 & 90.9 & \\
\hline
\end{tabular}

*Failed prematurely 


\section{Longitudinally reinforced tied square columns with wrap}

Reinforced tied square column showed good strength enhancement under Type B loading (Table 5.5). LWSCC column (S-LW-50T) strength gain was higher than its SCC counterpart (S-SC-50T). LWSCC column showed increased strength enhancement with increased thickness of ECC wrap. Column S-LW-20T showed 42.26\% increase, column S-LW-30T strength increased by 55.78\% and the column S-LW-50T experienced increased strength of 74.48\%. Reinforced tied SCC square column S-SC-50T showed $45.20 \%$ increase in its strength.

Table 5.5: Type B loading -Load increment due to ECC wrap in reinforced tied square columns experimental results

\begin{tabular}{|c|c|c|c|c|c|c|}
\hline \multirow{2}{*}{ Column } & \multirow{2}{*}{$\begin{array}{c}\text { Wrap } \\
\text { thickness } \\
(\mathrm{mm})\end{array}$} & \multirow{2}{*}{$\begin{array}{l}\text { Peak } \\
\text { Load } \\
(\mathrm{kN})\end{array}$} & \multirow{2}{*}{$\begin{array}{c}\text { Load } \\
\text { increment } \\
\text { due to } \\
\text { ECC } \\
(\mathrm{kN})\end{array}$} & \multicolumn{2}{|c|}{$\begin{array}{l}\text { Load contribution } \\
\qquad(\mathrm{kN})\end{array}$} & \multirow{2}{*}{$\begin{array}{c}\% \text { load } \\
\text { increment } \\
\text { due to } \\
\text { ECC } \\
\text { wrap }\end{array}$} \\
\hline & & & & Re-bar & Core & \\
\hline $\begin{array}{l}\text { S-LW-T } \\
\text { (control) }\end{array}$ & & 565.6 & & 99.9 & 465.7 & \\
\hline S-LW-20T & 20 & 804.7 & 196.8 & 142.2 & 662.5 & 42.26 \\
\hline S-LW-30T & 30 & 881.2 & 259.8 & 155.7 & 725.5 & 55.78 \\
\hline S-LW-50T & 50 & 986.9 & 346.8 & 174.4 & 812.5 & 74.48 \\
\hline $\begin{array}{l}\text { S-SC-T } \\
\text { (control) }\end{array}$ & & 709.0 & & 95.6 & 613.3 & \\
\hline S-SC-50T & 50 & 1293.8 & 505.9 & 174.5 & 1119.2 & 45.20 \\
\hline
\end{tabular}

The higher load capacity for Type A loading can be attributed to composite action of column rather than confining action because passive confinement is provided by tensile strength of the wrap whereas composite action is due to compressive strength of column components as shown in Tables 5.3 to 5.5 .

\subsubsection{Axial capacity of column based on CSA (2012)}

CSA - S806 (2012), section 11.4.2.5 gives confined compressive strength of concrete $\left(f^{\prime}{ }_{c c}\right)$ to determine the axial capacity of a confined column jacketed with fiber reinforced polymer (FRP) sheet. The axial capacity of column is given by:

$P=k_{e}\left(\alpha_{1} \varphi_{c} f_{c c}^{\prime}\left(A_{g}-A_{s t}\right)+\varphi_{s} f_{y} A_{s t}\right)$

where 
$k_{e}$ is the resistance factor of a column

$\varphi_{c}=0.6$ and $\varphi_{s}=0.85$, are resistance factors for concrete and steel, respectively

$\alpha_{1}=\left(0.85-0.0015 f_{c}^{\prime}\right) \geq 0.67$, is the average compression stress to the concrete strength ratio $f_{y}$ is the uniaxial yield stress of the steel, $A_{g}$ and $A_{s t}$ are gross sectional area of the column and area of the steel, respectively.

Confined strength $\left(f^{\prime} c c\right)$ of column is calculated based on following equation:

$f_{c c}^{\prime}=0.85 f_{c}^{\prime}+k_{l} k_{c} f_{l}$

where

$k_{l}=6.7\left(k_{c} f_{l}\right)^{-0.17}$

$k_{c}=1.0$ for circular and oval jackets

$=0.4$ for square and rectangular jack

$f_{l}=\frac{2 t f_{f}}{d}$

where

$t$ is the thickness of jacket

$d$ is the equivalent diameter (least dimension for rectangular/square column) of core concrete

$E_{f}$ is the modulus of elasticity of the wrap

$f_{y}$ is the ultimate tensile strength of wrap

$f_{f}=$ the smaller of $0.006 E_{f}$ or $\varphi_{f} f_{y}$

Table 5.6a: Code based axial capacity of non-reinforced cylindrical columns

\begin{tabular}{|c|c|c|c|c|c|c|}
\hline $\begin{array}{c}t \\
(\mathrm{~mm})\end{array}$ & $\begin{array}{c}\text { LWSCC } \\
\text { columns }\end{array}$ & $\begin{array}{c}\text { Confined } \\
\text { strength } \\
(M P a), f_{c c}^{\prime}\end{array}$ & $\begin{array}{c}\text { Axial } \\
\text { Capacity } \\
(\mathrm{kN})\end{array}$ & $\begin{array}{c}\text { SCC } \\
\text { columns }\end{array}$ & $\begin{array}{c}\text { Confined } \\
\text { strength } \\
(M P a), f_{c c}^{\prime}\end{array}$ & $\begin{array}{c}\text { Axial } \\
\text { Capacity } \\
(\mathrm{kN})\end{array}$ \\
\hline 20 & C-LW-20 & 35.99 & 509.1 & C-SC-20 & 43.64 & 606.9 \\
\hline 30 & C-LW-30 & 39.16 & 554.0 & C-SC-30 & 46.81 & 651.1 \\
\hline 50 & C-LW-50 & 45.03 & 637.0 & C-SC-50 & 52.68 & 732.7 \\
\hline
\end{tabular}

Table 5.6a gives the code based confined strength and axial capacity of confined LWSCC and SCC cylindrical columns based on Eqs. 5.18, 5.19 and 5.20. A sample calculation for C-LW-50 column is presented as follows:

Tensile strength of ECC wrap, $f_{f}=4.6 \mathrm{MPa}$, thickness of wrap $(t)=50 \mathrm{~mm}$, diameter of the column $=150 \mathrm{~mm}, f^{\prime}{ }_{c}=33 \mathrm{MPa}$

From Eq. 5.20; 
$\boldsymbol{f}_{l}=\frac{2 \boldsymbol{t} \boldsymbol{f}_{f}}{\boldsymbol{d}}=2 * 50 * 4.6 / 150=3.06$

Eq. 5.19 gives $\boldsymbol{f}_{c c}^{\prime}=\mathbf{0 . 8 5} \boldsymbol{f}_{c}^{\prime}+\boldsymbol{k}_{l} \boldsymbol{k}_{c} \boldsymbol{f}_{l}$

for cylindrical column $k_{c}=1, \boldsymbol{k}_{\boldsymbol{l}}=\mathbf{6 . 7}\left(\boldsymbol{k}_{\boldsymbol{c}} \boldsymbol{f}_{l}\right)^{-0.17}=6.7 *(1 * 3.06)^{-0.17}=6.7 * 0.925=5.54$

So, the confined strength is given by, $\boldsymbol{f}_{\boldsymbol{c} \boldsymbol{c}}^{\prime}=\mathbf{0 . 8 5} * \mathbf{3 3}+\mathbf{5 . 5 4} * \mathbf{1} * \mathbf{3 . 0 6}=45 \mathrm{MPa}$

Axial capacity of non-reinforced cylindrical column is given by Eq. 5.18 by removing all the partial factors and calculating $\boldsymbol{\alpha}_{\mathbf{1}}=\left(\mathbf{0 . 8 5}-\mathbf{0 . 0 0 1 5} \boldsymbol{f}_{\boldsymbol{c}}^{\prime}\right) \geq \mathbf{0 . 6 7}=0.85-0.0015 * 33=0.8$ $\boldsymbol{P}=\boldsymbol{\alpha}_{1} \boldsymbol{f}_{c c}^{\prime} \boldsymbol{A}_{\boldsymbol{g}}=0.8 * 45^{*} \pi^{*} 150^{2} / 4=637 \mathrm{kN}$.

It's evident from Table 5.6a that the confined strength and the axial capacity of columns increased with increasing thickness of ECC wrap.

Table 5.6b: Code based axial capacity of untied reinforced square columns

\begin{tabular}{|c|c|c|c|c|c|c|c|}
\hline $\mathrm{t}(\mathrm{mm})$ & $\begin{array}{c}\text { LWSCC } \\
\text { columns }\end{array}$ & $\begin{array}{c}\text { Confined } \\
\text { strength } \\
(M P a), f_{c c}^{\prime}\end{array}$ & $\begin{array}{c}\text { Axial } \\
\text { Capacity } \\
(\mathrm{kN})\end{array}$ & $\mathrm{t}(\mathrm{mm})$ & $\begin{array}{c}\text { SCC } \\
\text { columns }\end{array}$ & $\begin{array}{c}\text { Confined } \\
\text { strength } \\
(M P a), \\
f_{c c}^{\prime}\end{array}$ & $\begin{array}{c}\text { Axial } \\
\text { Capacity } \\
(\mathrm{kN})\end{array}$ \\
\hline 20 & S-LW-20 & 31.76 & 1034.7 & 10 & S-SC-10 & 37.79 & 1012.8 \\
\hline 25 & S-LW-25 & 32.52 & 1106.7 & 15 & S-SC-15 & 38.62 & 1086.0 \\
\hline 30 & S-LW-30 & 33.24 & 1178.2 & 20 & S-SC-20 & 39.41 & 1158.3 \\
\hline
\end{tabular}

Table 5.6b gives the code based confined strength and axial capacity of reinforced confined LWSCC and SCC square columns based on Eqs. 5.18, 5.19 and 5.20. Sample calculations for SLW-30 column under Type A loading are provided as follows:

Tensile strength of ECC wrap, $f_{f}=4.6 \mathrm{MPa}$, thickness of wrap $(t)=30 \mathrm{~mm}$, least dimension of the column $=150 \mathrm{~mm}, f^{\prime}{ }_{c}=33 \mathrm{MPa}$

From Eq. 5.20;

$\boldsymbol{f}_{\boldsymbol{l}}=\frac{2 \boldsymbol{t} \boldsymbol{f}_{\boldsymbol{f}}}{\boldsymbol{d}}=2 * 30 * 4.6 / 150=1.84$

Eq. 5.19 gives $\boldsymbol{f}_{c c}^{\prime}=\mathbf{0 . 8 5} \boldsymbol{f}_{c}^{\prime}+\boldsymbol{k}_{l} \boldsymbol{k}_{c} \boldsymbol{f}_{l}$

for square column $k_{c}=0.4, \boldsymbol{k}_{\boldsymbol{l}}=\mathbf{6 . 7}\left(\boldsymbol{k}_{\boldsymbol{c}} \boldsymbol{f}_{\boldsymbol{l}}\right)^{-\mathbf{0 . 1 7}}=6.7 *(0.4 * 1.84)^{-0.17}=6.7 * 1.053=7.06$

So, the confined strength is given by, $\boldsymbol{f}_{\boldsymbol{c c}}^{\prime}=\mathbf{0 . 8 5} * \mathbf{3 3}+\mathbf{7 . 0 6} * \mathbf{0 . 4} * \mathbf{1 . 8 4}=33.24 \mathrm{MPa}$

Axial capacity of non-reinforced cylindrical column is given by Eq. 5.18 by removing all the partial factors and calculating $\boldsymbol{\alpha}_{\mathbf{1}(\boldsymbol{L} \boldsymbol{W} \boldsymbol{S C C})}=\left(\mathbf{0 . 8 5}-\mathbf{0 . 0 0 1 5} \boldsymbol{f}_{\boldsymbol{c}}^{\prime}\right) \geq \mathbf{0 . 6 7}=0.85-0.0015 * 33=$ $0.8, \boldsymbol{\alpha}_{1(E C C)}=\left(\mathbf{0 . 8 5}-\mathbf{0 . 0 0 1 5} \boldsymbol{f}_{c}^{\prime}\right) \geq \mathbf{0 . 6 7}=0.85-0.0015 * 49.7=0.775$ 
The axial capacity of column under Type A loading is contributed by ECC wrap, core column and longitudinal steel.

Therefore,

$$
\begin{aligned}
& P=\left(\alpha_{1} f_{c c}^{\prime}\left(A_{g}-A_{s t}\right)+f_{y} A_{s t}\right)_{L W S C C}+\left(\alpha_{1} f_{c}^{\prime} * \text { Area of the wrap }\right)_{E C C} \\
& =(0.8 * 33.24 *(150 * 150-400)+567 * 400)_{L W S C C}+(0.775 * 49.7 * 9420){ }_{E C C} \\
& =815+363 \\
& =1178 \mathrm{kN}
\end{aligned}
$$

It can be seen from Table 5.6b that the confined strength and the axial capacity of columns increased with increasing thickness of ECC wrap.

Table 5.6c gives the code based confined strength and axial capacity of tied reinforced confined LWSCC and SCC square columns based on Eqs. 5.18, 5.19 and 5.20 showing sample calculations for S-LW-50T column.

Table 5.6c: Code based axial capacity of tied reinforced square columns

\begin{tabular}{|c|c|c|c|c|c|c|c|}
\hline $\mathrm{t}(\mathrm{mm})$ & $\begin{array}{c}\text { LWSCC } \\
\text { columns }\end{array}$ & $\begin{array}{c}\text { Confined } \\
\text { strength }(M P a), \\
f_{c c}^{\prime}\end{array}$ & $\begin{array}{c}\text { Axial } \\
\text { Capacity } \\
(\mathrm{kN})\end{array}$ & $\mathrm{t}(\mathrm{mm})$ & $\begin{array}{c}\text { SCC } \\
\text { columns }\end{array}$ & $\begin{array}{c}\text { Confined } \\
\text { strength } \\
(M P a), \\
f_{c c}^{\prime}\end{array}$ & $\begin{array}{c}\text { Axial } \\
\text { Capacity } \\
(\mathrm{kN})\end{array}$ \\
\hline 20 & S-LW-20T & 31.76 & 788.7 & 50 & S-SC-50T & 43.64 & 985.8 \\
\hline 30 & S-LW-30T & 33.24 & 814.9 & & & & \\
\hline 50 & S-LW-50T & 35.99 & 863.5 & & & & \\
\hline
\end{tabular}

S-LW-50T sample calculation

Tensile strength of ECC wrap, $f_{f}=4.6 \mathrm{MPa}$, thickness of wrap $(t)=30 \mathrm{~mm}$, least dimension of the column $=150 \mathrm{~mm}, f^{\prime}{ }_{c}=33 \mathrm{MPa}$

From Eq. $5.20 ; \boldsymbol{f}_{\boldsymbol{l}}=\frac{2 \boldsymbol{t} \boldsymbol{f}_{\boldsymbol{f}}}{\boldsymbol{d}}=2 * 50 * 4.6 / 150=3.06$

Eq. 5.19 gives $\boldsymbol{f}_{c \boldsymbol{c}}^{\prime}=\mathbf{0 . 8 5} \boldsymbol{f}_{\boldsymbol{c}}^{\prime}+\boldsymbol{k}_{\boldsymbol{l}} \boldsymbol{k}_{\boldsymbol{c}} \boldsymbol{f}_{\boldsymbol{l}}$

for square column $k_{c}=0.4, \boldsymbol{k}_{\boldsymbol{l}}=\mathbf{6 . 7}\left(\boldsymbol{k}_{\boldsymbol{c}} \boldsymbol{f}_{l}\right)^{-\mathbf{0 . 1 7}}=6.7^{*}\left(0.4^{*} 3.06\right)^{-0.17}=6.7 * 0.97=6.47$

So, the confined strength is given by, $f_{c c}^{\prime}=\mathbf{0 . 8 5} * 33+\mathbf{6 . 4 7} * \mathbf{0 . 4} * \mathbf{3 . 0 6}=36 \mathrm{MPa}$

Axial capacity of tied reinforced square column is given by Eq. 5.18 by removing all the partial factors and calculating $\boldsymbol{\alpha}_{\mathbf{1}}=\left(\mathbf{0 . 8 5}-\mathbf{0 . 0 0 1 5} \boldsymbol{f}_{\boldsymbol{c}}^{\prime}\right) \geq \mathbf{0 . 6 7}=0.85-0.0015 * 33=0.8$ $P=\alpha_{1} f_{c c}^{\prime}\left(A_{g}-A_{s t}\right)+f_{y} A_{s t}=0.8 * 36 *(150 * 150-400)+567 * 400=636.5+$ $226.8=863.3 \mathrm{kN}$ 
Table 5.6c shows that the confined strength and the axial capacity of columns increased with increasing thickness of ECC wrap.

\subsubsection{Finite element modelling of columns}

Commercially available software "Abaqus" was used to calculate the peak axial stress of columns from finite element models. Concrete Damage Plasticity (CDP) Model was used for the modelling. Material parameters were obtained from the experiments done in the laboratory. Bond (shear) stress between the interface of two concretes (core and wrap) was obtained from experiment. Coefficient of friction was assigned as suggested by PCI Handbook (2004). The FE model input parameters are shown in Table 5.7.

Table 5.7: Material and interaction input parameters for FE model

\begin{tabular}{|c|c|c|c|c|c|}
\hline Material & LWSCC & SCC & ECC & Steel $($ dia. $=11.3 \mathrm{~mm})$ & Steel $\quad(6 \mathrm{~mm})$ \\
\hline Modulus of Elasticity (MPa) & 16867 & 23213 & 18457 & 200000 & 200000 \\
\hline Poisson's Ratio & 0.16 & 0.23 & 0.17 & 0.3 & 0.3 \\
\hline Compressive Strength(MPa) & 33 & 42 & 49.7 & 567 & 449 \\
\hline True Yield Stress (MPa) & 30 & 41.7 & 43.9 & 449 & 449 \\
\hline Tensile Strength $(\mathrm{MPa})$ & 2 & 4 & 5 & 540 & 540 \\
\hline Density $\left(\mathrm{kg} / \mathrm{m}^{3}\right)$ & 1957 & 2271 & 2042 & 7850 & 7850 \\
\hline Density $\left(\mathrm{N} / \mathrm{mm}^{3}\right)$ & $1.92 \mathrm{E}-05$ & $2.23 \mathrm{E}-05$ & $2.00 \mathrm{E}-05$ & $7.70 \mathrm{E}-05$ & 7.70E-05 \\
\hline Fracture Energy, $K_{I}^{2} / \mathrm{E}(\mathrm{N} / \mathrm{mm})$ & 0.02 & 0.03 & 0.06 & & \\
\hline Interaction Property & LWSCC/ECC & $\mathrm{SCC} / \mathrm{ECC}$ & & & \\
\hline Coeff. of friction & 0.45 & 0.6 & & & \\
\hline Bond Strength (MPa) & 1.43 & 2.76 & & & \\
\hline
\end{tabular}

\subsubsection{Details of FE modelling}

The parts of FE model consisted of 3D deformable concrete wrap and core concrete whereas rebars and ties were modeled as a wire. Cylindrical concrete columns were modeled using half symmetry. Linear hexahedron type C3D8R for concrete and linear line type B31 for steel were used as elements for meshing. Concrete mechanical properties were derived from experimental tests done in the laboratory (Fig. 4.1). Concrete damage plasticity parameters were assigned as default values with eccentricity of 0.1 , initial equibiaxial compressive yield stress to initial uniaxial compressive yield stress $\left(\mathrm{f}_{\mathrm{b} 0} / \mathrm{f}_{\mathrm{c} 0}\right)$ as 1.16 , ratio of second stress invariant $(\mathrm{K})$ as 1.16 and viscosity parameter as 0. Dilation angle for SCC was taken as $35^{\circ}$ and ECC/LWSCC as $30^{\circ}$ as SCC has higher stiffness 
than ECC/LWSCC - the model was not found sensitive to dilation angle. Yield strength of concrete was taken as the value when the stress strain curve started to deviate from straight line before reaching peak stress. Tensile behavior was derived from fracture and splitting tests. The sections were assembled according to their geometric configuration to represent the actual specimen. Fig. 5.4 shows the assembly for tied reinforced column.

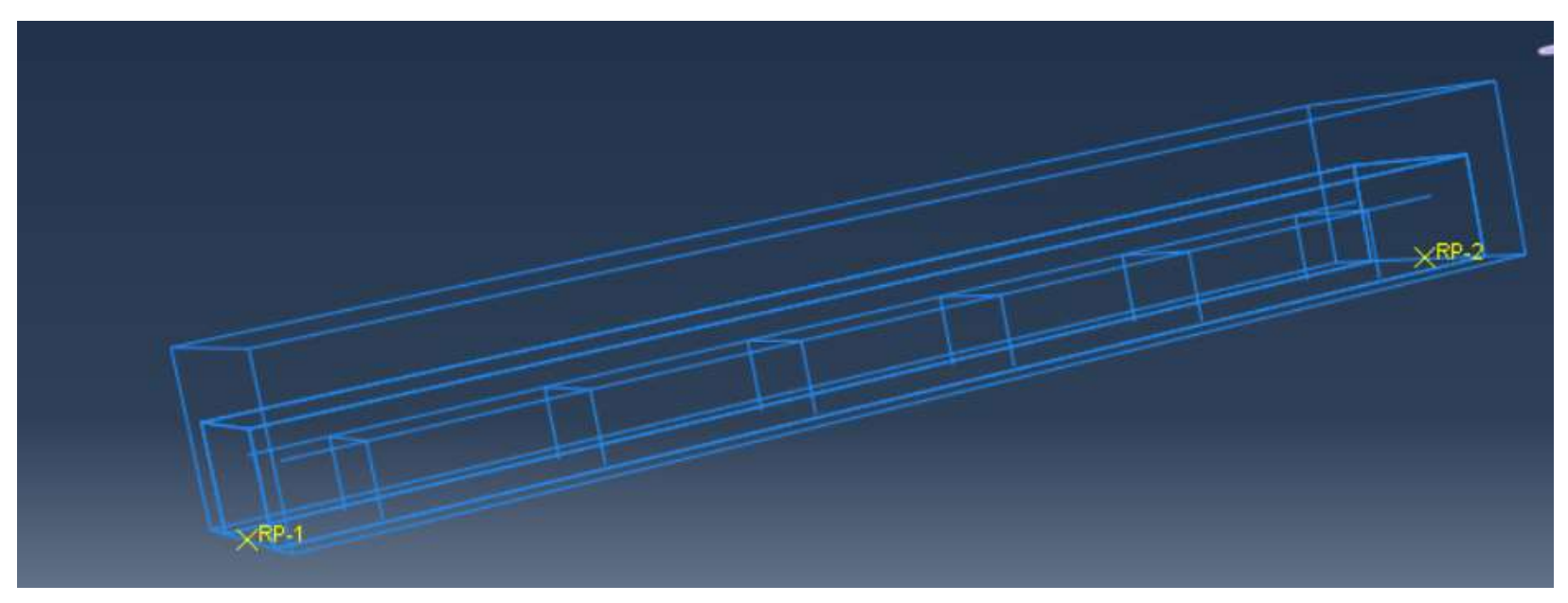

Fig. 5.3: Creating Assembly from Parts

Two steps using Abaqus Implicit were created for analysis by default. According to PCI Handbook (2004), coefficient of friction between concrete and concrete is $0.6 \lambda$. The value of $\lambda$ is suggested as 0.75 for LWSCC and 1.0 for normal concrete. The tangential behavior between concrete wrap and core was defined by Penalty using coefficient of friction for LWSCC as 0.45 and SCC as 0.6. Normal contact was defined as hard contact. Shear/bond stress between two concretes were obtained from laboratory test as shown in Table 5.7. The shear stress obtained from slant shear test is very high, so shear values were taken from bond test (Table 5.7). Reinforcement bars were embedded in core concrete. Symmetry was used to facilitate the computation for column model. Loads were applied as a displacement (Fig. 5.4) in displacement control analysis. 


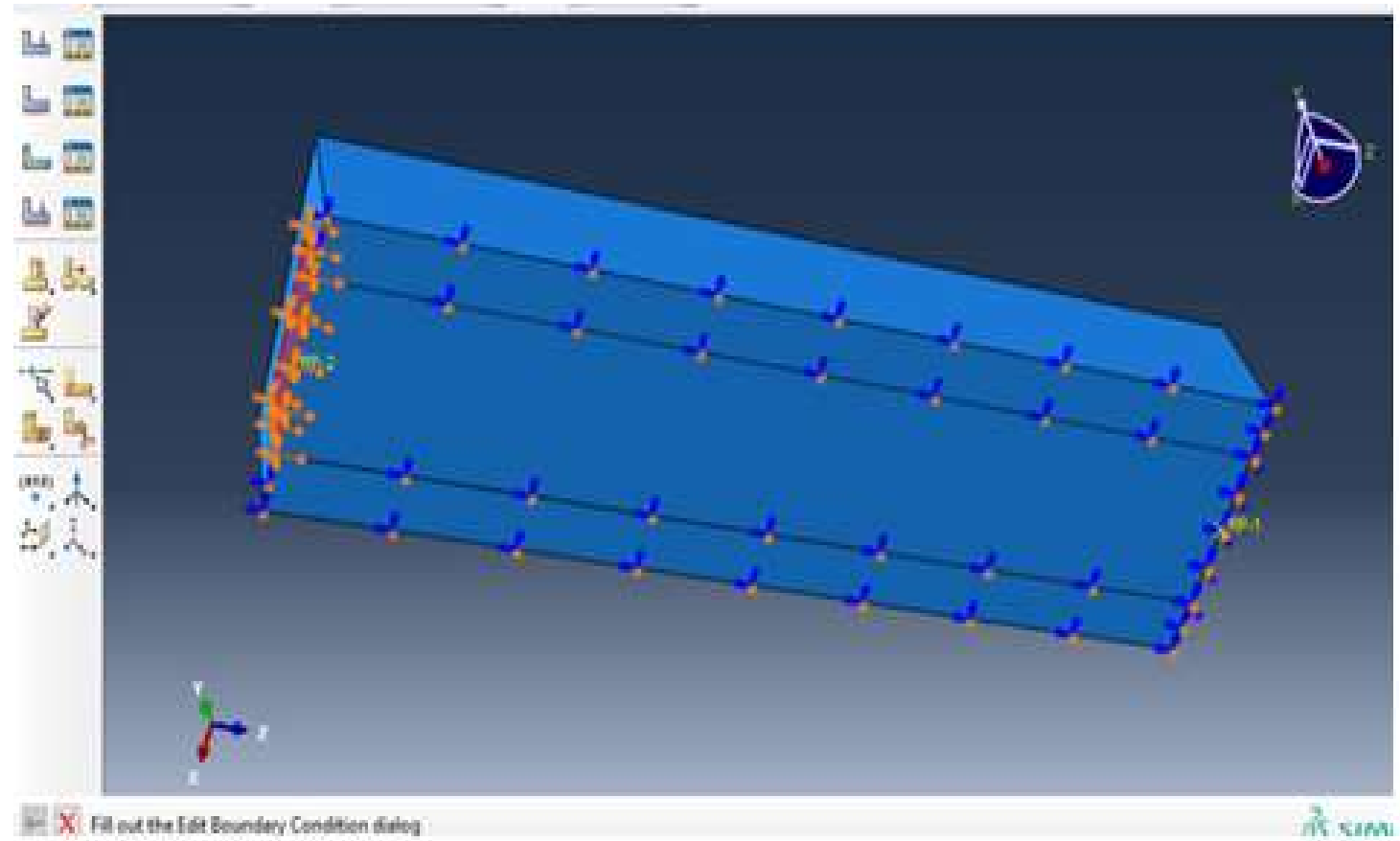

Fig. 5.4: Load and half-symmetry of column for analysis

\subsubsection{Analysis of FE results}

The contour maps showing distribution of axial stress (s33) for non-reinforced cylindrical columns (C-LW-50 and C-SC-50), reinforced untied column (S-LW-20) and reinforced tied columns (SLW-50T and S-SC-50T) at different load levels of 50\%, 75\% and 95\% of peak load are presented in Figs. 5.5 to 5.9. The axial stress development at different load levels in a chosen element (as indicated in Figures) is also shown in Figs. 5.5 to 5.9. When Type B load is applied in terms of $50 \%, 75 \%$ and $95 \%$ of experimental peak load, the maximum axial stress in cylindrical column CLW-50 core were $23 \mathrm{MPa}, 34 \mathrm{MPa}$ and $43 \mathrm{MPa}$ (compression), respectively compared to 0.156 $\mathrm{MPa}, 0.210 \mathrm{MPa}$ and $0.198 \mathrm{MPa}$ (tension) in ECC wrap. Similarly, for C-SC-50 cylindrical column the maximum axial stress in the core were $26 \mathrm{MPa}, 39 \mathrm{MPa}$ and $50 \mathrm{MPa}$ (compression), respectively compared to $0.208 \mathrm{MPa}, 0.273 \mathrm{MPa}$ and $0.289 \mathrm{MPa}$ (tension) in ECC wrap. 

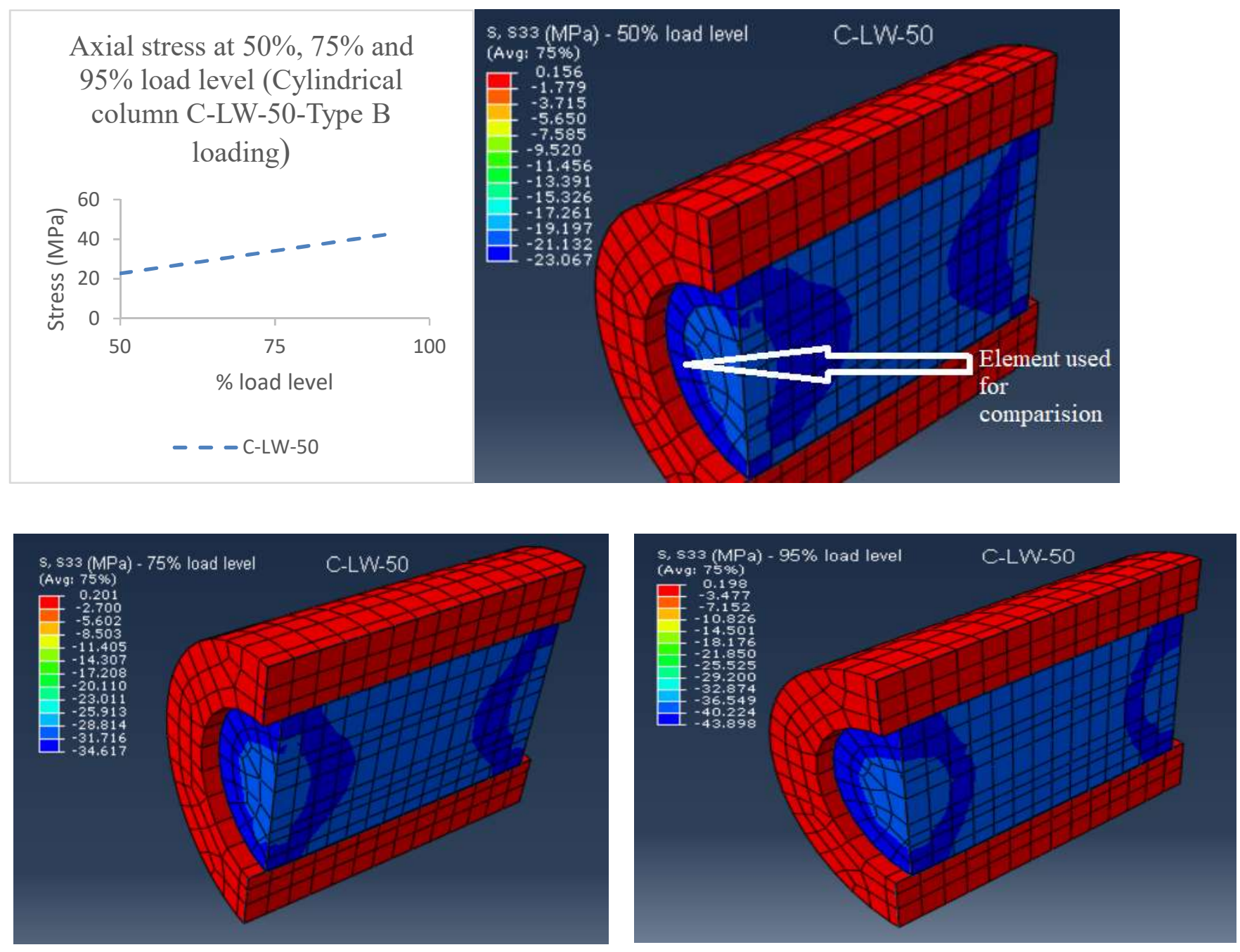

Fig. 5.5: Cylindrical column C-LW-50 response to increasing Type B load levels

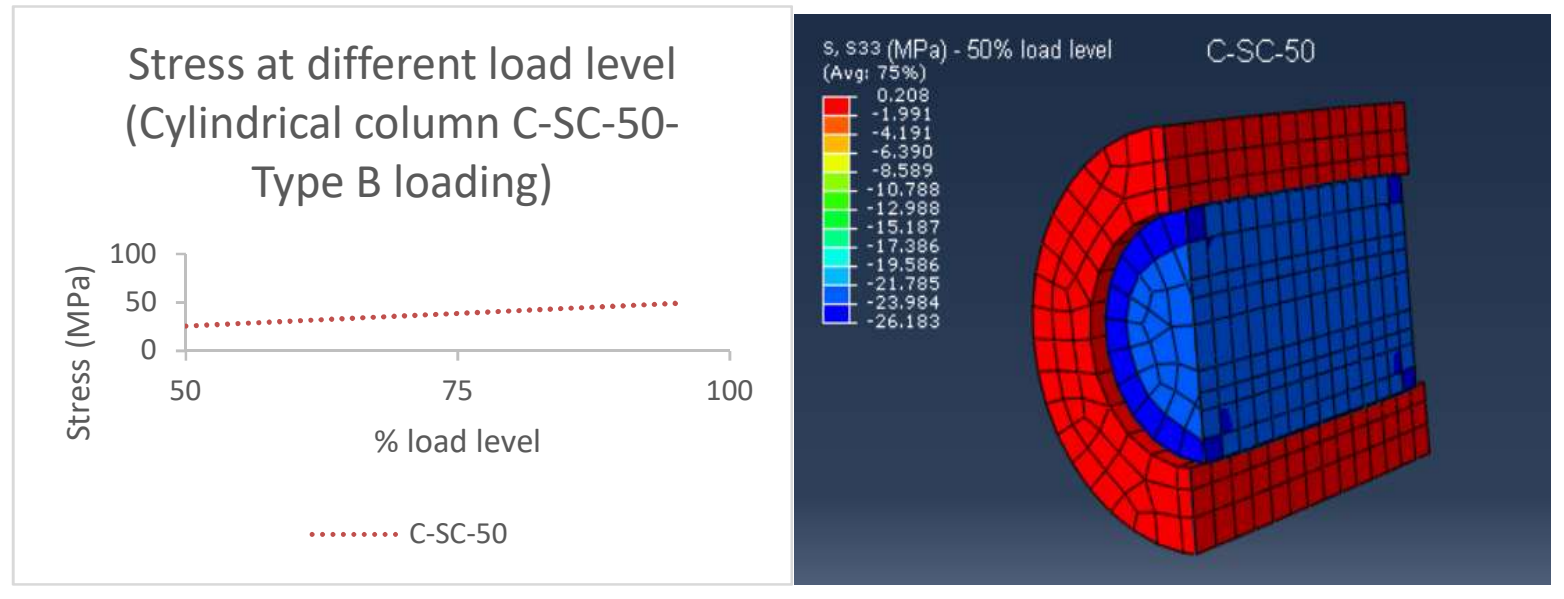




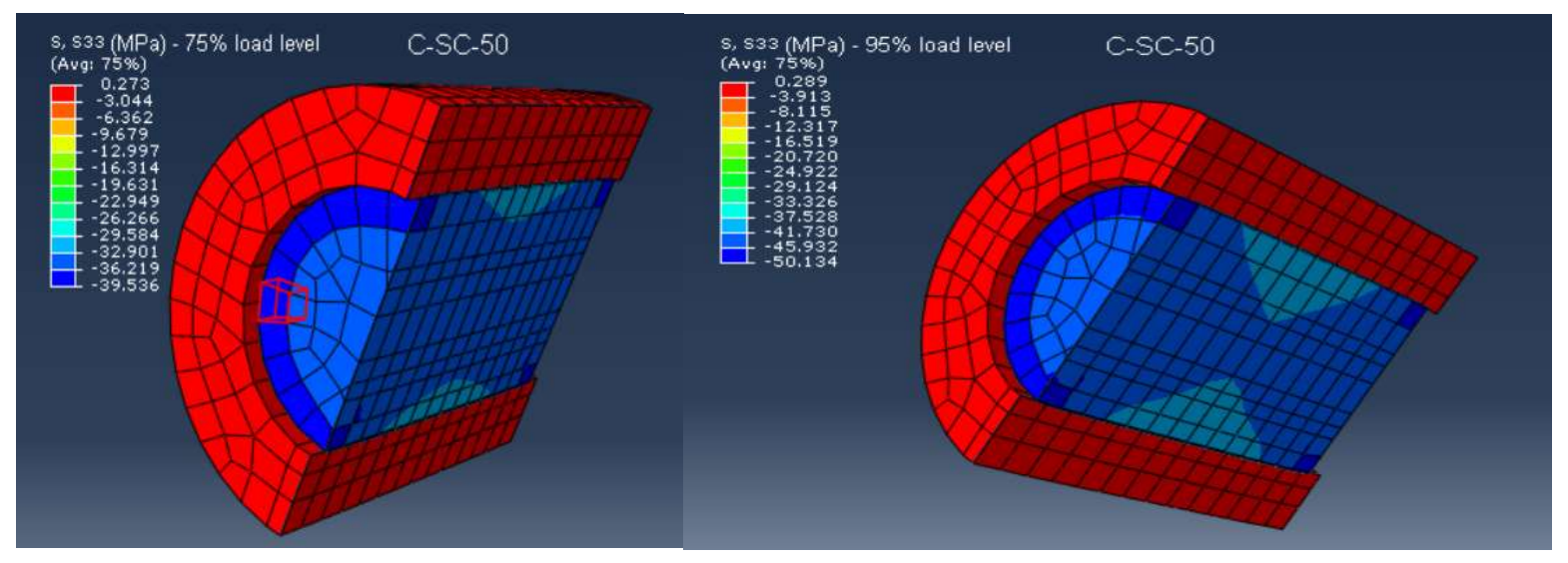

Fig. 5.6: Cylindrical column C-SC-50 response to increasing Type B load levels

Fig. 5.7 and Fig. 5.8 show the response of reinforced tied square column S-LW-50T and S-SC$50 \mathrm{~T}$ subjected to Type B loading corresponding to $50 \%, 75 \%$ and $95 \%$ of peak load. Elemental stress in top surface of LWSCC core increases from $50 \%$ to $75 \%$ of peak load and there is reduction in stress from $75 \%$ to $95 \%$ of peak load in the element due to transfer of stress to the longitudinal reinforcement bar from highly stressed concrete. As the column is loaded from the core only, ECC wrap experiences hoop (tensile) stress only. The maximum axial (compressive) stress for S-LW$50 \mathrm{~T}$ square column in the core were $39 \mathrm{MPa}, 57 \mathrm{MPa}$ and $40 \mathrm{MPa}$ (compression) compared to 0.111 MPa, 0.295 MPa and 2.233 MPa (tension) in ECC wrap subjected to tensile stress. Similarly for S-SC-50T cylindrical column, the maximum axial (compressive) stress in the core were 46 $\mathrm{MPa}, 72 \mathrm{MPa}$ and $54 \mathrm{MPa}$ compared to $0.129 \mathrm{MPa}, 0.316 \mathrm{MPa}$ and $1.125 \mathrm{MPa}$ (tensile stress) in ECC wrap. 

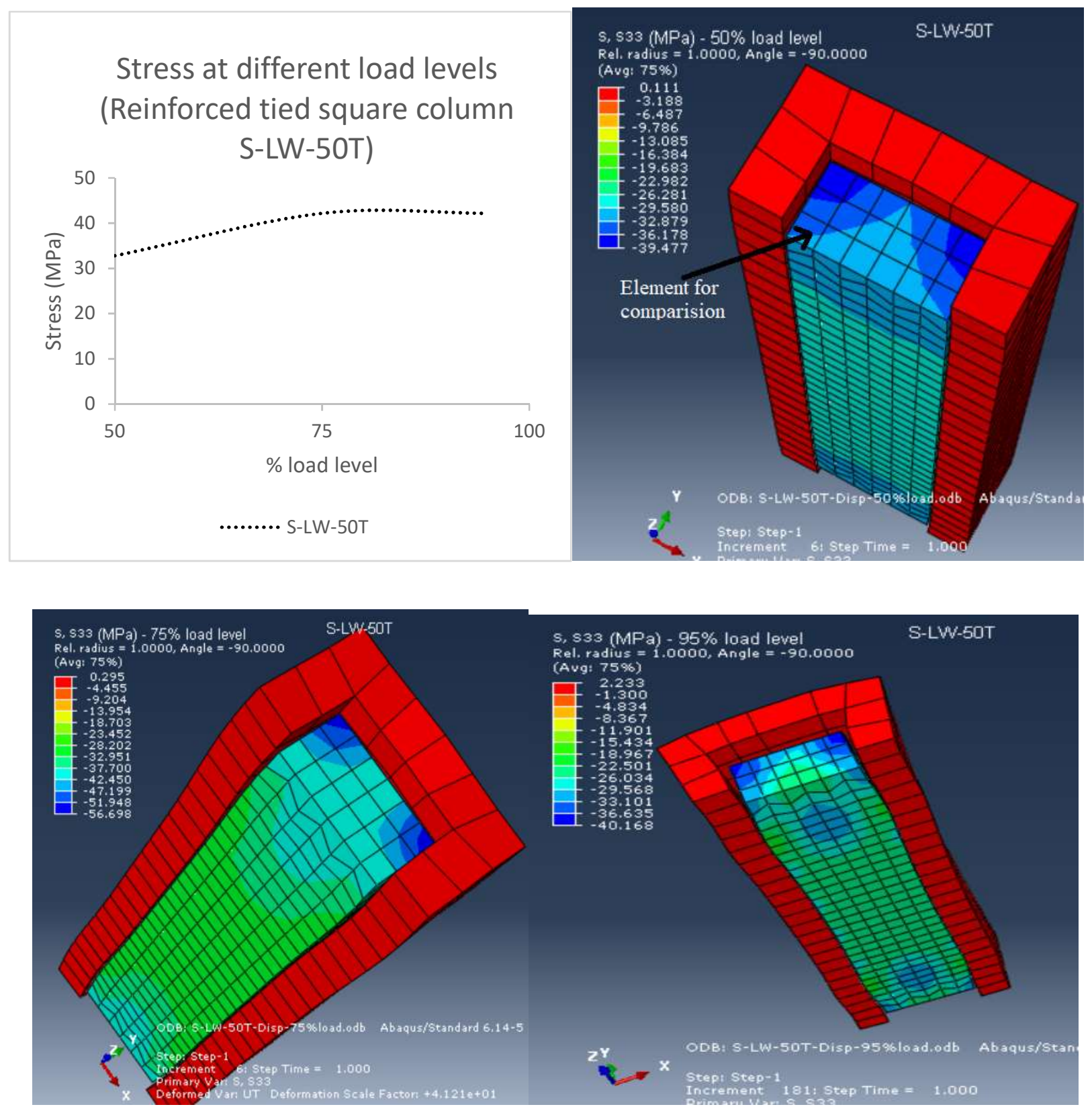

Fig. 5.7: Reinforced tied square column S-LW-50T response to increasing Type B load levels 

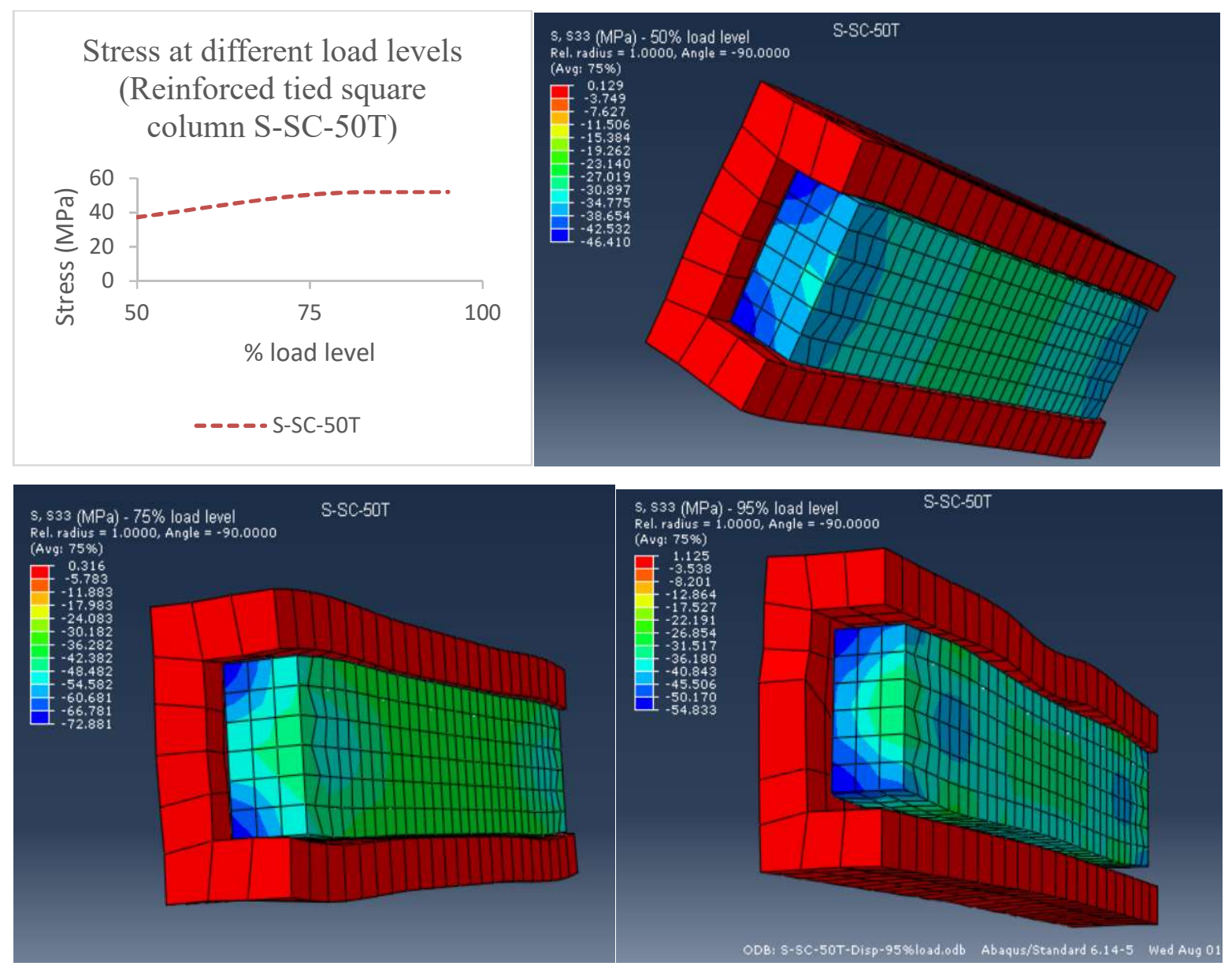

Fig. 5.8: Reinforced tied square column S-SC-50T response to increasing Type B load levels

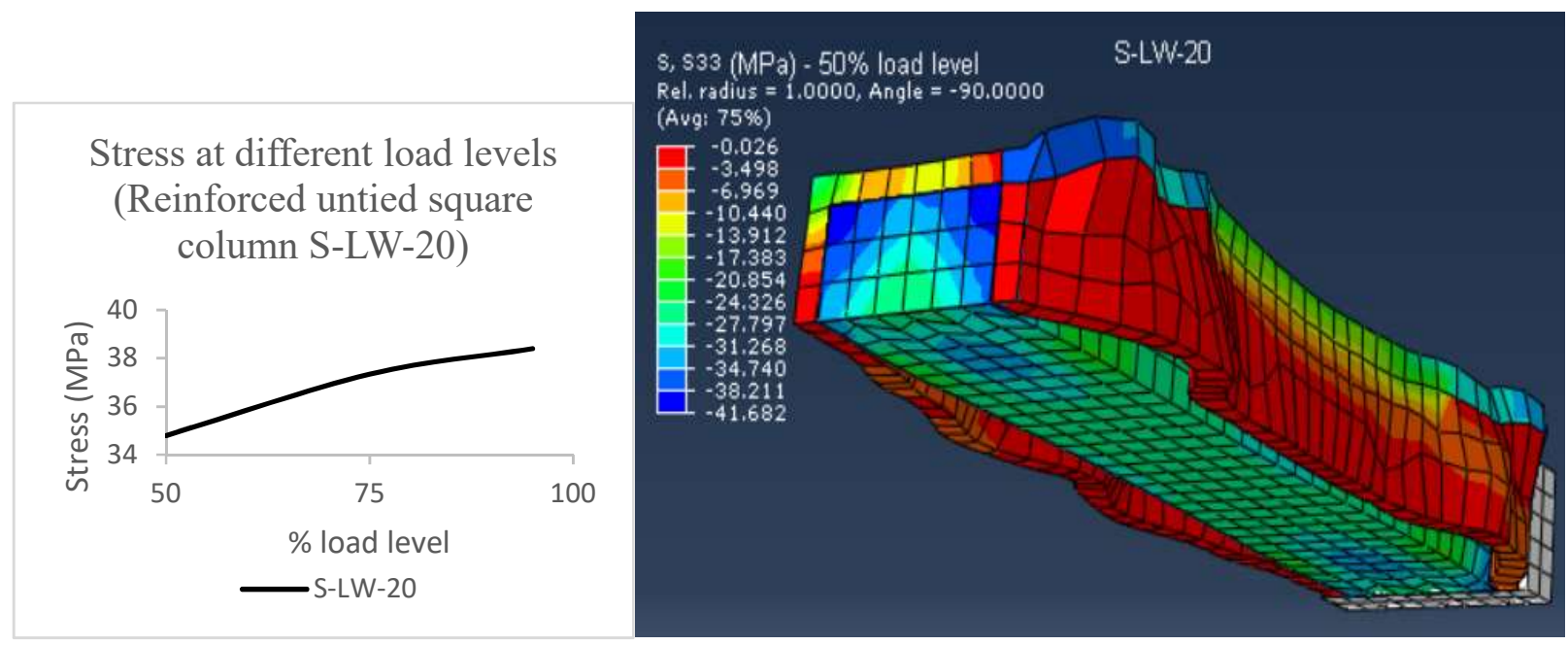




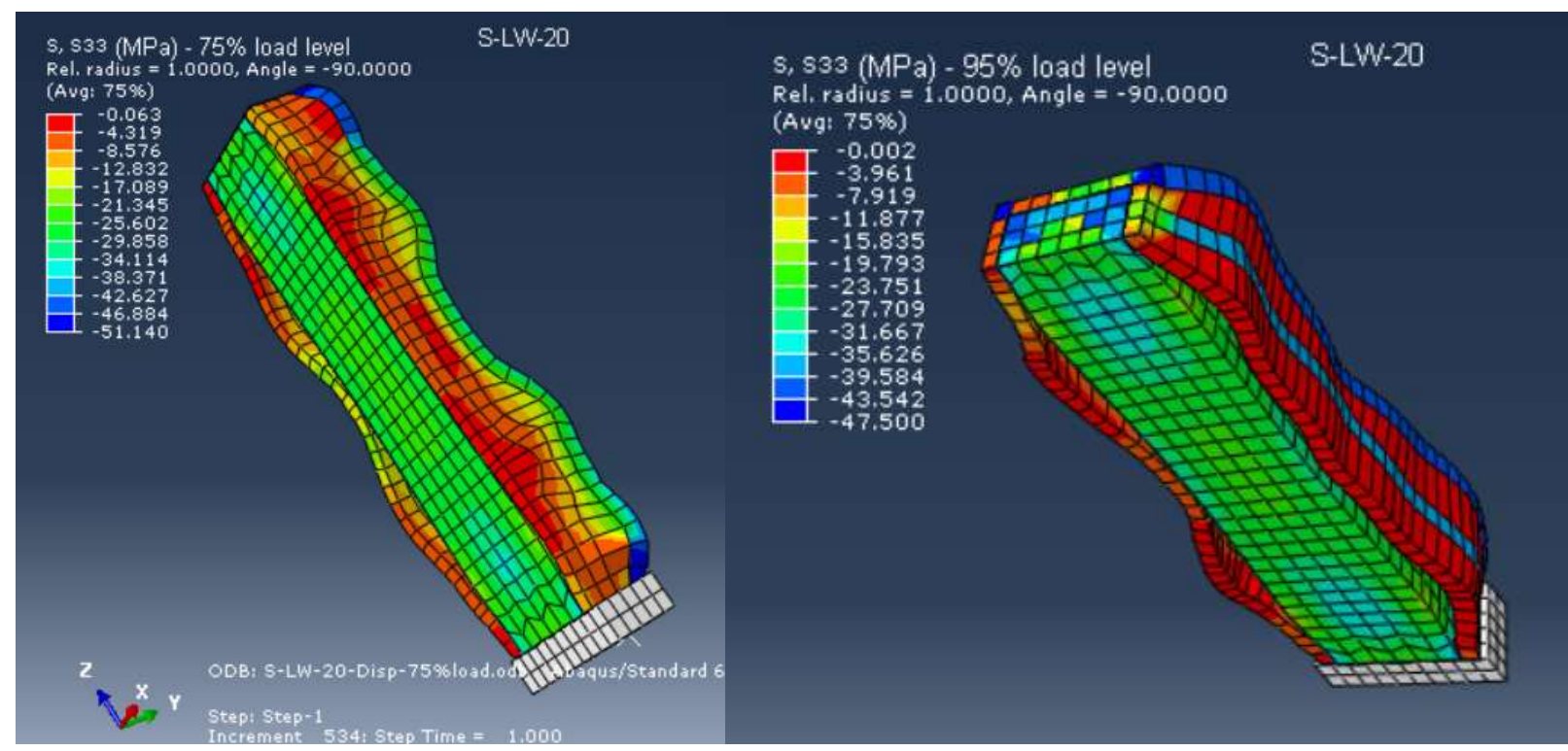

Fig. 5.9: Reinforced untied square column S-LW-20 response to increasing Type A load levels

Fig. 5.9 shows the response of reinforced untied square column S-LW-20 subjected to Type A loading at $50 \%, 75 \%$ and $95 \%$ of peak load. Elemental axial stress at top surface of LWSCC core increased up to $75 \%$ of peak load and decreased from $75 \%$ to $95 \%$ of peak load due to transfer of stress to longitudinal reinforcement bar from highly stressed concrete. The maximum axial (compressive) stress in the core were 41.7 MPa, 51.1 MPa and 47.5 MPa (compression) at 50\%, $75 \%$ and $95 \%$ of peak load, respectively. The difference in behavior between Type A and Type B loading is evident from. Type A loading caused ECC wrap to share axial compressive load and hence caused separation of ECC wrap from core with buckling of warp as can be seen in Fig. 5.9 (which were not observed in Type B loading).

The quantification of strength increase due to confinement was done based on peak axial stress developed in an element at the top surface of the concrete core from FE analysis. Fig. 5.10 shows axial stress-strain responses given by cylindrical and square SCC/LWSCC core column due to 50 mm ECC wrap. Table 5.8 summarizes the peak axial stress of cylindrical and square columns. FEM analysis showed that cylindrical columns had developed higher peak axial stress than square columns signifying more confining effect. The peak axial stress/strength in the concrete core increased with the increase of the thickness of the ECC wrap for both cylindrical and square columns as observed in experiments. 
Table 5.8: Peak axial stress in concrete core from $F E$ analysis

\begin{tabular}{|c|c|c|c|c|c|c|}
\hline \multirow{3}{*}{$\begin{array}{c}\text { Wrap } \\
\text { Thickness } \\
(\mathrm{mm})\end{array}$} & \multicolumn{3}{|c|}{$\begin{array}{c}\text { Non-reinforced cylindrical columns - } \\
\text { Type B loading }\end{array}$} & \multicolumn{4}{|c|}{ Reinforced square columns } \\
\cline { 2 - 7 } & \multicolumn{3}{|c|}{ (Peak axial Stress, MPa) } & \multicolumn{4}{|c|}{ (Peak axial Stress, MPa) } \\
\cline { 2 - 7 } & \multicolumn{2}{|c|}{$\begin{array}{c}\text { Untied-Type A } \\
\text { loading }\end{array}$} & $\begin{array}{c}\text { Tied-Type B } \\
\text { loading }\end{array}$ \\
\cline { 2 - 7 } & LWSCC & SCC & LWSCC & SCC & LWSCC & SCC \\
\hline 15 & & & & 45.06 & & \\
\hline 20 & 36.82 & 44.9 & 32.93 & 45.25 & 34.32 & \\
\hline 30 & 44.63 & 56 & 33.14 & & 37.2 & \\
\hline 50 & 51.01 & 62.69 & & & 43.83 & 52.26 \\
\hline
\end{tabular}

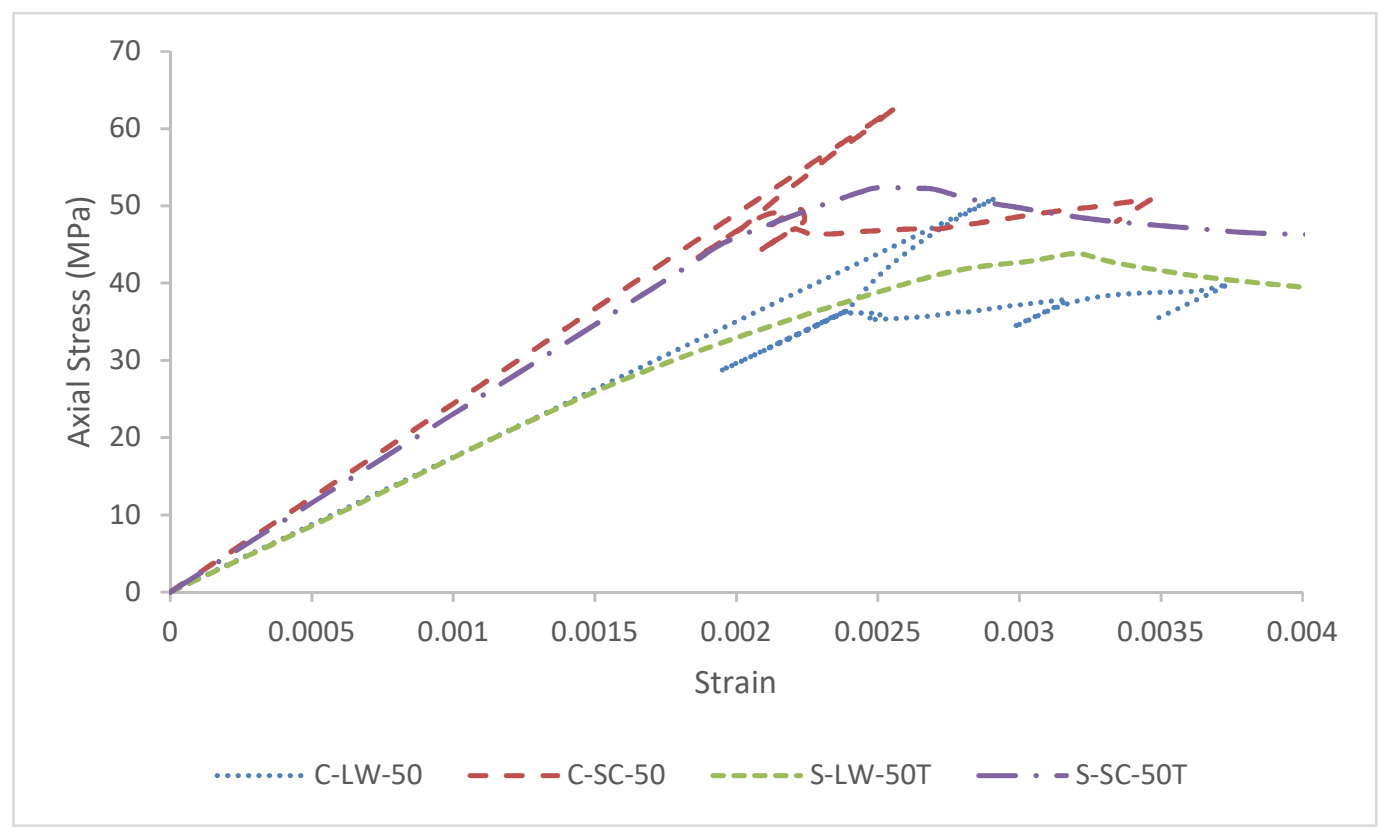

Fig.5.10: Axial stress-strain development in concrete core (top surface) for columns with $50 \mathrm{~mm}$ wrap

\subsection{Comparison between the results}

The ratios of confined to unconfined concrete strength $\left(f^{\prime} c d f^{\prime} c\right)$ from experiments, existing equations and FE analysis are compared to evaluate the performance. It should be noted that experimental and FE $f^{\prime}{ }_{c c}$ is taken as the peak stress in the concrete core (peak load divided by concrete core area from in experiment). 


\subsubsection{Non-reinforced cylindrical columns (Type B loading)}

From Table 5.9, it can be noted that Richart's model predicts lower value of $f^{\prime}{ }_{c c} / f^{\prime} c$ compared to all others for confined cylindrical columns. Mander's model is in close agreement to FEM and experimental results for these columns.

Table 5.9: Non-reinforced cylindrical column-Type B loading $\left(f^{\prime} c c \mid f^{\prime} c\right)$

\begin{tabular}{|c|c|c|c|c|c|c|c|c|c|}
\hline \multirow{3}{*}{$*_{t}(\mathrm{~mm})$} & \multirow{3}{*}{ Type } & \multicolumn{4}{|c|}{ Analytical $\left(f^{\prime} c d f^{\prime} c\right)$} & \multicolumn{2}{|c|}{ FEM } & \multicolumn{2}{|c|}{ Experimental $\left(f^{\prime} c d f^{\prime} c\right)$} \\
\hline & & \multicolumn{2}{|c|}{ Mander (1988) } & \multicolumn{2}{|c|}{ Richart (1929) } & \multirow{2}{*}{$f_{c c}^{\prime}$} & \multirow{2}{*}{$f_{c d}^{\prime} d f_{c}^{\prime}$} & \multirow{2}{*}{$f^{\prime} c c$} & \multirow{2}{*}{$f_{c c}^{\prime} f^{\prime} c$} \\
\hline & & $f_{c c}^{\prime}$ & $f_{c c}^{\prime} / f^{\prime} c$ & $f_{c c}^{\prime \prime}$ & $f^{\prime \prime c} / f^{\prime} c$ & & & & \\
\hline \multicolumn{10}{|c|}{ LWSCC } \\
\hline 20 & C-LW-20 & 40.81 & 1.24 & 38.03 & 1.15 & 36.82 & 1.12 & 42.95 & 1.30 \\
\hline 30 & C-LW-30 & 44.28 & 1.34 & 40.54 & 1.23 & 44.63 & 1.35 & 45.36 & 1.37 \\
\hline 50 & C-LW-50 & 50.54 & 1.53 & 45.57 & 1.38 & 51.01 & 1.55 & 42.69 & 1.29 \\
\hline \multicolumn{10}{|c|}{$\mathrm{SCC}$} \\
\hline 20 & C-SC-20 & 49.95 & 1.19 & 47.03 & 1.12 & 44.90 & 1.07 & 35.63 & $0.85^{* *}$ \\
\hline 30 & C-SC-30 & 53.56 & 1.28 & 49.54 & 1.18 & 56.00 & 1.33 & 51.59 & 1.23 \\
\hline 50 & C-SC-50 & 60.18 & 1.43 & 54.57 & 1.30 & 62.69 & 1.49 & 47.23 & 1.12 \\
\hline
\end{tabular}

${ }^{*} t$ : thickness of ECC wrap; $f_{c}^{\prime}\left(\right.$ LWSCC): $33 \mathrm{MPa}, f_{c}^{\prime}(S C C): 42 \mathrm{MPa} ;{ }^{* *}$ sample failed prematurely

\subsubsection{Untied reinforced square column (Type A loading)}

Table 5.10 compares $f^{\prime} c c / f^{\prime}$ ' for untied reinforced square columns. FEM and Richart model values were closer to experiments with Mander model being conservative.

Table 5.10: Untied reinforced square column-Type A loading $\left(f^{\prime} c c / f^{\prime} c\right)$

\begin{tabular}{|c|c|c|c|c|c|c|c|c|c|}
\hline \multirow{3}{*}{$* t(\mathrm{~mm})$} & \multirow{3}{*}{ Type } & \multicolumn{4}{|c|}{ Analytical $\left(f^{\prime} c c f_{c}^{\prime} c\right)$} & \multicolumn{2}{|c|}{ FEM } & \multicolumn{2}{|c|}{$\operatorname{Experimental}\left(f^{\prime} c d f^{\prime} c\right)$} \\
\hline & & \multicolumn{2}{|c|}{ Mander (1988) } & \multicolumn{2}{|c|}{ Richart (1929) } & \multirow{2}{*}{$f_{c c}^{\prime}$} & \multirow{2}{*}{$f_{c c}^{\prime} / f^{\prime}{ }_{c}$} & \multirow{2}{*}{$f^{\prime} c c$} & \multirow{2}{*}{$f^{\prime}{ }_{c c}^{\prime} / f^{\prime}{ }_{c}$} \\
\hline & & $f_{c c}^{\prime}$ & $f^{\prime}{ }_{c c}^{\prime} / f^{\prime}{ }_{c}$ & $f_{c c}^{\prime \prime}$ & $f^{\prime \prime} c d f^{\prime \prime} c$ & & & & \\
\hline \multicolumn{10}{|c|}{ LWSCC } \\
\hline 20 & S-LW-20 & 38.31 & 1.16 & 36.56 & 1.11 & 32.93 & 1.00 & 30.165 & 0.91 \\
\hline 25 & S-LW-25 & 39.54 & 1.20 & 37.45 & 1.13 & 32.74 & 0.99 & 27.259 & 0.83 \\
\hline 30 & S-LW-30 & 40.75 & 1.23 & 38.33 & 1.16 & 33.14 & 1.00 & 32.83 & 0.99 \\
\hline \multicolumn{10}{|c|}{ SCC } \\
\hline 10 & S-SC-10 & 44.75 & 1.07 & 43.78 & 1.04 & 42.52 & 1.01 & 49.573 & 1.18 \\
\hline 15 & S-SC-15 & 46.08 & 1.10 & 44.67 & 1.06 & 45.06 & 1.07 & 44.809 & 1.07 \\
\hline 20 & S-SC-20 & 47.37 & 1.13 & 45.56 & 1.08 & 45.25 & 1.08 & 46.517 & 1.11 \\
\hline
\end{tabular}

${ }^{*} t$ is the thickness of ECC wrap; $f_{c}^{\prime}($ LWSCC $)=33 \mathrm{MPa}, f_{c}{ }_{c}(S C C)=42 \mathrm{MPa}$ 


\subsubsection{Tied reinforced square column (Type B loading)}

Table 5.11 presents a comparision of $f^{\prime}{ }^{\prime} c f^{\prime}{ }^{\prime}$ for tied reinforced square columns. Richart's model gives lower values than Mander's model but higher than FE. Richart's model shows closeness to experimental results.

Table 5.11: Tied reinforced square column-Type B loading $\left(f^{\prime} c c / f^{\prime} c\right)$

\begin{tabular}{|c|c|c|c|c|c|c|c|c|c|}
\hline \multirow{3}{*}{$* t(\mathrm{~mm})$} & \multirow{3}{*}{ Type } & \multicolumn{4}{|c|}{ Analytical $\left(f^{\prime} c d f^{\prime} c\right)$} & \multicolumn{2}{|c|}{ FEM } & \multicolumn{2}{|c|}{$\operatorname{Experimental}\left(f^{\prime}{ }_{c d} / f^{\prime}{ }_{c}\right)$} \\
\hline & & \multicolumn{2}{|c|}{ Mander } & \multicolumn{2}{|c|}{ Richart } & \multirow{2}{*}{$f_{c c}^{\prime}$} & \multirow{2}{*}{$f^{\prime} c d f^{\prime} c$} & \multirow{2}{*}{$f^{\prime} c c$} & \multirow{2}{*}{$f^{\prime}{ }_{c c} / f^{\prime} c$} \\
\hline & & $f_{c c}^{\prime}$ & $f_{c c}^{\prime} / f_{c}^{\prime}$ & $f_{c c}^{\prime}$ & $f^{\prime} c d f^{\prime} c$ & & & & \\
\hline \multicolumn{10}{|c|}{ LWSCC } \\
\hline 20 & S-LW-20T & 41.33 & 1.25 & 41.02 & 1.24 & 34.32 & 1.04 & 37.489 & 1.14 \\
\hline 30 & S-LW-30T & 43.62 & 1.32 & 42.80 & 1.30 & 37.20 & 1.13 & 41.053 & 1.24 \\
\hline 50 & S-LW-50T & 47.90 & 1.45 & 46.36 & 1.40 & 43.83 & 1.33 & 45.979 & 1.39 \\
\hline \multicolumn{10}{|c|}{ SCC } \\
\hline 50 & S-SC-50T & 57.38 & 1.37 & 55.36 & 1.32 & 52.26 & 1.24 & 63.335 & 1.51 \\
\hline
\end{tabular}

${ }^{*} t$ is the thickness of ECC wrap; $f_{c}^{\prime}(L W S C C)=33 \mathrm{MPa}, f_{c}^{\prime}(S C C)=42 \mathrm{MPa}$

\subsubsection{Comparison between experimental and code based axial capacity of column}

Axial load capacities of columns were determined based on Eq. 5.18 and 5.19 as per CSA AS 806 (2012). Table 5.12 presents the experimental and code-based axial load capacities of cylindrical and square columns.

For non-reinforced cylindrical columns under Type B loading (as shown in Table $\mathbf{5 . 1 2}$ code is conservative $\left(\mathrm{P}_{\text {exp }} / \mathrm{P}_{\text {code }}\right.$ ranges between 1.04 and 1.49 with a mean value 1.28) and more conservative for columns with less thick ECC wrap. Code is also found generally conservative for tied or untied reinforced square columns as the ratio ranges between 0.87 and 1.38 with a mean value of 1.12 for untied and between 1.02 and 1.31 with a mean value of 1.14 for tied columns). 
Table 5.12: Comparison between experimental axial capacity with code based axial capacity

\begin{tabular}{|c|c|c|c|}
\hline Column Type & $\begin{array}{c}\text { Experimental axial } \\
\text { capacity }\left(\mathrm{P}_{\text {exp }}\right)\end{array}$ & $\begin{array}{c}\text { Code based axial } \\
\text { capacity, CSA-S806 } \\
\text { 2012 }\left(\mathrm{P}_{\text {code }}\right)\end{array}$ & $\mathrm{P}_{\text {exp }} / \mathrm{P}_{\text {code }}$ \\
\hline \multicolumn{4}{|c|}{ Non-reinforced cylindrical columns-Type B loading } \\
\hline C-LW-20 & 759.0 & 509.1 & 1.49 \\
\hline C-LW-30 & 801.6 & 554.0 & 1.45 \\
\hline C-LW-50 & 754.4 & 637.0 & 1.18 \\
\hline C-SC-20 & 629.7 & 606.9 & 1.04 \\
\hline C-SC-30 & 911.7 & 651.1 & 1.14 \\
\hline C-SC-50 & 834.6 & 732.7 & 0.99 \\
\hline \multicolumn{5}{|c|}{ Untied reinforced square columns-Type A loading } \\
\hline S-LW-20 & 1020.3 & 1034.7 & 1.87 \\
\hline S-LW-25 & 967.3 & 1106.7 & 1.38 \\
\hline S-LW-30 & 1219.7 & 1178.2 & 1.21 \\
\hline S-SC-10 & 1398.1 & 1012.8 & 1.23 \\
\hline S-SC-15 & 1317.9 & 1086.0 & 1.02 \\
\hline \multicolumn{5}{|c|}{ Tied reinforced square columns-Type B loading } \\
\hline S-LW-20T & 804.7 & 788.7 & 1.08 \\
\hline S-LW-30T & 881.2 & 814.9 & 1.14 \\
\hline S-LW-50T & 986.9 & 863.5 & 1.31 \\
\hline S-SC-50T & 1293.8 & 985.8 & \\
\hline
\end{tabular}

\subsection{Summary}

The confining effect of LWSCC and SCC columns with ECC wrapping was studied based on Codes, experiments, existing equations (by Mander and Richart) and finite element models. Code based analysis (CSA-S806 -2012) which was developed for FRP showed conservative predictions of axial load capacity and conservativeness increase with increasing thickness of ECC wrap. 


\section{CHAPTER SIX \\ CONCLUSIONS}

\subsection{General}

This research studied the axial load behavior of confined lightweight self-consolidating concrete (LWSCC) and self-consolidating concrete (SCC) columns with engineered cementitious composite (ECC) wrap. The variables used were concrete types for core columns (LWSCC and SCC), geometry of columns (cylindrical and square), non-reinforced and reinforced columns, reinforced tied and untied columns, types of loading (Type A: load applied through both core and wrap and Type B: load applied through core only) and thickness of ECC wrap. The following conclusions are drawn from experimental, analytical and finite element (FE) investigations:

- LWSCC/SCC columns showed increased axial load carrying and energy absorption capacities with the increase of ECC warp thickness.

- The ductility of columns did not generally increase significantly with the increase of ECC wrap, however, the highest ECC wrap thickness of $50 \mathrm{~mm}$ showed increase in ductility. ECC wrapping of columns increased the stiffness instead of ductility for thinner the wrap, however for thick ECC wrap, the ductility increased. There was an indication that confinement effect increased only up to some extent of thickness of the wrap. More experimental verification is needed.

- Type A loaded columns showed more load axial carrying capacity than columns under Type B loading. Type A loading caused the column to carry load by composite action whereas Type B loading showed the increased capacity of column due to confinement.

- Confinement of non-reinforced LWSCC/SCC core in cylindrical columns increased the hoop strain capacity of the confined concrete. LWSCC columns were more benefitted in terms of confinement (based on confined concrete strength and load carrying capacity enhancement) than their SCC counterparts.

- LWSCC columns under Type B loading were more benefitted by the ECC wrapping than their SCC counterparts in Type A loading as evident from the maximum 27.75\% load contribution of ECC wrap in LWSCC columns compared to maximum $16.57 \%$ in their SCC counterparts. 
- Existing theoretical equations and FE models were good in predicting the confined concrete strength and axial strength of both LWSCC/SCC columns with ECC wrapping. However, code based equations were conservative in predicting axial strength of columns with increasing thickness of ECC wrap.

\subsection{Recommendations for future research}

- More experiment is required on each variable to generalize the effect of confinement on core column.

- Behavior of ECC confinement under elevated temperature needs to be studied.

- The effect of bonding between core and wrap on confinement needs to be evaluated for deriving proper model for confinement.

- The performance of models for confinement and strength calculations using existing equations needs to be further investigated based on more experimental results and FE modelling.

- Economy of ECC wrap to produce effective confinement needs to be studied. 


\section{APPENDIX A}




\section{A1. Quantification for effective confinement and compressive strength models for confined concrete \\ Concrete properties}

Tensile strength of ECC wrap $\left(f_{y}\right)=4.6 \mathrm{MPa}$

\section{Geometry}

Diameter of cylindrical core column $(d)=150 \mathrm{~mm}$

Dimension of square core column $(b=h)=150 \mathrm{~mm}$

Equivalent diameter of square core column $=\sqrt{h^{2}+b^{2}}=\sqrt{ }\left(150^{2}+150^{2}\right)=212.13 \mathrm{~mm}$

Dimension of ties in square core column $\left(d_{t}=b_{t}\right)=(150-2 * 20)=110 \mathrm{~mm}$

Equivalent diameter of ties in square core column $=\sqrt{ }\left(d_{t}^{2}+b_{t}^{2}\right)=\sqrt{ }\left(110^{2}+110^{2}\right)=155.56 \mathrm{~mm}$

Spacing of ties $(s)=150 \mathrm{~mm}$

\section{Calculations:}

1. Non-reinforced cylindrical columns

\begin{tabular}{|c|c|c|}
\hline $\begin{array}{l}\text { Wrap } \\
\text { thickness } \\
(\mathrm{mm})\end{array}$ & Richart et.al (1929) & Mander et. Al (1988) \\
\hline & $\begin{array}{l}\text { Using Eq. 5.10: } \\
{f^{\prime}}_{l}=2 f_{y} t / d\end{array}$ & $\begin{array}{l}\text { Using Eq. 5.10: } \\
f^{\prime}{ }_{l}=2 f_{y} t / d \text { (Same as Richart et. } \\
\text { al, owing to its circular shape and } \\
\text { absence of steel reinforcement) }\end{array}$ \\
\hline $\mathrm{t}=20 \mathrm{~mm}$ & $\begin{array}{l}=2 * 4.6 * 20 / 150 \\
=1.23 \mathrm{MPa}\end{array}$ & \\
\hline $\mathrm{t}=30 \mathrm{~mm}$ & $\begin{aligned} f_{l}^{\prime} & =2 f_{y} t / d \\
& =2 * 4.6 * 30 / 150 \\
& =1.84 \mathrm{MPa}\end{aligned}$ & \\
\hline $\mathrm{t}=50 \mathrm{~mm}$ & Calculation is shown in Chapter 5 & \\
\hline
\end{tabular}

\section{Reinforced square columns}

Yield strength of tie $=449 \mathrm{MPa}$

Cross-sectional area of tie $=28.3 \mathrm{~mm}^{2}$

Cross-sectional area of longitudinal steel $=4 * 100=400 \mathrm{~mm}^{2}$ 


\section{Confinement provided by ties:}

\begin{tabular}{|c|c|c|}
\hline $\begin{array}{l}\text { Equivalent } \\
\text { diameter of ties } \\
\text { in square core } \\
\text { column }\end{array}$ & Richart et.al (1929) & Mander et. Al (1988) \\
\hline $\begin{array}{l}d \quad=\sqrt{ }\left(d_{t}^{2}+b_{t}^{2}\right) \\
=\sqrt{ }\left(110^{2}+110^{2}\right) \\
=155.56 \mathrm{~mm}\end{array}$ & $\begin{array}{l}\text { Eq. 5.8: } \\
\text { Ratio of volume of ties to the } \\
\text { volume of confined section: } \\
\rho_{h}=\frac{4 A_{S}}{d . s} \\
=4 * 28.3 / 155.56 * 150 \\
=0.0048\end{array}$ & $\begin{array}{l}\text { Longitudinal reinforcement ratio }\left(\rho_{s c}\right) \\
=\{\text { Cross-sectional area of steel/area } \\
\text { confined by tie }\}=(4 * 100) /\left(110^{*} 110\right) \\
=0.033 \\
\text { Eq. } 5.4 .2: \\
\text { Shape factor } k_{e}=1-\left[\frac{\left(b_{t}^{2}+d_{t}^{2}\right)}{6\left(1-\rho_{s c}\right) b_{t} d_{t}}\right] \\
=1\left(110^{2}+110^{2}\right) /\left(6^{*}(1-\right. \\
\left.\left.0.033) * 110^{*} 110\right)\right] \\
=0.655 \\
\text { Reinforcement ratio for ties }\left(\rho_{h}\right) \\
=\frac{\text { Cross-sectional area of tie }}{s * b_{t}} \\
=28.3 /\left(150^{*} 110\right) \\
=0.00172\end{array}$ \\
\hline & $\begin{array}{l}\text { Eq. 5.9: } \\
\text { Effective confinement: } \\
\begin{aligned} f^{\prime}{ }_{l} & =\rho_{h} \cdot f_{y} / 2 \\
& =0.0048 * 449 / 2 \\
& =1.08\end{aligned}\end{array}$ & $\begin{array}{l}\text { Eq. 5.3: } \\
\qquad f_{l x}^{\prime}=f_{l y}^{\prime}=k_{e} \rho_{h} f_{y} \\
=0.655^{*} 0.00172 * 449 \mathrm{MPa} \\
=0.505 \mathrm{MPa}\end{array}$ \\
\hline
\end{tabular}




\section{Confinement provided by ECC wrap:}

\begin{tabular}{|c|c|c|}
\hline $\begin{array}{l}\text { Thickness } \\
\text { of ECC } \\
\text { wrap (mm) }\end{array}$ & Richart et.al (1929) & Mander et. Al (1988) \\
\hline 10 & 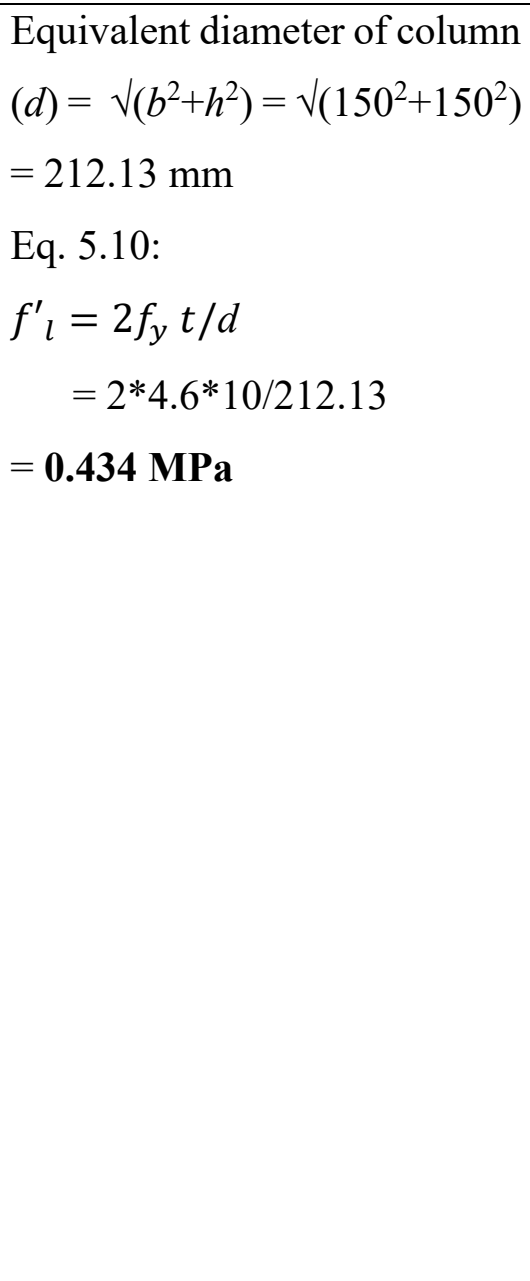 & $\begin{array}{l}\text { Longitudinal reinforcement ratio } \\
\left(\rho_{s c}\right)=\{\text { Cross-sectional area of } \\
\text { steel/area confined by ECC wrap }\} \\
=\left(4^{*} 100\right) /(150 * 150) \\
=0.0177 \\
\text { Eq. } 5.4 .1 \text { : } \\
\text { Shape factor }=1-\left[\frac{\left(b^{2}+h^{2}\right)}{6\left(1-\rho_{s c}\right) b h}\right] \\
=\quad 1- \\
\left.\left.0.0177)^{*} 150 * 150\right)\right] \\
=0.66 \\
\text { Reinforcement ratio for ECC } \\
\text { wrap }\left(\rho_{h}\right)=2 \frac{t}{b} \\
\quad=2 * 10 / 150=0.13 \\
\text { Eq. } 5.3: \\
\text { Confinement due to wrap } f_{l x}{ }^{\prime}= \\
f_{l y}^{\prime}=k_{e} \rho_{h} f_{y}=0.66 * 0.13 * 4.6 \\
=0.4 \mathbf{M P a}\end{array}$ \\
\hline 15 & $\begin{array}{l}\text { Eq. 5.10: } \\
\begin{aligned} f^{\prime}{ }_{l}=2 f_{y} t / d \\
\quad=2 * 4.6 * 15 / 212.13 \\
\quad=0.65\end{aligned}\end{array}$ & $\begin{array}{l}\text { Reinforcement ratio for ECC } \\
\begin{aligned} \operatorname{wrap}\left(\rho_{h}\right) & =2 \frac{t}{b} \\
& =2 * 15 / 150=0.2\end{aligned}\end{array}$ \\
\hline
\end{tabular}




\begin{tabular}{|c|c|c|}
\hline & & $\begin{array}{l}\text { Eq. 5.3: } \\
\text { Confinement due to wrap } f_{l x}{ }^{\prime}= \\
f_{l y^{\prime}}=k_{e} \rho_{h} f_{y}=0.66 * 0.2 * 4.6= \\
\mathbf{0 . 6 0}\end{array}$ \\
\hline 20 & $\begin{array}{l}\text { Eq. 5.10: } \\
\begin{aligned} f^{\prime}=2 f_{y} t / d \\
\quad=2 * 4.6 * 20 / 212.13 \\
=0.87\end{aligned}\end{array}$ & $\begin{array}{l}\text { Reinforcement ratio for ECC } \\
\text { wrap }\left(\rho_{h}\right)=2 \frac{t}{b} \\
\qquad=2 * 20 / 150=0.27 \\
\text { Eq. } 5.3 \text { : } \\
\text { Confinement due to wrap } \\
f_{l x}^{\prime}=f_{l y}^{\prime}=k_{e} \rho_{h} f_{y} \\
=0.66^{*} 0.27 * 4.6=\mathbf{0 . 8 1}\end{array}$ \\
\hline 25 & $\begin{array}{l}\text { Eq. 5.10: } \\
\begin{aligned} f^{\prime}=2 f_{y} t / d \\
\quad=2 * 4.6 * 25 / 212.13 \\
=1.08\end{aligned}\end{array}$ & $\begin{array}{l}\text { Reinforcement ratio for ECC } \\
\text { wrap }\left(\rho_{h}\right)=2 \frac{t}{b} \\
\qquad=2 * 25 / 150=0.34 \\
\text { Eq. } 5.3 \text { : } \\
\text { Confinement due to wrap } \\
f_{l x}{ }^{\prime}=f_{l y}{ }^{\prime}=k_{e} \rho_{h} f_{y} \\
=0.66^{*} 0.34 * 4.6=\mathbf{1 . 0 3}\end{array}$ \\
\hline 30 & $\begin{array}{l}\text { Eq. 5.10: } \\
\begin{aligned} f^{\prime}=2 f_{y} t / d \\
\quad=2 * 4.6 * 30 / 212.13 \\
=1.30\end{aligned}\end{array}$ & $\begin{array}{l}\text { Reinforcement ratio for ECC } \\
\text { wrap }\left(\rho_{h}\right)=2 \frac{t}{b} \\
\qquad=2 * 30 / 150=0.4 \\
\text { Eq. 5.3: } \\
\text { Confinement due to wrap } \\
f_{l x}{ }^{\prime}=f_{l y}^{\prime}=k_{e} \rho_{h} f_{y} \\
=0.66^{*} 0.4 * 4.6=1.21\end{array}$ \\
\hline 50 & $\begin{array}{l}\text { Eq. 5.10: } \\
\begin{aligned} f^{\prime}{ }_{l}=2 & f_{y} t / d \\
& =2 * 4.6 * 50 / 212.13 \\
& =2.17 \mathrm{MPa}\end{aligned}\end{array}$ & $\begin{array}{l}\text { Reinforcement ratio for ECC } \\
\text { wrap }\left(\rho_{h}\right)=2 \frac{t}{b} \\
=2 * 50 / 150=0.67\end{array}$ \\
\hline
\end{tabular}




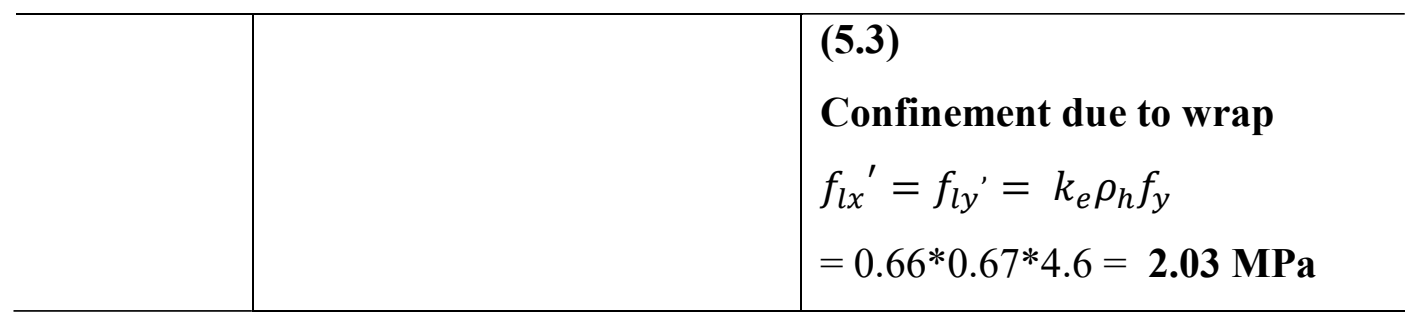

\section{A2.1 Strength increase due to confinement}

$$
\begin{aligned}
& \text { Mander's Model: } \frac{f^{\prime}{ }_{c c}}{f^{\prime}{ }_{c}}=-1.254+2.254 \sqrt{1+\frac{7.94 f^{\prime} l}{f^{\prime}{ }_{c}}}-2 \frac{f^{\prime}{ }_{l}}{f^{\prime}{ }_{c}} \\
& \text { Richart's Model: } \quad \frac{{f^{\prime}{ }_{c c}}_{f^{\prime}{ }_{c}}=1+4.1 \frac{f^{\prime}{ }_{l}}{f^{\prime}{ }_{c}}}{}
\end{aligned}
$$

$f^{\prime}{ }_{c}(\mathrm{LWSCC})=33 \mathrm{MPa}$

$f_{c}^{\prime}(\mathrm{SCC})=42 \mathrm{MPa}$

\section{Non-reinforced cylindrical column}

\begin{tabular}{|c|c|c|}
\hline $\begin{array}{l}\text { Thickness } \\
\text { of ECC } \\
\text { wrap (mm) }\end{array}$ & $\begin{array}{c}f^{\prime}{ }_{c c} \text {-Richart et.al } \\
(1929)\end{array}$ & $f^{\prime}{ }^{\prime} c^{-}$Mander et. Al (1988) \\
\hline 20 & $\begin{array}{l}\text { Eq. } 5.2: \\
\begin{aligned} f_{c c}^{\prime} & =f^{\prime}{ }_{c}+4.1^{*} f^{\prime}{ }_{l} \\
& =33+4.1 * 1.23 \\
& =38 \mathrm{MPa}\end{aligned}\end{array}$ & $\begin{array}{l}\text { Eq. 5.1: } \\
f_{c c}^{\prime}=f_{c}^{\prime} \quad\left(-1.254+2.254 \sqrt{1+\frac{7.94{ }^{\prime}}{f_{c}^{\prime}}}-\right. \\
\left.2 \frac{f_{l}^{\prime}}{f_{c}^{\prime}}\right) \\
=\quad 33 *(-1.254+2.254 *(\sqrt{ }(1+7.94 * 1.23 / 33)- \\
2 * 1.23 / 33) \\
=33 *(-1.254+2.254 * 1.13-0.0754) \\
=40.8 \mathrm{MPa}\end{array}$ \\
\hline
\end{tabular}

\section{$\underline{\text { LWSCC columns }}$}




\begin{tabular}{|c|c|c|}
\hline 30 & $\begin{array}{l}\text { Eq. } 5.2: \\
\begin{aligned} f^{\prime}{ }_{c c} & =f^{\prime}{ }_{c}+4.1^{*} f^{\prime}{ }_{l} \\
& =33+4.1 * 1.84 \\
& =40.54 \mathrm{MPa}\end{aligned}\end{array}$ & $\begin{array}{l}\text { Eq. 5.1: } \\
f_{c c}^{\prime}=f_{c}^{\prime} \quad\left(-1.254+2.254 \sqrt{1+\frac{7.94 f^{\prime}}{f_{c}^{\prime}}}-\right. \\
\left.2 \frac{f^{\prime}{ }_{c}^{\prime}}{f_{c}^{\prime}}\right) \\
=\quad 33 *(-1.254+2.254 *(\sqrt{ }(1+7.94 * 1.84 / 33)- \\
2 * 1.84 / 33) \\
=33 *(-1.254+2.254 * 1.201-0.112) \\
=44.28 \mathrm{MPa}\end{array}$ \\
\hline 50 & $\begin{array}{l}\text { Eq. 5.2: } \\
\begin{aligned} f_{c c}^{\prime}=f_{c}^{\prime}+4.1 * f^{\prime}{ }_{l} \\
\quad=\end{aligned} \\
\begin{array}{l}33+4.1 * 3.067 \\
=\end{array} \\
\quad 45.57 \mathrm{MPa}\end{array}$ & $\begin{array}{l}\text { Eq. 5.1: } \\
f_{c c}^{\prime}=f_{c}^{\prime} \quad\left(-1.254+2.254 \sqrt{1+\frac{7.94 f^{\prime} l}{f^{\prime}{ }_{c}}}-\right. \\
2 \frac{f^{\prime}{ }_{f^{\prime}}}{f_{c}} \\
=\quad 33 *(-1.254+2.254 *(\sqrt{ }(1+7.94 * 3.067 / 33)- \\
2 * 3.067 / 33) \\
=33 *(-1.254+2.254 * 1.318-0.186) \\
=50.54 \mathrm{MPa}\end{array}$ \\
\hline
\end{tabular}

\section{$\underline{\text { SCC columns }}$}

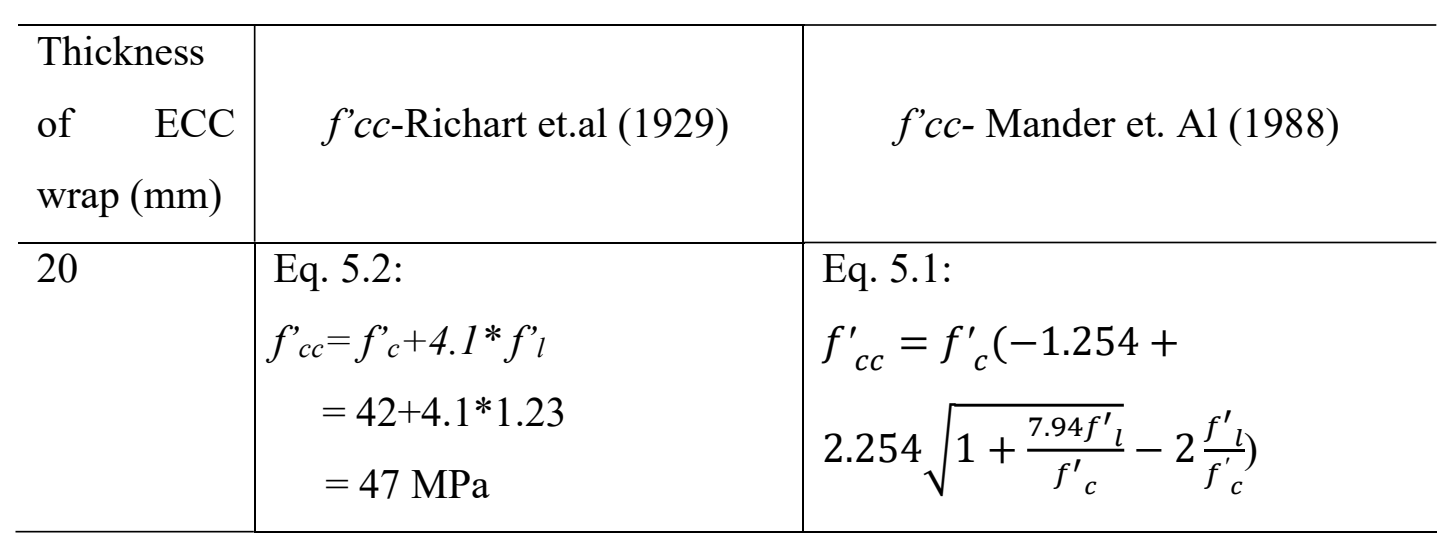




\begin{tabular}{|c|c|c|}
\hline & & $\begin{array}{l}=42 *(- \\
1.254+2.254 *(\sqrt{ }(1+7.94 * 1.23 / 42)- \\
2 * 1.23 / 42) \\
=42 *(-1.254+2.254 * 1.11-0.059) \\
=49.9 \mathrm{MPa}\end{array}$ \\
\hline 30 & $\begin{array}{l}\text { Eq. } 5.2: \\
\begin{aligned} f_{c c}^{\prime} & =f^{\prime}{ }_{c}+4.1^{*} f^{\prime}{ }_{l} \\
& =42+4.1 * 1.84 \\
& =49.5 \mathrm{MPa}\end{aligned}\end{array}$ & $\begin{array}{l}\text { Eq. 5.1: } \\
f_{c c}^{\prime}=f_{c}^{\prime} \\
2.254 \sqrt{1+\frac{7.94{ }_{l}^{\prime}}{f^{\prime}{ }_{c}}}-2 \frac{\left.{f_{l}^{\prime}}^{f_{f^{\prime}}}\right)}{(-1.254+} \\
= \\
1.254+2.254 *(\sqrt{ }(1+7.94 * 1.84 / 42)- \\
2 * 1.84 / 42) \\
=42 *(-1.254+2.254 * 1.16-0.087) \\
=53.5 \mathrm{MPa}\end{array}$ \\
\hline 50 & $\begin{array}{l}\text { Eq. } 5.2: \\
\begin{aligned} f_{c c}^{\prime} & =f^{\prime}{ }_{c}+4.1^{*} f^{\prime}{ }_{l} \\
& =42+4.1 * 3.067 \\
& =54.57 \mathrm{MPa}\end{aligned}\end{array}$ & $\begin{array}{l}\text { Eq. 5.1: } \\
f_{c c}^{\prime}=f_{c}^{\prime} \\
\left.2.254 \sqrt{1+\frac{7.94 f^{\prime}{ }_{l}}{{f^{\prime}}_{c}}}-2 \frac{{f^{\prime}}_{l}}{{f^{\prime}}_{c}}\right) \\
= \\
1.254+2.254 *(\sqrt{ }(1+7.94 * 3.067 / 42)- \\
2 * 3.067 / 42) \\
=42 *(-1.254+2.254 * 1.257-0.146) \\
=60.18 \mathrm{MPa}\end{array}$ \\
\hline
\end{tabular}




\section{Reinforced square column without ties}

$\underline{\text { LWSCC columns }}$

\begin{tabular}{|c|c|c|}
\hline $\begin{array}{l}\text { Thickness } \\
\text { of ECC } \\
\text { wrap (mm) }\end{array}$ & $f^{\prime} c c$-Richart et.al (1929) & $f^{\prime} c c-$ Mander et. Al (1988) \\
\hline 20 & $\begin{array}{l}\text { Eq. } 5.2: \\
\begin{aligned} f^{\prime}{ }_{c c} & =f^{\prime}{ }_{c}+4.1^{*} f^{\prime}{ }_{l} \\
& =33+4.1 * 0.87 \\
& =36.56 \mathrm{MPa}\end{aligned}\end{array}$ & 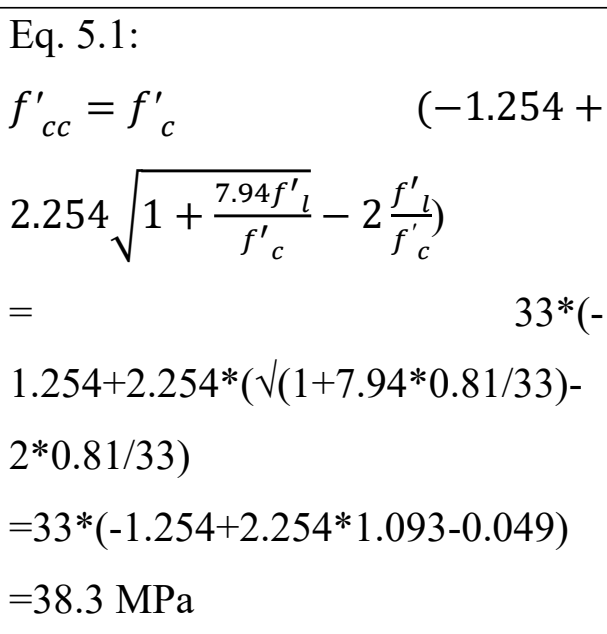 \\
\hline 25 & $\begin{array}{l}\text { Eq. } 5.2: \\
\begin{aligned} f^{\prime}{ }_{c c} & =f^{\prime}{ }^{\prime}+4.1 * f^{\prime}{ }_{l} \\
& =33+4.1 * 1.08 \\
& =37.45 \mathrm{MPa}\end{aligned}\end{array}$ & $\begin{array}{l}\text { Eq. 5.1: } \\
f^{\prime}{ }_{c c}=f^{\prime}{ }_{c} \\
2.254 \sqrt{1+\frac{7.94 f_{l}^{\prime}}{f^{\prime}{ }_{c}}}-2 \frac{{f^{\prime}}_{l}}{{f^{\prime}}_{c}} \\
= \\
1.254+2.254 *(\sqrt{ }(1+7.94 * 1.013 / 33)- \\
2 * 1.013 / 33) \\
=33 *(-1.254+2.254 * 1.115-0.062) \\
=39.5 \mathrm{MPa}\end{array}$ \\
\hline 30 & $\begin{array}{l}\text { Eq. } 5.2: \\
\begin{aligned} f^{\prime}{ }_{c c} & =f^{\prime}{ }^{\prime}+4.1^{*} f^{\prime}{ }_{l} \\
& =33+4.1 * 1.30 \\
& =38.33 \mathrm{MPa}\end{aligned}\end{array}$ & $\begin{array}{l}\text { Eq. 5.1: } \\
f^{\prime}{ }_{c c}=f_{c}^{\prime} \quad(-1.254+ \\
2.254 \sqrt{1+\frac{7.94 f_{l}^{\prime}}{{f^{\prime}{ }_{c}}}}-2 \frac{{f^{\prime} l}^{\prime}}{{f^{\prime}}_{c}}\end{array}$ \\
\hline
\end{tabular}




\begin{tabular}{r|l|l}
\hline & $=$ & $33 *(-$ \\
$1.254+2.254 *(\sqrt{ }(1+7.94 * 1.21 / 33)-$ & $2 * 1.21 / 33)$ \\
& $=33 *(-1.254+2.254 * 1.136-0.073)$ \\
& $=40.7 \mathrm{MPa}$
\end{tabular}

\section{$\underline{\text { SCC columns }}$}

\begin{tabular}{|c|c|c|}
\hline $\begin{array}{l}\text { Thickness } \\
\text { of ECC } \\
\text { wrap (mm) }\end{array}$ & $f^{\prime} c c$-Richart et.al (1929) & $f^{\prime} c c-$ Mander et. Al (1988) \\
\hline 10 & $\begin{array}{l}\text { Eq. 5.2: } \\
\begin{aligned} f_{c c}^{\prime} & =f^{\prime}{ }_{c}+4.1 * f^{\prime}{ }_{l} \\
& =42+4.1 * 0.434 \\
& =43.77 \mathrm{MPa}\end{aligned}\end{array}$ & $\begin{array}{l}\text { Eq. 5.1: } \\
f^{\prime}{ }_{c c}=f^{\prime}{ }_{c} \\
2.254 \sqrt{1+\frac{7.94{f^{\prime}}_{l}}{{f^{\prime}}{ }_{c}}}-2 \frac{{f^{\prime}{ }_{l}}_{{f^{\prime}}_{c}}}{=} \quad(-1.254+ \\
1.254+2.254 *(\sqrt{ }(1+7.94 * 0.405 / 42)- \\
2 * 0.405 / 42) \\
=42 *(-1.254+2.254 * 1.037-0.0192) \\
=44.7 \mathrm{MPa}\end{array}$ \\
\hline 15 & $\begin{array}{l}\text { Eq. } 5.2: \\
\begin{aligned} f_{c c}^{\prime} & =f^{\prime}{ }_{c}+4.1^{*} f^{\prime}{ }_{l} \\
& =42+4.1 * 0.65 \\
& =44.66 \mathrm{MPa}\end{aligned}\end{array}$ & $\begin{array}{l}\text { Eq. 5.1: } \\
f^{\prime}{ }_{c c}=f^{\prime}{ }_{c} \\
2.254 \sqrt{1+\frac{7.94^{\prime}{ }_{l}}{f^{\prime}{ }_{c}}}-2 \frac{{f^{\prime}}_{l}}{f^{\prime}{ }_{c}} \\
= \\
1.254+2.254 *(\sqrt{ }(1+7.94 * 0.608 / 42)- \\
2 * 0.608 / 42) \\
=42 *(-1.254+2.254 * 1.056-0.0289) \\
=46.08 \mathrm{MPa}\end{array}$ \\
\hline
\end{tabular}




\begin{tabular}{|c|c|c|}
\hline 20 & $\begin{array}{l}\text { Eq. } 5.2 \text { : } \\
\begin{aligned} f_{c c}^{\prime} & =f^{\prime}{ }_{c}+4.1^{*} f^{\prime}{ }_{l} \\
& =42+4.1 * 0.87 \\
& =45.56 \mathrm{MPa}\end{aligned}\end{array}$ & $\begin{array}{l}\text { Eq. 5.1: } \\
f^{\prime}{ }_{c c}=f_{c}^{\prime} \\
2.254 \sqrt{1+\frac{7.94{ }^{\prime}{ }_{l}}{f^{\prime}{ }_{c}}}-2 \frac{f^{\prime}{ }_{l}^{\prime}}{f_{c}^{\prime}} \\
= \\
1.254+2.254 *(\sqrt{ }(1+7.94 * 0.81 / 42)- \\
2 * 0.81 / 42) \\
=42 *(-1.254+2.254 * 1.074-0.0386) \\
=47.37 \mathrm{MPa}\end{array}$ \\
\hline
\end{tabular}

\section{Reinforced square column with ties}

\section{$\underline{\text { LWSCC columns }}$}

Total effective confinement $\left(f^{\prime} l\right)=$ confinement due to ties and wrap

Confinement due to ties:

- Richart: $1.09 \mathrm{Mpa}$

- Mander: $0.505 \mathrm{Mpa}$

\begin{tabular}{|c|c|c|}
\hline $\begin{array}{l}\text { Thickness } \\
\text { of ECC } \\
\text { wrap (mm) }\end{array}$ & $f^{\prime} c c$-Richart et.al (1929) & $f^{\prime} c c-$ Mander et. Al (1988) \\
\hline 20 & $\begin{array}{l}\text { Eq. } 5.2 \text { : } \\
\begin{aligned} f_{c c}^{\prime} & =f^{\prime}{ }_{c}+4.1 * f^{\prime}{ }_{l} \\
& =33+4.1 *(0.87+1.08) \\
& =41 \mathrm{MPa}\end{aligned}\end{array}$ & $\begin{array}{l}\text { Eq. 5.1: } \\
f_{c c}^{\prime}=f_{c}^{\prime} \quad\left(-1.254+2.254 \sqrt{1+\frac{7.94 f^{\prime} l}{f_{c}{ }_{c}}}-\right. \\
\left.2 \frac{f^{\prime}{ }_{l}^{\prime}}{f_{c}}\right) \\
= \\
1.254+2.254 *(\sqrt{ }(1+7.94 *(0.81+0.505) / 33)- \\
2 *(0.81+0.505) / 33) \\
=33 *\left(-1.254+2.254^{*}\right) \\
=38.3 \mathrm{MPa}\end{array}$ \\
\hline
\end{tabular}




\begin{tabular}{|c|c|c|}
\hline 30 & $\begin{array}{l}\text { Eq. 5.2: } \\
\begin{aligned} f_{c c}^{\prime} & =f^{\prime}{ }^{\prime}+4.1^{*} f^{\prime} l \\
& =33+4.1 *(1.30+1.08) \\
& =42.8 \mathrm{MPa}\end{aligned}\end{array}$ & $\begin{array}{l}\text { Eq. 5.1: } \\
f_{c c}^{\prime}=f_{c}^{\prime} \quad\left(-1.254+2.254 \sqrt{1+\frac{7.94 f^{\prime}}{f_{c}^{\prime}}-}-\right. \\
\left.2 \frac{f^{\prime}{ }_{c}}{f_{c}^{\prime}}\right) \\
= \\
1.254+2.254 *(\sqrt{ }(1+7.94 *(1.21+0.505) / 33)- \\
2 *(1.21+0.505) / 33) \\
=33 *(-1.254+2.254 * 1.188-0.104) \\
=43.6 \mathrm{MPa}\end{array}$ \\
\hline 50 & $\begin{array}{l}\text { Eq. } 5.2 \text { : } \\
\begin{aligned} f_{c c}^{\prime} & =f^{\prime}{ }^{\prime}+4.1 * f^{\prime} l \\
& =33+4.1 *(2.17+1.08) \\
& =46.3 \mathrm{MPa}\end{aligned}\end{array}$ & $\begin{array}{l}\text { Eq. 5.1: } \\
f_{c c}^{\prime}=f_{c}^{\prime} \quad\left(-1.254+2.254 \sqrt{1+\frac{7.94 f^{\prime} l}{f^{\prime}{ }_{c}}}-\right. \\
\left.2 \frac{f^{\prime}{ }_{l}}{f^{\prime}}\right) \\
= \\
1.254+2.254 *(\sqrt{ }(1+7.94 *(2.026+0.505) / 33)- \\
2 *(2.026+0.505) / 33) \\
=33 *(-1.254+2.254 * 1.268-0.153) \\
=47.9 \mathrm{MPa}\end{array}$ \\
\hline
\end{tabular}

\section{$\underline{\text { SCC columns }}$}

\begin{tabular}{l|l|l}
\hline $\begin{array}{l}\text { Thickness } \\
\text { of ECC } \\
\text { wrap (mm) }\end{array}$ & $f^{\prime} c c$-Richart et.al (1929) & \multicolumn{1}{|c}{$f^{\prime} c c$-Mander et. Al (1988) } \\
\hline 50 & $\begin{array}{l}\text { Eq. 5.2: } \\
f^{\prime}{ }_{c c}=f^{\prime}{ }^{\prime}+4.1^{*} f^{\prime}{ }_{l} \\
=42+4.1^{*}(2.17+1.08) \\
=55.3 \mathrm{MPa}\end{array}$ & $\begin{array}{l}f^{\prime}{ }_{c c}=f^{\prime}{ }_{c} \quad\left(-1.254+2.254 \sqrt{1+\frac{7.94 f^{\prime} l}{f^{\prime}{ }_{c}}}\right. \\
2 \frac{f^{\prime}{ }_{l}}{f_{c}^{\prime}}\end{array}$ \\
\hline
\end{tabular}




\begin{tabular}{l|l|l}
\hline & $=$ & $42 *(-$ \\
& $1.254+2.254 * \sqrt{ }(1+7.94 *(2.026+0.505) / 42)-$ \\
$2 *(2.026+0.505) / 42)$ & $=42 *(-1.254+2.254 * 1.216-0.12)$ \\
& $=57.38 \mathrm{MPa}$ \\
& \\
\hline
\end{tabular}

\section{A2.2 Type A loading}

Type A loading - Load sharing between different components of reinforced untied square columns Modulus of elasticity

$\operatorname{ECC} \operatorname{wrap}\left(E_{W}\right) \quad=18457 \mathrm{MPa}$

$\operatorname{LWSCC}\left(E_{C-L W S C C}\right)=16867 \mathrm{MPa}$

$\operatorname{SCC}\left(E_{C-S C C}\right) \quad=23213 \mathrm{MPa}$

Steel $\left(E_{S}\right) \quad=200000 \mathrm{MPa}$

Net area of concrete core $\left(\boldsymbol{A}_{\boldsymbol{c}}\right)=\mathbf{2 2 1 0 0} \mathrm{mm}^{2}$

Area of longitudinal steel $\left(\boldsymbol{A}_{\boldsymbol{s}}\right)=\mathbf{4 0 0} \mathrm{mm}^{2}$

\section{Reinforced untied SCC column S-SC}

Experimental peak load $(P)=870.7 \mathrm{kN}$

Area of wrap $\left(A_{w}\right)=0 \mathrm{~mm}^{2}$

Strain based on Eq. 5.8:

$$
\begin{aligned}
\varepsilon & =P /\left(A_{w} E_{w}+A_{c} E_{c-S C C}+A_{s} E_{s}\right) \\
& =870.7 * 1000 /(0 * 18457+23213 * 22100+400 * 200000) \\
& =0.00146
\end{aligned}
$$

From Eq. 5.10, the load shared by each component is obtained as:

$P_{s}=\varepsilon * E_{S} * A_{s}=0.00146 * 200000 * 400 / 1000=117.46 \mathrm{kN}$

$P_{c}=P-P S=870.7-117.46=753.24 \mathrm{kN}$

\section{Reinforced untied SCC column S-SC-10}

Experimental peak load $(P)=1398.1 \mathrm{kN}$

Area of wrap $\left(A_{w}\right)=3340 \mathrm{~mm}^{2}$ 
Strain based on Eq. 5.8:

$$
\begin{aligned}
\varepsilon & =P /\left(A_{w} E_{w}+A_{c} E_{c-S C C}+A_{s} E_{S}\right) \\
& =1398.1 * 1000 /(3340 * 18457+23213 * 22100+400 * 200000) \\
& =0.00213
\end{aligned}
$$

From Eq. 5.10, the load shared by each component is obtained as:

Steel: $P_{S}=\varepsilon * E_{S} * A_{s}=0.00213 * 200000 * 400 / 1000=170.85 \mathrm{kN}$

Wrap: $P_{w}=\varepsilon * E_{w} * A_{w}=0.00213 * 18457 * 3340=131.65 \mathrm{kN}$

Core: $P_{c}=P-(P s+P w)=1398.1-(170.85+131.65)=1095.57 k N$

\section{Reinforced untied SCC column S-SC-15}

Experimental peak load $(P)=1317.9 \mathrm{kN}$

Area of wrap $\left(A_{w}\right)=4860 \mathrm{~mm}^{2}$

Strain based on Eq. 5.8:

$$
\begin{aligned}
\varepsilon & =P /\left(A_{w} E_{w}+A_{c} E_{c-S C C}+A_{s} E_{s}\right) \\
& =1317.9 * 1000 /(4860 * 18457+23213 * 22100+400 * 200000)=0.00193
\end{aligned}
$$

From Eq. 5.10, the load shared by each component is obtained as:

Steel: $P_{s}=\varepsilon * E_{S} * A_{s}=0.00193 * 200000 * 400 / 1000=154.43 \mathrm{kN}$

Wrap: $P_{w}=\varepsilon * E_{w} * A_{w}=0.00193 * 18457 * 4860=173.16 \mathrm{kN}$

Core: $P_{c}=P-(P s+P w)=1317.9-(154.43+173.16)=990 k N$

\section{Reinforced untied SCC column S-SC-20}

Experimental peak load $(P)=1424.3 \mathrm{kN}$

Area of wrap $\left(A_{w}\right)=6380 \mathrm{~mm}^{2}$

Strain based on Eq. 5.8:

$$
\begin{aligned}
\varepsilon & =P /\left(A_{w} E_{w}+A_{c} E_{c-S C C}+A_{s} E_{s}\right) \\
& =1424.3 * 1000 /(6380 * 18457+23213 * 22100+400 * 200000)=0.0020
\end{aligned}
$$

From Eq. 5.10, the load shared by each component is obtained as:

Steel: $P_{s}=\varepsilon * E_{S} * A_{s}=0.0020 * 200000 * 400 / 1000=160.32 \mathrm{kN}$

Wrap: $P_{w}=\varepsilon * E_{w} * A_{w}=0.0020 * 18457 * 6380=235.98 \mathrm{kN}$

Core: $P_{c}=P-(P s+P w)=1028.03 k N$ 


\section{REFERENCES}

ABAQUS Documentation (2014), Dassault Systems Simulia Corp. Providence, RI, USA.

ACI Committee 440.2R-08. (2008). Guide for the design and construction of externally bonded FRP systems for strengthening concrete structures. ACI committee 440, American Concrete Institute, Farmington Hills, MI 48331, USA, 34 - 37.

ASTM C39/C39M (2016). Standard test method for static modulus of elasticity and Poisson's ratio of concrete in compression. American Society for Testing and Materials, West Conshohocken, Pennsylvania, USA, $1-5$.

ASTM C150/C150M (2018). Standard specification for portland cement, American Society for Testing and Materials, West Conshohocken, Pennsylvania, USA, 1 - 9.

ASTM C469/C469M (2014). Standard test method for compressive strength of cylindrical concrete specimens. American Society for Testing and Materials, West Conshohocken, Pennsylvania, USA, 1 - 7.

ASTM C330/C330M (2017). Standard specification for lightweight aggregates for structural concrete. American Society for Testing and Materials, West Conshohocken, Pennsylvania, USA, $1-4$.

ASTM C496/C496M (2011). Standard test method for splitting tensile strength of cylindrical

concrete specimens. American Society for Testing and Materials, West Conshohocken, Pennsylvania, USA, 1 - 5.

Balmer G.G. (1949). Shearing strength of concrete under high triaxial stress, computation of Mohr's envelope as a curve. Bureau of Reclamation Laboratory report, SP-23, National government publication, Denver, Colorado.

Bažant, Z. P. (1992). Fracture mechanics of concrete structures. ACI committee 446 on fractures mechanics, Vol. 140, 1 - 140.

Campion, M.J. and Jost, P. (2000). Self-compacting concrete. Concrete International: Design and Construction, Vol. 22, Issue 4, 31 - 34 .

CSA A23.3-14 (2014). Design of concrete structures. Canadian Standard Association, Rexdale, Ontario.

CSA S806-12 (2012). Design and construction of building components with fibre-reinforced polymers. Canadian Standard Association, Rexdale, Ontario. 
CEB-FIP model code 1990 (1993). Design code. London, Thomas Telford, 240p.

Dymond, B. Z. (2007). Shear strength of a PCBT-53 girder fabricated with lightweight, selfconsolidating concrete. Master's thesis, Virginia Polytechnic Institute and State University, USA.

EFNARC (2005). The European guidelines for self-compacting concrete, specification, production and use the self-compacting concrete European project group, 63p.

Elfgren, L., and Shah, S.P. (1989). Analysis of concrete structures by fracture mechanics. First edition, Chapman and Hall, London.

Fardis, M. N., and Khalili, H. H. (1982). FRP-encased concrete as a structural material. Magazine of Concrete Research, Vol. 34, Issue 121, 191 - 202.

Fischer, G., Li, V. and Wang, S. (2003). Design of engineered cementitious composites for processing and workability requirements, seventh international symposium on brittle matrix composites. Warsaw, Poland, $29-36$.

Hassan, A. A. A., Hossain, K.M.A. and Lachemi, M. (2010). Strength, cracking and deflection performance of large-scale self-consolidating concrete beams subjected to shear failure. Engineering Structures, Vol. 32, Issue 5, 1262 - 1271.

Hassan, M., and Chaallal, O. (2007). Fiber-reinforced polymer confined rectangular columns: Assessment of models and design guidelines. ACI Structural Journal, Vol. 104, Issue 6, 693 -702 .

Hockett, J.E. and Gillis, P.P. (1971). Mechanical testing machine stiffness. International Journal of Mechanical Sciences, Vol. 13, 265 - 275.

Hossain, K.M.A (2003). Axial load behavior of thin walled composite columns. Composites: Part B, Vol. 34, Issue 8, $715-725$.

Hossain, K. M. A., Alam, S., Anwar, M. S., and Julkarnine, K. M. Y. (2016). High performance composite slabs with profiled steel deck and engineered cementitious composite - strength and shear bond characteristics. Construction and Building Materials, Vol. 125, 227 - 240.

Hossain, K.M.A., and Lachemi, M. (2010). Fresh, mechanical, and durability characteristics of self-consolidating concrete incorporating volcanic ash. Journal of Materials in Civil Engineering, Vol. 22, Issue 7, $651-657$.

Hubertova, M., and Hela, R. (2007). The effect of metakaolin and silica fume on the properties of lightweight self-consolidating concrete, ACI Special Publication, Vol. 243, 35 - 48. 
Huei Jeng Lin; CI Liao (2004). Compressive strength of reinforced concrete column confined by composite material. Composite Structures, Vol. 65, Issue 2, 239 - 250.

Hunaiti, Y. M. (1996). Composite section of foamed and lightweight aggregate concrete. Journal of Materials in Civil Engineering, Vol. 8, No. 3, $111-113$.

Jiang, J.F. and Wu., Y.F. (2012). Identification of material parameters for Drucker-Prager plasticity model for FRP confined circular concrete columns. International Journal of Solids and Structures, Vol. 49, Issue 3-4, 445 - 56.

JSCE (1998). Guide to construction of high flowing concrete. Japanese Society of Civil Engineers, Gihoudou publication, Tokyo, Japan.

Karbhari, V. M. and Gao, Y. (1997). Composite jacketed concrete under uniaxial compression Verification of simple design equations. Journal of Materials in Civil Engineering, Vol. 9, Issue 4, $185-193$.

Khayat, K.H., Bickley, J., and Lessard, M. (2000). Performance of self-consolidating concrete for casting basement and foundation walls, ACI Materials Journal, Vol. 97, Issue 3, 374- 380.

Kriegh, J.D. (1976) - Arizona slant shear test: A method to determine epoxy bond strength. American Concrete Institute, Journal of the American Concrete Institute, Vol. 73, No. 3,372 -373 .

Lam, L. and Teng, J. G. (2003). Design-oriented stress-stain model for FRP-confined concrete in rectangular columns. Journal of Reinforced Plastics and Composites, Vol. 22, Issue 13, 1149 $-1186$.

Lachemi, M., Hossain, K.M.A., Lambros, V.B., and Bouzoubaâ, N. (2003). Development of cost effective self-consolidating concrete incorporating fly Ash, slag Cement or viscosity modifying admixtures, ACI Materials Journal, Vol. 100, Issue 5, 419 - 425.

Lacombe, P., Beaupre, D. and Pouliot, N. (1999). Rheology and bonding characteristics of self levelling concrete as a repair material. Materials and Structures, Vol. 32, Issue 222, 593 600.

Li, V. C. (1993). From micromechanics to structural engineering - the Design of cementitious composites for civil engineering applications. JSCE Journal of Structural Mechanics/ Earthquake Engineering, Vol. 10, Issue I-24, 37 - 48. 
Li, V.C. (1998). Engineered cementitious composites (ECC) - Tailored composites through micromechanical modeling. Fiber Reinforced Concrete: Present and Future, Edited by Banthia et al., Canadian Society for Civil Engineering, Montreal, 64 - 97.

Li, V.C., (2003). On engineered cementitious composites (ECC). A review of the material and its applications. Journal of Advanced Concrete Technology, Vol. 1, Issue 3, 215 - 230.

Li, V. C., Lepech, M. and Li, M., (2005). Field demonstration of durable link slabs for jointless bridge decks based on strain-hardening cementitious composites. Michigan DOT report.

Li, V. C. (2007). Engineered cementitious composites (ECC)-Material, structural, and durability Performance. University of Michigan, Ann Arbor, MI 48109, USA.

Li, V. C. (2008). Engineered cementitious composites (ECC) - Material, structural and durability performance. Concrete Construction Engineering Handbook, Edited by Nawy, E., Second edition, CRC Press, Boca Raton.

Lotfy, A., Hossain, K.M.A., and Lachemi, M. (2016). Durability properties of lightweight selfconsolidating concrete developed with three types of aggregates. Construction and Building Materials, Vol. 106, 43 - 54.

Mander, J.B., Priestley, M.J.N., and Park, R. (1988). Theoretical stress-strain model for confined concrete. Journal of Structural Engineering, Vol. 114, Issue 8, $1804-1826$.

Maruta, M., Kanda, T., Nagai, S. and Yamamoto, Y. (2005). New high-rise RC structure using pre-cast ECC coupling beam. Concrete Journal, Vol. 43, Issue 11, 18 - 26.

Mazars, J. (1986). A description of micro- and macroscale damage of concrete structures. Engineering Fracture Mechanics, Vol. 25, Issue 5-6, 729 - 737.

Mazzucco, G., Salomoni, V. A., Majorana, C. E., Pellegrino, C., and Ceccato, C. (2016). Numerical investigation of concrete columns with external FRP jackets subjected to axial loads. Construction and Building Materials, Vol. 111, 590 - 599.

Mirmiran, A., Shahawy, M., Samaan, M., Echary, H. E., Mastrapa, J. C. and Pico, O. (1998). Effect of column parameters on FRP-confined concrete. Journal of Composite for Construction, Vol. 2, Issue 4, $175-185$.

Nanni, A. and Bradford, N. M. (1995). FRP Jacketed Concrete Under Uniaxial Compression, Construction and Building Materials, Vol. 9, Issue 2, 115 - 124. 
Newman, K., and Newman, J. B. (1972). Failure theories and design criteria for plain concrete. Proceedings of the International Civil Engineering Materials Conference on Structure, Solid Mechanics and Engineering Design (Southampton), Wiley Interscience, New York.

Nisticò, N., Pallini, F., Rousakis, T., Wu, Y.F., and Karabinis, A. (2014). Peak strength and ultimate strain prediction for FRP confined square and circular concrete sections. Composites Part B: Engineering, Vol. 67, 543 - 554.

Nisticò, N, and Monti, G. (2013). RC square sections confined by FRP: Analytical prediction of peak strength. Composites Part B: Vol. 45, Issue 1, 127 - 37.

Okamura, H. (1996). Self-compacting high-performance concrete, Concrete International, Vol. 19, Issue 7, 50 - 54.

Okamura H. and Ouchi M. (2003). Self-compacting concrete. Journal of Advanced Concrete Technology, Vol.1, Issue 1, 5 - 15.

Ozawa, K., Maekawa, K., Kunishima, H. and Okamura, H. (1989). Performance of concrete based on the durabiity design of concrete structures, Proce. The second East-Asia-Pacific Conference on Structural Engineeing and Construction, Vol. 1, $445-456$.

Ozbakkaloglu, T., and Lim, J.C. (2013). Axial compressive behavior of FRP-confined concrete: Experimental test database and a new design-oriented model. Composites Part B: Engineering, Vol. 55, $607-34$.

PCI ESIGN HANDBOOK (2004). Precast/Prestressed Concrete Institute, $6^{\text {th }}$ edition, Chicago, Illinois, USA.

Popovics, S. (1973). A numerical approach to the complete stress-strain curves for concrete. Cement and Concrete Research., Vol. 3, Issue 5, 583 - 599.

Qian, S., Lepech, M.D., Kim, Y.Y., Li, V.C. (2009). Introduction of transition zone design for bridge deck link slabs using ductile concrete. ACI Structural Journal, Vol. 106, Issue 1, 96 -105 .

Richart, F., Brandtzaeg, A., Brown, R. L. (1929). The failure of plain and spirally reinforced concrete in compression. University of Illinois Bulletin, Vol. XXVI, Issue 31.

Rochette, P., and Labossiere, P. (2000). Axial testing of rectangular column models confined with composites. Journal of Composites for Construction, Vol. 4, Issue 3, 129 - 136.

Saafi, M., Toutanji,, H. A., and Li, Z. J. (1999). Behavior of concrete columns confined with fiber reinforced polymer tubes. ACI Materials Journal, Vol. 96, Issue 4, 500 - 509. 
Samaan, M., Mirmiran, A., and Shahawy, M. (1998). Model of concrete confined by fiber composites. Journal of Structural Engineering, Vol. 124, Issue 9, 1025 - 1031.

Santos, P. (2009). Assessment of the shear strength between concrete layers. PhD thesis, University of Coimbra, Portugal.

Sakata, K., Kanda, T., and Hiraishi, M. (2004). Application of direct sprayed ECC for retrofitting dam structure surface-Application for Mitaka-dam. Japan Concrete Institute Concrete Journal, Vol. 42, Issue 5, 135 - 139.

Shah, S., Swartz, S., and Ouyang, C. (1995). Fracture mechanics of concrete. Wiley and Sons, New York.

Shahawy, M., Mirmiran, A., and Beitelman, T. (2000). Tests and modeling of carbon-wrapped concrete columns. Composite Part: B Engineering, Vol. 31, Issue 6-7, 471 - 480.

Sherir, M., Hossain, K.M.A., Lachemi, M. (2015). Structural performance of polymer fiber reinforced engineered cementitious composites subjected to static and fatigue flexural loading. Polymers, Vol. 7, Issue 7, 1299 - 1330.

Sherir, M. A. A., Hossain, K. M. A., and Lachemi, M. (2017). The influence of MgO-type expansive agent incorporated in self-healing system of engineered cementitious composites. Construction and Building Materials, Vol. 149, $164-185$.

Sozen, M.A., Ichinose, T., and Pujol, S. (2014). Principles of reinforced concrete design. CRC Press, Boca Raton, USA.

Teng, J. G., Chen, J. F., Smith, S. T., and Lam, L. (2002). FRP strengthened RC structures. WileyBlackwell, Chichester.

Thériault, M., and Neale, K. W. (2000). Design equations for axially loaded reinforced concrete columns strengthened with fibre reinforced polymer wraps. Canadian Journal of Civil Engineering, Vol. 27, Issue 5, $1011-1020$.

Toutanji, H., Han, M., Gilbert, J., and Matthys, S. (2010). Behavior of large-scale rectangular columns confined with FRP composites. Journal of Composites for Construction, Vol. 14, Issue $1,62-71$.

Turner, M. J., Clough, R. W., Martin H. C. and Topp, L. J. (1956). Stiffness and deflection analysis of complex structures. Journal of the Aeronautical Sciences, Vol. 23, No. 9, $805-823$.

Yahia, A., Tanimura M., Shimabukur,o A. and Shimoyama, Y. (1999). Effect of rheological parameter on self-compactibility of concrete containing various mineral admixtures, 
Proceeding of the First RILEM International Symposium on Self -Compacting Concrete, Stockholm, Sweden, 523 - 535.

Yu, T., Teng, J. G., Wong, Y. L., and Dong, S. L. (2010). Finite element modeling of confined concrete-II: Plastic-damage model. Engineering Structures, Vol. 32, Issue 3, 680 - 691. www.oboa.on.ca. Self-consolidating concrete - Ontario Building Officials Association. Retrieved on: June 12, 2018. 